\title{
O Uso dos Dados da Missão GOCE para a \\ Caracterização e a Investigação das Implicações na \\ Estrutura de Densidade das Bacias Sedimentares do \\ Amazonas e Solimões, Brasil
}

\section{The use of the GOCE mission data for characterizations and implications on the density structure of the Sedimentary Basins of Amazon and Solimões, Brazil} by

\author{
Everton Bomfim, M.Sc.
}

Thesis

Presented to the Double Diploma between Universidade de São Paulo (USP) in São Paulo, Brazil and Università degli Studi di Trieste (UNITS) in Trieste, Italy, in partial fulfillment of the requirements for the degree Doctor of Philosophy Degree in Geosciences

Major Subject: Gravity Field

University of Sao Paulo

University of Trieste

São Paulo, SP, Brazil

Trieste, TS, Italy

October, 2012 
O Uso dos Dados da Missão GOCE para Caracterização e a Investigação das Implicações na Estrutura de Densidade das Bacias Sedimentares do Amazonas e do Solimões, Brasil

\section{The use of the GOCE mission data for characterizations and implications on the density structure of the Sedimentary Basins of Amazon and Solimões, Brazil} by Everton Bomfim, M.Sc.

Thesis

Major Subject: Gravity Field

University de Sao Paulo

São Paulo, SP, Brazil
University of Trieste

Trieste, TS, Italy

Corrected Version. Original version is available on the IAG/USP Library. Versão Corrigida. O original encontra-se disponível na Unidade. 
Approved by the

Examining Committee:

Prof. Dr. Eder Molina, Thesis Adviser (USP, Brazil) and Chair of Defense

Prof. Dr. Carla Braitenberg, Thesis Adviser (UNITS, Italy)

Prof. Dr. De Min Angelo, Member (UNITS, Italy)

Prof. Dr. Valéria Barbosa, (ON, Brazil)

Prof. Dr. Wladimir Shukowsky, (USP, Brazil)

SÃO PAULO, SP - BRAZIL

DICEMBER 2012 
(C) Copyright 2012

by

Everton Bomfim

All Rights Reserved 


\title{
O Uso dos Dados da Missão GOCE para Caracterização e Implicações na Estrutura de Densidade das Bacias Sedimentares do Amazonas e do Solimões, Brasil
}

\author{
Everton Bomfim, Ph.D \\ Universidade de São Paulo e Università Degli Studi di Trieste, São Paulo, 2012
}

Orientadores: Eder Molina (USP)

Carla Braitenberg (UNITS)

\begin{abstract}
A maneira mais direta de detectar as anomalias da densidade é pelo estudo do potencial gravitacional e de suas derivadas. A disponibilidade global e a boa resolução dos dados do satélite GOCE, aliadas à disponibilidade de dados de gravimetria terrestre, são ideais para a comparação e classificação das bacias de larga escala, como as bacias sedimentares do Solimões e do Amazonas dentro do Craton amazônico. Foram processados um conjunto de dados, produtos GOCE EGG_TRF_2 Level 2, ao longo das trajetórias do satélite para remover o ruído (shift/drift) nos gradientes da gravidade a partir da técnica crossover (XO).

Calculamos a redução das massas topográfica a fim de obter os componentes do gradiente da gravidade e anomalia da gravidade usando modelagem direta com prismas esféricos a partir do modelo de elevação digital, ETOPO1. Desta maneira, a comparação dos dados somente do satélite GOCE com as reduções das massas topográficas referentes aos componentes do gradiente da gravidade permitiram estimar quantidades invariantes que trouxeram uma melhoria na interpretação dos dados do tensor de gravidade. Além disso, comparamos dados terrestres do campo de gravidade com dados do campo de
\end{abstract}


gravidade dos modelos geopotenciais EGM2008 e GOCE, uma vez que os dados terrestres podem ser afetados por erros em longos comprimentos de onda devido a erros de nivelamento, diferentes referenciais de altitudes, e aos problemas em interligar diferentes campanhas de medidas da gravidade.

Portanto, estimamos uma melhora e uma nova representação dos mapas das anomalias de gravidade e do tensor gradiente da gravidade nas áreas inacessíveis do Craton Amazônico. As observações forneceram novas entradas para determinar campos regionais a partir dados brutos pre-processados (gradiente de gravidade EGG_TRF_2 L2), bem como a partir de um modelo geopotencial mais recente até grau e ordem 250 dos harmonicos esféricos derivados de dados somente do satélite GOCE para a representação do campo de gravidade como geóide, anomalias da gravidade e os componentes tensor da gravidade, os quais foram quantidades importantes para interpretação, modelagem e estudo dessas estruturas.

Finalmente, obtivemos um modelo isostático considerando a estrutura de densidade litosférica estudada através de uma modelagem direta 3D da distribuição de densidade por prismas esféricos usando a geometria do embasamento e descontinuidade do Moho. Além do que, constatamos através da modelagem direta das soleiras de diabásios dentro dos sedimentos mostramos que somente as soleiras dentro da Bacia do Amazonas não são as únicas responsáveis pela anomalia de gravidade positiva que coincide aproximadamente com as espessuras máximas dos sedimentos da Bacia. Talvez, isso possa ser também um resultado de movimentos relativos do Escudo das Guianas situado ao norte da Bacia, e o Escudo Brasileiro situado ao sul. Embora isso seja apenas uma evidência adicional preliminar, não podemos confirmá-las a partir das estimativas do campo da gravidade. Portanto, é necessário outros tipos de dados geofísicos, como por exemplo, evidências mais claras advindas do paleomagnetismo. 
RIASSUNTO

\section{L'utilizzo dei dati della missione GOCE per caratterizzare ed determinare la Struttura di Densità dei Bacini Sedimentari di Amazon e Solimões in Brasile}

Everton Bomfim, Ph.D

L’Università di Sao Paulo e L’Università Degli Studi di Trieste, São Paulo, 2012

Supervisori: Eder Molina (USP)

Carla Braitenberg (UNITS)

Il modo più diretto per rilevare le variazioni di densità è lo studio del campo potenziale di gravità e delle sue derivate. La disponibilità globale e buona risoluzione dei dati della missione satellitare GOCE, unitamente alla disponibilità dei dati gravimetrici terrestri sono l'ideale per intraprendere la comparazione e classificazione dei due grandi bacini sedimentari Amazon e Solimões nell'area del cratone amazzonico. Il set di dati GOCE ottenuti dalle tracce satellitari sono stati elaborati dal prodotti GOCE EGG_TRF_2 Level 2 generati con la correzione necessaria per rimuovere il rumore GOCE (spostamento/deriva) e così, noi abbiamo anche processato (da rimuovere la tendenza lineare) per recuperare i singoli componenti del tensore gradiente di gravità usando la tecnica crossover $(\mathrm{XO})$.

Sono state calcolate le riduzioni delle masse topografiche al fine di rilevare $\mathrm{i}$ componenti del tensore gradiente e le anomalie di gravità (componente verticale) usando la modellazione dai tesseroidi col Modello di Elevazione digitale, ETOPO1. Di conseguenza, la comparazione dei dati satellitari GOCE con le riduzione delle masse topografiche per i componenti gradienti ha permesso di stimare le quantità invariate per 
un miglioramento dell'interpretazione dei dati dei tensori di gravità. Inoltre, abbiamo comparato il campo di gravità dei dati terresti con modellazione gravimetrica del modello EGM2008 e del modello gravimetrico fornito da GOCE, in quanto i campi terrestri potrebbero essere colpiti da errori nelle lunghezze d'onda grandi, dovuto a errori di livellamento, dei diversi sistemi di riferimento impiegati nelle campagne dei diversi paese e quindi la difficoltà nel collegamento ed omogeneatà dei dati delle diverse campagne di misurazione.

Tuttavia, è stato riscontrato un miglioramento, e le nuove rappresentazioni nelle mappe sulle anomalie di gravità (Bouguer e free-air) e i componenti dei tensori gradienti di gravità principalmente in aree inaccessibili, come ad esempio il cratone amazzonico. Le osservazioni GOCE forniscono nuovi indizi per determinare i campi regionali dai dati grezzi (gradienti di gravità EGG_TRF_2 L2 ). Inoltre, è stato usato il più recente modello gravimetrico globale disponibile fino al grado e all'ordine 250, sviluppato dalle armoniche sferiche, derived solo dai dati del satellite GOCE per rappresentare il campo di gravità con le anomalie gravimetriche. Anche, sono stati presi in considerazione il geoide e le componenti del tensore gradiente, che sono quantità importanti per la modellazione e lo studio di queste strutture.

Infine, abbiamo ottenuto il modello isostatico considerando la struttura di densità della litosfera, studiata attraverso una modellazione 3D diretta della distribuzione di densità, usando la geometria del basamento e la discontinuità Moho, conosciuti come vincolo iniziale. Inoltre, abbiamo trovato attraverso la modellazione diretta con davanzali e sedimenti ha dimostrato che le soglie diabase non sono le sole responsabili per le anomalie gravimetriche positive che tagliano il Bacino Amazzonico, grosso modo coincidente con lo spessore massimo delle rocce sedimentarie o con il solco del bacino. Ciò potrebbe essere il risultato dei movimenti dello scudo della Guiana, situato a nord del Bacino Amazzonico, e lo scudo brasiliano, situato a sud. Sebbene questa sia solo una prova preliminare, ciò non può essere confermato solo dai dati di gravità. Infatti, sono necessari altri tipi di dati geofisici, ad esempio, evidenze più chiare ottenute dal paleomagnetismo. 
ABSTRACT

\title{
The use of the GOCE Mission Data for Characterizations of and Implications on the Density Structure of the Sedimentary Basins of Amazon and Solimões
}

\author{
Everton Bomfim, Ph.D
}

The University of Sao Paulo and the University of Trieste, São Paulo, 2012

Supervisors: Eder Molina (USP)

Carla Braitenberg (UNITS)

The most direct way to detect density anomalies is the study of the gravity potential field and its derivatives. The global availability and good resolution of the GOCE mission coupled with the availability of terrestrial gravity data are ideal for the scope of intercomparison and classification of the two large-scale Amazon and Solimoes sedimentary basins into area of the Amazon Craton. The GOCE data set obtained in satellite tracks were processed from EGG_TRF_2 Level 2 Products generated with the correction needed to remove the noise (shift/drift), and so, to recover the individual components of the gravity gradient tensor using the crossover $(\mathrm{XO})$ points technique.

We calculated the topographic masses reductions in order to obtain the gravity gradient components and gravity anomaly (vertical component) using forward modelling from tesseroids from Digital Elevation Model, ETOPO1. Thus, the comparison of the only-satellite GOCE data with the reductions of the topographic masses for the gradient components allowed to estimate invariants quantities for bring an improvement in the interpretation of the gravity tensor data. Furthermore, we compared the terrestrial data gravity field with EGM2008 and GOCE-deduced gravity field because the terrestrial 
fields may be affected by errors at long wavelengths due to errors in leveling, different height references, and problems in connecting different measurement campaigns.

However, we have estimated an improvement and new representations of the gravity anomalies maps and gravity gradient tensor components primary in inaccessible areas of the Amazon Craton. GOCE observations provide new inputs to determine the regional fields from the preprocessed raw data (EGG_TRF_2 L2 gravity gradients), as well from the most recent global geopotential model available up to degree and order 250 developed in spherical harmonics derived only-satellite GOCE data for representing of geoid and others gravity field as gravity anomaly and gravity gradient tensor components, which are important quantities for modelling and studying these structures.

Finally, we obtained the isostatic model considering the lithospheric density structure studied through a 3D direct modelling of density distribution using the geometry of basement and Moho discontinuity, assumed to be known as initial constraint. In addition, we found through direct modeling sills and sediment has shown that the diabase sills are not the only ones responsible for positive gravity anomaly map that transects the Amazon Basin, roughly coincident with the maximum thickness of sedimentary rocks or the trough of the basin. Maybe, this could be the result of the relative movements of the Guiana Shield, situated at the north of the Amazon basin, and the Brazilian Shield, situated at the south. Although this is only a preliminary additional evidence, we cannot confirm it only from the data of gravity. It is necessary others types of geophysical data, for example, more clear evidences obtained from paleomagnetism. 


\section{DECLARATION}

I certify that, to the best of my knowledge, my thesis does not infringe upon anyone's copyright nor violate any proprietary rights and that any ideas, techniques, quotations, or any other material from the work of other people included in my thesis, published or otherwise, are fully acknowledged in accordance with the standard referencing practices. Furthermore, to the extent that I have included copyrighted material that surpasses the bounds of fair dealing within the meaning of the Brazil Copyright Act, I certify that I have obtained a written permission from the copyright owner(s) to include such material(s) in my thesis and have included copies of such copyright clearances to my Annex and appendix.

I declare that this thesis is the result of work I have carried out since the commencement of my research. It is being submitted a true copy, including any final revisions, as approved by my thesis committee and the Graduate Studies Office for the degree of Doctor of Philosophy in international academic cooperation for the cosupervision of PhD students and double diploma between the University of São Paulo in São Paulo, Brazil, and the University of Trieste in Trieste, Italy. It has not been submitted before to any degree or examination to any other University or institution. 
"Science does not rest upon solid bedrock. The bold structure of its theories rises, as it were, above a swamp. It is like a building erected on piles. The piles are driven down from above into the swamp, but not down to any natural or 'given' base; and when we cease our attempts to drive our piles into a deeper layer, it is not because we have reached firm ground. We simply stop when we are satisfied that they are firm enough to carry the structure, at least for the time being. (1959)" 
Dedicated to my family, especially to my mother for all the love, support and friendship she has given me all over my entire life 


\section{ACKNOWLEDGEMENTS}

Special thanks go to my supervisors, Prof. Eder Molina and Prof. Carla Braitenberg, for their patient support, guidance and also for giving me the opportunity to complete this research. Worth of special mention is Prof. Eder, who tolerated me since the beginning of my master's dissertation, many years ago.

As in any major academic work, this one would have not been possible without the support of many incredible people and organizations, all staff of the computing, audio visual, graphical, security, graduate office of the IAG/USP and the girls of the Geophysical office, Teca and Virgínia. I wish to express my gratitude to all staff of the office for doctoral students at the University of Trieste who gave me support in whole bureaucracy of the co-guardianship program. I would also like to thank Prof. Carla, Patrizia, Ildiko and Tommaso for supporting me during my stay in Trieste, Italy.

I cordially acknowledge Prof. Naomi Ussami (University of Sao Paulo) for her constructive suggestions and useful advice during my thesis work, and also for making it possible for my $\mathrm{PhD}$ thesis to be the initial link to the International Academic Agreement For Co-Supervision and Double Diploma between the University of Sao Paulo (Dept. of Geophysical) and the University of Trieste (Dept. of Earth Sciences) due to the her role as co-investigator in the GOCE Project (ID: 4323, entitled: "Implications on the density structure below large scale basins from GOCE observations") without whom it wouldn't have been possible. I also want to thank Prof. Wladimir Shukowsky, my academic rapporteur, for his help and suggestions issued in all my semiannual academic reports.

I would like to thank Capes, CNPq and Capes PDEE, who provided the financial support for this research.

I thank IAG-USP for allowing me to use terrestrial data, and the Italian Space Agency (ASI) for supporting the GOCE-Italy project. I acknowledge the use of the combined model of EGM2008 (Pavlis et al., 2008), GOCE-only (Pail et al., 2011) gravity models, and Leonardo Uieda ( $\mathrm{PhD}$ student at $\mathrm{ON}$ - Observatório Nacional, Brasil) for allowing me to use his tesseroids - 1.0 software. 
Friendship provided inspirational insight and ideas into the world of geophysics, and I thank to all my colleagues in the graduation, whose that like me or not, as well as my friends in the everyday life in my hometown, buddies whom I went to pubs, parties and barbecues with, the new friends with whom I had the pleasure to meet around the world and many many more: guys, thanks for all the adventures, all the laughs, the motivation, the coffee and the tea! In specially, my friend Silvia Udovicic for leads me to a adventure in Machu Picchu...lol (joke) and also for her advices and encouragements to finish this thesis, as well as her pre-correction of the English edition of this thesis.

Finally, my special thank go to my family who has been very close to me through all these years. Specially to Mom, Dad, sister and maternal grandmother there are no words for how much I appreciate and love you guys. To my aunt Lia, Lurdes and Dora who have always been present, as far as possible, when I needed them most. I have got you all under my affection and gratitude.

Big hug to you all,

Everton Bomfim 


\section{TABLE OF CONTENTS}

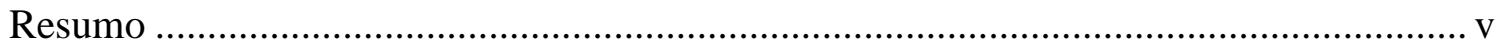

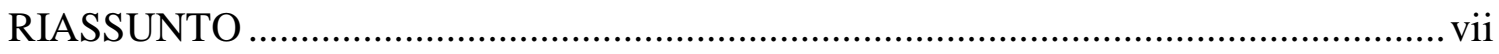

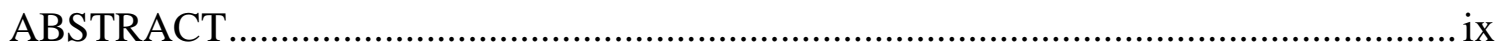

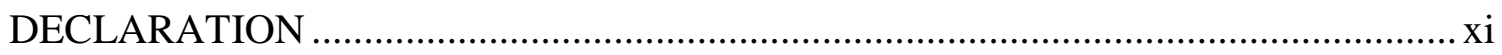

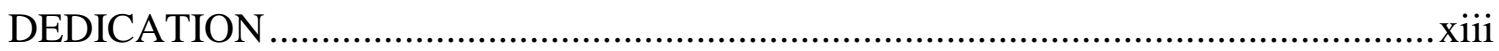

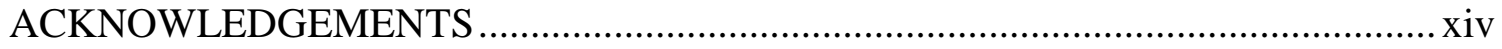

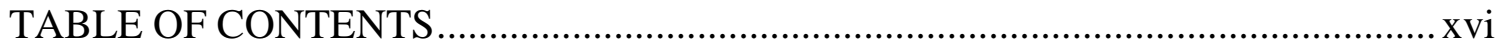

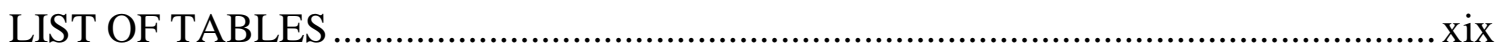

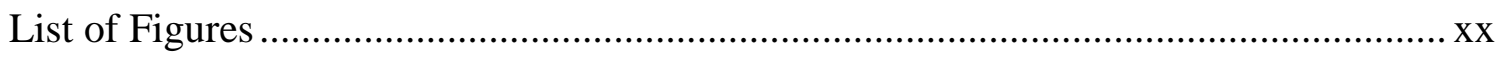

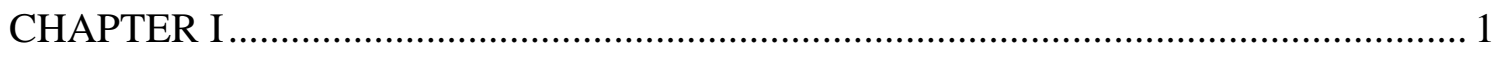

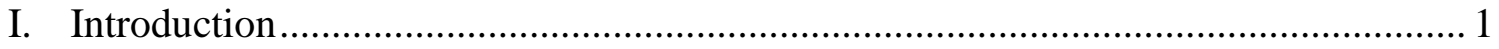

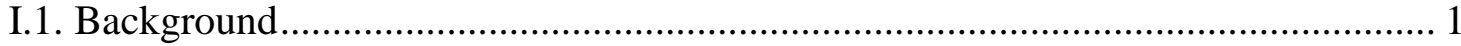

I.2. Modelling 3D: A Direct Problem ............................................................. 3

I.3. Problem Statement ................................................................................... 4

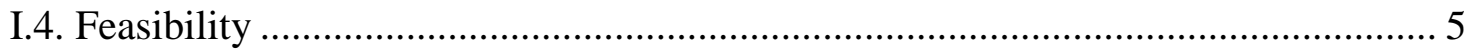

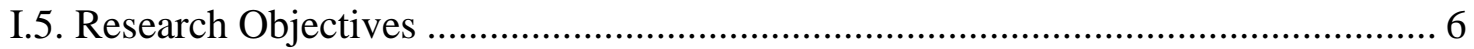

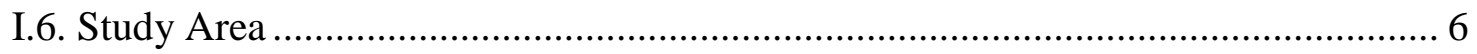

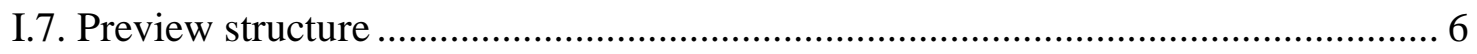

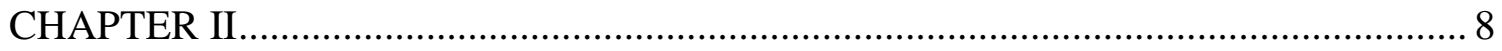

II. Literature Review: An Outline of the Geology in Amazon and Solimões Basin ........ 8

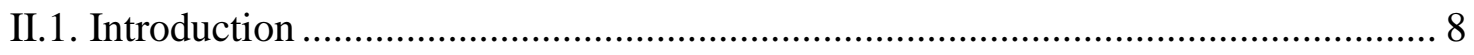

II.2. Geochronological Provinces of the Amazonian Craton ................................... 10

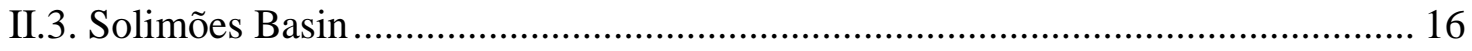

II.4. Amazon Basin .................................................................................................... 18

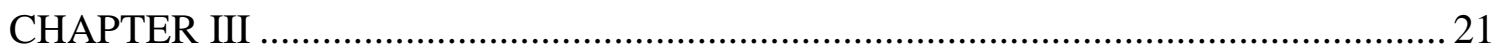

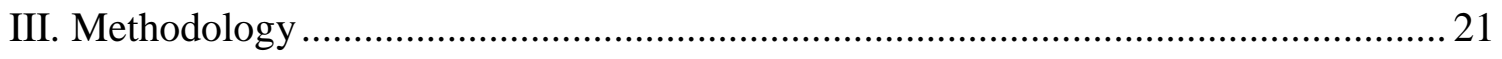

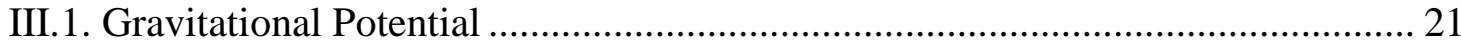


III.2. The gravitational potential and its second derivatives for the prism

III.3. Gravitational potential and its second derivatives for the tesseroid 28

III.4. Gravity field representation in spherical harmonics 35

III.4.1. Applications of global geopotential models in Geodesy and Geophysics .... 36 III.4.1.1. Parameters of the gravity field from the global geopotential models .... 37 III.4.1.2. Geoid height, gravity anomalies and deflection of the vertical

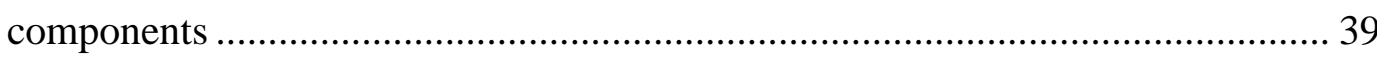

III.4.1.3. Gravimetric Reductions ............................................................ 41

III.4.1.4. Gradiometry: gravity gradient components ..................................... 42

III.4.1.5. Methods for Error Estimation ........................................................ 44

III.4.1.5.1. Errors GOCE: From Degree Amplitude to Gravity Anomaly errors in Spherical Harmonic .................................................................................. 44

III.4.1.5.2. Systematic errors of low spherical harmonic degrees in the surface

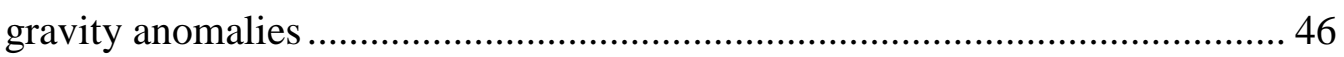

III.4.1.5.3. Spatial Averaging............................................................... 47

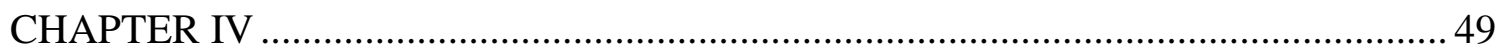

IV. Understanding and Interpreting the Gradients of Gravity with a Prism Approach for

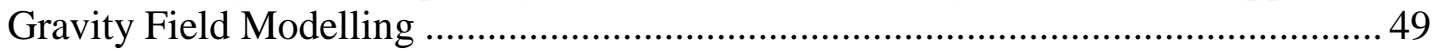

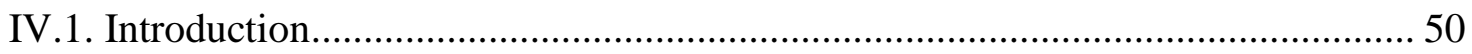

IV.2. Literature Review: History of Gravity Gradiometry .................................. 50

IV.3. Satellite Gradiometry Technology with GOCE ............................................. 57

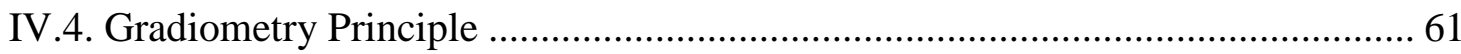

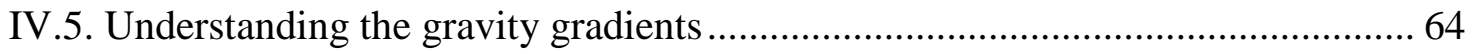

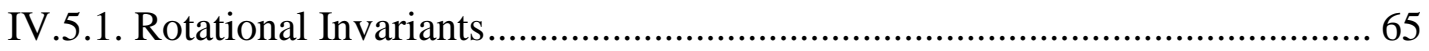

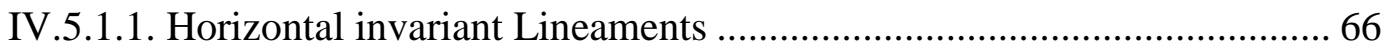

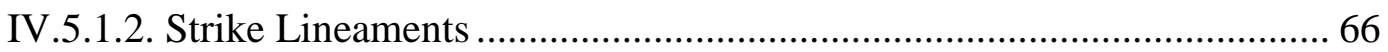




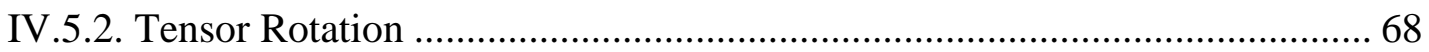

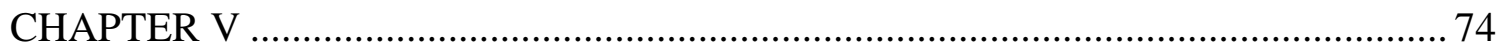

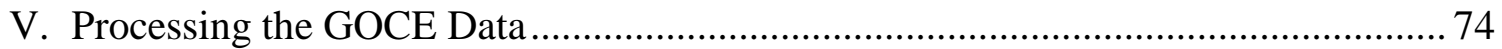

V.1. GOCE Satellite Track Cross-Overs ................................................................ 75

V.2. Linear Trend Estimation ................................................................................. 78

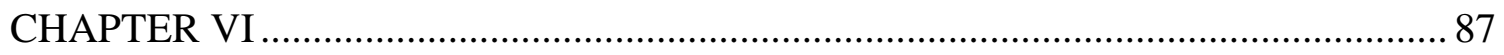

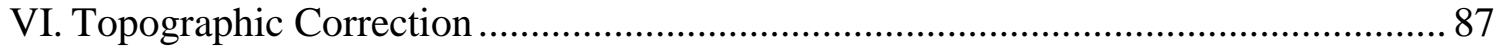

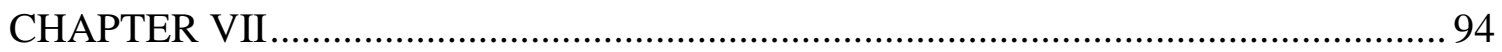

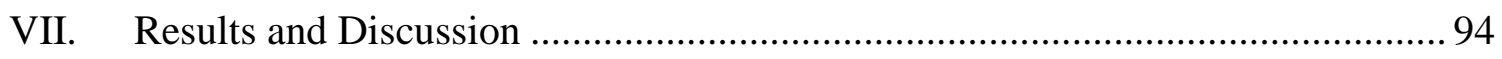

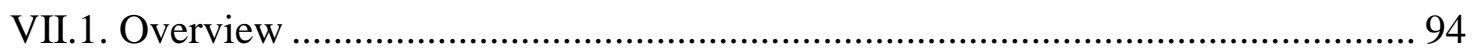

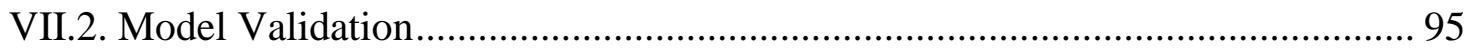

VII.3. Challenges and Limitations ........................................................................... 113

VII.4. Significant Contributions and Insights ................................................................ 114

VII.5. Recommendations for Future Research .................................................... 114

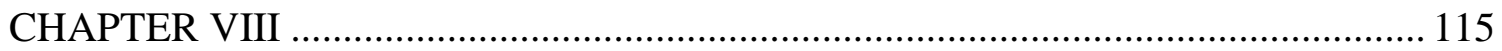

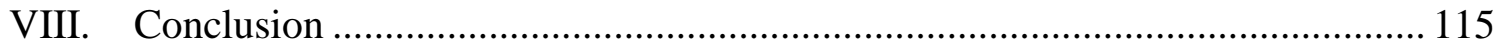

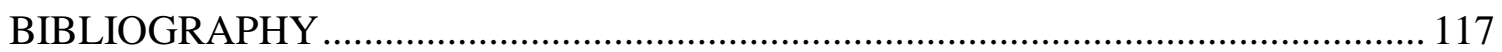

Annex A. Frames and Time System in GOCE Satellite........................................... 126

A.1. GRF - Gradiometer Reference Frame \& ARF - Accelerometer Reference Frame 126

APPEDIX A Mutual Evaluation of Global Gravity Models (EGM2008 and GOCE) and Terrestrial data in Amazon Basin, Brazil.......................................................... 130 


\section{LIST OF TABLES}

Table II-1: Evolution of the main interpretions of subdivisions in the Amazonian Craton (modified from Bizzi et al., 2004). ............................................................................. 11

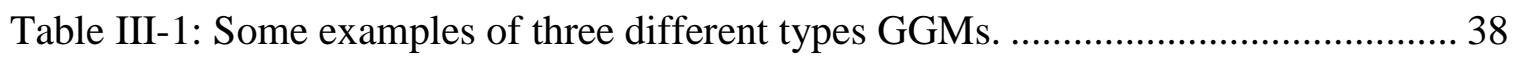

Table VII-1: Estimation of linear trends from XO gravity gradient differences $\left(\Delta \mathrm{V}_{\mathrm{zz}}\right)$ of the GOCE data set using different combinations (in height variation) of the tracks in the

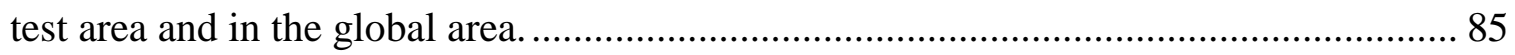




\section{LIST OF FIGURES}

Figure II-1: Main Brazilian Phanerozoic interior sedimentary basins and the study area the Solimões and Amazon Basins. Data: CPRM (after Bizzi et al., 2004)......................... 9

Figure II-2: Evolution of models for interpretation of the Amazon Craton. Models:1 Amaral (1974); 2 - Cordani et al. (1979); 3 - Teixeira et al (1989); 4 - Tassinari (1996); 5 - Santos et al. (2000) modified of Bizzi et al. (2004)................................................ 13

Figure II-3: Amazonian Craton Provinces modified from CPRM data (after Bizzi et al., 2004) draped over ETOPO1 digital elevation model, Amante and Eakins (2008).

Figure II-4: Tectonic framework of South America with emphasis on the Amazonian Craton and its tectonic provinces in the northeastern Brazilian region the Borborema province (B) predominates; the Tocantins province (T) is present in the Central Brazil region, which includes the Goiás Magmatic Arc (GMA) and the Mantiqueira province (M) (extracted from Cordani and Teixeira, 2007). 15

Figure III-1: Gravitational potential of a solid body. 22

Figure III-2: Right rectangular prism and Cartesian coordinate system of the computation point $\mathrm{P}$ and the element point $\mathrm{Q}$ (modified after Nagy et al., 2000). 26

Figure III-3: Schematic model of discretizing of the Earth's interior in $M$ regular prisms ( $\mathrm{j}$ $=1,2 \ldots M)$ and $N$ computation points on the surface $(\mathrm{i}=1,2 \ldots N)$ of the gravitational

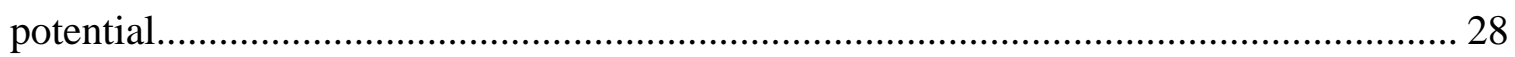

Figure III-4: Geometry of a spherical tesseroid and spherical coordinate system of the computation point $P$ and the element point $Q$ (modified after Heck and Seitz, 2007).... 29

Figure III-5: Terrestrial surface for description of the external gravity field at $P$ point involving three surfaces in geodesy and gravity field: the physical surface of the Earth, the geoid surface and the ellipsoidal surface, where $n$ and $v$ are the normal and vertical directions at the $P$ point.

Figure III-6: RMS errors in the gravity anomaly from the geopotential models and degree amplitudes for GOCE and EGM08 in the gravity anomaly (free-air), signal, error and difference between EGM08 and GOCE. 
Figure III-7: (a) Spatial averaging: Gaussian averaging function $W(\alpha)$ (continuous line) for the averaging radius $r=40 \mathrm{~km}$, (vertical stippled line); (b) Spherical harmonic coefficients of Gaussian averaging function for the same averaging radius $r=80 \mathrm{~km}$. Modified from Wahr et al. (1998) 48

Figure IV-1: Single Eötvös' Torsion Balance designed for field work. The first Gravity Gradiometer. Courtesy of the Loránd Eötvös Geophysical Institute (Szabo, 1998). ....... 51

Figure IV-2: Concept of GOCE Gravity Gradiometer Satellite with satellite to satellite tracking (SST) (modified after ESA, 1999). 58

Figure IV-3: Payload Electrostatic Gravity Gradiometer. Courtesy: European Space Agency

Figure IV-4: Position of the 6 accelerometers in the GOCE gradiometer in GRF (Gradiometer reference Frame) and all ARF (Accelerometer Reference Frame). The axes of the ARF are shown by solid arrows ultra-sensitivite aligned with the axes of the accelerometer. The axes of ARF shown by the dotted arrows are aligned to the axes of the accelerometer less sensitive. Each colour represents a one-axis gradiometer. The shadowed surfaces represent the locations of the lower plates (and the sole plates) (Gruber et al., 2009; See ANNEX A).

Figure IV-5: Power spectrum schematic of the first (vertical component, $\mathrm{T}_{\mathrm{z}}$ ) and second $\left(\mathrm{T}_{\mathrm{zz}}\right.$ component) derivatives of gravitational potential. The graphic on left illustrates the theoretical curves flattening gravity power spectrum indicating the resolution limit of the data. On the right the power spectrum shows a more realistic pattern of the gravity and the gradient gravity data (modified after Bell et al. 1997) 65

Figure IV-6: Anomalous mass represented by a rectangular prism with dimensions $(\Delta \mathrm{x}$, $\Delta y, \Delta z)=(50,50,4) \mathrm{km}$ at an average depth of $4 \mathrm{~km}$ centered in the origin of the xy-plane of the north-east-down (NED) coordinate system, which the positive $x$-axis correspond to north, which the positive $y$-axis correspond to east and positive $z$ to down.

Figure IV-7: Example of the gravity gradients derived from anomalous mass (prism) with dimensions $(\Delta \mathrm{x}, \Delta \mathrm{y}, \Delta \mathrm{z})=(50,50,4) \mathrm{km}$ at an average depth of $4 \mathrm{~km}$. The vertical gravity component $\mathrm{T}_{\mathrm{z}}$ is displayed in the lower left corner together with schematic 3-D prism for 
viewing at depth. Gradients $\mathrm{T}_{\mathrm{ij}}$ (with $i, j$ representing the three axes $x, y, z$,) are plotted together with the white box in the xy-plane representing the lateral dimension of the $3 \mathrm{D}$ prism model.

Figure IV-8: At the top the profiles AA' along $\mathrm{x}$-axis to $\mathrm{y}=0$ are plotted together with the vertical components of the gravity field (gravity anomaly $-T_{z}$ and gravity gradient $-T_{z z}$, respectively). At the bottom the gravity field values (in the left) and the power spectrum (in the right) along the profile AA' show the enhanced curve and resolution of the gravity field components $\mathrm{T}_{\mathrm{z}}$ and $\mathrm{T}_{\mathrm{z} z}$ 71

Figure IV-9: Representation of the gravity tensor using some invariances for highlight the anomalous mass, according eqs. IV-8 to IV -15 . 72

Figure IV-10: Response derived from hypothetical single prism model (dashed white box) in a rotated tensor coordinate system of 120 degrees about the $\mathrm{x}$-axis, simulating a structural feature to be enhanced in the northwest direction.

Figure V-1: Track files coverage of the GOCE gradiometric data provided by GOCE level 2 products covering the period from 10/2009 to 04/2011 (each bar corresponds to the time span of the orbit).

Figure V-2: Cross-over geometry of the SGG satellite tracks. Schematization of the satellite orbit cross-over in (a) "the same position in 3D space", (Modified from Bouman et al., 2005); and (b) the same geographical position on a two-dimensional projection over the surface of the study area.

Figure V-3: Satellite ground orbit based on the GOCE data track arc (blue and red lines represent the ascending and descending tracks, respectively) from 18 orbit days acquired on February, 2011 in a test area for the crossover analysis.

Figure V-4: XO differences of the whole data set of GOCE level 2 products covering the period from 10/2009 to 04/2011 (in 361 days) discussed in Figure V-1, showing a linear trend clearly visible from the least-squares estimation.

Figure V-5: Comparison of the Vzz component from (a) EGG_TRF_2 products GOCE Level 2 data without XO errors removal and (b) from geopotential GOCE-only gravity 
model (Pail et al., 2011) up to degree and order 250 calculatade in the satellite altitude of $250 \mathrm{~km}$.

Figure V-6: Covered on all Earth for 1 day track from GOCE Level 2 Products Track_GO_CONS_EGG_TRF_2 at 31 October 2009. 85

Figure V-7: Gravity gradients at the mean satellite height $(\mathrm{h} \approx 250 \mathrm{~km})$ from cross-over corrections. 86

Figure VI-1: Topography and bathymetry from ETOPO1 global relief model (Amante \& Eakins, 2008). 90

Figure VI-2: Effect caused by topographic masses using tesseroids at $250 \mathrm{~km}$ altitude for gravity anomalies from resampled ETOPO1 DEM 10' grid.

Figure VI-3: The resulting gravity effect on topography corresponding gravity gradients at altitude higher than regional height from resampled of the ETOPO1 DEM per 10 by 10 arc minute grid cell. 91

Figure VI-4: Effect caused by topographic masses using tesseroids at $250 \mathrm{~km}$ height for gravity anomalies from resampled of 10 arc-minutes ETOPO1 DEM. 92 Figure VI-5: Effect caused by topographic masses using tesseroids at GOCE satellite height $(\mathrm{h}=250 \mathrm{~km})$ for GGT from resampled ETOPO1 10' grid DEM. 93

Figure VII-1: Forward gravity modellig for sediment package and diabase sills from our assumed density models. 96 Figure VII-2: Gravity components along the profile A-A' that transects the Amazon Basin. See profile location plotted in Figure VII-3. 98

Figure VII-3: Representation of the Bouguer gravity anomaly in different aspects: (a) gravity anomaly calculated by tesseroids without the topographic effects; (b) Bouguer anomaly from the available terrestrial measurements; and (c) Bouguer gravity anomaly calculated in spherical harmonics removing the Bouguer plate effect from the classic gravity anomaly. 100

Figure VII-4: (a) Geoid calculated by harmonic expansion up to degree and order 250; (b) geoid calculated by harmonic expansion up to degree and order 10; (c) Residual geoid, 
being the difference (a)-(b); (d) gravity anomaly - free-air (mGal) calculated by harmonic expansion up to degree and order 250; (e) free-air anomaly (mGal) calculated by harmonic expansion up to degree and order 10 (f) Residual free-air anomaly (mGal) on Amazon and Solimões Basin, being (d)-(e). Data: GO_CONS_GCF_2_TIM_R3 ........ 101

Figure VII-5: Profiles of the Bouguer anomalies presented in Figure VII-3 in comparison with the modeled crustal thickness.

Figure VII-6: (a) Gravity disturbance; Deflection of the vertical components: (b) the meridian east/west $(\eta)$ components and (c) the prime vertical or north/south $(\xi)$. Data obtained from GO_CONS_GCF_2_TIM_R3 model 104

Figure VII-7: (a) Moho depth map (crustal thickness) in the Solimões, Amazonas Basin (from Lloyd et al. 2010) and the (b) gravity anomaly from it. 106

Figure VII-8: Gravity tensor components from GOCE only-satellite from GO_CONS_GCF_2_TIM_R3 (Pail et al. 2011). The Txy and Tyz components were despicted together with the major structures of the basin (black line). Data CPRM (Bizzi et al. 2004). 107

Figure VII-9: Gravity tensor components from GOCE at $250 \mathrm{~km}$ satellite height. 108

Figure VII-10: (a) Amplitude of the horizontal gradient; (b) Amplitude of the total gradient or analytic signal of $T_{z}$; and (c) The differential curvature from data obtained in Figure VII-8. (d), (e) and (f) are the same previous definitions however for the GOCE satellite height at $250 \mathrm{~km}$.

Figure VII-11: (a) An "equivalent Bouguer anomaly" at the height of $250 \mathrm{~km}$; (b) The gravity isostatic model; (c) $V_{z z}$ calculated at the height of the GOCE satellite $(250 \mathrm{~km})$ and (d) $V_{z z}$ calculated at the surface (both (c) and (d) corrected for the effect of the topographic masses in the respective height). (Dotted white lines show the probable structures of the mantle inferred in the present study) 112 


\section{INTRODUCTION}

\section{I.1. Background}

In some cases sedimentary basins appear to have an anomalous isostatic state if the classic isostatic hypothesis is considered, which assumes that the topographic and sedimentary loads are sustained by crustal thickening or thinning. In some cases, the high density of the material in the lower crust or upper mantle has been supposedly an important component in the formation of large scale sedimentary basins and in contributing to the isostatic equilibrium. Often, the high density anomalous mass can be related to phase changes in lower crust or upper mantle following a heating event.

Normally, the first phase in the formation of the large basins can be viewed from crustal or upper mantle loads leading to subsidence ages, presence of volcanism that last for several hundreds of million years and their classification according to the geoid, potential field and gravity anomalies provide important constraints for determining the geological properties and history of the Earth. In general, the gravity anomaly has been widely used in exploration geophysics due to technological restrictions and to the simplicity of its measurement and interpretation.

Historically, the use of the second derivatives of the gravitational potential began to solve geological problems in 1896 with the development of the Torsion Balance instrument by Baron Loránd von Eötvös, which quickly made the gravity gradiometry possible to oil prospectors around the world, becoming the predominant geophysical technique for exploration purposes. The use of gravity gradiometry continues to grow, and consequently, its measurements have also increased the resolution in the upper geologic section. The Earth's gravity field together with satellite missions has contributed to determine and improve the understanding of the Earth's gravity field in the past decade. In the years 1960's and 1980's, geodetic satellites have provided information about medium and long-wavelength components in geopotential models of Earth's gravity field represented in spherical harmonics. Indeed, a variety of global geopotential models express the earth's gravity field and therefore the geoid height in terms of spherical harmonics and have been computed by various groups, for example, GPM98 A, B and C (Wenzel, 1998), EGM96 (Lemoine et al., 1998). Recently, the CHAMP (CHAllenging Minisatellite Payload) Mission (Reigber et al., 2002) and the Gravity Recovery And Climate Experiment (GRACE) Mission (Tapley et al., 2004), as well as its latest geopotential models, e.g. EGM2008 model 
(Pavlis et al., 2012), led to significant contributions with respect to knowledge about long wavelength and consequently long-wavelength geoid for providing global and high-resolution estimates of the Earth's gravity field and its temporal variations (Keller and Sharifi, 2005; Kiamehr and Eshagh, 2008; Rummel et al., 2002; Yi et al., 2010).

Finally, the GOCE (Gravity field and steady-state Ocean Circulation Explorer) Mission applies the principle of Satellite Gravity Gradiometry (SGG) that is being used in space with a tridimensional (3-D) gradiometer on board to measure the gravity gradient components of the Earth's gravity field, providing a new regional aspect for global geopotential models (ESA, 1999; Keller and Sharifi, 2005; Rummel et al., 2002; Yi et al., 2010).

The most direct way to detect crustal density anomalies is the study of the earth gravity potential field and its derivatives. Thus, the global availability and good resolution of the GOCE satellite gravity gradiometry mission, coupled with the availability of data from terrestrial gravity surveys, are ideal for the scope of intercomparison and classification of the Amazon and Solimões sedimentary basins, which in geological terms are very old and classified as intracratonic or Paleozoic basins in an area of almost $1,000,000 \mathrm{~km}^{2}$ separated by the Purus Arch.

Although modern gravity measurements have recorded with great precision the Earth's gravity, this field is known to not identify body's edges and to contain no directional information; this is the reason why there is a large variety of inversion and interpretation methods using gravity gradients. The gravity gradients directly recover sharp signals over the edges of structures, where the concept of gravity gradiometry is a 3D gravity and its anomalies reflect the edges and shapes of sources rather than just the mass distribution (Bell et al., 1997). Each individual information of the gravity tensor can be related to geological attributes (subsurface geology) and are used to locate bodies or to map geological contact information (horizontal components: $T_{x x}, T_{x z}, T_{x y}, T_{y y}$ and $\left.T_{x z}\right)$ whereas the vertical component $\left(T_{z z}\right)$ provides additional constraint and information relating to size, depth and isopachs of geological targets.

The impact of working with these pieces of information of the gravity tensor can be significative as an 'engine' that facilitates to identify not only the geology of the target but also mapping its geological configuration in any survey area in terms of shape, size and orientation of target structures (Murphy and Dickinson, 2010).

The use of invariant analysis with gravitational and magnetic gradients is one of the methods studied by Pedersen and Rasmussen (1990) describing a procedure which combines all the 
horizontal components of the tensor using the invariance to isolate the signature patterns emerging from the underlying geology to produce a series of lineament maps that indicate the dimensionality of the sources.

Hence, the lithospheric density structure can be studied through a 3D modelling of density distribution using the geometry of basement and Moho discontinuity, assumed to be known as initial constraint. Furthermore the Earth's gravity field in terms of geoid, gravity anomalies and gravity gradient tensor components can be studied to allow modelling and studying of these structures.

\section{I.2. Modelling 3D: A Direct Problem}

Suppose that the shape of the earth and the density variations within it are exactly known. With this information, a unique value of the actual potential, $W$, can be found. That is, the determination of the actual potential is a well-posed "direct" problem. Thus, due to its simplicity and its approximate expressions relating to gravitational potential, the use of rectangular prisms has been target of interest in gravity modelling. Here, a three-dimensional density distribution can be approximated with desired accuracy using the prisms. This can be represented with the discretization within the Earth in regular prisms which are associated with homogeneous density contrast values for the calculation of the potential gravitational and gravity gradients independently of the other neighbor prism of different density.

The formulation of Nagy et al. (2000) gives the field of the rectangular prism, which limits the applicability over large areas because it implies an approximation of the flat earth, but even so it is a good alternative for describing the density distribution and especially useful in studies for gravitational potential modelling.

The gravitational potential and its derivatives of a spherical prism in spherical coordinates, being defined as tesseroid, was obtained by Heck \& Seitz (2007). This geometry provides the formulas for the topographic-isostatic reduction of the vertical deflections to reveal the advantage using tesseroids instead of prism due to its better approximation of the spherical earth. However, the representation of the Earth in spherical tesseroids only can be computed numerically because no approximated form yet has been found to solve the triple integral analytically due to the occurrences of elliptic integrals. Thus, Heck \& Seitz (2007) suggested to use an approximated integral solution that reduces to a surface integral by numerical integration with respect to the radial coordinate. 
Although the use of gravity gradients data in hydrocarbon and mineral exploration is more common, nevertheless interpretation of these data is not as easy as standard gravity data. There is a study (Saad, 2006) showing that for a given source, regardless of its simplicity, gravity gradients produce a complex pattern of anomalies compared to the simple single-amplitude gravity anomalies. The gravity gradients are maximum over the edges, corners and center of mass of the causative body, according to the component. This has been observed differently by Bell et al. (1997), showing that integration of gravity gradiometry measurements into standard gravity (vertical component) significantly changes the power spectrum slope, indicating improved resolution of small features by the gradients. The steepness of the power spectrum obtained by gradiometry can reflect enhanced curve suggesting that gravity gradients significantly improve the capability of gravity to constrain the location of structures. In contrast to the flattening of the standard gravity curve indicating a limitation of resolution to constrain the anomalous masses using only the traditional gravimetric proceeding.

\section{I.3. Problem Statement}

This research is part of a greater project that has as the goal to use the GOCE products of the gravity potential to study large scale basins of the South American continent (Amazon, Solimões, Parnaíba, Paraná), the Tarim Basin and the Michigan Basin for intercomparison, which will allow to classify the basins according to their potential field signal. The project is one of the GOCE user projects, with ID: 4323, entitled: "Implications on the density structure below large scale basins from GOCE observations.

In this work, in the first phase a digital database of constraining data was constructed, which extended over the study area and included basement depth, sediment densities, sediment depth variation, Moho depth, lithospheric thickness (where available). Then the estimation of anomalies and derivatives generated by variations in topography and thickness of sediment and crust/mantle variations was done, as well as the mapping of the observed gravity anomalies and other terrestrial data available. Phase one is a feasibility study to SGG (Satellite Gravity Gradiometry) of GOCE to investigate the gravity field signal in Amazon and Solimões sedimentary basins. Phase two involves a comparison of the GOCE products data, gravity potential and its derivatives, with the available terrestrial gravity data. The final phase involves residual fields in order to determine crustal and upper mantle density anomalies. 


\section{I.4. Feasibility}

First and foremost, the definition of feasibility within the scope of this study follows also a part of the Science Goals of the GOCE Mission (e.g. Table 4.1 of GOCE Level 2 Product Data Handbook) (Gruber, et al., 2009). Particularly, this research is constrained to a greater project described above and which has as principal-investigator my adviser in University of Trieste, Carla Braitenberg, who is also the promotor of the International Academic Agreement For CoSupervision and Double Diploma between the University of São Paulo (Dept. of Geophysical), Brazil, and the University of Trieste (Dept. of Earth Sciences), Italy, making my $\mathrm{PhD}$ thesis feasible in this frame.

The gravity field and gradient tensor data have been observed in the GOCE mission and I use the geopotential models GOCE and EGM2008.

This study concerns understanding the density anomalies on Paleozoic Amazon and Solimões Basins on the Amazon Craton that cover enormous, partly inaccessible areas; only partially terrestrial gravity data, irregularly distributed, are available, wherefore high-resolution global satellite gravity gradiometry data produced by GOCE are essential for fulfilling this research.

I use other data available from open literature, as sediment thickness and Moho depth.

I compare the terrestrial data gravity field with EGM2008 and GOCE-deduced gravity field because the terrestrial fields may be affected by errors at long wavelengths due to errors in leveling, different height references, and problems in connecting different measurement campaigns. In inaccessible areas the GOCE observations provide new inputs to determine the regional fields (See APPENDIX A).

The GOCE data will improve the representation of the regional field, which is also one of the main objectives of the mission.

Innovation: A systematic screening of the gravity potential field and its derivatives as well as a study of the gravity field for these intra-cratonic sedimentary basins has not been made before, although the partial screening of geologic properties and gravity modelling are available in Milani \& Zalán (1999), Tassinari and Macambira (1999) and Nunn \& Aires (1988), respectively. Indeed, these types of basins have in common the fact that the Moho discontinuity is not shallow in correspondence to basin, which implies that the mass deficit in the basin could be compensated by high density in the crustal or upper mantle levels. Hypothetically, this fact could be essential to the formation of these types of basins and could be related to an eclogite phase change. 
Contribution: The proposed research contributes to the improvement of the understanding of the solid Earth processes, in particular to the subject Lithosphere and upper mantle structure underlying sedimentary basins here studied by Satellite Gravity Gradiometry GOCE measurements.

\section{I.5. Research Objectives}

The objective of this research is to use the GOCE Level 2 products of the gravity potential and its derivatives to improve the understanding of Amazon and Solimões sedimentary basins also known as cratonic or intracratonic basins and which bear important natural hydrocarbon resources in Brazil.

Of particular interest in the gravity anomaly map is the chain of gravity highs that transects the Amazon Basin, roughly coincident with the maximum thickness of sedimentary rocks or the trough of the basin. This can be primarily due to the presumed downward deflection of the crust/mantle boundary beneath the basin.

\section{I.6. Study Area}

This study is concentrated in the gravity observations of the Paleozoic Basins in Amazon Craton, Brazil: the Solimões and Amazon Sedimentary intracratonic basins are situated $-10^{\circ} \leq \varphi \leq 5^{\circ}$ in latitude and $-75^{\circ} \leq \lambda \leq-45^{\circ}$ in longitude and are discussed in the next chapters.

\section{I.7. Preview structure}

This thesis is divided into eight chapters. The Chapters I through V are dedicated to highlights, statements, understanding and objectives of the problem setup, literature review with history of gravity gradiometry, the history of gravity satellite missions and global geopotential models for the gravity field, methodologies and methods required to collect and enhance data used in this research. Among the five subsequent chapters, the Chapter II gives a brief geological description of the study area. Chapter III summarizes briefly basic gravity field principles, the methods and tools as satellite gradiometry, terrestrial gravity observations and a representation of the Geopotential Gravity Model (GGM) in spherical harmonics, a short review of previous gravity (geodetic) satellite missions and global geopotential models, as well as methodology for forward modelling and topographic reduction. Chapter IV encompasses the history of gravity gradiometry and a review of the satellite gravity gradiometer GOCE technology. Furthermore, a study was done on the modelling of gravity gradients based on the formulas of Nagy et al. (2000) (prism models) and Heck and Seitz (2007) (tesseroid models) . 
Chapter V covers the processing of the GOCE Level 2 Products data, EGG_TRF_2, which requires the extraction and preparation of additional corrections needed in order to remove the GOCE GGs noise (shift/drift) on XO points due to different orbit heights.

In the chapter VI the calculation of the topographic masses reductions is obtained for gravity gradient components and gravity anomaly (vertical component) using tesseroids from Digital Elevation Model (DEM) such as ETOPO1. Chapter VII also provides the results, analysis and discussion of the gravity field serving to report the findings from the feasibility study. Furthermore, the Chapter VII provides other data found in the study area as basement depth, sediment densities, sediment depth variation, Moho depth. Estimation of anomalies and derivatives generated by variations in topography and thickness of sediment and crust/mantle thickness and mapping of the gravity anomalies and other available terrestrial data. Also how gravity gradient maps were constructed from GOCE and geopotential models in order to determine resolution and precision. Finally, the Chapter VIII is a closing discussion that will conclude the thesis with significant contributions and insights. Also, a summary of the research and possible challenges and future work recommendations will be discussed. 


\section{LITERATURE REVIEW: AN OUTLINE OF THE GEOLOGY IN AMAZON AND SOLIMÕES BASIN}

It is essential to understand the driving mechanism, when considering the evolution and subsidence history of the basins as well as the age from geochronology, which provides the duration and magnitude of independent subsidence episodes. The relative subsidence due to thermal contraction following a heating event continues, whether or not the basin is exposed to a eustatic lowering of sea level suggesting that sequences of sediments between craton-wide unconformities reflect separate mechanical episodes of subsidence. However, these reasonable eustatic sea level changes could cause the main unconformities observed in rapidly subsiding platform basins according to Nunn and Aires (1988).

As such, we have Paleozoic sedimentation preserved when referring to the remnants of significant, mostly undisturbed basins. The large Brazilian basins (Figure II-1), for instance Solimões, Amazonas, Parnaíba and Paraná, are named after large rivers that flow along their major axes.

In particular, the present study is localized on the Amazon and Solimões Basins that follow a EW trend overlying the Amazonian Craton (AC) which is considered as one of the largest cratonic areas in the world between exposures of two large Precambrian shields, Guiana Shield to the north and the Brazilian Shield to the south. It is located in the northern part of South America covering about $440,000 \mathrm{~km}^{2}$ surrounded to the east by the Neoproterozoic Tocantins province, in which the active orogenic systems Araguaia and Paraguay mobile belts generated during the Brasiliano Orogenic Cycle. The AC is concealed beneath the Phanerozoic coverage of several basins as to the Northeast (Maranhão), South (Xingu and Alto Tapajós), Southwest (Parecis), West (Solimões), North (Takutu) and in its center (Amazon basin) (Matos and Brown 1992; Milani and Zalán 1999; Bizzi et al. 2004; Cordani et al. 2009).

\section{II.1. Introduction}

The Solimões and Amazon Basins comprise an area of almost 1,000,000 $\mathrm{km}^{2}$, and were formed overlying the central part of the region, starting in the Lower Paleozoic. These structures show many tectonic and magmatic features always related to major tectonic events occurring at their margins. To the North and West, the Andean belt was the source of the stresses responsible for some important tectonic reactivations, mainly related to compressional or transpressional 
stresses. To the north-east, extensional features are the result of the opening of the North Atlantic, starting at about $200 \mathrm{Ma}$.

Due to the paleomagnetic and geologic evidences that have been described in Tohver et al. (2006), Cordani et al. (2009) and Bipo-Santos et al. (2012), there is practically no doubt about the existence of the Pangea at the end of Paleozoic, and also about the position of the different cratonic nuclei within the Amazonian Craton, as suggested by Cordani and Teixeira (2007).

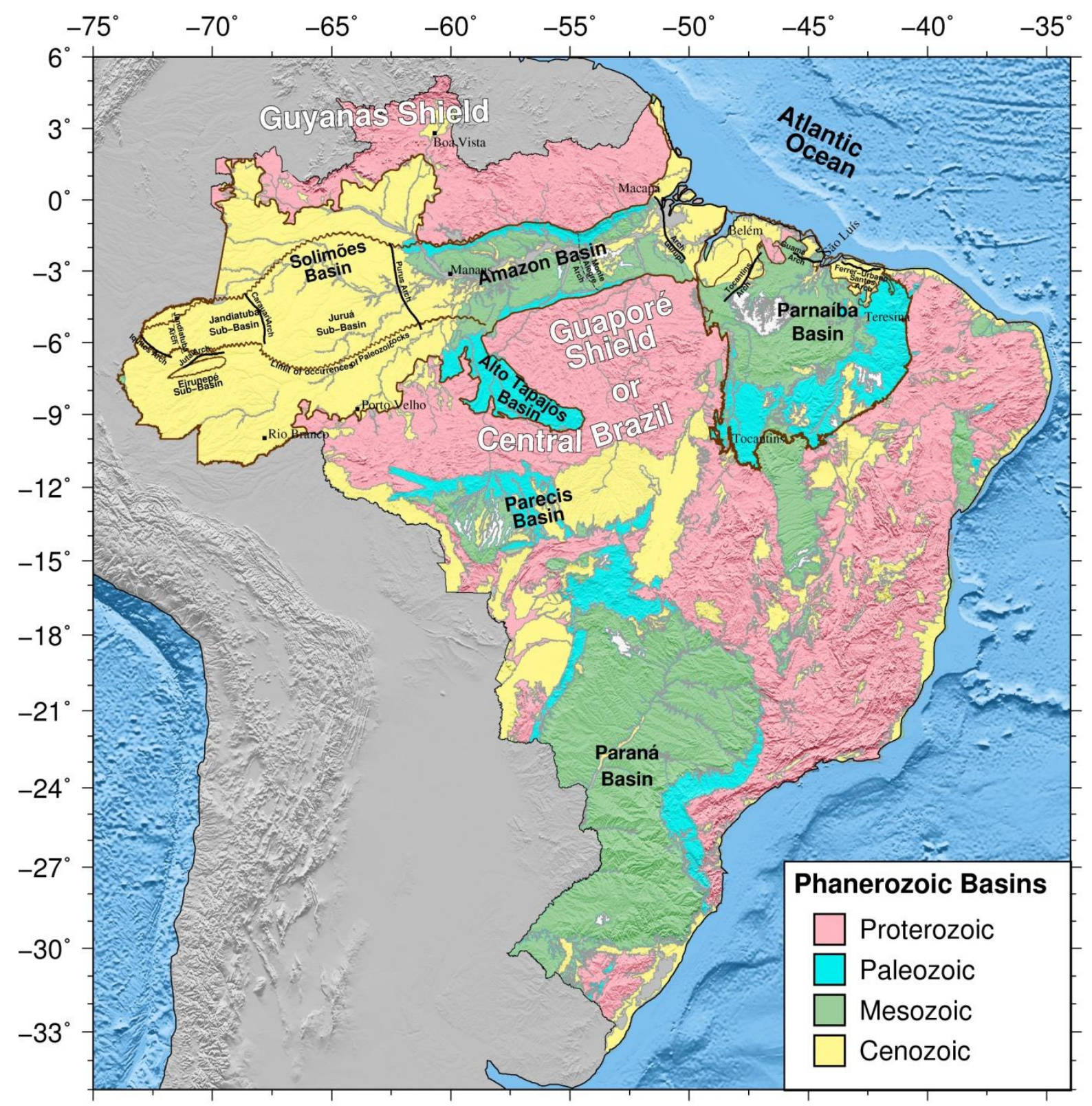

Figure II-1: Main Brazilian Phanerozoic interior sedimentary basins and the study area - the Solimões and Amazon Basins. Data: CPRM (after Bizzi et al., 2004).

The tectonic units in the AC compose a large crustal province known as the South American platform, and, in association with the Andean belt and the adjacent sub-andean flats, they 
constitute the bulk of the South American continent and remained tectonically stable in Phanerozoic times (Milani and Zalán 1999; Bizzi et al. 2004; Cordani et al. 2009).

\section{II.2. Geochronological Provinces of the Amazonian Craton}

The isotopic studies and the definition of geochronological provinces are useful for providing a basis for the understanding of the crustal evolution processes and their tectonic implications on a continental scale. Here the geochronological pattern of the AC will be summarized, attempting to describe the isotopic and geological data to understand the geological evolutionary history, based on the works of Amaral (1974); Cordani et al. (1979); Teixeira et al. (1989); Tassinari et al. (1996); Tassinari (1996); Santos et al. (2000); and Bizzi et al. (2004).

The suggested tectonic evolution controlled by crustal episodes of accretions partially follow the principles of Stockweel (1968) obtained in the Canadian Shield study, based on the occurrences of the geological similarity between this unit and other cratonic regions in the world. For example, Africa and Australia, are major zones within cratonic areas, where a characteristic geochronological pattern predominates, and the age determinations obtained by different isotopic methodologies for different geological units characterizes the divisions mainly on the basis of the ages of the metamorphic basement and the geological characteristics. However, these provinces may include one or more orogenic episodes within their respective time-periods, considering orogeny as a period of metamorphic episodes accompanied by deformation, partial melting and syntectonic granitic intrusions, and not as the broader concept of a complete orogenic cycle, involving subsidence, deposition of sediments, metamorphism, syn- and post-tectonic magmatic activities and anorogenic episodes. Thus, the provinces mainly differ from each other in the ages of metamorphic terranes and their geological history (Tassinari and Macambira, 1999; Coutinho, 2008).

According to Tassinari and Macambira (1999), the geographical boundaries between geochronological provinces in the AC have been reasonably well-defined mainly according to the geochronological and the geophysical-structural models, although some limits are still not well characterized due to the overprint of age determinations and/or lack of reliable geological information. Therefore some boundaries already defined were questioned regarding the precise location of the geochronological boundaries observed in the field that are increasingly being established from detailed geological studies since Amaral (1974), passing through Cordani et al. (1979), Teixeira et al. (1989), Tassinari et al. (1996), Tassinari and Macambira (1999), Tassinari et al. (2000), Santos et al. (2000), Bizzi et al. (2004), Cordani and Teixeira (2007) and Cordani et al. (2009). 
Based on the radiometric data from the Precambrian rocks of the Brazilian Amazon, predominantly Rb-Sr analysis, different authors proposed an evolutionary model for the Amazonian Craton.

Table II-1: Evolution of the main interpretions of subdivisions in the Amazonian Craton (modified from Bizzi et al., 2004).

\begin{tabular}{|c|c|c|c|c|c|c|c|c|}
\hline $\begin{array}{l}\text { Amaral } \\
(1974)\end{array}$ & $\begin{array}{l}\text { Cordani et } \\
\text { al. (1979) }\end{array}$ & $\begin{array}{l}\text { Teixeira et al. } \\
(1989)\end{array}$ & $\begin{array}{l}\text { Tassinari et al. } \\
\text { (1996). }\end{array}$ & Tassinari (1996). & $\begin{array}{l}\text { Tassinari and } \\
\text { Macambira (1999). }\end{array}$ & Santos et al. (2000) & Bizzi et al. (2004) & $\begin{array}{l}\text { Cordani and Teixeira } \\
(2007)\end{array}$ \\
\hline \multirow[t]{2}{*}{$\begin{array}{l}\text { Eastern } \\
\text { Amazon }\end{array}$} & \multirow{2}{*}{$\begin{array}{l}\text { Maroni- } \\
\text { Itacaiúnas } \\
2100-1800 \\
\text { Ma (with } \\
\text { Carajás) }\end{array}$} & $\begin{array}{l}\text { Maroni-Itacaiúnas } \\
\text { Mobile Belt } \\
\text { (including K'Mudku } \\
\text { Belt) 2250-1900 } \\
\text { Ma. }\end{array}$ & $\begin{array}{l}\text { Maroni-Itacaiúnas } \\
\text { (including } \\
\text { K'Mudku Belt) } \\
\text { 2200-1900 Ma. }\end{array}$ & $\begin{array}{l}\text { Maroni-Itacaiúnas } \\
2200-1950 \text { Ma. } \\
\text { (including only part } \\
\text { of the K’Mudku Belt) }\end{array}$ & $\begin{array}{l}\text { Maroni-Itacaiúnas } \\
2200-1950 \text { Ma. } \\
\text { (including only part } \\
\text { of the K'Mudku } \\
\text { Belt) }\end{array}$ & \begin{tabular}{lr}
\multicolumn{2}{l}{ Trans-Amazonian } \\
$2250-2000$ & Ma. \\
(including & the \\
K'Mudku Belt) &
\end{tabular} & $\begin{array}{lr}\text { Trans-Amazonian } \\
2250-2000 & \text { Ma. } \\
\text { (including } & \text { the } \\
\text { K'Mudku Belt) } & \end{array}$ & $\begin{array}{l}\text { Maroni-Itacaiunas } \\
2.25-2.05 \quad \mathrm{Ga} \\
\text { Paleoproterozoic } \\
\text { belts. }\end{array}$ \\
\hline & & \multirow{5}{*}{$\begin{array}{l}\text { Central Amazonian } \\
\text { Province (including } \\
\text { Carajás) }>2500 \mathrm{Ma} .\end{array}$} & \multirow{5}{*}{$\begin{array}{l}\text { Central Amazonian } \\
\text { (including Carajás) } \\
>2200 \text { Ma. }\end{array}$} & \multirow{3}{*}{$\begin{array}{l}\text { Central Amazonian } \\
\text { (including Carajás) > } \\
2300 \mathrm{Ma}\end{array}$} & \multirow{3}{*}{$\begin{array}{l}\text { Central Amazonian } \\
\text { (including Carajás) } \\
>2300 \mathrm{Ma}\end{array}$} & $\begin{array}{l}\text { Carajás 2530-3100 } \\
\text { Ma. }\end{array}$ & $\begin{array}{l}\text { Carajás } \\
\text { Ma. }\end{array}$ & \multirow{2}{*}{$\begin{array}{l}\text { Central Amazonian > } \\
2.6 \text { Ga. Archean } \\
\text { nuclei (including } \\
\text { Carajás and the } \\
\text { Xingu-Iricoumé) }\end{array}$} \\
\hline \multirow{4}{*}{$\begin{array}{l}\text { Central } \\
\text { Amazon }\end{array}$} & \multirow{4}{*}{$\begin{array}{l}\text { Central } \\
\text { Amazonian } \\
>2100 \mathrm{Ma} \text {. }\end{array}$} & & & & & $\begin{array}{l}\text { Central Amazon } \\
1800-1700 \mathrm{Ma} .\end{array}$ & $\begin{array}{l}\text { Central Amazon } \\
2600-1700 \mathrm{Ma} \text {. }\end{array}$ & \\
\hline & & & & & & \multirow[t]{2}{*}{$\begin{array}{l}\text { Tapajós-Parima } \\
2100-1870 \mathrm{Ma}\end{array}$} & \multirow[t]{2}{*}{$\begin{array}{l}\text { Tapajós-Parima 2100- } \\
1870 \mathrm{Ma}\end{array}$} & $\begin{array}{l}\text { Ventuari-Tapajós } \\
1.98-1.81 \mathrm{Ga}\end{array}$ \\
\hline & & & & \multirow{2}{*}{$\begin{array}{l}\text { Tapajós-Ventuari } \\
\text { 1900-1800 Ma. }\end{array}$} & \multirow{2}{*}{$\begin{array}{l}\text { Tapajós-Ventuari } \\
\text { 1950-1850 Ma. }\end{array}$} & & & \\
\hline & & & & & & Rio Negro $1860-1520$ & Rio Negro $1860-1520$ & $\begin{array}{l}\text { Rio Negro-Juruena } \\
1.78-1.55 \mathrm{Ga} \text { - soft- }\end{array}$ \\
\hline \multirow{5}{*}{$\begin{array}{l}\text { Western } \\
\text { Amazon }\end{array}$} & \multirow{2}{*}{$\begin{array}{l}\text { Rio Negro- } \\
\text { Juruena } \\
1700-1450 \\
\text { Ma. }\end{array}$} & \multirow{2}{*}{$\begin{array}{l}\text { Rio Negro-Juruena } \\
\text { Mobile Belt 1750- } \\
1500 \mathrm{Ma} \text {. }\end{array}$} & \multirow[b]{2}{*}{$\begin{array}{l}\text { Rio Negro-Juruena } \\
\text { 1800-1550 Ma. }\end{array}$} & \multirow[b]{2}{*}{$\begin{array}{l}\text { Rio Negro-Juruena } \\
\text { 1800-1550 Ma. }\end{array}$} & \multirow[b]{2}{*}{$\begin{array}{l}\text { Rio Negro-Juruena } \\
\text { 1800-1550 Ma. }\end{array}$} & & $\mathrm{Ma}$ & $\begin{array}{l}\text { collision/accretion } \\
\text { processes }\end{array}$ \\
\hline & & & & & & \multirow{2}{*}{$\begin{array}{l}\text { Rondônia-Juruena } \\
\text { 1760-1470 Ma. }\end{array}$} & $\begin{array}{l}\text { Rondônia-Juruena } \\
\text { 1810-1520 Ma. }\end{array}$ & Rondonian-San \\
\hline & \multirow{3}{*}{$\begin{array}{l}\text { Rondonian } \\
1400-1100 \\
\text { Ma. }\end{array}$} & \multirow{2}{*}{$\begin{array}{l}\text { Rodonian Mobile } \\
\text { Belt 1450-1250 Ma. }\end{array}$} & \multirow{2}{*}{$\begin{array}{l}\text { Rondonian-San } \\
\text { Ignacio 1450-1300 } \\
\text { Ma. }\end{array}$} & \multirow{2}{*}{$\begin{array}{l}\text { Rondonian-San } \\
\text { Ignacio } \quad 1500-1300 \\
\text { Ma. }\end{array}$} & \multirow{2}{*}{$\begin{array}{l}\text { Rondonian-San } \\
\text { Ignacio } 1500-1300 \\
\text { Ma. }\end{array}$} & & \multirow{3}{*}{ Sunsás 1450-990 Ma. } & \\
\hline & & & & & & \multirow{2}{*}{ Sunsás 1330-990 Ma. } & & \\
\hline & & $\begin{array}{l}\text { Sunsás Mobile Belt } \\
\text { 1100-900 Ma. }\end{array}$ & $\begin{array}{l}\text { Sunsás } 1250-1000 \\
\text { Ma. }\end{array}$ & $\begin{array}{l}\text { Sunsás } \quad 1250-1000 \\
\text { Ma. }\end{array}$ & $\begin{array}{l}\text { Sunsás } 1300-1000 \\
\text { Ma. }\end{array}$ & & & Sunsas $1.28-0.95 \mathrm{Ga}$ \\
\hline
\end{tabular}


Amaral (1974) divided the craton into three geochronological provinces (i.e.: Eastern, Central and Western Amazon Provinces), in a model that was refined by many authors such as Cordani et al. (1979), Teixeira et al. (1989), Tassinari et al. (1996), Tassinari et al. (2000), Santos et al. (2000), Cordani and Teixeira (2007). The CPRM (Geological Service of Brazil) has developed a broad geochronological program in the Amazon region, focusing on Sm-Nd and U-Pb SHRIMP analysis. Part of the results of this program, together with contemporaneous works mainly at the Federal University of Pará, were incorporated in the work described in Bizzi et al. (2004), which allowed some changes and promoted important improvements in the model of Santos et al. (2000).

These geochronological evolution models can be resumed in Table II-1 with a short synthesis of the main geologic features, and to some extent the related geochronological control, for the Archean and Proterozoic tectonic units of the AC. Figure II-2 shows the model adopted in Bizzi et al. (2004), presented by Santos et al. (2000), who reinterpreted the previously defined AC provinces based on $\mathrm{U}-\mathrm{Pb}$ and $\mathrm{Sm}-\mathrm{Nd}$ data contained on several regional maps produced by CPRM.

Major advances have occurred in the period of 2000 to 2002 in the geochronological evolution model presented by Bizzi et al. (2004) and Cordani and Teixeira (2007), that can be summarized in Table II-1 and Figure II-3.

According to Bizzi et al., (2004), there are seven AC geological provinces of distinct ages, evolution, and structural patterns, namely (Figure II-3): (i) Carajás, with two domains - Rio Maria (Mesoarchean) and Carajás (Neoarchean); (ii) Central Amazônia (Archean-Paleoproterozoic), with the Iriri-Xingu and Curuá-Mapuera domains; (iii) Trans-Amazonian (Rhyacian), with the Amapá and Bacajá domains; (iv) Tapajós-Parima (Orosirian), with the Peixoto de Azevedo, Tapajós, Uaimiri and Parima domains; (v) Rondônia-Juruena (Statherian), with the Jamari, Juruena and Jauru domains; (vi) Rio Negro (Statherian), with the Rio Negro and Imeri domains; and (vii) Sunsás (Meso-Neoproterozoic), with the Santa Helena and Nova Brasilândia domains. Despite the deficiency of $\mathrm{U}-\mathrm{Pb}$ and $\mathrm{Sm}-\mathrm{Nd}$ data over large areas it is possible to state that each of the Provinces was generated by a succession of orogenies. Some of the Provinces, such as the Trans-Amazonian (2.26-2.01 Ga) and Tapajós-Parima (2.03-1.87 Ga) Provinces, are composed by four distinctive orogenies; while the Sunsás Province $(1.45-1.10 \mathrm{Ga})$ was generated by three orogenies (Santa Helena, Candeias and Nova Brasilândia).

According Coutinho (2008), the almost total absence of terrestrial access, the presence of extensive vegetation cover, the absence of an appropriate scale geologic maps, the absence of profiles in airborne geophysical surveys with spacing of less than $1 \mathrm{~km}$ and the lack of a geochronological support enabling the understanding of the geological-tectonic evolution of the region are the causes 
that makes the AC remains in one of the lowest levels in the Archaean geological knowledge, especially in the part comprised by the Brazilian territory, despite of the existence of minerals resources (iron, gold), oil and gas, in the region.
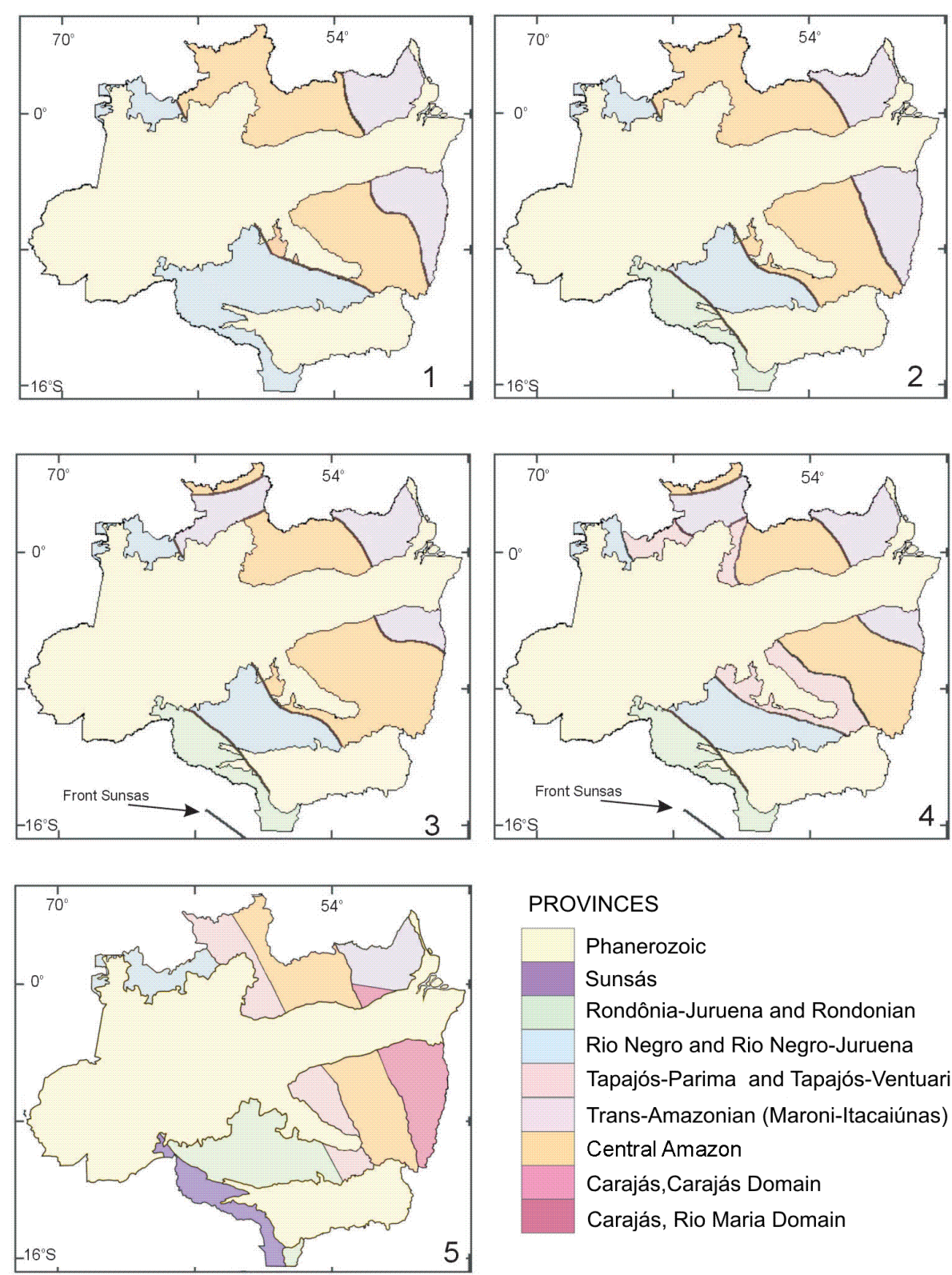

Figure II-2: Evolution of models for interpretation of the Amazon Craton. Models:1 - Amaral (1974); 2 - Cordani et al. (1979); 3 - Teixeira et al (1989); 4 - Tassinari (1996); 5 - Santos et al. (2000) modified of Bizzi et al. (2004).

Hence over the time these tectonic provinces have been modified with increasing amount of geochronological, geological and geophysical data. Recent works brought new insights in the geochronological boundaries of the Amazonian Craton and its tectonic provinces, leaded by Cordani and Teixeira (2007) and corroborated by Cordani et al. (2009), who has subdivided the tec- 


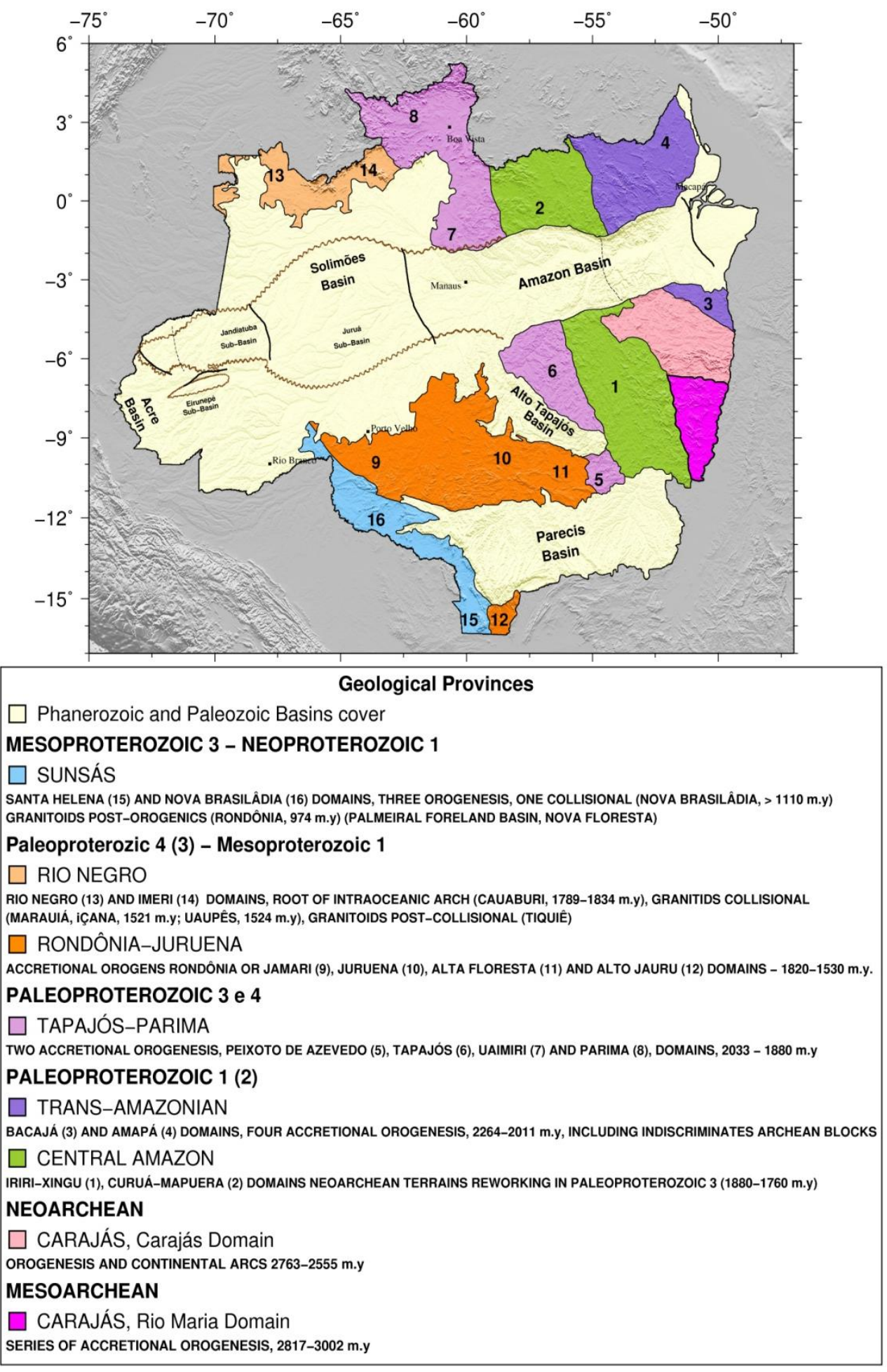

Figure II-3: Amazonian Craton Provinces modified from CPRM data (after Bizzi et al., 2004) draped over ETOPO1 digital elevation model, Amante and Eakins (2008).

tonic provinces modified from Cordani et al. (2000) into two Archean cores and five accretionary Paleoproterozoic belts (provinces) (Figure II-4). Two small ancient nuclei of the CentralAmazonian Province (with ages > $2600 \mathrm{Ma}$ ) consisted of the large Carajás granite-greenstone terrain, and the Xingu-Iricoumé block, where the extensive Paleoproterozoic cratonic covers of the 
Roraima Supergroup occurs, overlying gneissic and granitoid rocks. Established Archean crust is restricted to the Carajás region, located at southeast of the Amazon basin, whose rocks yielded radiometric ages between 2600 and $3200 \mathrm{Ma}$ (Cordani et al. 2009). Proterozoic tectonic provinces with radiometric ages in the interval about 2250-2050 Ma (Maroni-Itacaiunas), 1980-1810 Ma (Ventuari-Tapajós), 1780-1550 Ma (Rio Negro-Juruena), 1550-1300 Ma (Rondonian-San Ignacio) and 1280-950 Ma (Sunsás) are described in these works.

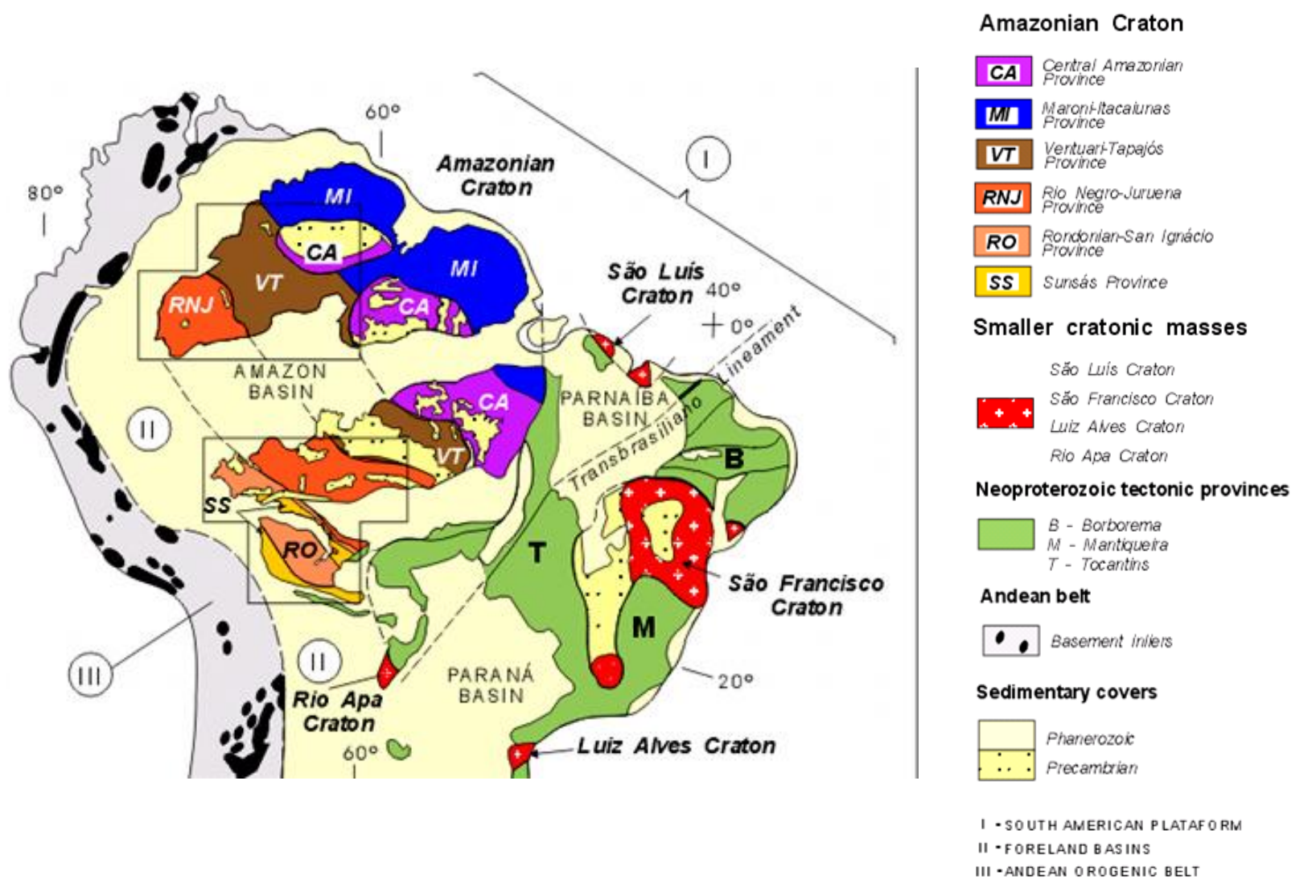

Figure II-4: Tectonic framework of South America with emphasis on the Amazonian Craton and its tectonic provinces in the northeastern Brazilian region the Borborema province (B) predominates; the Tocantins province $(\mathrm{T})$ is present in the Central Brazil region, which includes the Goiás Magmatic Arc (GMA) and the Mantiqueira province (M) (extracted from Cordani and Teixeira, 2007).

As discussed in Milani and Zalán (1999), it is interesting to notice that the basins had their subsidence mechanisms reactivated during additional tectonic events, resulting in a pile of sedimentary and volcanic strata that can reach cumulative thickness of more than $7,000 \mathrm{~m}$ in the Amazon Basin. For instance, rifts are known below the Amazon, Solimões and Parnaíba Paleozoic basins, that have in their sediments about $240,000 \mathrm{~km}^{3}$ of intruded diabase, mainly in the form of 
sills. Such igneous rocks are essentially constituted of plagioclase, pyroxene, quartz, biotite and hornblende, and were united under the named Penatecaua Episode (Wanderley Filho et al. 2006).

However, older ages strata and even their restricted areal distribution, contradicted the hypothesis that considers them as the direct predecessors of the overlying intracratonic sags (Milani and Zalán 1999), and several papers have been published as an attempt to understand the intrusion mechanism, the age and the variation in the chemical composition of these sills, as well as their influence on the oil generation. Francis (1982), for example, studied igneous features in North of England showing that when the diabase is still fluid, it can migrate dip down, by gravity, in the direction to the structural depocenter and if there is any lithological and/or structural change, it "seeks the easier way" to continue its flow towards the structural trough (Milani and Zalán 1999; Wanderley Filho et al., 2006).

Hence, as discussed in Milani and Zalán (1999), there was an initial subsidence mechanism from a Proterozoic crustal stretching associated with their formation or Early Paleozoic extensional reactivation of the Precambrian structural grain. Subsequent subsidence would have been achieved either by different episodes of reactivation by crustal stretching, always using the existing grain, or, in addition, by flexural mode due to the cratonward influence of distant, plate-margin collisional tectonics.

According to Milani and Zalán (1999) whatever have been the driving mechanisms of the subsidence events, the depressions were filled with essentially siliciclastic sedimentary sections with the notable exception of an evaporite-carbonate cycle in the Solimões and Amazon basins, corresponding to a large-scale Paleozoic transgressive-regressive cycles. The inital cycles usually show marked glacial influences with Devonian age (Solimões and Amazon) with respect to the location of the basin over the Gondwana supercontinent, that always wandered close to the South Pole. In these basins the last transgressive-regressive cycle is almost uniformly terminated by late Permian to Triassic continental red beds that mark the drying out of the interior sags and the definitive disappearance of the seas from the cratonic areas of South America. The Mesozoic history of these basins is recorded as continental sedimentary packages and large volumes of magmatic rocks.

\section{II.3. Solimões Basin}

The Solimões Basin (Figure II-1) is situated in the northern Brazil, right in the heart of the Amazon forest and comprises an area of over $600,000 \mathrm{~km}^{2}$. Only two-thirds of this area corresponds to the region of occurrence of Paleozoic strata $\left(400,000 \mathrm{~km}^{2}\right)$, the remainder being dominated by a sandy, 
Cretaceous-to-Recent continental cover that prevents outcrops of the Paleozoic successions in the basin. Its sedimentary fill ranges from the Ordovician to the Permian, grouped into three sequences. The sedimentary environment of these rocks is in general marine, with brief intervals of continental sedimentation (Milani and Zalán, 1999).

This basin, together with its eastern counterpart, the Amazon Basin, constitutes an impressive E-W oriented interior basin, 2,500 km long, $500 \mathrm{~km}$ wide and up to 5,000 m deep. The flexural arches of Iquitos and Purus separate the Solimões Basin from, respectively, to the west from the Acre Basin, which is interpreted as a retroarc foreland basin related to the Andean orogenesis, and the Amazon Basin to the east. Inside the Solimões Basin, a prominent NW-SE-striking positive feature, the Carauari Arch, divides it internally in two sub-basins: to west and to east of the Carauari high, respectively, the Jandiatuba and Juruá sub-basins were placed beneath igneous and metamorphic rocks. Southwest of the Solimões Basin, below the sub-basin Jandiatuba, is located the Eirunepé sub-basin separated by Jutaí Arch (Alves and Vaz 2006; Bizzi et al. 2004; Eiras 1996).

Particularly during the pre-Pennsylvanian times, this structural high exerted a decisive control on the sedimentary thickness distribution and facies. The easternmost Juruá sub-basin has hydrocarbon reserves in the Paleozoic cratonic sequences with a package of sedimentary rocks up to $3,800 \mathrm{~m}$ thick and Proterozoic rifts (Bizzi et al. 2004). Its axis is marked by the presence of the Solimões mega-shear zone, a classic example of an intraplate deformation belt that comprises a fault-and-fold system in a $\mathrm{N}^{\circ} 0^{\circ}-80^{\circ} \mathrm{E}$ direction, with a total length of about $1,000 \mathrm{~km}$, caused by Jurassic to Cretaceous right-lateral wrenching constituting the main structural style of hydrocarbon traps in this basin, as described by Milani and Zalán (1999).

Indeed, diabase sills and dykes occurred during late Triassic to early Jurassic ages, which played an important role in the hydrocarbon generation from the Devonian source rocks. The diabase sills can occur through hundreds of kilometers in this sedimentary basin. Its trajectory can be facilitated by fissile materials or diverted by lateral variations of facies and by faults. In cases where the intruded rocks are sandstones, they frequently jump abruptly, forming a variety of patterns. These rocks strongly influence the exploratory activities in the basin. Diabase sills occur also over Purus Arch, although with minor expression, since the natural behavior of these bodies is to follow down dip the sedimentary beds (Wanderley Filho et al., 2006).

The stratigraphic structure of the Solimões Basin is constituted of four Paleozoic supersequences covered by two units, one of Cretaceous age and the other of Early Cenozoic to Recent ages, passing through the Ordovician, Silurian-Devonian and Devonian-Carboniferous Sequences. The Paleozoic sedimentary units were intruded by igneous rocks, which have a maximum thickness 
drilled by the well in the Solimões Basin of 1038 m, during the Late Triassic and Early Jurassic, an event known as the Penatecaua magmatism (200 Ma). Such igneous rocks are essentially constituted of plagioclase, pyroxene, quartz, biotite and hornblende, and they present a dominant subofític texture. Finally, as described in Milani and Zalán (1999), a partial continentalization of the Solimões Basin took place during the initial stages of the Carboniferous-Permian Sequence sediments, until it completely surpass the Purus arch linking the Solimões and Amazon Basins into a single depositional site (Milani and Zalán 1999; Wanderley Filho et al. 2006).

\section{II.4. Amazon Basin}

This basin may be classified as produced by extensional stresses and Interior Sag, caused by vertical movements covering about $515,000 \mathrm{~km}^{2}$ of the northern Brazilian region, lying completely under the Amazon jungle (Figure II-1). Its main axis trends East-West and its sedimentary and intrusive rocks are between the two main Precambrian provinces, Guyanas shield and Central Brazil shield, cropping out along both sides of the northern and southern basins, respectively (Bizzi et al. 2004; Milani and Zalán 1999; Nunn and Aires 1988).

The basement of the Amazon Basin is dominantly constituted and filled by igneous (maximum thickness of $915 \mathrm{~m}$ drilled by a well in the Amazon Basin) and metamorphic rocks ranging from Ordovician to Cretaceous ages in marine to deltaic, alluvial, fluvial and lacustrine sedimentary environment in some Proterozoic rift successions occured in its western portion, composing the Purus Group. The northernmost basin of the province is the Tacutu Basin. To the east, the Amazon Basin is separated from the Mesozoic Marajó rift by the Gurupá arch. To the west, the Amazon Basin is separated from the Solimões Basin by the roughly N-S-trending Purus arch. In its depocenter, the basin holds a stratigraphic record up to 5,000 meters thick including three Paleozoic supersequences covered by Cretaceous to Recent continental clastics. The oldest Paleozoic age sedimentary rocks drilled in Amazon Basin are from the Middle Ordovician (Bizzi et al. 2004; Milani and Zalán 1999; Nunn and Aires 1988; Wanderley Filho et al. 2006).

The existence of strong, positive gravity anomalies, coincident with the trough (major axis) of the Amazon Basin, suggested the presence of shallow ultrabasic bodies (Milani and Zalán, 1999), later confirmed with the observation of diabase sills and dikes as showed in seismic lines and wells (Wanderley Filho et al., 2006), together with the underlying aulacogenic strata. This led to the classic interpretation of a rifting mechanism as the initial driving mechanism for the basin subsidence although igneous activity can occur substantially before and/or after the continental rifting. As described in Nunn and Aires (1988), the rifting or intrusion of magmatic bodies beneath the Amazon Basin is assumed to have occured in the Cambrian or the Early Ordovician age, as a 
large pyroxenite body beneath of the basin has been dated as Early Cambrian $(565+70 \mathrm{Ma})$ using the $\mathrm{Nd} / \mathrm{Sm}$ method.

According to Nunn and Aires (1988) the preliminary interpretation analysis of the tectonic subsidence curves from deep wells in the basin indicated that the Ordovician/Silurian and Devonian/early Carboniferous sequences are consistent with thermal subsidence following rifting or intrusion of the lithosphere, in close agreement with the results from studies of the Illinois, Michigan and Williston basins. However, the Late Silurian/Early Devonian unconformity can be explained by a eustatic sea level fall of less than $100 \mathrm{~m}$. Smaller deviations from the exponential subsidence expected from the thermal contraction of the lithosphere are probably owing to sedimentological effects or errors in the time scale.

Milani and Zalán (1999) suggested a second transgressive-regressive cycle recorded by the sedimentary rocks composing the Devonian-Carboniferous Sequence, which was considered as the record of maximum paleobathymetric conditions during the history of the basin. In the upper units this sequence recorded the regressive portion of the cycle. During the final stages of the Mississipian age, a regional erosive process affected the Amazon Basin.

Therefore, possible explanations as suggested in Nunn and Aires (1988) for rapid subsidence late in the evolution of a sedimentary basin include a second rifting or intrusion event, thermal and/or stress relaxation of the lithosphere, and buckling by horizontal compression. According to Milani and Zalán (1999), a renewed cycle of subsidence and sediment accommodation took place from the Pennsylvanian onwards. The lowermost package of the Carboniferous-Permian Sequence is a blanket of eolian sandstones covered by a section of carbonates and evaporites, with subordinated sandstones and shales that may reach 1,600 meters in thickness. The cycle is closed by continental red beds of Permian age. East-West regional extension allowed a pervasive intrusion of magmatic bodies during the early stages of the Penatecaua Event.

According Nunn and Aires (1988), during the Permian there is a rapid subsidence not compatible with a rifting or intrusion event occurred in Penatecaua magmatism. There is another inconsistency in the magnitude of the late Carboniferous/Permian subsidence (maximum thickness of approximately $2.5 \mathrm{~km}$ ) with a single thermal event in the Cambrian. If one assumes that only the vertical heat flow is important, it is known that the thermal subsidence of a sedimentary basin cannot overcome for more than about $150 \mathrm{My}$.

In summary, Nunn and Aires (1988) suggested the simplest explanation for the Paleozoic subsidence in the Amazon Basin from the (1) initial rifting or intrusion event during the Cambrian 
or Early Ordovician followed by (2) an eustatic sea level fall in the Early Devonian temporarily that exposed the basin to erosion, and (3), a rifting or intrusion event, lithospheric relaxation, or horizontal buckling, that produce a rapid subsidence in the late Carboniferous/Permian, and finally in (4) The Paleozoic sediments are uplifted, eroded, and intruded by basaltic rocks during the Mesozoic.

Milani and Zalán (1999) point out a great similarity with the Solimões Basin in terms of source rocks and cap rocks. The most probable ones are extensional fault-blocks, salt tectonics and transcurrent movements during the Cenozoic. Significant differences with respect to the Solimões Basin may also have occured by an early maturation of the organic matter by normal subsidence since the Late Carboniferous with a peak in the Late Permian. The thermal effects of the Mesozoic magmatism accelerated rates of maturation or promoted jumps in certain areas into higher thermal levels. 


\section{METHODOLOGY}

This chapter describes in a simple way the main gravity field principles, the methods and the tools used to the development this work, as the satellite gradiometry method, the terrestrial gravity data uses and the Geopotential Gravity Models (GGM). First, the GGM to be used for evaluating the gravity anomalies was analyzed, and then a topographic correction was calculated to the gravity data for removing the significant high- and mid-frequency components caused by the attraction of the Earth's topographic and isostatic masses. The geopotential models comission errors were then analyzed by the comparison with the available terrestrial gravity data. The gravity gradient tensor values caused by a prism and a tesseroid model was then calculated in order to help in the forward gravity modelling.

For the described approach, the density distribution in the mantle/crust in the region of the Amazon and Solimões sedimentary Basins was chosen as a study case, mainly because their large size, and by the lack of terrestrial data and the difficulty in the access of the area, the use of satellite mission derived fields is essential.

\section{III.1. Gravitational Potential}

According to Heiskanen \& Moritz (1967), to calculate the gravitational potential $V$ of a body in a point $P$ in the configuration shown in Figure III-1, it is necessary to consider the dimensions and the density distribution of the body, so a body of mass $m$ can be divided into infinitesimal pieces of volume $d v^{\prime}$ with density $\rho$.

The gravitational potential $V$ originated by a body of mass $m$ at the point $P$ also defines the work realized by the attractive force of gravity per unit mass, to move a body from that point to infinity. The potential is a scalar or a tensor of zero order. From the theory of potential the gravitational potential at a point $P$ in the Cartesian coordinate system $(x, y, z)$ due to the attraction of a mass distribution at point $Q\left(x^{\prime}, y^{\prime}, z^{\prime}\right)$ with a density function $\rho\left(x^{\prime}, y^{\prime}, z^{\prime}\right)$ and volume $v^{\prime}$ can be written generically by the following volumetric integral

$$
V=G \iiint_{v^{\prime}} \frac{\rho}{r} d v^{\prime}
$$


where $r=\sqrt{\left(x-x^{\prime}\right)^{2}+\left(y-y^{\prime}\right)^{2}+\left(z-z^{\prime}\right)^{2}}$ denotes the distance between the computation point $P(x, y, z)$ and the element point (integration point) $Q\left(x^{\prime}, y^{\prime}, z^{\prime}\right)$, known as the Euclidian distance, defined in the local Cartesian coordinate system with axes pointing in the east, north, and up, where $\rho$ is the density, $d v^{\prime}=d x^{\prime} d y^{\prime} d z^{\prime}$ is the element of volume, and $G$ is Newton's gravitational constant. The gravitational force vector $\vec{F}$ is defined as the gravitational potential gradient.

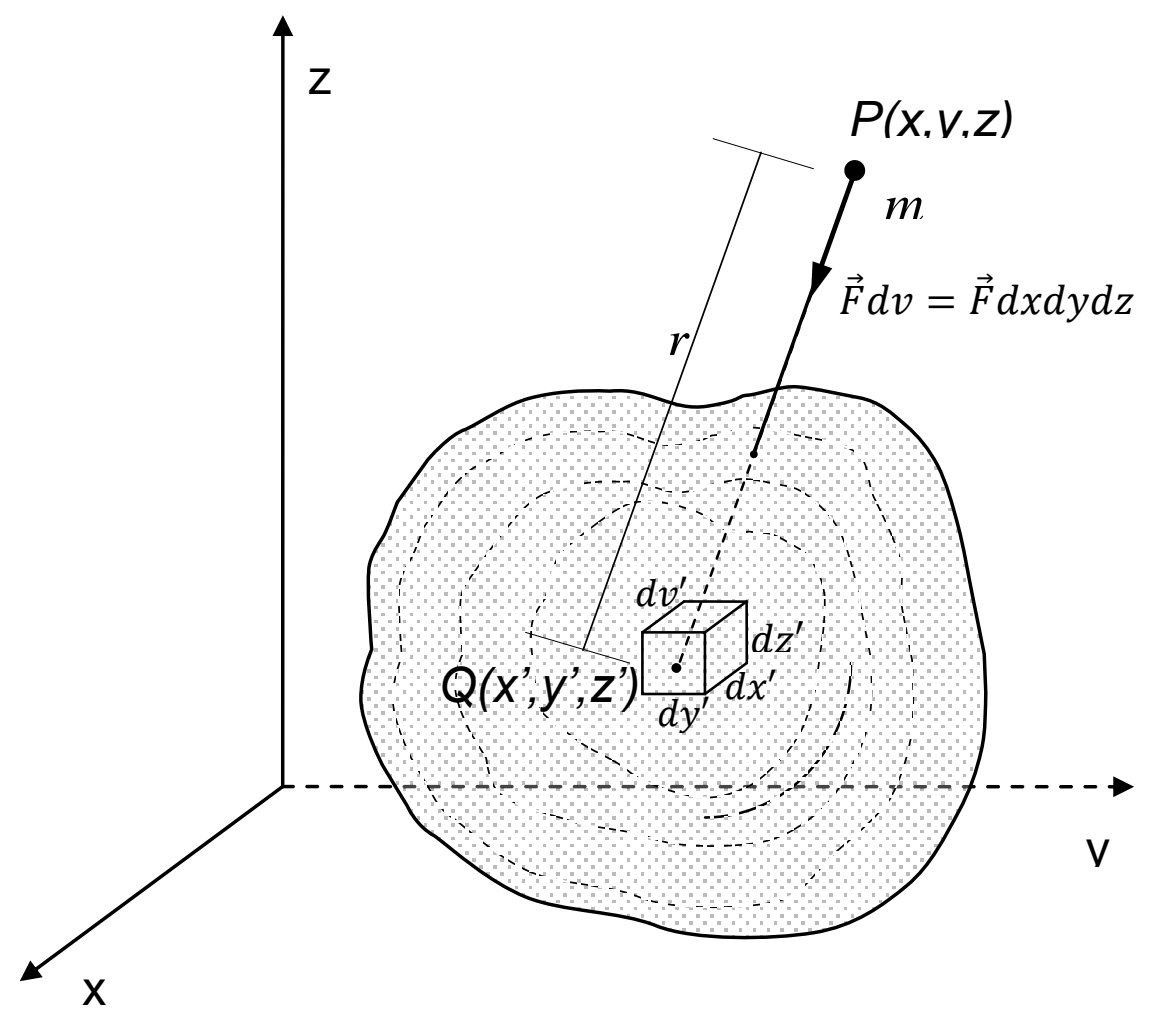

Figure III-1: Gravitational potential of a solid body.

$$
\vec{F}=(X, Y, Z)=\vec{\nabla} V=\left[\frac{\partial U}{\partial x}, \frac{\partial U}{\partial y}, \frac{\partial U}{\partial z}\right]^{T}
$$

The gravitational potential $V(x, y, z)$ is continuous throughout the space and vanishes at the infinity, decaying with $1 / r$. This is due to the fact that for very large values of $r$, the body acts approximately as a point mass. Therefore, in celestial mechanics, the planets are generally considered as point masses (Heiskanen \& Moritz, 1967).

The theoretical fundament of the gravity gradiometry follows Rummel (1986). The gravity gradients are the second order derivatives of the gravitational potential $V,\left(\partial^{2} V / \partial x_{i} \partial x_{j}=V_{i j}\right)$, which form the nine components of the tensor (also known as components of the symetric Marussi tensor): 


$$
V_{i j}=\vec{\nabla} F=\Delta V=\left(\begin{array}{ccc}
\frac{\partial^{2} V}{\partial x^{2}} & \frac{\partial^{2} V}{\partial x \partial y} & \frac{\partial^{2} V}{\partial x \partial z} \\
\frac{\partial^{2} V}{\partial y \partial x} & \frac{\partial^{2} V}{\partial y^{2}} & \frac{\partial^{2} V}{\partial y \partial z} \\
\frac{\partial^{2} V}{\partial z \partial x} & \frac{\partial^{2} V}{\partial z \partial y} & \frac{\partial^{2} V}{\partial z^{2}}
\end{array}\right)=\left(\begin{array}{lll}
V_{11} & V_{12} & V_{13} \\
V_{21} & V_{22} & V_{23} \\
V_{31} & V_{32} & V_{33}
\end{array}\right)=\left(\begin{array}{lll}
V_{x x} & V_{x y} & V_{x z} \\
V_{y x} & V_{y y} & V_{y z} \\
V_{z x} & V_{z y} & V_{z z}
\end{array}\right)
$$

The symbol $\Delta$, called Laplacian Operator, is represented by $\frac{\partial^{2}}{\partial x^{2}}+\frac{\partial^{2}}{\partial y^{2}}+\frac{\partial^{2}}{\partial z^{2}}$ with $i, j \epsilon\{1,2,3\}$ or $i, j$ $\epsilon\{x, y, z\}$ for the three axes of the adopted coordinate system.

The first derivatives of the gravitational potential $V$ generate the gravitational force components, which are also continuous in the whole space, but this is not true for the second derivatives. At the points where the density changes discontinuously (i.e., inside of the source masses), some second derivatives present discontinuity, and so, the gravitational potential $V$ (i.e., the trace of the tensor) satisfies Poisson's equation $\Delta V=-4 \pi G \rho$ (Heiskanen \& Moritz, 1967).

The gradient tensor $\Delta V$ (a $3 \times 3$ matrix) is symmetrical. Also, $\Delta V$ is a rotational vector field and in the empty space (vacuum), as the density is zero $(\rho=0), V$ satisfies Laplace's equation, and hence, the trace of the tensor is zero: $V_{x x}+V_{y y}+V_{z z}=0$. Thus, due to the symmetry confirmed by Laplace equation, the gradient tensor only contains five independent components, because $V_{z z}=$ $-\left(V_{x x}+V_{y y}\right)$.

According to Equation III-1, the potential linearly decreases when the distance $r$ increases. Consequently, the gravitational force and gravitational potential gradients attenuate as a function of $r^{2}$ and $r^{3}$, respectively.

Gravity is a more familiar term, and with regard to a body at rest on the Earth's surface, the term expresses the resultant gravitational plus centrifugal (due to Earth's rotation) force vector. These combined forces acting on a unit mass denote the gravity vector $\boldsymbol{g}$. Gravity is the magnitude of the vector $\boldsymbol{g}$ and has acceleration units.

The gravitational acceleration vector $\boldsymbol{g}$ is given by

$$
\boldsymbol{g}=\left(\boldsymbol{g}_{x}, \boldsymbol{g}_{\boldsymbol{y}}, \boldsymbol{g}_{z}\right)^{\boldsymbol{T}}=\boldsymbol{\nabla} \boldsymbol{W}=\left[\frac{\partial W}{\partial x}, \frac{\partial W}{\partial y}, \frac{\partial W}{\partial z}\right]^{T}
$$

and the gravitational gradient (second derivate of the potential) is a tensor derived from these values. 
The potential of the Earth (or geopotential), $\boldsymbol{W}$, may be split into a gravitational part $V$ and a rotational part $\Phi$

$$
\boldsymbol{W}=\boldsymbol{V}+\boldsymbol{\Phi}
$$

where the rotational potential is given by

$$
\Phi=\frac{1}{2} \omega^{2} r^{2}
$$

and $\omega$ is the velocity of rotation (in units of $\sec ^{-1}$ ) (Heiskanen \& Moritz, 1967).

In geophysical applications, an ellipsoid of revolution is chosen to approximate the Earth's figure which is assumed to have an equipotential surface and defines a normal gravity potential $\boldsymbol{U}$. The difference between the geopotential $(W)$ and the normal potential $(U)$ is defined as the disturbing potential $\mathrm{T}$, such that

$$
\mathrm{T}=\mathrm{W}-\mathrm{U}
$$

In the same way we get for the potential gradients:

$$
T_{i j}=\left(\begin{array}{ccc}
\frac{\partial^{2} T}{\partial x^{2}} & \frac{\partial^{2} T}{\partial x \partial y} & \frac{\partial^{2} T}{\partial x \partial z} \\
\frac{\partial^{2} T}{\partial y \partial x} & \frac{\partial^{2} T}{\partial y^{2}} & \frac{\partial^{2} T}{\partial y \partial z} \\
\frac{\partial^{2} T}{\partial z \partial x} & \frac{\partial^{2} T}{\partial z \partial y} & \frac{\partial^{2} T}{\partial z^{2}}
\end{array}\right)=\left(\begin{array}{ccc}
T_{x x} & T_{x y} & T_{x z} \\
T_{y x} & T_{y y} & T_{y z} \\
T_{z x} & T_{z y} & T_{z z}
\end{array}\right)
$$

where $T_{x x}$ is the rate of change of gravity in the $x$ direction while a reference mass moves a known distance in the $x$ direction, and the same apply for the rest of the tensor; for example, $T_{x y}$ expresses how the $x$ component of the gravity changes in the y direction.

The disturbing potential, such as the gravitational potential tensor, satisfies Laplace's equation outside of the masses and is symmetric relative to the main diagonal, and so, only five independent tensor components $\left(T_{x x}, T_{x y}, T_{x z}, T_{y y}\right.$ and $\left.T_{y z}\right)$ remain.

\section{III.2. The gravitational potential and its second derivatives for the prism}

According to Nagy et al. (2000), we can define a rectangular prism as a solid body given by $X_{1}, X_{2}$, $Y_{1}, Y_{2}, Z_{1}$ and $Z_{2}$ coordinates (Figure III-2). The first simplification is to define the point $P$ where one wants to calculate the gravitational potential located at the origin of the coordinate system. In 
practice, the coordinates defining the prism should be transformed if the orientation of the coordinate system has not been changed. This result in coordinates of integration as follow:

$$
\begin{aligned}
& x_{1}=X_{1}-X_{P} \\
& x_{2}=X_{2}-X_{P} \\
& y_{1}=Y_{1}-Y_{P} \\
& y_{2}=Y_{2}-Y_{P} \\
& z_{1}=Z_{1}-Z_{P} \\
& z_{2}=Z_{2}-Z_{P}
\end{aligned}
$$

This simplification can be done without any loss of generality. Thus, all the computed values are valid at $O(0,0,0) \equiv P(X, Y, Z)$ (i.e., at $x=0, y=0$ and $z=0)$ (Nagy et al., 2000).

The disturbing potential at a point $P(x, y, z)$ in the $\mathcal{R}^{3}$ space due to the prism is given by Eq.III- 1 and may be rewritten as

$$
T(P)=G \Delta \rho \int_{x_{1}}^{x_{2}} \int_{y_{1}}^{y_{2}} \int_{z_{1}}^{z_{2}} \frac{d x^{\prime} d y^{\prime} d z^{\prime}}{r}
$$

where $r=\sqrt{x^{2}+y^{2}+z^{2}}$ is Euclidian distance between the point $P(x, y, z)$ and the mass element localized in the center of the prism (at point $Q$ ), $\Delta \rho$ is the density and $G$ is the gravitational constant. The disturbing gravitational potential $T(P)$ at $P$ is evaluated as a volumetric integration on the body of volume $v$ ' represented by the $A B C D E F G H$ prism with contrast of density constant shown in Figure III-2.

Figure III-2 shows the notation used for the rectangular prism in Nagy et al. (2000). Note that the coordinate system used here is north-east-down (NED), where the positive $x$ axis points to north, the positive $y$ axis points to east and positive $z$ downwards. 


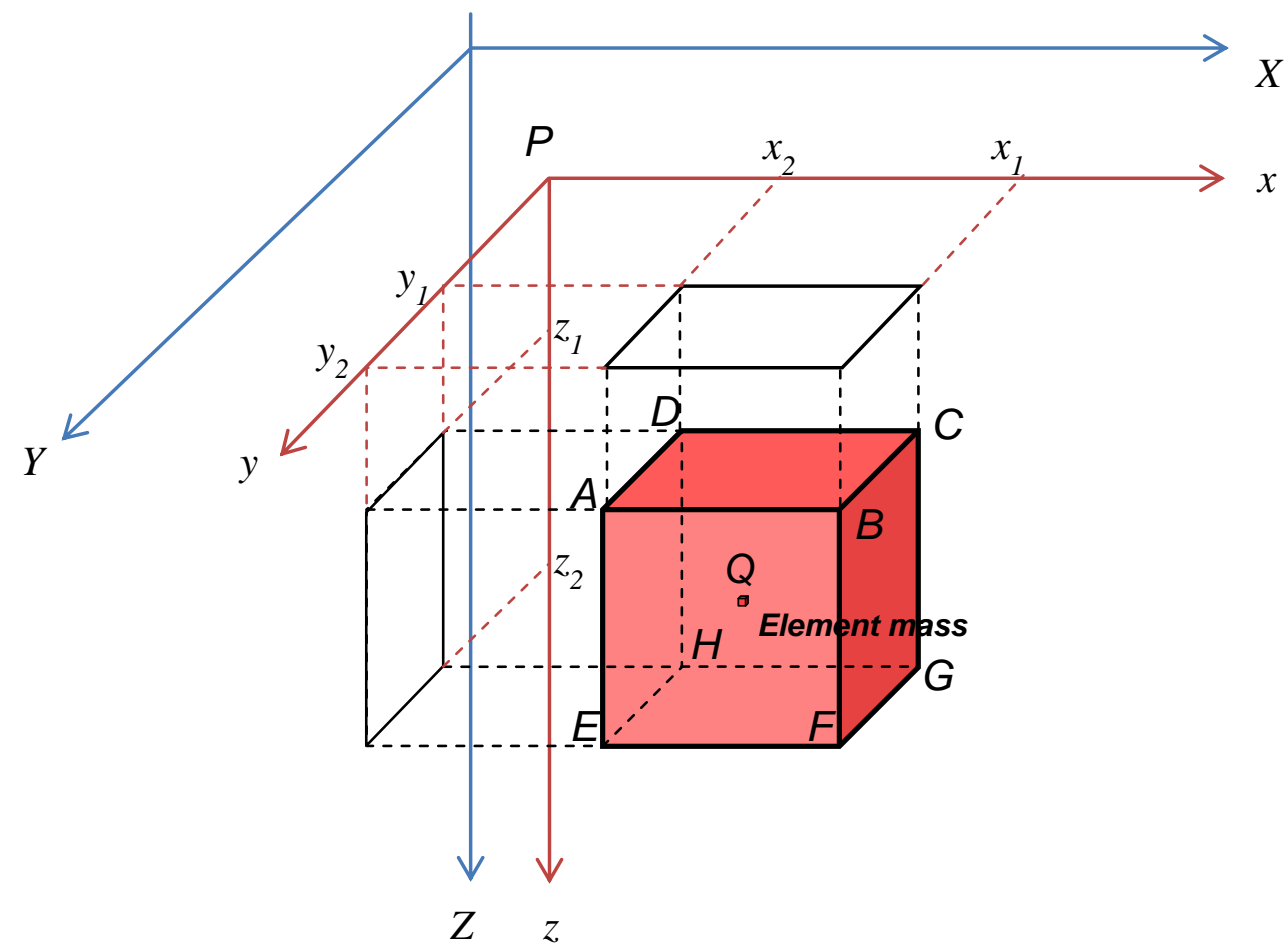

Figure III-2: Right rectangular prism and Cartesian coordinate system of the computation point $\mathrm{P}$ and the element point Q (modified after Nagy et al., 2000).

The integral in the Eq.III-10 can be solved using the volume element of the prism (Montana et al. 1992; Nagy et al. 2000, 2002), resulting in formulae due to the potential $T(x, y, z)$ :

$$
\begin{gathered}
T(P)=G \Delta \rho \||| x y \ln (z+r)+y z \ln (x+r)+z x \ln (y+r)-\frac{x^{2}}{2} \tan ^{-1} \frac{y z}{x r} \\
-\frac{y^{2}}{2} \tan ^{-1} \frac{z x}{y r}-\left.\left.\left.\frac{z^{2}}{2} \tan ^{-1} \frac{x y}{z r}\right|_{x_{1}} ^{x_{2}}\right|_{y_{1}} ^{y_{2}}\right|_{z_{1}} ^{z_{2}}
\end{gathered}
$$

Replacing all the limits of the gravitational potential equation for the rectangular prism results in an expression with 48 terms.

Although the potential $T$ exists and is continuous in the whole $\mathcal{R}^{3}$ space, Eq.III-1 when applied to the rectangular prism model as an analytical solution is not defined at all the points of $\mathcal{R}^{\mathbf{3}}$, because it can generate problems due to numerical estimation. At points where these terms are undefined they should be assumed to be zero since they have a finite limit (Nagy et al., 2000).

The gradient of $T$ is also continuous in the $\mathcal{R}^{3}$ space. Thus, the vertical component may be estimated by differentiating the Eq.III-11 with respect to $z$, 


$$
T_{z}(P)=\left.\left.G \Delta \rho||\left|x \ln (y+r)+y \ln (x+r)-z \tan ^{-1} \frac{x y}{z r}\right|_{x_{1}}^{x_{2}}\right|_{y_{1}} ^{y_{2}}\right|_{z_{1}} ^{z_{2}}
$$

The other two remaining derivatives, $T_{x}$ and $T_{y}$, can be obtained from $T_{z}$ by cyclic permutation, i.e.,

$$
T_{x}(P)=\left.\left.G \Delta \rho||\left|y \ln (z+r)+z \ln (y+r)-x \tan ^{-1} \frac{y z}{x r}\right|_{x_{1}}^{x_{2}}\right|_{y_{1}} ^{y_{2}}\right|_{z_{1}} ^{z_{2}}
$$

and

$$
T_{y}(P)=G \Delta \rho \|\left.\left|z \ln (x+r)+x \ln (z+r)-y \tan ^{-1} \frac{z x}{y r}\right|_{x_{1}}^{x_{2}}\right|_{y_{1}} ^{y_{2}} z_{z_{1}}^{z_{2}}
$$

In the case where the second derivatives of the gravitational potential exist, we can obtain the following expressions:

$$
\begin{gathered}
T_{x z}(P)=\left.\left.G \Delta \rho|||\ln (y+r)|_{x_{1}}^{x_{2}}\right|_{y_{1}} ^{y_{2}}\right|_{z_{1}} ^{z_{2}} \\
T_{y z}(P)=\left.\left.G \Delta \rho|||\ln (x+r)|_{x_{1}}^{x_{2}}\right|_{y_{1}} ^{y_{2}}\right|_{z_{1}} ^{z_{2}} \\
T_{x y}(P)=\left.\left.G \Delta \rho|||\ln (z+r)|_{x_{1}}^{x_{2}}\right|_{y_{1}} ^{y_{2}}\right|_{z_{1}} ^{z_{2}} \\
T_{x x}(P)=G \Delta \rho \|||-\left.\left.\left.\tan ^{-1} \frac{y z}{x r}\right|_{x_{1}} ^{x_{2}}\right|_{y_{1}} ^{y_{2}}\right|_{z_{1}} ^{z_{2}} \\
T_{y y}(P)=G \Delta \rho \|\left.\left.\left|-\tan ^{-1} \frac{z x}{y r}\right|_{x_{1}}^{x_{2}}\right|_{y_{1}} ^{y_{2}}\right|_{z_{1}} ^{z_{2}} \\
T_{z z}(P)=G \Delta \rho \|||-\left.\left.\left.\tan ^{-1} \frac{x y}{z r}\right|_{x_{1}} ^{x_{2}}\right|_{y_{1}} ^{y_{2}}\right|_{z_{1}} ^{z_{2}}
\end{gathered}
$$

Discretizing the Earth in $m$ prisms, the disturbing potential $T(P)$ generated for this forward model composed of prisms is given by

$$
T(P)=\sum_{i=1}^{m} T(P)_{i}
$$

Now, considering $n$ computation points on the Earth's surface and $M$ prisms, once the parameter $\Delta \rho$ is constant within each prism (i.e., constant density contrast), we can rewrite the potential equation and/or the gravity tensor as a linear system of equations of the type 
which is equivalent to

$$
\left[\begin{array}{c}
T_{1} \\
T_{2} \\
\vdots \\
T_{n}
\end{array}\right]=\left[\begin{array}{cccc}
G_{11} & G_{12} & \cdots & G_{1 m} \\
G_{11} & \ddots & & \vdots \\
\vdots & & \ddots & \vdots \\
G_{11} & \cdots & \cdots & G_{n m}
\end{array}\right] \times\left[\begin{array}{c}
\Delta \rho_{1} \\
\Delta \rho_{2} \\
\vdots \\
\Delta \rho_{n}
\end{array}\right]
$$

where $\boldsymbol{G}$ or $G_{n m}$ is a matrix $(n \times m)$ usually called the sensitivity matrix of the system. In the forward method, the variables $G$ and $\Delta \rho$ are supposedly known.

Figure III-3 represents a subdivision (discretization) within the Earth in regular prisms which are associated with density contrast values for the calculation of the potential gravitational and gravity gradients.

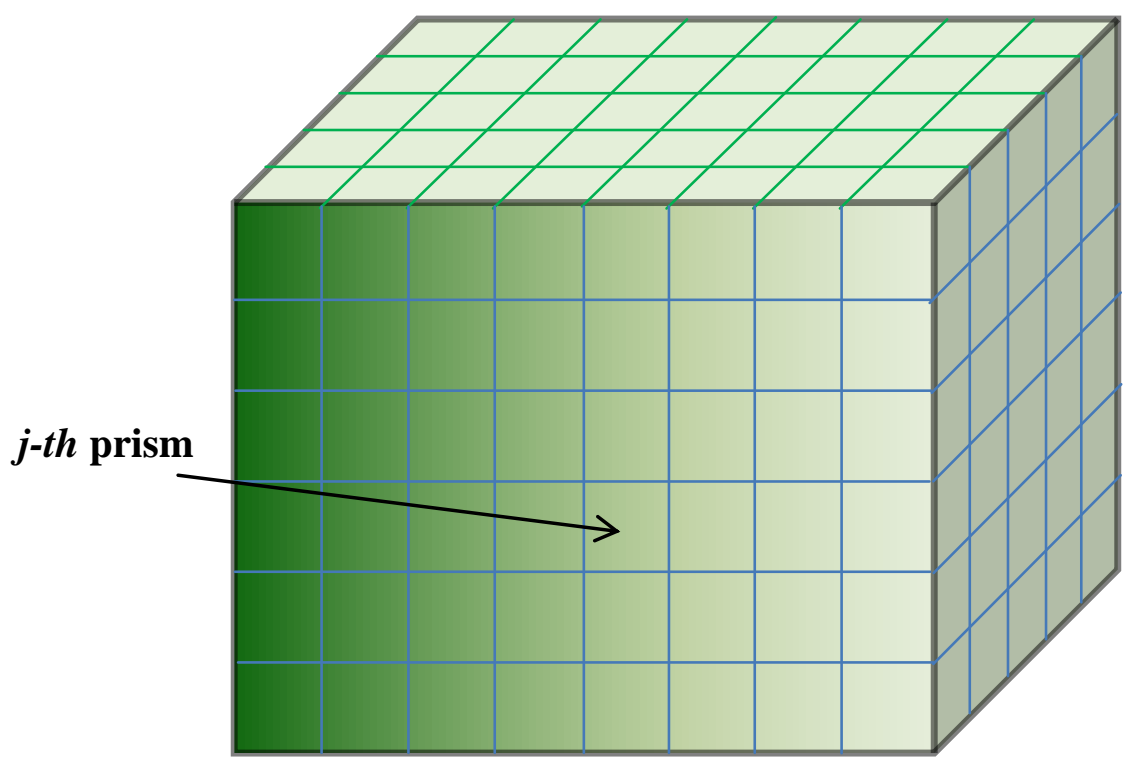

Figure III-3: Schematic model of discretizing of the Earth's interior in $M$ regular prisms $(\mathrm{j}=1,2 \ldots$ $M)$ for $N$ computation points on the surface $(\mathrm{i}=1,2 \ldots N)$ of the gravitational potential.

\section{III.3. Gravitational potential and its second derivatives for the tesseroid}

Based in the geometry of a spherical prism, we can define the tesseroid (Figure III-4) with its spatial arrangement of six faces bounded by geographical lines on the spherical reference surface and constant spherical height (i.e., bounded by a pair of meridional planes of $\lambda_{1}$ and $\lambda_{2}$ constants, a pair parallels planes of $\varphi_{1}$ and $\varphi_{2}$ constants, and a pair spherical curved surfaces of $r_{1}$ and $r_{2}$ constants) (Smith et al., 2001; Heck and Seitz, 2007). 


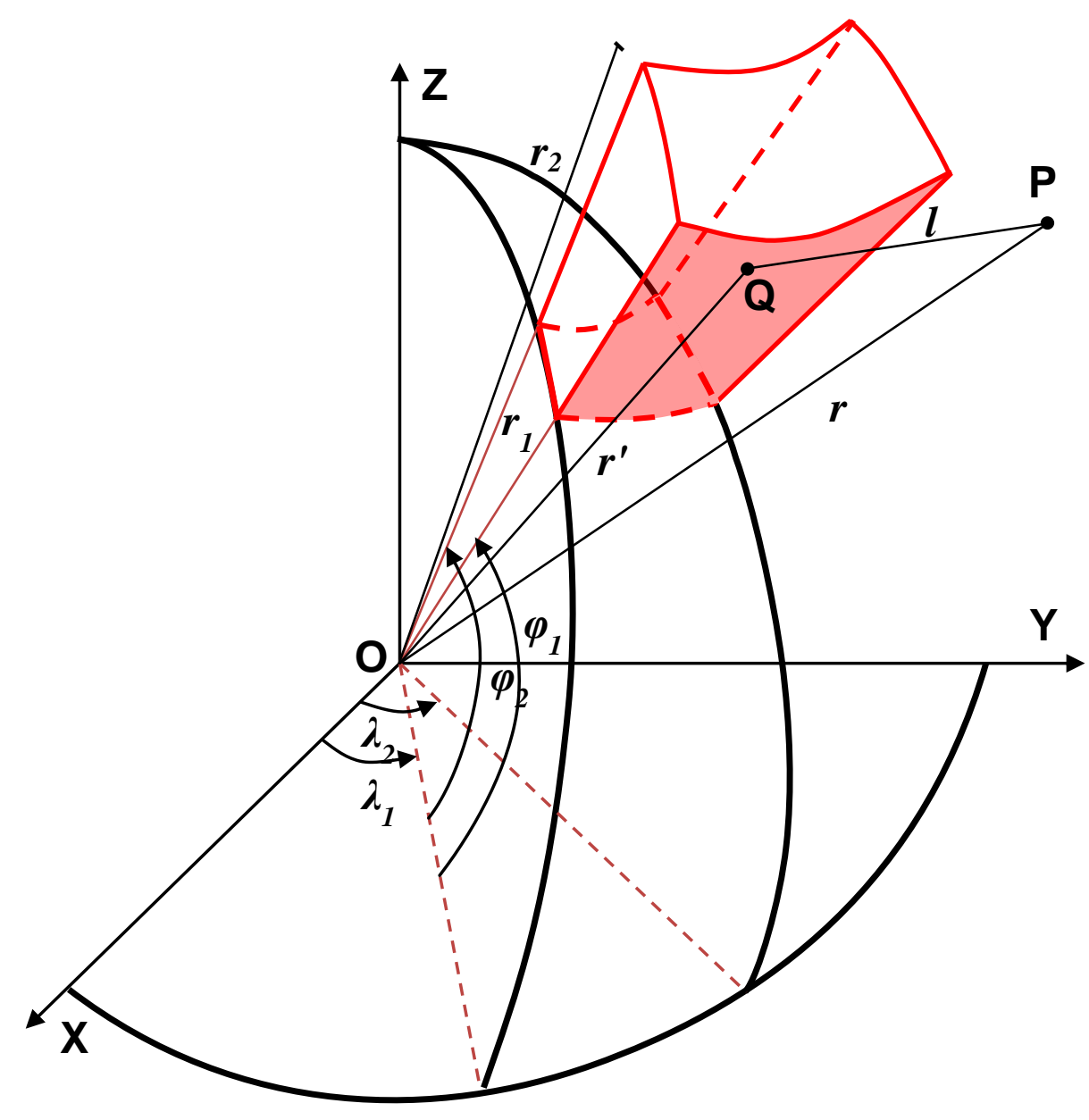

Figure III-4: Geometry of a spherical tesseroid and spherical coordinate system of the computation point $P$ and the element point $Q$ (modified after Heck and Seitz, 2007).

The gravitational potential $v$ at point $P(x, y, z)$ due to the "spherical prism" (tesseroid) with homogeneous mass density $\rho$ can be equally described by Newton's integral as in Eqs. (III-1) and (III-10) for example; however in this case the expression must be rewritten in spherical coordinates for the spherical tesseroid given by Figure III-4:

$$
v(r, \varphi, \lambda)=G \rho \int_{\lambda_{1}}^{\lambda_{2}} \int_{\varphi_{1}}^{\varphi_{2}} \int_{r_{1}}^{r_{2}} \frac{r^{\prime 2} \cos \varphi^{\prime} d r^{\prime} d \varphi^{\prime} d \lambda^{\prime}}{l}
$$

where

$$
l=\sqrt{r^{2}+r^{\prime 2}-2 r r^{\prime} \cos \psi}
$$

is the Euclidian distance in spherical coordinates between the computation point $P(r, \varphi, \lambda)$ and the observation point $Q\left(r^{\prime}, \varphi^{\prime}, \lambda^{\prime}\right)$, and $\psi$ is the angle between the position vectors of $P$ and $Q$, 


$$
\cos \psi=\sin \varphi \sin \varphi^{\prime}+\cos \varphi \cos \varphi^{\prime} \cos \left(\lambda^{\prime}-\lambda\right)
$$

Unlike the gravitational potential of the rectangular prism given by Eq. (III-10), no approximated form has yet been found for the solution to the triple integral given in Eq. (III-24), since an elliptic integral occurs; thus, the potential of the tesseroid cannot be solved exactly. However, this integral with respect to the radial coordinate $r$ ' can be reworked approximating the solution by numerical integration, using the formula (Martinec, 1998):

$$
\begin{aligned}
v(r, \varphi, \lambda)=\frac{1}{2} G \rho \int_{\lambda_{1}}^{\lambda_{2}} \int_{\varphi_{1}}^{\varphi_{2}} \cos \varphi^{\prime}\left[l\left(r^{\prime}+3 r \cos \psi\right)\right. \\
\left.\quad+r^{2}\left(3 \cos ^{2} \psi-1\right) \ln \left(l+r^{\prime}-r \cos \psi\right)\right]\left.\right|_{r^{\prime}=r_{1}} ^{r^{\prime}=r_{2}} d \varphi^{\prime} d \lambda^{\prime}
\end{aligned}
$$

Eq. (III-24) is rather complex and time-consuming due to the decrease of the gravitational effect with increasing distance, so Heck \& Seitz (2007) used MacMillan's expansion, based on a Taylor expansion, in its integrand, obtaining the maximum efficiency when the Taylor point is fixed at the geometrical center of the tesseroid,

$$
\begin{gathered}
r_{o}=\left(r_{1}+r_{2}\right) / 2, \\
\varphi_{o}=\left(\varphi_{1}+\varphi_{2}\right) / 2, \\
\lambda_{o}=\left(\lambda_{1}+\lambda_{2}\right) / 2 .
\end{gathered}
$$

Formally, the Taylor expansion of the integral kernel $\boldsymbol{r}^{\prime 2} \cos \varphi^{\prime} / \boldsymbol{l}$ expressed in Heck \& Seitz (2007) is given by

$$
K\left(r^{\prime}, \varphi^{\prime}, \lambda^{\prime}\right)=\frac{r^{\prime 2} \cos \varphi^{\prime}}{l}=\sum_{i, j, k} K_{i j k}\left(r^{\prime}-r_{o}\right)^{i}\left(\varphi^{\prime}-\varphi_{o}\right)^{j}\left(\lambda^{\prime}-\lambda_{o}\right)^{k}
$$

where

$$
K_{i j k}=\left.\frac{1}{(i+j+k) !} \frac{\partial^{i+j+k} K\left(r^{\prime}, \varphi^{\prime}, \lambda^{\prime}\right)}{\partial r^{\prime i} \partial \varphi^{\prime j} \partial \lambda^{\prime k}}\right|_{\begin{array}{c}
r^{\prime}=r_{o} \\
\varphi^{\prime}=\varphi_{o} \\
\lambda^{\prime}=\lambda_{o}
\end{array}}
$$

Inserting Eq. (III-29) into Eq. (III-24) yields integrals with respect to each coordinate to be reduced in the form 


$$
\begin{gathered}
v(r, \varphi, \lambda)=G \rho \int_{\lambda_{1}}^{\lambda_{2}} \int_{\varphi_{1}}^{\varphi_{2}} \int_{r_{1}}^{r_{2}} \sum_{i, j, k} K_{i j k}\left(r^{\prime}-r_{o}\right)^{i}\left(\varphi^{\prime}-\varphi_{o}\right)^{j}\left(\lambda^{\prime}-\lambda_{o}\right)^{k} d r^{\prime} d \varphi^{\prime} d \lambda^{\prime} \\
\int_{r_{1}}^{r_{2}}\left(r^{\prime}-r_{o}\right)^{i} d r^{\prime}=\int_{-\Delta r / 2}^{+\Delta r / 2}\left(r^{\prime \prime}\right)^{i} d r^{\prime \prime}=\frac{1-(-1)^{i+1}}{(i+1) 2^{i+1}}(\Delta r)^{i+1}=\left\{\begin{array}{cl}
0 & \text { if i odd }-31 \\
(\Delta r)^{i+1} /(i+1) 2^{i} & \text { if i even, }
\end{array}\right.
\end{gathered}
$$

where $\Delta r=r_{2}-r_{1}=h_{2}-h_{1}$ (and similarly $\Delta \varphi=\varphi_{2}-\varphi_{1}, \Delta \lambda=\lambda_{2}-\lambda_{1}$ ) denote the dimensions of the tesseroid, and, consequently, only terms for $i, j$, and $k$ even will remain in the power series, while all other terms cancel out due to choice of the Taylor point $P_{o}\left(r_{o}, \varphi_{o}, \lambda_{o}\right)$ in the tesseroid's center (Heck \& Seitz, 2007).

The gravitational potential of the homogeneous spherical tesseroid has its terms of order four and higher (represented in Landau symbol of order four $O\left(\Delta^{4}\right)$ ), in $\Delta r, \Delta \varphi, \Delta \lambda$ omitted.

$$
v(r, \varphi, \lambda)=G \rho \Delta r \Delta \varphi \Delta \lambda\left[K_{000}+\frac{1}{24}\left(K_{200} \Delta r^{2}+K_{020} \Delta \varphi^{2}+K_{002} \Delta \lambda^{2}\right)+O\left(\Delta^{4}\right)\right]
$$

the second-order coefficients $K_{i j k}$ in Eq. (III-33) are according to MacMillan's formula given by Heck \& Seitz (2007)

$$
K_{000}=\frac{r_{o}^{2} \cos \varphi_{o}}{l_{o}}
$$

where $\boldsymbol{l}_{\boldsymbol{o}}=\sqrt{\boldsymbol{r}^{2}+\boldsymbol{r}_{\boldsymbol{o}}^{2}-\mathbf{2 r} \boldsymbol{r}_{\boldsymbol{o}} \cos \psi_{o}}$ denotes the Euclidean distance between the computation point $P$ and the geometrical centre $P_{o}$ of the tesseroid

$$
\begin{gathered}
K_{200}=\frac{r^{2} \cos \varphi_{o}}{l_{o}^{5}}\left\{2 l_{o}^{2}-3 r_{o}^{2} \sin ^{2} \psi_{o}\right\} \\
K_{020}=\frac{r_{o}^{2}}{l_{o}^{5}}\left\{-\cos \varphi_{o}\left(r^{2}-r_{o}^{2}\right)\left[r^{2}+r_{o}^{2}-r r_{o} \sin \varphi \sin \varphi_{o}\right]\right. \\
+r^{2} r_{o}^{2} \cos \varphi_{o}\left[\sin ^{2} \varphi\left(3-\sin ^{2} \varphi_{o}\right)-\cos ^{2} \varphi\left(2-\sin ^{2} \varphi_{o}\right) \cos ^{2} \delta \lambda\right] \\
\left.+r r_{o} \cos \varphi\left(3-\sin ^{2} \varphi_{o}\right)\left[r^{2}+r_{o}^{2}-r r_{o} \sin \varphi \sin \varphi_{o}\right] \cos \delta \lambda\right\}
\end{gathered}
$$




$$
K_{002}=-\frac{r r_{o}^{3} \cos \varphi \cos ^{2} \varphi_{o}}{l_{o}^{5}}\left\{l_{o}^{2} \cos \delta \lambda-3 r r_{o} \cos \varphi \cos \varphi_{o} \sin ^{2} \delta \lambda\right\}
$$

With $\delta \lambda=\lambda_{o}-\lambda$ and $\psi_{o}$ is the angle between the position vector $P$ and $P_{o}$.

Considering the total mass of the tesseroid and the series expansion at $P_{o}\left(r_{o}, \varphi_{o}, \lambda_{o}\right)$, respectively

$$
\begin{gathered}
m=\rho \int_{\lambda_{1}}^{\lambda_{2}} \int_{\varphi_{1}}^{\varphi_{2}} \int_{r_{1}}^{r_{2}} r^{\prime 2} \cos \varphi^{\prime} d r^{\prime} d \varphi^{\prime} d \lambda^{\prime}=\frac{\rho}{3}\left(r_{2}^{3}-r_{1}^{3}\right)\left(\sin \varphi_{2}-\sin \varphi_{1}\right) \Delta \lambda \\
m=\rho r_{o}^{2} \cos \varphi_{o} \Delta \mathrm{r} \Delta \varphi \Delta \lambda\left[1+\frac{1}{12}\left(\frac{\Delta r}{r_{o}}\right)^{2}-\frac{1}{24}(\Delta \varphi)^{2}+\cdots\right]
\end{gathered}
$$

The closed zero-order term in Eq. (III-33), is essentially identical to the potential of a point-mass $m$ at $P_{o}$ when the total mass of the tesseroid $m=\rho \Delta \mathbf{r} \Delta \boldsymbol{\varphi} \Delta \lambda K_{\mathbf{0 0 0}}$ is concentred in the geometrical centre $P_{o}$ :

$$
v(r, \varphi, \lambda)=\frac{G m}{l_{o}}\left[1+O\left(\Delta^{2}\right)\right]=G \rho \Delta r \Delta \varphi \Delta \lambda K_{000}\left[1+O\left(\Delta^{2}\right)\right]
$$

The residual terms in Eq. (III-33) take into account the deviations from a point-mass.

The first order derivative of the potential generates the effect of the tesseroid mass on the gravity vector at $P(r, \varphi, \lambda)$, and can be found by differentiation of the integral kernel $1 / l_{o}$ in Eq. (24) or (27) with respect to $r, \varphi$ and $\lambda$.

$$
\delta g=-\frac{\partial v(r, \varphi, \lambda)}{\partial r}=G \rho \int_{\lambda_{1}}^{\lambda_{2}} \int_{\varphi_{1}}^{\varphi_{2}} \int_{r_{1}}^{r_{2}} \frac{r^{\prime 2}\left(r-r^{\prime} \cos \psi\right) \cos \varphi^{\prime} d r^{\prime} d \varphi^{\prime} d \lambda^{\prime}}{l^{3}}
$$

Once again, no approximated form has been found yet for solving analytically the triple integral given in Eq. (III-41) due to the occurrences of the elliptic integrals. However, Heck \& Seitz (2007) used an approximated integral solution that reduces Eq. (III-41) to a surface integral by numerical integration with respect to radial coordinate $r$ ' using the formula given by Martinec (1998):

$$
\begin{aligned}
\delta g=\frac{G \rho}{r} \int_{\lambda_{1}}^{\lambda_{2}} \int_{\varphi_{1}}^{\varphi_{2}} \cos \varphi^{\prime}\left[\frac{r^{\prime 3}}{l}-l\left(r^{\prime}+3 r \cos \psi\right)\right. \\
\left.\quad-r^{2}\left(3 \cos ^{2} \psi-1\right) \ln \left(l+r^{\prime}-r \cos \psi\right)\right]\left.\right|_{r^{\prime}=r_{2}} ^{r^{\prime}=r_{1}} d \varphi^{\prime} d \lambda^{\prime}
\end{aligned}
$$


Equations (III-41) and (III-42) can be computed numerically. Alternatively, the gravitational effect for tesseroids at distances from the computation point $P$ can be computed by fixing the point of the Taylor expansion at the geometrical centre of the integral kernel of Eq. (III-41) at $P_{o}\left(r_{o}, \varphi_{o}, \lambda_{o}\right)$.

$$
L\left(r^{\prime}, \varphi^{\prime}, \lambda^{\prime}\right)=\frac{r^{\prime 2}\left(r-r^{\prime} \cos \psi\right) \cos \varphi^{\prime \prime}}{l^{3}}=\sum_{i, j, k} L_{i j k}\left(r^{\prime}-r_{o}\right)^{i}\left(\varphi^{\prime}-\varphi_{o}\right)^{j}\left(\lambda^{\prime}-\lambda_{o}\right)^{k}
$$

where

$$
L_{i j k}=\left.\frac{1}{(i+j+k) !} \frac{\partial^{i+j+k} L\left(r^{\prime}, \varphi^{\prime}, \lambda^{\prime}\right)}{\partial r^{\prime i} \partial \varphi^{\prime j} \partial \lambda^{\prime k}}\right|_{\begin{array}{l}
r^{\prime}=r_{o} \\
\varphi^{\prime}=\varphi_{o} \\
\lambda^{\prime}=\lambda_{o}
\end{array}}
$$

Only terms with even power $i, j$, and $k$ will remain in the resulting series, while all the other terms cancel out due to the choice of the Taylor point $P_{o}\left(r_{o}, \varphi_{o}, \lambda_{o}\right)$ from inserting Eq. (III-43) into Eq. (III-41) (Heck \& Seitz, 2007).

$$
\delta g(r, \varphi, \lambda)=G \rho \Delta r \Delta \varphi \Delta \lambda\left[L_{000}+\frac{1}{24}\left(L_{200} \Delta r^{2}+L_{020} \Delta \varphi^{2}+L_{002} \Delta \lambda^{2}\right)+O\left(\Delta^{4}\right)\right]
$$

Thus, the coefficients $L_{i j k}$ in Eq. (III-45) for zero-order is

$$
L_{000}=\frac{r_{o}^{2}\left(r-r_{o} \cos \psi_{o}\right) \cos \varphi_{o}}{l_{o}^{3}}=\frac{\partial K_{000}}{\partial r}
$$

The second-order coefficients $L_{200}, L_{020}$ and $L_{002}$ of Eq. (III-45) are computed with MacMillan's formulaes given by Heck \& Seitz (2007)

$$
L_{200}=-\frac{\partial K_{200}}{\partial r}=\frac{r \cos \varphi_{o}}{l_{o}^{3}}\left\{2-\frac{3 r_{o}^{2}}{l_{o}^{2}}\left[5 r_{o}-\left(2 r+3 r_{o} \cos \psi_{o}\right) \cos \psi_{o}\right]+\frac{15 r_{o}^{3}}{l_{o}^{4}} \sin ^{2} \psi_{o}\left(r_{o}-\right.\right.
$$

$r \cos \psi 0$ 


$$
\begin{aligned}
L_{020}=-\frac{\partial K_{020}}{\partial r} & \\
& =\left(\frac{r_{o}}{l_{o}}\right)^{3} \cos \varphi\left(1-2 \sin ^{2} \varphi_{o}\right) \cos \delta \lambda \\
& +\frac{r_{o}^{2}}{l_{o}^{5}}\left\{-r\left(r^{2}+r_{o}^{2}\right) \cos \varphi_{o}\right. \\
& +r_{o} \sin \varphi\left[r r_{o}\left(\sin \varphi \cos \varphi_{o}-\cos \varphi \sin \varphi_{o} \cos \delta \lambda\right)\right. \\
& \left.+\sin \varphi_{o} \cos \varphi_{o}\left(2 r^{2}+4 r_{o}^{2}-3 r r_{o} \sin \varphi \sin \varphi_{o}\right)\right] \\
& \left.+r r_{o}^{2} \cos \varphi \sin \varphi_{o} \cos \varphi_{o} \cos \delta \lambda\left[3 \sin \varphi \cos \varphi_{o}-4 \cos \varphi \sin \varphi_{o} \cos \delta \lambda\right]\right\} \\
& +\frac{5 r r_{o}^{3}}{l_{o}^{7}}\left\{-r\left(r^{2}+r_{o}^{2}\right) \sin \varphi_{o}\right. \\
& +r_{o}^{2} \cos \varphi \sin \varphi_{o} \cos \varphi_{o} \cos \delta \lambda\left(r_{o}+r \cos \varphi \cos \varphi_{o} \cos \delta \lambda\right) \\
& +r_{o} \sin \varphi\left[2 r^{2}-r_{o}^{2}-r r_{o} \cos \psi_{o}\right. \\
& \left.\left.+\sin ^{2} \varphi_{o}\left(r^{2}+2 r_{o}^{2}-r r_{o} \sin \varphi \sin \varphi_{o}\right)\right]\right\}\left(\sin \varphi \cos \varphi_{o}-\cos \varphi \sin \varphi_{o}\right)
\end{aligned}
$$

$$
L_{002}=-\frac{\partial K_{002}}{\partial r}
$$

$$
\begin{aligned}
& =\left(\frac{r_{o}}{l_{o}}\right)^{3} \cos \varphi \cos ^{2} \varphi_{o}\{\cos \delta \lambda \\
& -\frac{3 r}{l_{o}^{2}}\left[2 r_{o} \cos \varphi \cos \varphi_{o} \sin ^{2} \delta \lambda+\left(r-r_{o} \cos \psi_{o}\right) \cos \delta \lambda\right] \\
& \left.+\frac{15 r^{2} r_{o}}{l_{o}^{4}} \cos \varphi \cos \varphi_{o}\left(r-r_{o} \cos \psi_{o}\right) \sin ^{2} \delta \lambda\right\}
\end{aligned}
$$

Again, the zero-order approximation in Eq. (III-45) is formally identical to the potential of a pointmass $m$ at $P_{o}$ on the gravitational field on $P$. In this case $m$ represent the total mass of the tesseroid located in geometrical centre $P_{o}$ and residual terms represent the deviations of the tesseroid from a point-mass geometry.

$\delta g(r, \varphi, \lambda)=\frac{G m}{l_{o}^{3}}\left(r-r_{o} \cos \psi_{o}\right)\left[1+O\left(\Delta^{2}\right)\right]=G \rho \Delta r \Delta \varphi \Delta \lambda L_{000}\left[1+O\left(\Delta^{2}\right)\right]$

Similarly, the second gravitational potential derivatives in $v(r, \varphi, \lambda)$ with respect to $\varphi$ and $\lambda$ will provide the formulas for the (topographic-isostatic) reduction of the vertical deflections at $P$. This section follows the methodology based on the calculation of the gravitational potential from 
tesseroids defined by Heck \& Seitz (2007). Notice that all the formulas obtained here are valid only for computation points located outside the tesseroid.

Based on Newton's formula, the effect of a tesseroid on Marussi tensor components (III-3) can be estimated as given in Grombein et al. (2010) by optimizing the non-singular tesseroid formulas:

$$
V_{i j}=G \rho \int_{\lambda_{1}}^{\lambda_{2}} \int_{\varphi_{1}}^{\varphi_{2}} \int_{r_{1}}^{r_{2}}\left(\frac{3 \Delta x_{i} \Delta x_{j}}{l^{5}}-\frac{\delta_{i j}}{l^{3}}\right) r^{\prime 2} \cos \varphi^{\prime} d r^{\prime} d \varphi^{\prime} d \lambda^{\prime}
$$

where

$i, j \in\{1,2,3\}$

$\Delta x_{1}=r^{\prime} \cos \varphi \sin \varphi^{\prime}-\sin \varphi \cos \varphi^{\prime} \cos \left(\lambda^{\prime}-\lambda\right)$

$\Delta x_{2}=-r^{\prime} \cos \varphi^{\prime} \sin \left(\lambda^{\prime}-\lambda\right) ;$ and

$\Delta x_{3}=r^{\prime} \cos \psi-r$

Once again, the integrals for gravity gradients from tesseroids cannot be solved analytically, i.e., they should be obtained numerically.

\section{III.4. Gravity field representation in spherical harmonics}

The recovery of the gravity field from airborne and satellite data are based on the fundamental ideas of the global gravity field determination based on spherical harmonics expansion and differential (satellite) orbit improvement. In the following sections we review the contribution of the global geopotential models to improve the understanding of the Earth's gravity field and the basic theories of the gravity anomalies and gradient components in spherical harmonic representations from global geopotential models.

The spherical harmonics allow to derive the elements of the gravity field from the global geopotential models as the geoid, gradient tensor, Bouguer and free-air gravity anomaly, gravity disturbance (the radial derivative of the disturbing potential), the deflection of the vertical components (the first meridian and vertical) from the most recent geopotential models available. In this section we will give a brief description of this methodology and its use for the interpretation of possible geophysical patterns and strong correlations present on the various elements of the gravity field, as the geoid model and the diagonal elements of the gradient tensor in the Amazon and Solimões Paleozoic basins of Brazil. 
Only with satellites it is possible to cover the entire Earth's gravity field with measurements of uniform quality within a short period of time, resulting in a global geopotential model (GGM) in terms of the representation in spherical harmonic coefficients. However, the determination of the gravity gradient components from global geopotential models is a new regional approach that was expected to be fulfilled with the GOCE satellite mission, which uses measures of the gravity gradiometry to obtain the geopotential models and the second derivatives of the Earth's gravitational potential.

\section{III.4.1. Applications of global geopotential models in Geodesy and Geophysics}

The global geopotential models is used in different branches of geodesy. The determination of precise regional geoids are usually performed from a global geopotential model together with a set of points or mean terrestrial gravity anomalies and topographic information. In order to determine the most appropriate geopotential model for this combination it is necessary to check the statistical fit of several high degree models for the gravity field. This includes setting the geopotential model for obtain the geoid height geometrically in the study region (Kiamehr \& Eshagh, 2008). The best geopotential model can be estimated by combining of the gravity data using the Stokes' formula method. The theoretical foundations for the representation of the geoid were developed by Stokes (1819 - 1903) in his work "On the Variation of Gravity and the Surface of the Earth", which expresses geoid heights as a function of the gravity anomalies with the basic assumption of the existence of topography only below the geoid.

Still in the area of the geodesy, the conventional levelling is being replaced by the determination of altitudes by using the global positioning system (GPS). The GPS technique is used for levelling projects, for example, to monitor the subsidence of the dam due to the removal of water or natural gas, crustal movements and for control heights in connection with the bridge construction and other engineering projects. The altitude obtained directly from the GPS measurement is the geometric altitude, a quantity that is referred to the reference ellipsoid. Figure III-5 shows the basic relationship between the geometric altitude $h$, the orthometric altitude $H$ and the geoid height $N$. In a first approximation, the altitudes are related by:

$$
h \cong H+N
$$

The main problem of transforming the geometric height obtained by GPS to orthometric height is to determine a reliable geoid height quantity. This geoid height can be obtained using a gravimetric method or a geopotential global model. In countries where there are no precise gravimetric geoid models, the geoid height obtained from global geopotential models plays an important role in this 
transformation. Furthermore, the geoid height and the gravity anomalies have geophysical applications to study the properties within the Earth.

The deflection of the vertical is the angle between the normal of the reference ellipsoid and the plumb line (vertical) passing through the same point. This deflection is usually used to reduce the observations, transforming the astronomical coordinates in geodesic coordinates and vice versa. Since the deflection of the vertical may represent variations in density within the earth it can be used in geophysical exploration. Studies of the horizontal and vertical components of the gravity tensor and the deflection of the vertical components made by Kiamehr et al. (2008) showed a good correlation between these quantities of the gravity field. Kiamehr (2006) found a good correlation between tectonic structure and deflection of the vertical. Therefore, the general pattern of deflection of the vertical computed by a global geopotential model can help in getting the information about the lateral variation in density of the Earth.

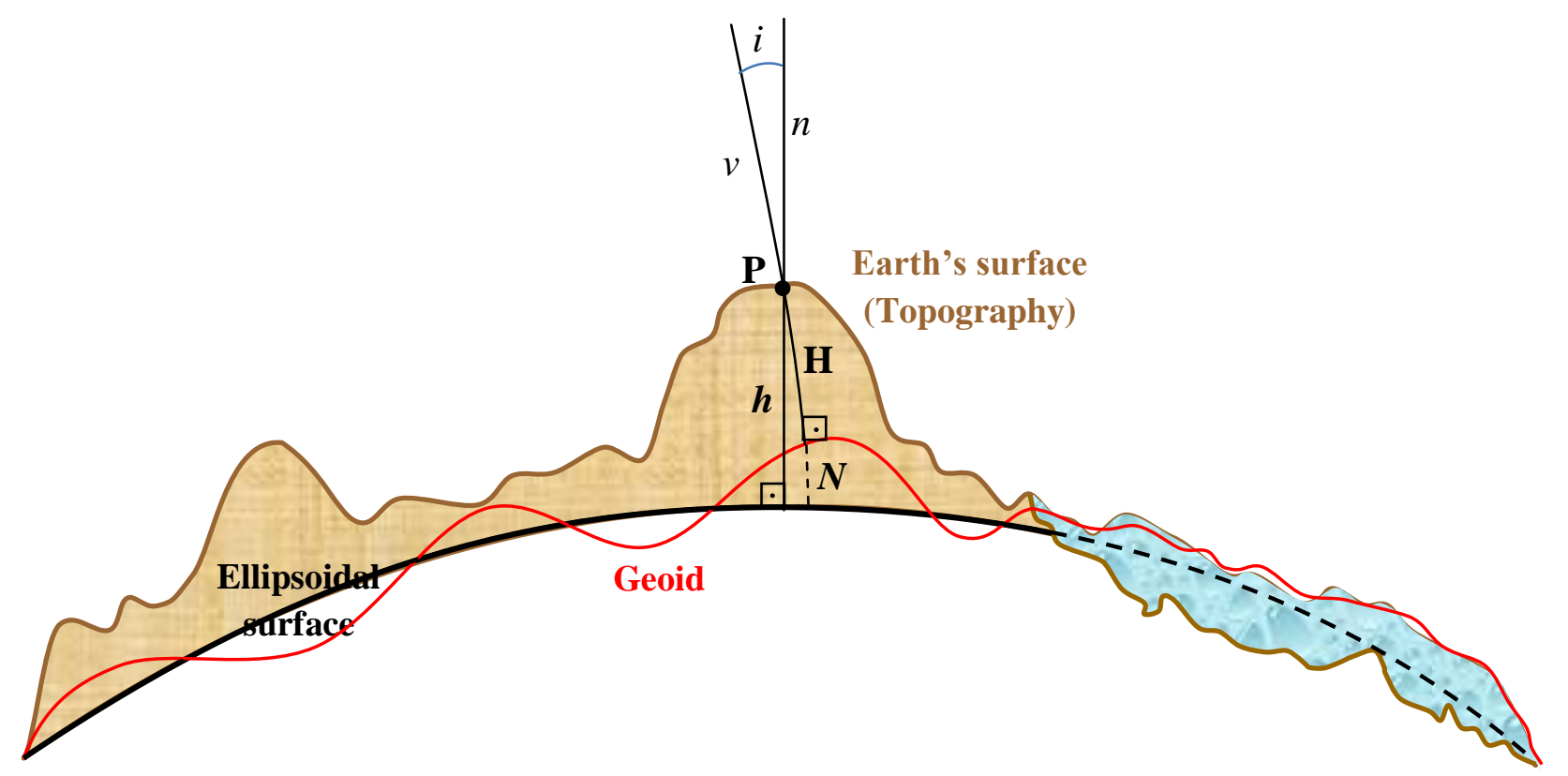

Figure III-5: Terrestrial surface for description of the external gravity field at $P$ point involving three surfaces in geodesy and gravity field: the physical surface of the Earth, the geoid surface and the ellipsoidal surface, where $n$ and $v$ are the normal and vertical directions at the $P$ point.

\section{III.4.1.1. Parameters of the gravity field from the global geopotential models}

According to Kiamehr \& Eshagh (2008), from the 1960's to 1980's geodetic satellites provided the components of medium and long wavelength of the gravity field, which are represented in spherical harmonics. Additionally, in 2000's with satellite gravimetry missions CHAMP (Reigber et al. 2002), GRACE (Tapley et al. 2005) and more recently the satellite gradiometry mission GOCE 
(Pail et al. 2011), the quality of GGMs have significantly improved, especially in the long wavelengths associated with the Earth's gravity field. These missions have provided a homogeneous coverage of the gravity field and at almost throughout all the globe, insofar as their orbits are nearly polar.

There are many areas in the Earth that are still with no significant gravity data measurements. In the oceans the gravity anomalies are mostly determined from satellite altimetry, but the effects of the ocean circulation currents and bias deteriorate these data. One important aspect about the solutions of the gravity field derived from satellite-only data is that they are not contaminated by systemetic errors (see Appendix A for details).

However, a variety of the Global Geopotential Models (GGMs) which represented the Earth's gravity field in terms of the spherical harmonic functions have been computed for many groups, for instance, GPM98 A, B, C (Wenzel, 1998), EGM96 (Lemoine et al. 1998) and more recent GGMs obtained from satellite gravimetry/gradiometry missions as CHAMP (Reigber et al. 2002), GRACE (Förste et al. 2008) and GOCE (Pail et al. 2011) (Table III-1). This GGMs can be divided in three different classes (Amos and Featherstone, 2008):

- Satellite-only GGMs: are computed solely from the analysis of the orbits of artificial Earth satellites (see examples in GGMs listed in the Table III-1);

- Combined GGMs: are obtained from the combination of satellite data, land and ship track gravity observations, and marine gravity anomalies derived from radar altimetry, and airborne and/or gradiometer gravity data; and

- Tailored GGMS: are derived from an adjust of a GGM (only-satellite or combined) using gravity data that may not necessarily have been used before (in this case, the GGM can be often extended to higher degrees).

Table III-1: Some examples of three different types GGMs.

\begin{tabular}{|l|c|l|l|}
\hline \multicolumn{1}{|c|}{ Model } & Degree & \multicolumn{1}{c|}{ Class } & \multicolumn{1}{c|}{ author } \\
\hline JGM-3 & 70 & combined & Tapley et al. (1996) \\
\hline EGM96S & 70 & satellite-only & Lemoine et al. (1998) \\
\hline GEM5 & 12 & satellite-only & Lerch et al (1974) \\
\hline GRIM5-S1 & 99 & satellite-only & Biancale et al. (2000) \\
\hline EIGEN-1S & 119 & satellite-only & Reigber et al. (2002) \\
\hline GGM03C & 360 & combined & Tapley et al (2007) \\
\hline GRIM5-S1 & 120 & combined & Gruber et al. (2000) \\
\hline TEG-4 & 200 & combined & Tapley et al. (1997) \\
\hline EGM96 & 360 & combined & Lemoine et al. (1998) \\
\hline PGM2000A & 360 & combined & Pavlis et al. (2000) \\
\hline EGM2008 & 2156 & combined & Pavlis et al. (2012) \\
\hline
\end{tabular}




\begin{tabular}{|l|c|l|l|}
\hline EIGEN-5S & 360 & satellite-only & Förste et al. (2008) \\
\hline GO_CONS_GCF_2_TIM_R3 & 250 & satellite-only & Pail et al (2011) \\
\hline GO_CONS_GCF_2_DIR_R3 & 240 & satellite-only & Bruinsma et al (2010) \\
\hline EIGEN-6C & 1420 & combined & Förste et al (2011) \\
\hline GPM98C & 1800 & Tailored & Wenzel et al. (1998) \\
\hline
\end{tabular}

\section{III.4.1.2. Geoid height, gravity anomalies and deflection of the vertical components}

The gravity field may be subdivided into two main spatial components, the long wavelengths ( $\sim 400$ $\mathrm{km})$ and short wavelengths ( $25-100 \mathrm{~km})$. The information of the long wavelength can be obtained by analysis of disturbing of the satellite orbits and from terrestrial gravimetric data or satellite altimetry. The result of this computation can be simplified in terms of a global geopotential model. In Geodesy, the gravity data is used to define the figure of the Earth. In Geophysics, the gravity data is used to estimate the density variations in subsurface and to help to solve problems related to tectonic and geophysical exploration.

In this context, the geodesists seek to use the differences between the difficulty of measuring the potential of the real Earth (or geopotential) and the potential of the normal Earth (or spheropotential). Such normal potential is obtained from a mathematical model and the residual potential is called the disturbing potential. The disturbing potential can be used to obtain very important quantities, which show how much the geopotential differs of the spheropotential. Also, it can be considered as the potential produced by the terrestrial anomalous masses. Quantities of the gravity field such as the geoid height, the gravity anomaly and the deflection of the vertical components are the main elements that can express the departure of the real gravity field in relation to the normal gravity field and can be interpreted geophysically.

Another useful quantity of the gravity field is the gravity tensor (second derivatives of the gravitational potential) that is again referred to the disturbing potential. Generally the gravity gradient components are referenced in a reference system oriented to the north. The origin of this system can be considered in the terrestrial surface or even in the satellite orbit. The z-axis is pointed in the geocentric radial direction and upward, the $\mathrm{x}$-axis points to north and, consequently, the $\mathrm{y}$ axis takes the west direction.

For the analysis of the gravity field, the disturbing potential $(T)$ at any point can be represented by a spherical harmonic series (Heiskanen \& Moritz, 1967): 


$$
\mathrm{T}(r, \varphi, \lambda)=\frac{G M}{a} \sum_{l=2}^{L} \sum_{m=0}^{l}\left(\frac{a}{r}\right)^{l+1}\left[\bar{C}_{l m} \cos m \lambda+\bar{S}_{l m} \sin m \lambda\right] \bar{P}_{l m}(\cos \varphi)
$$

where $r, \varphi, \lambda$ are the geocentric distance, geodesics latitude and longitude respectively, $G M$ is the product of the gravitational constant and of the mass of the Earth, $a$ is the major semi-axis of the reference ellipsoid, $L$ is the maximum degree of the expansion, $l, m$ are the degree and order of the spherical harmonic expansion, $\overline{\boldsymbol{C}}_{\boldsymbol{l m}}$ and $\overline{\boldsymbol{S}}_{\boldsymbol{l m}}$ are the fully normalized geopotential coefficients and $\overline{\boldsymbol{P}}_{\boldsymbol{l m}}(\cos \varphi)$ are the normalized associated Legendre functions. According to Bruns' formula (Heiskanen \& Moritz, 1967), it follows that

$$
\mathrm{N}(r, \varphi, \lambda)=\frac{G M}{a \gamma} \sum_{l=2}^{L} \sum_{m=0}^{l}\left(\frac{a}{r}\right)^{l+1}\left[\bar{C}_{l m} \cos m \lambda+\bar{S}_{l m} \sin m \lambda\right] \bar{P}_{l m}(\sin \varphi)
$$

where $\gamma$ is the normal gravity at the sea level at the latitude point estimated by Somigliana's formula. So, according to Heiskanen \& Moritz (1967), the gravity anomaly can be written as a function of the geopotential coefficients:

$$
\Delta \mathrm{g}(r, \varphi, \lambda)=\frac{G M}{a} \sum_{l=2}^{L} \sum_{m=0}^{l}\left(\frac{a}{r}\right)^{l+1}\left(\frac{l-1}{r}\right)\left[\bar{C}_{l m} \cos m \lambda+\bar{S}_{l m} \sin m \lambda\right] \bar{P}_{l m}(\sin \varphi)
$$

The deflection of the vertical is the angle between the gravity vector or the plumb line (the vertical line passing through a point) and the corresponding vector of the normal gravity on the ellipsoid at the same point. The deflection of the vertical is typically given as north/south and east/west components in seconds of arc, denoting the slope of the geoid with respect to the ellipsoid (Heiskanen \& Moritz, 1967). The deflection of the vertical components are also called the prime vertical or north/south $(\boldsymbol{\xi})$ and the meridian or east/west $(\boldsymbol{\eta})$ components. Thus, the deflection of the vertical components can be represented as: 


$$
\begin{aligned}
& \xi(r, \varphi, \lambda)=\frac{G M}{a r \gamma^{2}} \sum_{l=2}^{L} \sum_{m=0}^{l}\left(\frac{a}{r}\right)^{l+1}\left[\bar{C}_{l m} \cos m \lambda\right. \\
& \left.+\bar{S}_{l m} \sin m \lambda\right]\left[\gamma \sqrt{(l-m)(l+m-1)\left(1+\delta_{m}\right)} \bar{P}_{l, m+1}(\sin \varphi)\right. \\
& \left.-\left(\gamma m \tan \varphi-\frac{d \gamma}{d \varphi}\right) \bar{P}_{l m}(\sin \varphi)\right] \\
& \eta(r, \varphi, \lambda)=\frac{G M}{a \gamma r \sin \varphi} \sum_{l=2}^{L} \sum_{m=0}^{l}\left(\frac{a}{r}\right)^{l+1} m\left[\bar{C}_{l m} \cos m \lambda+\bar{S}_{l m} \sin m \lambda\right] \bar{P}_{l m}(\sin \varphi)
\end{aligned}
$$

where,

$$
\frac{d \gamma}{d \varphi}=\frac{\gamma_{0} \cos \varphi \sin \varphi}{\left(1-e^{2} \sin ^{2} \varphi\right)^{\frac{3}{2}}}\left(2 k+e^{2}\left(1-k \sin ^{2} \varphi\right)\right)
$$

and $\gamma_{\mathbf{0}}$ is the normal gravity at equator, $\boldsymbol{e}^{\mathbf{2}}$ is the first eccentricity of the reference ellipsoid and $\mathrm{k}$ is a constant based on the Somigliana's formula with $\mathrm{k}=0.00193185353 . \delta$ is the Kronecker delta.

\section{III.4.1.3. Gravimetric Reductions}

The gravity anomaly is subject to different types of reductions depending on the purpose for which it is being determined. The gravity anomaly is the difference between the gravity acceleration measured at the physical (or terrestrial) surface $\left(\boldsymbol{g}_{\mathbf{0}}\right)$ (corrected the periodic variations and topography) and the acceleration of gravity produced by a model of normal Earth $(\boldsymbol{\gamma})$. The gravity anomalies are the values of the greatest interest in the applications of the gravimetry.

It is known that the Stokes' formula assumes the knowledge of gravity over the whole surface of the geoid, i.e. reduced the gravity at sea level, and it also assumes the absence of topographical masses (mass outside the geoid). However, it is necessary the application of methods of gravimetric reductions to eliminate or transfer to other positions the masses above the geoid (Heiskanen $\&$ Moritz, 1967).

The gravity anomaly so far described as a function of geopotential coefficients can also be rewritten as

$$
\Delta \mathrm{g}=g_{0}-\gamma
$$

when the gravity observed in the physical surface is reduced at sea level using the free-air correction $\left(\mathrm{C}_{\mathrm{FA}}\right)$, it generates the free-air anomaly 


$$
\Delta g_{F}=g_{0}+C_{F A}-\gamma
$$

Since the gravity is reduced to the sea level (geoid), for using the Stokes' integral it is necessary to remove the masses above the geoid (topographic masses), as well as the isostatic balance masses (i.e., the topographic-isostatic reduction of gravity) which accounts for an additional correction called Bouguer correction $\left(\mathrm{C}_{\mathrm{B}}\right)$, being the corresponding gravity anomaly the Bouguer anomaly (Heiskanen \& Moritz, 1967)

$$
\Delta \mathrm{g}_{\mathrm{B}}=g_{0}+C_{F A}+C_{B}-\gamma
$$

The isostasy postulates the existence of an equilibrium state in the lithosphere, where the topographic masses are floating in the mantle. There are two main types of isostatic compensation models of topographic masses: the first assumes that the topography is locally compensated and such compensation (local compensation) occurs directly below the topography by thickening of the crust with constant density (Airy model) or by a lateral change in the crustal density (Pratt model). In the second type, the flexure model, loads are partially supported by elastic stresses in a thin lithospheric plate lying on a fluid and the compensation occurs on a regional base (Vening-Meinesz model). In this model, the most important assumption is that the lithosphere behaves like a perfectly elastic plate.

The flexural model is similar to the Airy model, where the compensation of the topographic loads occurs due to the flexure down and a correspondent crustal thickening. The Airy model corresponds to a flexural rigidity of zero. A common approach to understand the form of the isostatic compensation is to study the relationship between the topography and the gravity anomaly created by the mass anomalies in subsurface that compensate the topography.

In the areas where the crust is in isostatic equilibrium, it is appropriate to calculate the isostatic correction and therefore the isostatic anomaly corresponding can be given by:

$$
\Delta \mathrm{g}_{\mathrm{I}}=g_{0}+C_{F A}+C_{B}+C_{I}-\gamma
$$

\section{III.4.1.4. Gradiometry: gravity gradient components}

The expansions for gravity gradients in the local north-oriented reference frame have a complicated form depending on the first and second derivatives of the associated Legendre functions with respect to the latitude, which contain, generally, factors tending to infinity when it approaches the poles. Here were used non-singular expressions for gravity gradients as presented by Petrovskaya \& Vershkov (2006). The first and second order derivatives of the disturbing potential $T$ in the local 
north-oriented reference frame $\{x, y, z\}$ are considered by proceeding from a known relationship (Reed, 1973), but presented in terms of latitude rather than co-latitude. Thus, the ratio between the components in the Cartesian coordinate in the local frame and in the geocentric spherical coordinates becomes:

$$
\begin{gathered}
T_{z z}=T_{r r} \\
T_{x x}=\frac{1}{r} T_{r}+\frac{1}{r^{2}} T_{\varphi \varphi} \\
T_{y y}=\frac{1}{r} T_{r}+\frac{1}{r^{2} \cot \varphi} T_{\varphi}+\frac{1}{r^{2} \cos ^{2} \varphi} T_{\lambda \lambda}, \\
T_{x y}=\frac{1}{r^{2} \cos \varphi} T_{\varphi \lambda}-\frac{\sin \varphi}{r^{2} \cos ^{2} \varphi} T_{\lambda} \\
T_{\mathrm{xz}}=\frac{1}{r^{2}} T_{\varphi}-\frac{1}{r} T_{r \varphi} \\
T_{y z}=\frac{1}{r^{2} \cos \varphi} T_{\lambda}-\frac{1}{r \cos \varphi} T_{\mathrm{r} \lambda}
\end{gathered}
$$

The parameters of the gravity gradient are presented in an alternative form of Petrovskaya \& Vershkov (2006) and their relations follow in Kiamehr et al. (2008):

$$
\begin{aligned}
& T_{z z}=\frac{G M}{a^{3}} \sum_{l=2}^{L} \sum_{m=0}^{l}(l+1)(l+2)\left(\frac{a}{r}\right)^{l+3}\left[\bar{C}_{l m} \cos m \lambda+\bar{S}_{l m} \sin m \lambda\right] \bar{P}_{l m}(\sin \varphi) \\
& T_{x x}=\frac{G M}{a^{3}} \sum_{l=2}^{L} \sum_{m=0}^{l}\left(\frac{a}{r}\right)^{l+3}\left[\begin{array}{c}
\bar{C}_{l m} \cos m \lambda+ \\
\bar{S}_{l m} \sin m \lambda
\end{array}\right]\left\{\begin{array}{c}
a_{l m} \bar{P}_{l m-2}(\sin \varphi)+ \\
{\left[b_{l m}-(l+1)(l+2)\right] \bar{P}_{l m}(\sin \varphi)+} \\
c_{l m} \bar{P}_{l m+2}(\sin \varphi)
\end{array}\right\} \\
& T_{y y}=-\frac{G M}{a^{3}} \sum_{l=2}^{L} \sum_{m=0}^{l}\left(\frac{a}{r}\right)^{l+3}\left[\begin{array}{c}
\bar{C}_{l m} \cos m \lambda+ \\
\bar{S}_{l m} \sin m \lambda
\end{array}\right]\left\{\begin{array}{c}
a_{l m} \bar{P}_{l m-2}(\sin \varphi)+ \\
b_{l m} \bar{P}_{l m}(\sin \varphi)+c_{l m} \bar{P}_{l m+2}(\sin \varphi)
\end{array}\right\}
\end{aligned}
$$

and

$$
\begin{gathered}
T_{x y}=\frac{G M}{a^{3}} \sum_{l=2}^{L} \sum_{m=1}^{l}\left(\frac{a}{r}\right)^{l+3}\left[\begin{array}{c}
\bar{C}_{l m} \sin m \lambda- \\
\bar{S}_{l m} \cos m \lambda
\end{array}\right]\left\{\begin{array}{c}
d_{l m} \bar{P}_{l-1, m-2}(\sin \varphi)+g_{l m} \bar{P}_{l-1, m} \\
(\sin \varphi)+\bar{P}_{l-1, m+2}(\sin \varphi)
\end{array}\right\} \\
T_{x y}=\frac{G M}{a^{3}} \sum_{l=2}^{L} \sum_{m=1}^{l}\left(\frac{a}{r}\right)^{l+3}\left[\begin{array}{c}
\bar{C}_{l m} \cos m \lambda+ \\
\bar{S}_{l m} \sin m \lambda
\end{array}\right]\left\{\begin{array}{c}
\beta_{l m} \bar{P}_{l, m-1}(\sin \varphi)+ \\
\gamma_{l m} \bar{P}_{l, m+1}(\sin \varphi)
\end{array}\right\} \\
T_{y z}=\frac{G M}{a^{3}} \sum_{l=2}^{L} \sum_{m=1}^{l}\left(\frac{a}{r}\right)^{l+3}\left[\begin{array}{c}
\bar{C}_{l m} \sin m \lambda- \\
\bar{S}_{l m} \cos m \lambda
\end{array}\right]\left\{\begin{array}{c}
\mu_{l m} \bar{P}_{l-1, m-1}(\sin \varphi)+ \\
v_{l m} \bar{P}_{l-1, m+1}(\sin \varphi)
\end{array}\right\}
\end{gathered}
$$

The coefficients of the Legendre functions are numerical constants given by Petrovskaya \& Vershkov (2006). Using these formulae, the gravity gradient components from GOCE mission data can be used to construct a global geopotential model (Petrovskaya Vershkov, op. cit.). In addition, 
some components, such as $T_{z z}$, can have a geophysical meaning most easily related to the subsurface geology.

\section{III.4.1.5. Methods for Error Estimation}

\section{III.4.1.5.1. Errors GOCE: From Degree Amplitude to Gravity Anomaly errors in Spherical Harmonic}

Wahr et al. (1998) supposed that the geoid is averaged over a time interval, and defined the error of this averaged geoid in terms of the GGM estimate as:

$$
\delta N(\theta, \phi)=a \sum_{l=0}^{\infty} \sum_{m=0}^{l} P_{l m}(\cos \theta)\left(\delta C_{l m} \cos (m \phi)+\delta S_{l m} \sin (m \phi)\right)
$$

where $\delta C_{l m}$ and $\delta S_{l m}$ are the errors of the geopotential models coefficients. Then the spatial variance of the geoid error, taken over the entire globe, is

$$
\delta \sigma_{s p}^{2}=\frac{1}{4 \pi} \int_{0}^{2 \pi} d \phi \int_{0}^{\pi} \sin \theta d \theta \delta N^{2}(\theta, \phi)=a^{2} \sum_{l=0}^{\infty} \sum_{m=0}^{l}\left(\delta C_{l m}^{2}+\delta S_{l m}^{2}\right)
$$

The degree amplitude or degree variances from the geopotential model error is defined as

$$
\delta N_{l}=a \sqrt{\sum_{m=0}^{l}\left(\delta C_{l m}^{2}+\delta S_{l m}^{2}\right)}
$$

The error estimate of the gravity anomaly is obtained similarly. Therefore the RMS (Root Mean Square) anomaly errors per degree were computed by:

$$
\delta g_{l}=\left[\left(\frac{G M(l-1)}{a^{2}}\right)^{2} \sum_{m=0}^{l}\left(\delta C_{l m}^{2}+\delta S_{l m}^{2}\right)\right]^{1 / 2}=\left(\frac{G M(l-1)}{a^{2}}\right) \sqrt{\sum_{m=0}^{l}\left(\delta C_{l m}^{2}+\delta S_{l m}^{2}\right)}
$$

$\delta N_{l}^{2}$ and $\delta g_{l}^{2}$ are the total contributions to the variance of the geopotential model to the geoid and gravity anomaly error from all terms up to degree $l$. The degree $l$ is a measure of the spatial scale of a spherical harmonic. The half-wavelength of a $(l, \mathrm{~m})$ spherical harmonic serves as an approximate representation of the spatial scale and is roughly given by $20,000 \mathrm{~km} / l$. So $\delta N_{l}^{2}$ and $\delta g_{l}^{2}$ are a measure of the contribution to the variances from all the terms up to a given spatial scale. 
Wahr et al. (1998) assumed that uncertainties in the estimates of $\delta C_{l m}$ and $\delta S_{l m}$ depend on $l$ but not on $m$ (i.e., that the geoid error depends on wavelength but not on spatial orientation) and that the errors in coefficients with different values of $l$ and $m$ are uncorrelated (equivalent to assuming that, on average, this geopotential models will determine the geoid and gravity anomaly equally well over all regions of the globe). The geoid and gravity anomaly uncertainties can then be summarized by providing estimates of the expected $\delta N_{l}$ and $\delta g_{l}$ as a function of $l$, and this is the form in which the uncertainties were provided by the geopotential models. Since each $\delta N_{l}$ and $\delta g_{l}$ involve the sum over $(2 l+1)$ coefficients (note that $S_{10}=0$ for each $l$ ), then an individual uncertainty $\delta C_{l m}$ or $\delta S_{l m}$ is equal to $\delta N_{l}$ or $\delta g_{l}$ divided by $\sqrt{2 l+1}$.

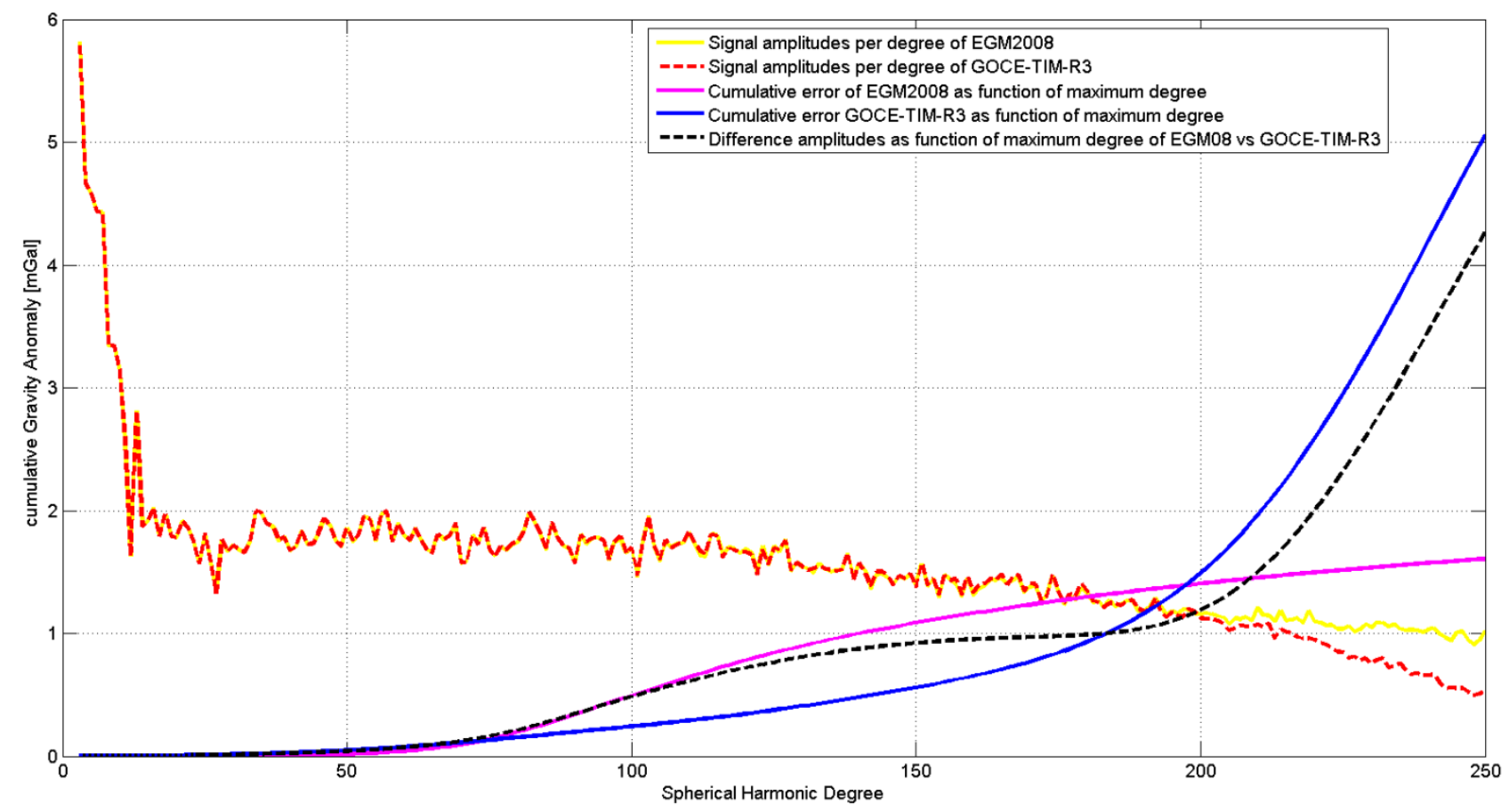

Figure III-6: RMS errors in the gravity anomaly from the geopotential models and degree amplitudes for GOCE and EGM08 in the gravity anomaly (free-air), signal, error and difference between EGM08 and GOCE.

The cumulative error in gravity anomaly for spherical harmonics coefficients of the GGMs up to degree and order 250 is about $0.75 \mathrm{mGal}$ for EGM2008 (Pavlis et al., 2008) and $1.39 \mathrm{mGal}$ for the GOCE GGM (Pail et al., 2011). 


\section{III.4.1.5.2. Systematic errors of low spherical harmonic degrees in the surface gravity anomalies}

The systematic errors of the low spherical harmonic degrees in the terrestrial gravity anomalies were studied by Huang et al. (2008) supposing that the Earth gravity field determined by GGMs can be modeled by spherical harmonics as follows

$$
\Delta g^{G G M}=\sum_{n=2}^{L} g_{n}+\epsilon_{L}^{G G M}
$$

where $\Delta g^{G G M}$ is the gravity anomaly, $L$ is the maximum degree of the global geopotential model (GGM) in spherical harmonics; $g_{n}$ is the spherical harmonic component of degree $n$ and $\epsilon_{L}^{G G M}$ is the commission error associated with the GGM.

Similarly, the terrestrial gravity anomaly $\Delta g^{T G}$ described in spherical harmonics can be expressed by

$$
\Delta g^{T G}=\sum_{n=2}^{\infty} g_{n}+\epsilon_{L}^{T G}+\epsilon_{H}^{T G}+\epsilon_{n}
$$

The second and third terms on the right hand side are the low and high-degree systematic errors, respectively. The last term $\epsilon_{n}$ is the random error. By subtracting eq. (III-70) from eq. (III-71), we obtain

$$
\Delta g^{T G}-\Delta g^{G G M}=\sum_{n=L+1}^{\infty} g_{n}+\delta \epsilon_{L}+\epsilon_{H}^{T G}+\epsilon_{n}
$$

where

$$
\delta \epsilon_{L}=\epsilon_{L}^{T G}-\epsilon_{L}^{G G M}
$$

Huang et al. (2008) assumed that if the error of the satellite models is much smaller than the systematic error in the surface gravity data, $\delta \epsilon_{L}$ is approximately the low-degree systematic error in the terrestrial data below degree $L$. Thus, we can rewrite eq. (III-72) as

$$
\delta \epsilon_{L}=\Delta g^{T G}-\sum_{n=L+1}^{\infty} g_{n}-\epsilon_{H}^{T G}-\epsilon_{n}-\Delta g^{G G M} .
$$

In order to estimate $\delta \epsilon_{L}$, Huang et al. (2008) smoothed $\Delta g^{T G}$ in order to remove the high degree components and the high degree systematic and random errors. 


\section{III.4.1.5.3. Spatial Averaging}

There are many mathematical tools developed for smoothing the gravity field (Jekeli, 1981). In our case we have calculated a grid of gravity anomaly values obtained from the GGMs, GOCE and EGM2008, with the standard spherical approximation that follows the series representation of Heiskanen and Moritz (1967) and terrestrial gravity anomaly values which we must reduce in a mean gravity anomaly through smoothing that correspond only to the long-wavelength part of the terrestrial gravity anomaly.

In general, the global geopotential model approach uses the idea of constructing spatial averages to compensate for poorly known, short-wavelength spherical harmonic coefficients to improve estimates of the Earth's gravity field. The terrestrial gravity anomalies encompass gravity components with higher spherical harmonic degrees than those from the satellite data. However these higher degree components require that an effective filtering or smoothing process to be performed to the terrestrial data to make them comparable with the satellite data. Here, we will use the Gaussian averaging function (Jekeli, 1981) to average the terrestrial data.

The terrestrial data have more detailed and accurate information with regard to short-wavelengths, which will be used to obtain a mean gravity anomaly corresponding to long-wavelengths. The idea is to get the mean gravity anomaly from the terrestrial data with a Gaussian smoothing in at corresponding grid point of the gravity anomalies calculated from the geopotential global models (for example: EGM08 and GOCE up to degree and order 250). So that we can make comparisons between the gravity anomalies at long wavelengths obtained from the global geopotential models and the terrestrial data, and so estimate the errors of the geopotential models when compared to the terrestrial data, or vice-versa, to estimate the errors of the terrestrial data. Below, we follow Jekeli's Gaussian averaging function (Jekeli, 1981) normalized so that the global integral of $W$ is 1 as in Wahr et al. (1998):

$$
W(\alpha)=\frac{b}{2 \pi} \frac{e^{-b(1-\cos \alpha)}}{1-e^{-2 b}}
$$

where

$$
b=\frac{\ln 2}{(1-\cos (r / a))}
$$

$r$ is the averaging radius (i.e., the distance on the Earth's surface at which $W$ has dropped to half its value at origin $(\alpha=0)$; distance on the Earth's surface $=a \alpha)$ and $a$ is the mean radius or mean Earth 
radius $(\sim 6371 \mathrm{~km})$. In terms of the spherical harmonic development, Jekeli (1981) showed that the Gaussian weighting function can be obtained following the recursion formula to regard to coefficients $W_{l}$ :

$$
\begin{gathered}
W_{0}=\frac{1}{2 \pi} \\
W_{1}=\frac{1}{2 \pi}\left[\frac{1+e^{-2 b}}{1-e^{-2 b}}-\frac{1}{b}\right] \\
W_{l+1}=-\frac{2 l+1}{b} W_{l}+W_{l-1}
\end{gathered}
$$

Figure III-7 shows the Gaussian weighting function $W(\alpha)$ and the spherical harmonic coefficients $W_{l}$ up to degree and order 250 corresponding to the averaging radius $r=80 \mathrm{~km}$ that was used for smoothing the terrestrial data.
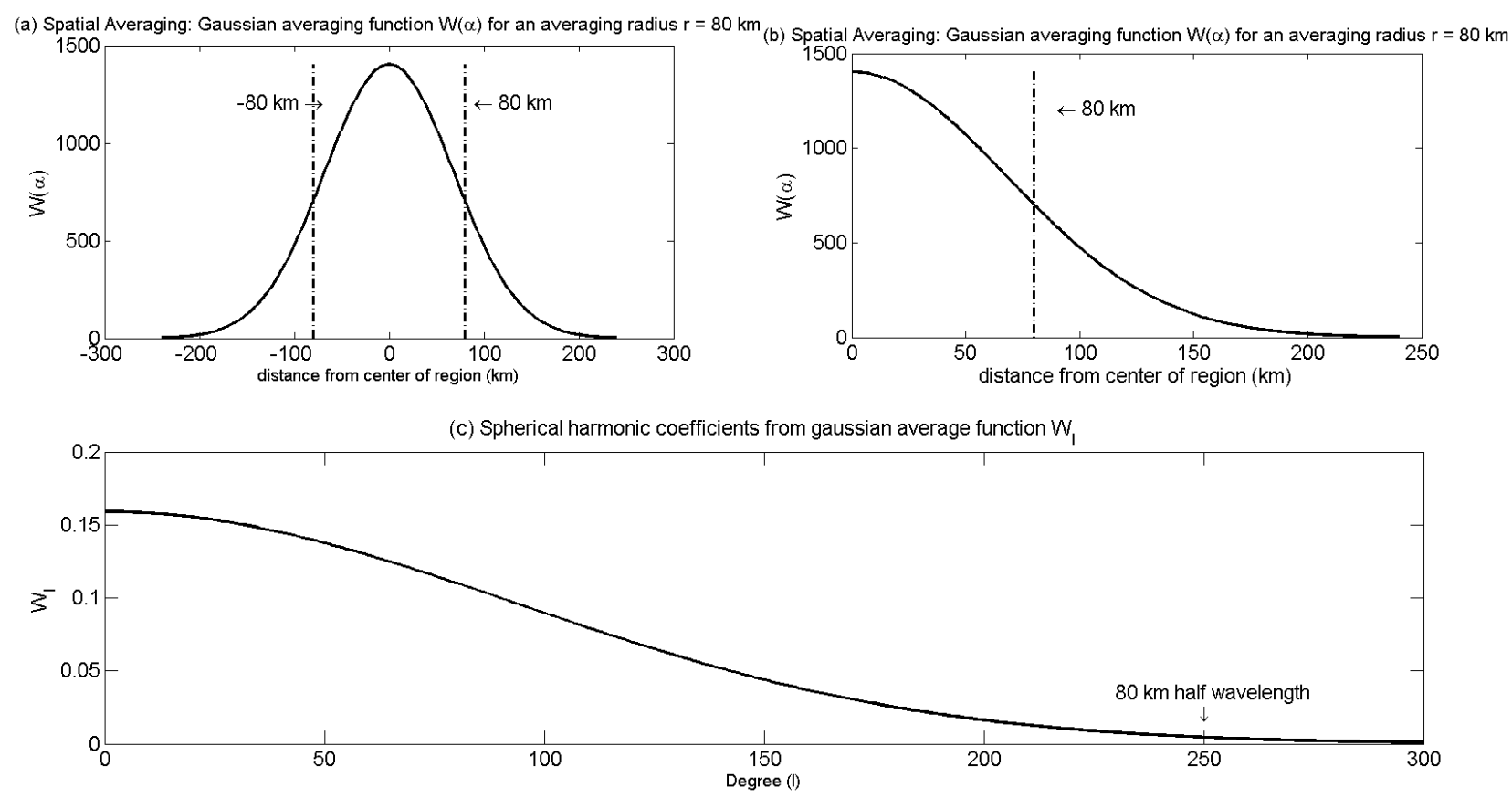

Figure III-7: (a) Spatial averaging: Gaussian averaging function $W(\alpha)$ (continuous line) for the averaging radius $r=80 \mathrm{~km}$, (vertical stippled line); (b) Spherical harmonic coefficients of Gaussian averaging function for the same averaging radius $r=80 \mathrm{~km}$. Modified from Wahr et al. (1998). 


\section{UNDERSTANDING AND INTERPRETING THE GRADIENTS OF GRAVITY WITH A PRISM APPROACH FOR GRAVITY FIELD MODELLING}

"Red October's captain is a man named Marko Ramius. That is a Lithuanian name, although we believe his internal passport designates his nationality as Great Russian. He is the son of a high party official and as good a submarine commander as they have. He's taken out the lead ship of every Soviet submarine class for the past ten years... Ramius inspected his status board. The Red October was heading southwest on track eight, the westernmost surveyed route on what Northern Fleet submariners called Gorshkov's Railroad. His speed was thirteen knots. It never occurred to him that this was an unlucky number, an Anglo-Saxon superstition. They would hold this course and speed for another twenty hours. Immediately behind him, Kamarov was seated at the submarine's gravitometer board, a large rolled chart behind him. The young lieutenant was chainsmoking, and looked tense as he ticked off their position on the chart. Ramius did not disturb him. Kamarov knew this job, and Borodin would relieve him in another two hours.

Installed in the Red October's keel was a highly sensitive device called a gradiometer, essentially two large lead weights separated by a space of one hundred yards. A laser-computer system measured the space between the weights down to a fraction of an angstrom. Distortions of that distance or lateral movement of the weights indicated variations in the local gravitational field. The navigator compared these highly precise local values to the values on his chart. With careful use of gravimeters in the ship's inertial navigation system, he could plot the vessel's location to within a hundred meters, half the length of the ship.

The mass-sensing system was being added to all the submarines that could accommodate it. Younger attack boat commanders, Ramius knew, had used it to run the Railroad at high speed. Good for the commander's ego, Ramius judged, but a little hard on the navigator. He felt no need for recklessness. Perhaps the letter had been a mistake. No, it prevented second thoughts. And the sensor suites on attack submarines simply were not good enough to detect the Red October so long as he maintained his silent routine. Ramius was certain of this; he had used them all. He would get where he wanted to go, do what he wanted to do, and nobody, not his own countrymen, not even the Americans, would be able to do a thing about it. That's why earlier he had listened to the passage of an Alfa thirty miles to his east and smiled.” 


\section{IV.1. Introduction}

This section describes a brief history of the gravity gradiometry history and its uses in the interpretation from gravity gradients (GGs) based in the formulas of Nagy et al. (2000) and Heck and Seitz (2007)

In order to analyze the feasibility of using rectangular prisms or tesseroids to calculate and to model the geological structures, two simple models were constructed using the tesseroid and the prism approaches for calculation of the gravitational quantities: the first derivative of gravitational potential (vertical component of gravity) and the GG components. The quantities in gravity fields were simulated at ground and at a height up to $250 \mathrm{~km}$ for analyze the gravity fields in the same height of the GOCE satellite.

\section{IV.2. Literature Review: History of Gravity Gradiometry}

The cited passage at the beginning of this chapter is a fragments from the submarine novel The Hunt for submarine Red October, (Clancy, 1984), written twenty eight years ago, which was also readapted to the theater in 1990 by a movie of the same name receiving highly positive reviews and making it one of the top grossing films of the year. As pointed by Bell et al. (1997), in the geophysical viewpoint, the tripulation of the Red October has gone as close to their goal as any exploration geophysicist would like to go using gravity gradiometry.

During the cold war, as an effort to devise more stealthy aids to the underwater navigation, the United States (U.S.) and the Soviet Union defense department designed sensitive instruments that could measure tiny variations in the pull of the gravity field caused by underwater ridges or mountains. This system is somewhat more complex than the one installed on the fictional submarine Red October, but the main ideia is quite the same. With the end of the Cold War, the introduction of military technology for exploration geophysics and other fields has started. Three years earlier, the U.S. Navy had already started the technological application of the gravity gradient in the underwater exploration industry (Bell et al. 1997; Bell, 1998).

However, the history of gravity gradiometry began early in 1896 with the development of an instrument known as the Eötvös Torsion Balance, essentially a gravity gradiometer, by Baron Loránd von Eötvös, a Hungarian physicist, to measure the minute variations in gravity over a short distance. Thus, his instrument was the first geophysical device capable of delineating underground geological structures. (Bell et al. 1997; Szabo, 1998; Nabighian et al. 2005; Rogers, 2009). 
Initially, the torsion balance was developed to measure the basic physical constants. Indeed, this "gradiometer", or instrument for the measurement of the spatial derivatives or gradients of the Earth's gravity field measured the local distortion of the gravity field rather than its intensity. It was a large instrument mounted on a tripod assembly (Figure IV-1), made of a metal beam that recorded the gradient of the gravity suspended by a wire, with weights present at each end. If the gravity varied with the position along the axis, the weights were placed on, and the force exerted on each weight would be different, thus causing a rotational force on the beam and in turn causing the wire to twist. So, Eötvös measured the amount of twist to determine the gravity gradient (Hopkins, 1975; Jekeli \& Zhu, 2006; Rogers, 2009).

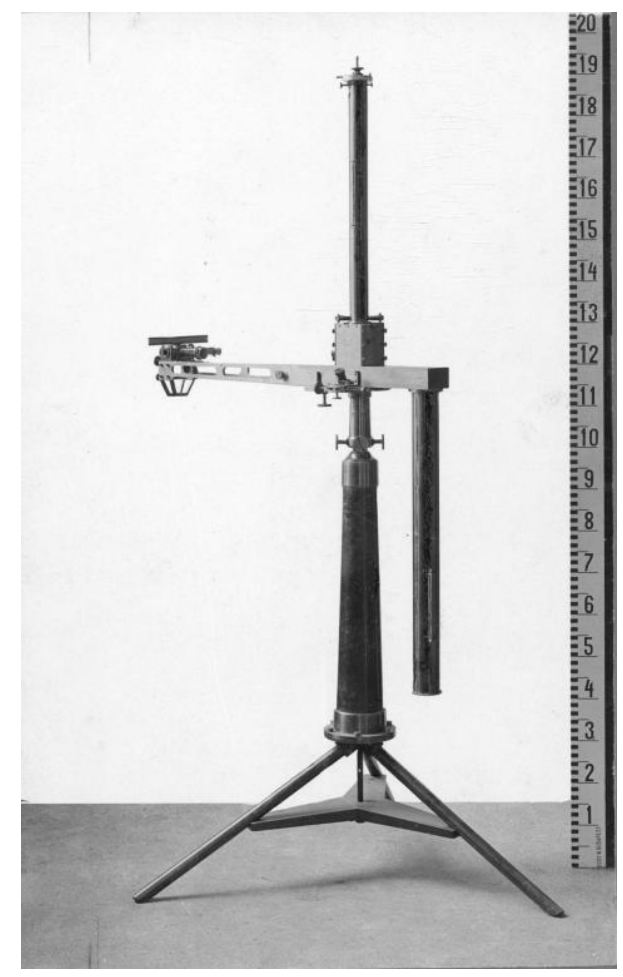

Figure IV-1: Single Eötvös' Torsion Balance designed for field work. The first Gravity Gradiometer. Courtesy of the Loránd Eötvös Geophysical Institute (Szabo, 1998).

As described in Rogers (2009), in 1901 the head of the Hungarian geologic survey convinced Eötvös to test the real-world usefulness of the torsion balance (i.e., the first investigations of the Earth's gravity field) to map the shape of a frozen lake basin, which had been already well mapped from previous summertime measurements made from a line and a sinker. The test was a success because the contour map so obtained matched the previously made maps. Eötvös and Hugo de Boeckh then performed more difficult geological surveys in the region. 
Thereafter, Eötvös presented his results and demonstrated the operation of his torsion balance at the 1906 World Congress of Geodesy (then the International Erdmessung). As a result, the Congress petitioned the Hungarian government requesting that an increased financial help should be given for Eötvös' gravitational research. The Hungarian government agreed with the suggestion and from 1907 onwards a separate fund was allocated for Eötvös' gravitational studies (Szabo, 1998). Based on the governmental support Eötvös established the first applied geophysical Institute of the world in Budapest, which is now named the Eötvös Loránd Geophysical Institute (ELGI).

On a global scale, understanding the details of the gravity field as well as developing the technology in general are critical in military applications. Despite the World War I has not introduced the use of the gravity gradiometer technique, since World War II the research and the development in the areas of gravity instrumentation and building of global data bases were greatly encouraged. On an exploration scale, gravity has been widely used for both mining and oil exploration (particularly in the U.S. Gulf Coast), and even at the reservoir scale for the hydrocarbon exploration development. However, the use of this technique began in U.S. only after the World War I, in 1922 and 1924, when American geologists of the Amerada Hess Corporation and Gulf identified the first salt domes (i.e., mushroom shaped underground diapiric salt geologic structures that often have oil and gas deposits along their sides; since the salt is less dense than most rocks, it exerts a weaker gravitational force relative to the sediments surrounding it due to the large density contrast). As such, the gravity gradients can highlight a buried salt dome (Bell et al., 1997; Nabighian et al. 2005; Rogers, 2009).

Suddenly the Eötvös' torsion balance success quickly spread to the oil prospectors around the world and the gravity method became the first geophysical technique to be used in oil and gas exploration. Thus, officially the gravity gradiometry was born (Bell, 1998; Nabighian et al. 2005; Rogers, 2009). Historically, hundreds of oil fields were discovered throughout the world with the help of Eötvös' ingenious instrument from the end of the 1910's and up to about 1940. The first geophysics gradiometer efforts occurred in Europe in 1915, in the upper Rhine Valey, and in northern Germany over a salt dome in 1918 which led to the mapping of the Czechoslovakian Egbell Oil Field (Schweydar, 1918 apud Nabighian et al. 2005; Bell et al. 1997). In U.S. other salt domes and oil fields were initially identified with gravity gradiometer, including the Lovell Lake field in Jefferson Country, Texas and the South Houston Oil Field. When these salt domes were confirmed by others techniques, drilling and seismic, the use of the gravity gradiometer had a boom, making this technique the most useful and routinely used technique in exploration technology for subsurface surveys, particularly to oil exploration (Nabighian et al. 2005; Jekeli \& Zhu, 2006; Rogers, 2009). 
On the other hand, despite the great success of the torsion balance, primarily in oil exploration to locate salt domes, the difficulty to use it in the field caused it to be abandoned soon. The history reported that geoscientists could no longer afford the expense and the time required to obtain a reliable measurement (Nabighian et al. 2005).

Rogers (2009) told that explorationists had to first clear a 100 meter long swath in eight directions, in a star pattern, from the location of the torsion balance to prevent the mass of the trees and rocks from corrupting the measurements; additionally, a small building had to be erected in order to protect the instrument from the wind and from temperature changes. This in turn generated data often misinterpreted which led to erroneous survey because of the sensitivity of the device that could corrupt its measurements even by the large belt buckles often worn by geoscientists. So, these issues led to the explosion of the use of the simpler gravimeters.

The gradiometers were quickly replaced in the 1930's and 1940's with the development of modern portable relative gravimeters that achieved sufficient accuracy for geophysical exploration as a consequence of being inherently less sensitive than gradiometers, what required no extensive measurement site preparation and permitted the surveys to be carried on in only a fraction of the time, about 10 times faster (Jekeli \& Zhu, 2006; Rogers, 2009).

Another important point is that the data from gravimeters was easiest interpreted. Firstly in the 1930's, spring gravimeters came into their own and quickly displaced the torsion balance gradiometer. After that the first compact gravimeters proved to be portable, rugged and robust instruments, capable of taking dozens of measurements on a daily basis. This led to increased investments in gravimeters and by the 1950's, gravimeters had replaced gradiometers in most of the gravity field measurement applications. So, the Eötvös gravity gradiometer was dismissed, leaving a brief passage on the historical sections of the gravity gradiometry (Nabighian et al. 2005; Jekeli \& Zhu 2006; Rogers, 2009).

With the advent of robust and practical field instruments, the use of gravity rapidly expanded in both mining and hydrocarbon exploration for any targets for which there were a density contrast at depth, such as salt domes, ore bodies, buried structures, and regional geology. However, even with the success of the gravimeters, at that moment, the gravity gradiometer was temporarily gone, but certainly it was not forgotten (Nabighian et al. 2005; Rogers, 2009).

In the 1970's, there was a new wave of research about the importance of gravity gradiometers developed into moving based systems, which basic physical principles are identical to the case of 
the satellite, capable of conducting a gravity survey over large areas with minimum expenditure of time (Hopkins, 1975).

At the same time, the U.S. Air Force had abandoned their gravity systems for Airborne surveys due to the problem of sensitivity to the aircraft accelerations, which was the main cause of the inertial and kinematic acceleration afflicting any gravimeter (or accelerometer) on a moving base, according to Einstein's well known equivalence principle, and then overwhelmed the anomalous gravimetric signal on the aircraft in flight. However, gravity gradiometers are not affected by this inability of separating inertial from attractional effects (due to the pure local validity of Einstein's aforementioned principle) and gradiometers approximate the (infinitesimal) gradients by finite difference observations. Modern three-dimensional gravity gradiometers have meanwhile been developed, which can successfully measure the second derivatives of the potential in satellites.

So, airborne gradiometry tecnology was considered the only way to solve the problem of movingbase gravimetry. With the advent of the modern Global Positioning System (GPS), positioning quickly upgraded to a high level of precision, and kinematic accelerations could be determined independently with sufficient accuracy to be used in aerogravimetry in general. Furthermore, gradiometers devices equipped with this GPS technology could flown on surveys with very closelyspaced lines (Groten, 1989; Nabighian et al. 2005; Jekeli \& Zhu 2006; Rogers, 2009).

In 1973, Bell Aerospace Textron, nowadays owned by Lockheed Martin, developed the first modern gravity gradiometer FTG (Full Tensor Gradient) system for the U.S. defense department, commissioned by the U.S. Navy. The device was deployed on board ships and housed in a recreational vehicle. Its applications were to assist navigation in stealth mode for U.S. submarines using inertial navigation systems, as the data provided the most accurate mapping of the bathymetry, and also to the Air Force Geophysics Laboratory (AFGL) for its regional airborne gravity survey system. The FTG configuration consisted of 12 individual accelerometers mounted on 3 rotating disks (gravity gradiometers). All the five independent tensor components of the gravity field were successfully measured by this configuration (Nabighian et al. 2005; Zuidweg and Mumaw, 2007; Rogers, 2009).

Although the submarine fiction mentioned in the beginning of this chapter had described that both U.S. and Russian navies had the technology of submarine launched ballistic missiles, which depended greatly upon a precise knowledge of gravity at the time of missile launch, it is known that at that time no Soviet vessel actually carried such elaborate gear of ballistic-missiles. In that occasion, only the U.S. Navy had invested hundreds of millions of dollars in developing a FTG 
system driven by the requirements for navigation and launching of missiles (Bell et al. 1998, Nabighian et al. 2005; Jekeli \& Zhu 2006; Rogers, 2009).

In the mid 1980's, part of this technology was declassified and eventually used in 1987 by the Defense Mapping Agency (DMA) flight tests of the Gravity Gradiometer Survey System (GGSS). In the 1994, the Bell Geospace commercialized it in offshore surveys on smaller ocean-going vessels, in the region of the Gulf of Mexico, for the marine oil exploration, as the Marine-FTG ${ }^{\mathrm{TM}}$ system. Later, this test was accomplished by AFGL and the system was successfully tested on a single engine aircraft in 2001, constituting the first airborne gravity gradiometer survey published in the open literature (Nabighian et al. 2005; Rogers, 2009). Thus, in 2002, the Airborne FTG system has been migrated operationally from marine to airborne use, and the Air-FTG ${ }^{\circledR}$ was quickly adopted by the mineral industry as a promising exploration tool (Hammond and Murphy, 2003; Murphy, 2004; Nabighian et al. 2005; Zuidweg and Mumaw, 2007; Rogers, 2009).

Since those initial marine trials from 1994, several systems have been deployed up to date; there are basically two types of gravity gradiometers designed by Lockheed Martin that are operational: the FTG and the BHP Falcon. This latter was the first airborne gravity gradiometer, FALCON ${ }^{\circledR}$, designed 1999 by BHP Billiton, primarily for shallow targets of interest to mineral exploration. It consists of four accelerometers configured to measure the horizontal curvature, from which the vertical gradient and vertical component of the gravity field are computed (Lee, 2001). Nevertheless, Nabighian et al. (2005) commented that there were three teams that were designing new systems to add to the suite of airborne gravity gradiometers: Stanford University, ArkEx and University of Western Australia.

By the early 2000's, gradiometers experienced also a resurgence, at least on paper initially, with the advent of satellites since only the curvature of the gravitational potential field can be sensed on a freely falling body (such as a satellite), and so the gravity field missions have given they contribution to determine the Earth's gravity field in the past decade. However, the gradiometer technology continued with the promise of the eventual deployment of such a system in space, and, after two potential missions were abandoned, the CHAMP (CHAllenging Minisatellite Payload) Mission (Reigber et al. 2002) was launched in July 2000, as the first mission that combined satellite-to-satellite tracking in mode high-low (SST-hl) with 3-D accelerometry (ESA, 1999; Rummel et al. 2002; Nabighian et al. 2005).

In March of 2002 Gravity Recovery And Climate Experiment (GRACE) Mission was launched, based on the pioneer low-low satellite-to-satellite tracking (LL-SST) concept. The mission consists of two identical satellites following each other in the same orbit, at the height of $500 \mathrm{~km}$, and a 
distance between the satellites of about $220 \pm 50 \mathrm{~km}$, providing global and high-resolution estimates of the Earth's gravity field and its temporal variations (Tapley et al., 2004). Hence, both GRACE satellites carried on board a 3-D accelerometer, and although in practice they are not satellites using gravity gradiometry (SGG), the configuration itself can be viewed as a huge one-component gradiometer with an arm length of $250 \mathrm{~km}$. Consequently, the GRACE mission can be considered potentially a precise one dimensional (1-D) virtual gradiometer (Rummel et al. 2002; Keller and Sharifi, 2005; Yi et al. 2010).

Finally, in March of 2009, the GOCE (Gravity field and steady-state Ocean Circulation Explorer) Mission was launched by the European Space Agency's (ESA), being the first core explorer mission in the Living Planet program, putting in practice by the first time in history the principle of SGG used in space with a tri-dimensional gradiometer on board to measure the GGs of the Earth (ESA, 1999; Rummel et al. 2002; Keller and Sharifi, 2005; Yi et al. 2010).

Today, airborne gravity gradiometry systems are used mainly for geological surveys in the search for valuable natural resources as oil, gas, copper, iron, ore, diamond mineral deposits to mining exploration, and also to better understand the Earth's gravity field and the overall structure in a regional and global geologic scale (Nabighian et al. 2005; Rogers, 2009).

The use of gravity gradiometry for exploration purposes continues to grow. The most promising results so obtained are the instrument drift reduction, the common cancellation of the platform accelerations, and the fact that several independent channels (tensor components and standard gravity) are recorded simultaneously. All this facts probably play a major role in assessing the added value of tensor gravity data over using the gravity data alone. According with Jorgensen et al. (2001), a key value of the tensor data lies in the ability to achieve a high level of enhancement of the signal-to-noise ratio for each of the tensor channels and the gravity channel. This enhancement is achieved by operating on all the channels simultaneously, using techniques that remove noise sources from all the input channels.

Many world-renowned exploration companies, such as Bell Geospace, ARKex, Gedex and Fugro provide airborne gravity gradiometry surveys to customers who desire such data. This data have enormous advantage over the conventional gravity (land, marine and airborne) due to their noisereduction capabilities, the speed of acquisition, and the improved accuracy. With appropriate processing, the gradiometer sensitivity can be as low as 3 to 8 Eotvos ( 1 Eotvos $=0.1 \mathrm{mGal} / \mathrm{km}$ ), and it can resolve wavelengths of about 300 to 1000 meters (Nabighian et al. 2005; Rogers, 2009). 
Of all the applications and purposes described above, gradiometers have been installed and used with success on ships, aircraft and now in satellites. This latter are being used primarily to understand the Earth's gravity field globally from gravity gradients measurements by GOCE SSG. In this context this thesis uses the GOCE gradiometric data for the geophysical proposal presented in the previous chapters.

\section{IV.3. Satellite Gradiometry Technology with GOCE}

The drag free satellite of SST can be viewed as a set of proof masses in free fall, subject only to the influence of the gravitational field, with their relative line-of-sight movement being measured. The satellite gradiometer senses the gravitational field simultaneously in several directions. In other words, the complete curvature structure of the local gravitational field is measured.

GOCE's system consisting of the sensor and the control elements form one 'gravity-measuring device' orbiting at the height of about $250 \mathrm{~km}$. The satellite itself also acts as a prime sensor, so, in contrast to most remote-sensing missions, there is virtually no division between the satellite and the instruments.

GOCE carry an electrostatic gravity gradiometer (EGG), a GPS receiver to allow use of high-low Satellite-to-Satellite Tracking Instrument (SSTI), a compensation system for all non-gravitational forces acting on the spacecraft (such as air-drag and radiation pressure), a very sophisticated propulsion system, a laser retro-reflector to enable tracking by ground-based lasers as well as star cameras to control the satellite attitude providing the absolute orientation (i.e., angular measurements into rates and angles) and a set of very-low frequency components; the twiceintegrated angular accelerations are deduced from the accelerometer readings of the gradiometer (Figure IV-2). Thus, the gradiometer is used as a gyroscope, and its observations are used to stabilize the attitude information. (ESA, 1999; Pail, 2005; Bouman et al. 2009). 


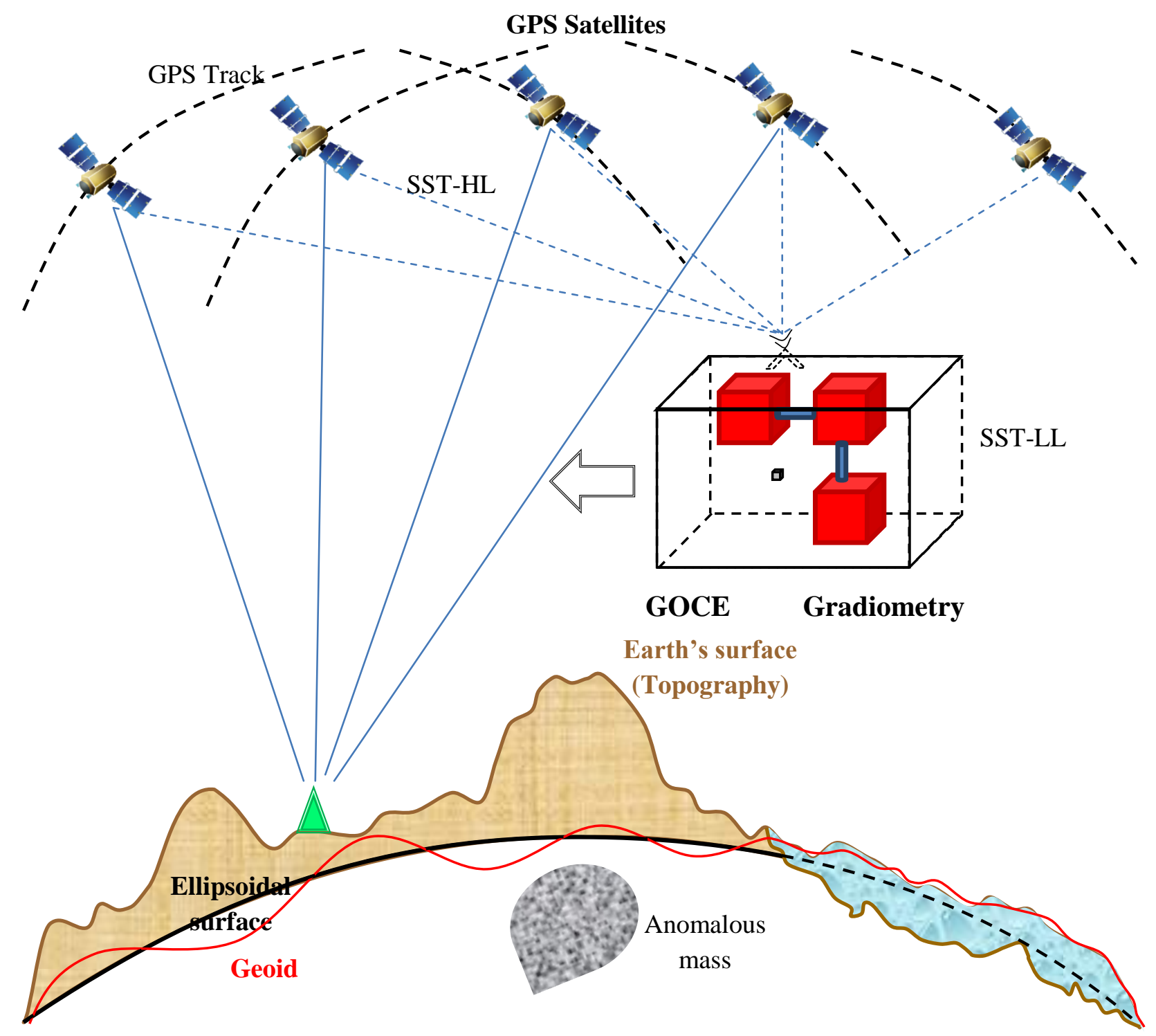

Figure IV-2: Concept of GOCE Gravity Gradiometer Satellite with satellite to satellite tracking (SST) (modified after ESA, 1999).

The GOCE satellite gradiometer consists of three pairs of ultra-sensitive accelerometers which measure acceleration differences, ideally in all three spatial dimensions, between the test-masses of an ensemble of accelerometers present inside the satellite (Figure IV-3). Every accelerometer has two high sensitive axes, and one less sensitive axis (Figure IV-4). The measured signal is the difference in the gravitational acceleration at the test-mass locations inside the spacecraft. 


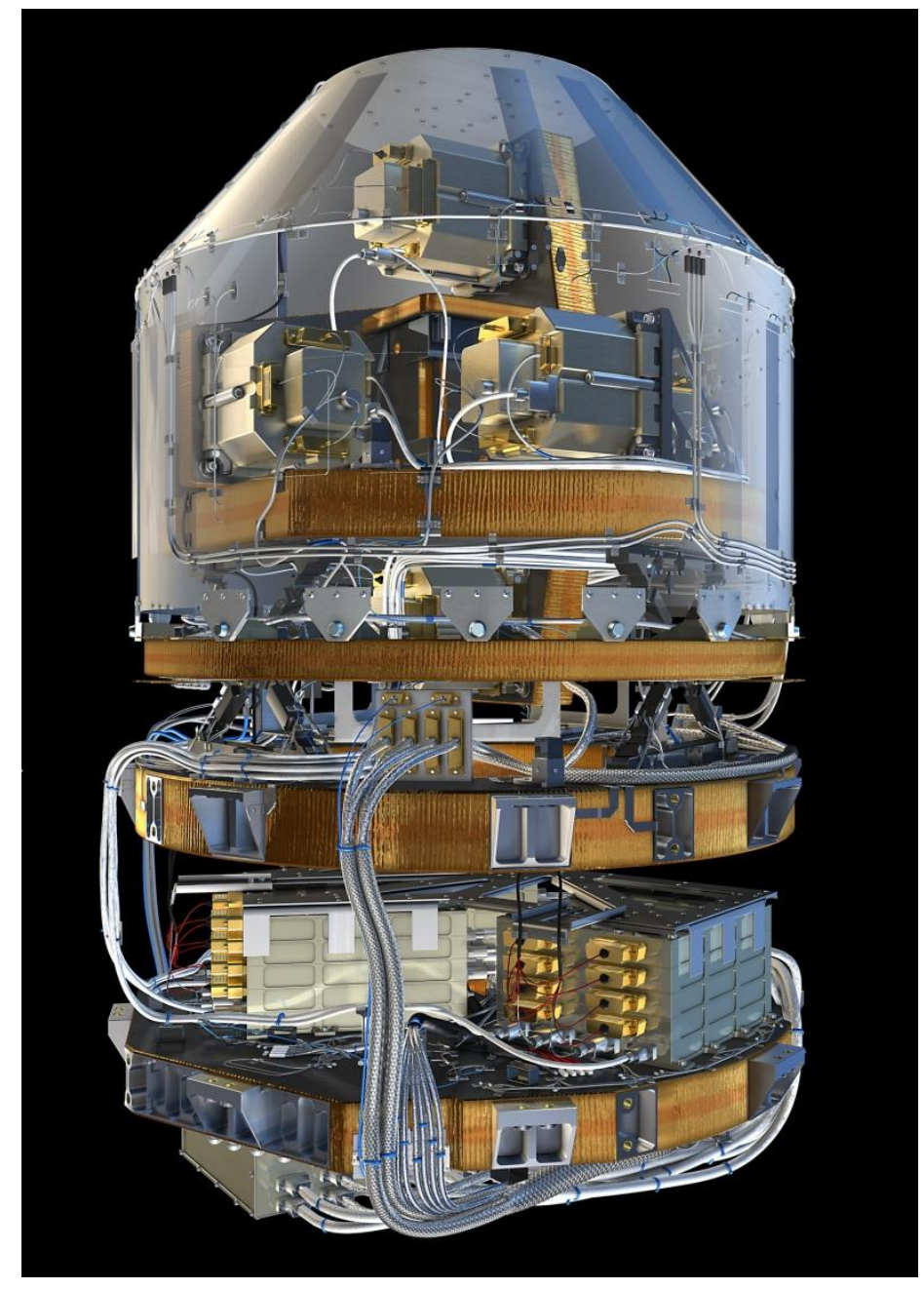

Figure IV-3: Payload Electrostatic Gravity Gradiometer. Courtesy: European Space Agency

The spacecraft is kept Earth-oriented with its $\mathrm{x}$-axis pointing along-track, the y-axis cross-track and the $\mathrm{z}$-axis radially outwards. The orientation of the satellite is maintained by an active attitude control using proportional thrusters and, as control elements, a star tracker and the gradiometer.

The Satellite-to-Satellite Tracking Instrument (SSTI) consists of an advanced dual-frequency, 12channel GPS receiver and an L-band antenna. The SSTI receiver is capable of acquiring signals simultaneously broadcasted from up to 12 spacecraft in the GPS constellation. The SSTI delivers, at $1 \mathrm{~Hz}$, pseudo-range and carrier-phase measurements on both GPS frequencies, as well as a realtime orbit navigation solution. 


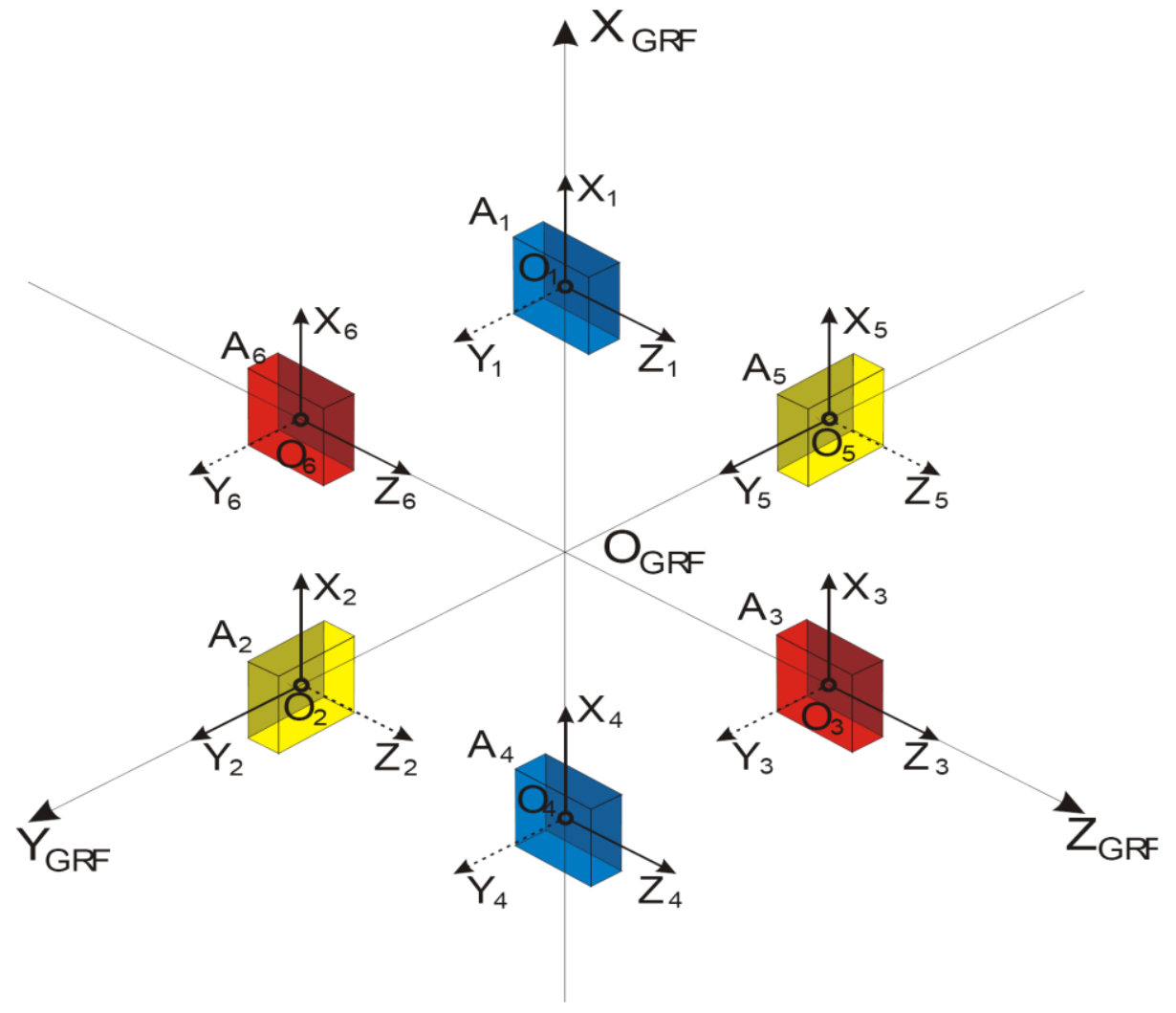

Figure IV-4: Position of the 6 accelerometers in the GOCE gradiometer in GRF (Gradiometer reference Frame) and all ARF (Accelerometer Reference Frame). The axes of the ARF are shown by solid arrows ultra-sensitivite aligned with the axes of the accelerometer. The axes of ARF shown by the dotted arrows are aligned to the axes of the accelerometer less sensitive. Each colour represents a one-axis gradiometer. The shadowed surfaces represent the locations of the lower plates (and the sole plates) (Gruber et al., 2009; See ANNEX A).

The advanced drag compensation and the attitude-control system is a key feature required to keep the accelerometer sensor heads in near 'free fall motion' and to maintain the orbit altitude at about $250 \mathrm{~km}$. The system is based on ion-propulsion technology. The electric ion propulsion system comprises two thruster units (one as backup) mounted at the back of the satellite. The thrusters can be throttled between 1 and 20 millinewtons $(\mathrm{mN})$, which is set automatically, depending on the actual real-time drag that the satellite experiences in orbit.

A particular feature of the GOCE system design is that the drag-free and attitude-control system use the scientific payload as a sensor. The laser retroreflector allows GOCE's precise orbit to be tracked by a global network of ground-based stations through the Satellite Laser Ranging Service. This provides accurate positioning for orbit determination and data products. 
Science data are continuously delivered to ground (1 Hz data rate); there are no gaps in the gradiometer data stream.

\section{IV.4. Gradiometry Principle}

The theoretical foundations of the gravity gradiometry is presented by Rummel (1986); the basic observable elements of the mission are GGs, the second order derivatives $\partial^{2} V / \partial x_{i} \partial x_{j}=V_{i j}$ of the gravitational potential $V$ with nine components, as showed in Chapter III. These GGs can be defined in a local north oriented frame (LNOF), i.e., $x$-axis is pointing North, $y$-axis towards West and $z$ axis pointing radially outward in geocentric radial direction.

The principle of operation of the gradiometer relies on measuring the forces that maintain a proof mass at the centre of a specially engineered cage. Servo-controlled electrostatic suspension provides control of the proof masses in terms of linear and rotational motion. Two of the floors support the gradiometer, which is mounted at the heart of the satellite close to its centre of mass. Three pairs of identical accelerometers, which form three gradiometer arms, are mounted on the ultra-stable structure. The difference between accelerations are measured by each of two accelerometers (which are about $50 \mathrm{~cm}$ apart), in the direction joining them contains the basic gradiometric information.

The average of the two accelerations is proportional to the externally-induced drag acceleration (common mode measurement). The three arms are mounted orthogonally to each another: one aligned with the satellite's trajectory, one perpendicular to the trajectory, and one pointing approximately towards the centre of Earth. By combining these different acceleration measurements, it is possible to derive the gravity-gradient components.

The gradiometer in GOCE Satellite consists of six 3-axis accelerometers mounted in pairs along three orthogonal arms (Figure IV-4). Each accelerometer with three axes $i=1,2,3$ (or $x, y, z$ ) senses e.g. the acceleration

$$
f_{i}=-\partial V(0) / \partial x_{i}-V_{i j}(0) d x_{j}+\Omega_{i k} \Omega_{k j} d x_{j}+\dot{\Omega}_{i j} d x_{j}-b_{i}(0)
$$

with $b_{i}(0)$ the sum of all non-gravitational accelerations (atmospheric drag for instance) acting on the satellite along the $i$-axis at the centre of mass 0 or so-called common mode (CM).

In the case of GOCE the gravity gradients are derived from differential mode (DM) observations, consisting of the difference of the measured accelerations $f_{i}$ of two accelerometers $\mathrm{A}$ and $\mathrm{B}$ along one arm, e.g. the i-axis, separated by a distance $\Delta x_{j}$ along the $\mathrm{j}$-axis of the diamond configuration. Comparing with Rummel, (1986), one can write 


$$
\frac{f_{i}(B)-f_{i}(A)}{\Delta x_{j}}=\Gamma_{i j}=-V_{i j}+\Omega_{i k} \Omega_{k j}+\dot{\Omega}_{i j} .
$$

One observes that the components $V_{i j}$ are not observable directly but only their combination with two other terms. These two express the effect of centrifugal acceleration $(\Omega \Omega)$ and the angular acceleration $(\dot{\Omega})$. They are caused by the measurement in a moving frame fixed to the satellite. Closer inspection shows that $\Omega_{i k} \Omega_{k j}$ like $V_{i j}$ is symmetric, whereas $\dot{\Omega}_{i j}$ is antisymmetric. In detail:

$$
\Gamma_{i j}=\left(\begin{array}{ccc}
V_{x x}-\left(\omega_{y}^{2}+\omega_{z}^{2}\right) & V_{x y}+\omega_{x} \omega_{y}+\dot{\omega}_{z} & V_{x z}+\omega_{z} \omega_{x}-\dot{\omega}_{y} \\
V_{y x}+\omega_{x} \omega_{y}-\dot{\omega}_{z} & V_{y y}-\left(\omega_{z}^{2}+\omega_{x}^{2}\right) & V_{y z}+\omega_{z} \omega_{y}+\dot{\omega}_{x} \\
V_{z x}+\omega_{z} \omega_{x}+\dot{\omega}_{y} & V_{z y}+\omega_{y} \omega_{z}-\dot{\omega}_{x} & V_{z z}-\left(\omega_{x}^{2}+\omega_{y}^{2}\right)
\end{array}\right) .
$$

Thus, a separation into symmetric and antisymmetric part yields:

$$
\frac{1}{2}\left(\Gamma_{i j}+\Gamma_{j i}\right)=V_{i j}+\Omega_{i k} \Omega_{k j}
$$

and

$$
\frac{1}{2}\left(\Gamma_{i j}-\Gamma_{j i}\right)=\dot{\Omega}_{i j}
$$

In addition, one finds:

$$
\operatorname{trace} \Gamma=\Gamma_{x x}+\Gamma_{y y}+\Gamma_{z z}=-2\left(\omega_{x}{ }^{2}+\omega_{y}{ }^{2}+\omega_{z}{ }^{2}\right)=-2 \omega^{2} .
$$

One should keep in mind that $\omega_{y}$, the angular velocity about a vector perpendicular to the orbital plane, is much greater than $\omega_{x}$ and $\omega_{z}$. It represents the once-per-revolution rotation of the Earth pointing satellite: $\omega_{y} \gg \omega_{x}, \omega_{z}$.

So, one can draw the following conclusions:

- Ideally, when differencing the accelerations $f_{i}$, all non-gravitational accelerations $b_{i}(0)$ drop out, as well as the gravitational accelerations $\partial V(0) / \partial x_{i}$, see eq. (IV-1 and IV-2).

- The gravitational gradients cannot be sensed in isolation. They are mixed with centrifugal and angular acceleration terms, see eq. (IV-3). 
- The angular accelerations can be isolated and, after integration, they can be employed for the angular control of the spacecraft.

- One time-integration of the angular accelerations yields to the angular velocities, which are used to isolate $V_{i j}$ from $\Omega_{i k} \Omega_{k j}$.

- For GOCE, with one axis of each accelerometer weaker than the two others, the arrangement of the six 3-D accelerometers is chosen such as to permit precise determination of $\omega_{y}$, whereas $\omega_{x}$ and $\omega_{z}$ are not determined as well. Consequently, only $V_{x x}, V_{y y}, V_{z z}$ and $V_{x z}$ can be reproduced with highest precision.

- Below $3 \cdot 10^{-2} \mathrm{~Hz}$ the component $V_{x z}$ is less accurate than the three diagonal components. This is caused by the uncertainty in the orientation angles, which results in a projection of the large diagonal components onto the off-diagonals. Nevertheless $V_{x z}$ has a positive effect on the overall results.

- The sum, i.e. the common mode accelerations $f_{i}(\mathrm{~A})+f_{i}(\mathrm{~B})$, are a measure of the nongravitational accelerations

$$
f_{i}(A)+f_{i}(B)=-2 b_{i}(0)
$$

if the accelerometers are arranged symmetrically with respect to the centre of mass of the spacecraft, for then $\partial V(0) / \partial x_{i} \approx 0$, see eq. (IV-1). They are then employed for drag-free control (together with the GPS orbits).

Three critical areas emerge that deserve careful attention:

- The accelerometers are "no perfect twins". This is caused by imperfect scale factor matching, alignment and positioning along one axis. As a result one needs a comprehensive calibration scheme that includes laboratory, on-board and post-mission tests. Another remedy is to keep linear and angular disturbances (non-gravitational and apparent forces) low by active drag and angular control.

- Centrifugal and angular accelerations mix inevitably into the gravitational gradients. Separation of the anti-symmetric from the symmetric tensor part will help to determine $\omega_{y}$ and to a lesser extent $\omega_{x}$ and $\omega_{z}$. The trace condition will yield the sum of $\omega_{x}{ }^{2}+\omega_{y}{ }^{2}+\omega_{z}{ }^{2}$ as control information. Finally star trackers provide absolute orientation at 10 seconds intervals. An additional option is the parameterization of misorientation angles in the context of the data processing. Thus an isolation of the gravitational tensor alone is feasible. 
- The third error source is the effect of time variable self-gravitation of the spacecraft. On the one hand it can be kept below the required threshold by choosing a very stiff instrument and satellite construction (no moving parts). On the other hand thruster fuel consumption is of concern. The choice of ion thrusters for the attitude control and cold gas thrusters for the drag control eliminates this problem.

\section{IV.5. Understanding the gravity gradients}

Nowadays, the use of gravity gradients (GGs) data in exploration is relatively common. Nevertheless, interpretation of GG data is not as easy as with the familiar vertical gravity data. Saad (2006) showed that for a given source, regardless of its simplicity, GGs often produce a complex pattern of anomalies (single, doublet, triplet, or quadruplet) as compared to the simple single (monopolar) gravity anomalies. The six independent GGs recovered from gravity gradiometry provide a powerful tool for delineating the shape of the body. The GGs can detect the edges, corners and center of the mass distribution.

Since 1990's, moving-platform gravity gradiometers had become available and played an important role in exploration. Data reduction, filtering, and visualization, together with low-cost, powerful personal computers and color graphics, have transformed the interpretation of gravity data (Nabighian et al. 2005).

Many authors (e.g.: Montana et al. 1992; Nagy et al. 2000; Saad 2006; Heck and Seitz 2007) have demonstrated the complex pattern of anomalies associated to gravity gradient components calculated from gravitational potential generated from a basic building block - a rectangular prism. In this work a forward modelling using the rectangular prism approach developed by Nagy et al. (2000) is used.

Due to its simplicity and its closed expressions relating to the gravitational potential, the use of the rectangular prism is of great interest in gravity modelling. Any three-dimensional density distribution can be approximated with the desired accuracy using the prisms.

Although the geometry of the rectangular prism limit its applicability over large areas because it implies an approximation of the flat Earth, it is still a good alternative for describing the density distribution and it is especially useful in studies for gravitational potential modelling (Nagy et al. 2000).

As discussed by Bell et al. (1997), the Figure IV-5 illustrates an schematic example and shows the comparison of the power spectrum of standard gravity data (in dashed lines) against the gravity gradients data (solid line). One can observe that the power spectrum of the standard gravity begins 
to flatten in a hypothetical value given in a certain wavelength indicating the resolution of the data. The integration of the gravity gradiometry measurements into gravity data (actually, the vertical component) significantly changes the power spectrum slope, indicating an improvement of the resolution for small features. The steepness of the power spectrum below the resolution suggests that gravity gradients significantly improve the capability of gravity to constrain the location of structures.
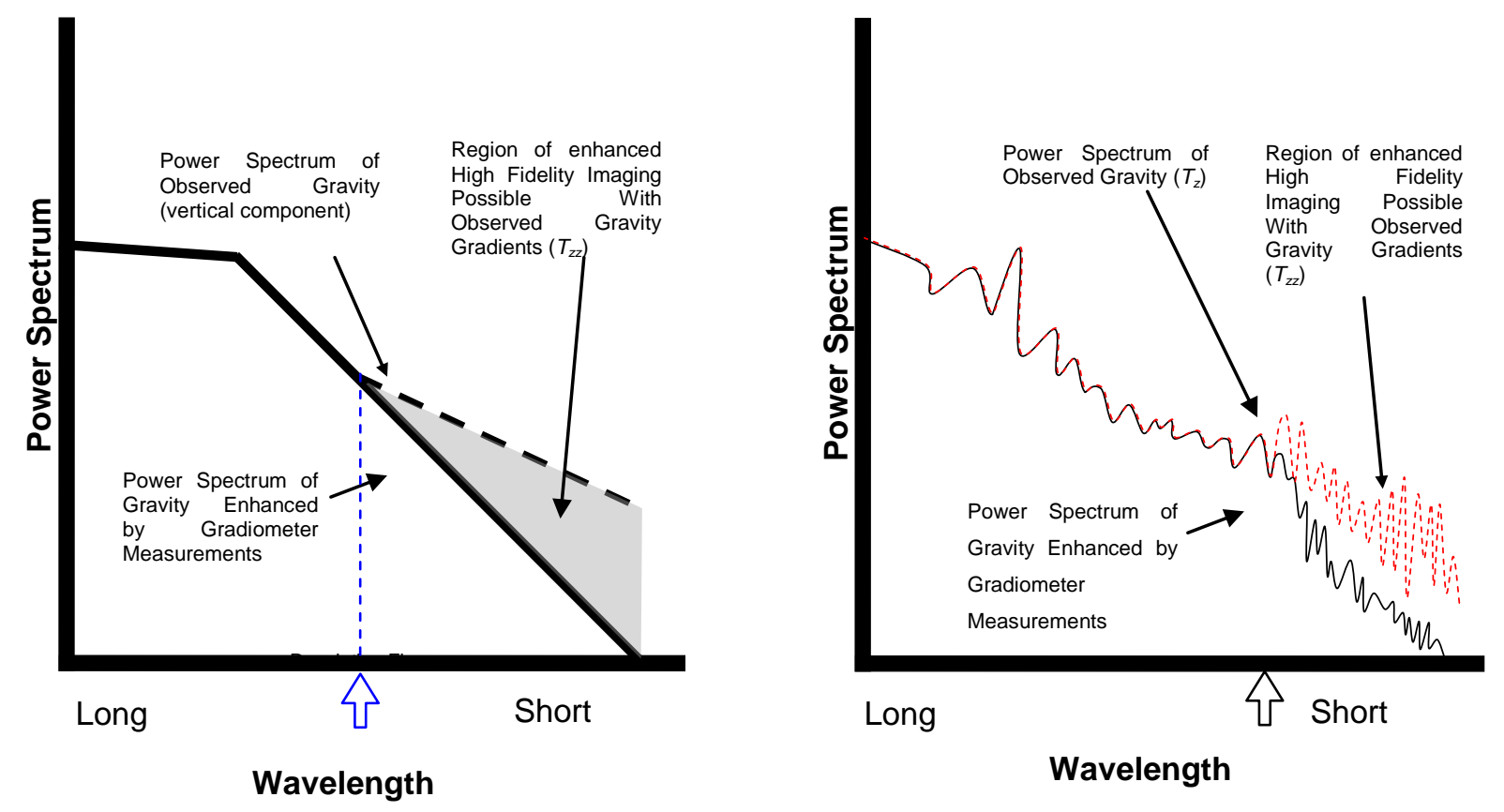

Figure IV-5: Power spectrum schematic of the first (vertical component, $\left.\mathrm{T}_{\mathrm{z}}\right)$ and second $\left(\mathrm{T}_{\mathrm{zz}}\right.$ component) derivatives of gravitational potential. The graphic on left illustrates the theoretical curves flattening gravity power spectrum indicating the resolution limit of the data. On the right the power spectrum shows a more realistic pattern of the gravity and the gradient gravity data (modified after Bell et al. 1997).

\section{IV.5.1. Rotational Invariants}

Pedersen and Rasmussen (1990) described the use of the invariance to obtain a new representation of the gravity and magnetic tensor components. They described two sets of combinations that make use simultaneously of all components. The impact of the resultant computation is that the anomalous signature pattern is independent of the choice of the axes of the observer.

$$
I_{1}=\sqrt{\left(T_{x x} T_{y y}+T_{y y} T_{z z}+T_{x x} T_{z z}\right)-\left(T_{x y}^{2}+T_{y z}^{2}+T_{x z}^{2}\right)}
$$




$$
I_{2}=\left(\left(T_{x x}\left(T_{y y} T_{z z}-T_{y z}^{2}\right)+T_{x y}\left(T_{y z} T_{x z}-T_{x y} T_{z z}\right)+T_{x z}\left(T_{x y} T_{y z}-T_{x z} T_{y y}\right)\right)\right)^{1 / 3} \quad \text { IV }-9
$$

The $I_{1}$ facilitates the general mapping of the regional stratigraphy on areas of surveys, which identify the dominant density contrast. It is used in practice of mapping on a regional scale and extract trends in dominant regional density distribution. $I_{2}$ focuses highlighting the 3D shape of the anomalous targets. This makes it useful for mapping the geometry of a fault block, an igneous intrusion and salt bodies directly from the gravity gradient data.

\section{IV.5.1.1. Horizontal invariant Lineaments}

Murphy (2007) described an invariance approach for horizontal components only. These invariants can be used to map linear features making it an effective edge mapper. The representations of the horizontal components are:

$$
\begin{gathered}
\operatorname{InVar}_{T_{x z} T_{y z}}=\sqrt{\left(T_{x z}^{2}+T_{y z}^{2}\right)} \\
\operatorname{InVar}_{T_{x y} T_{x x} T_{y y}}=\sqrt{\left(T_{x y}^{2}+\left(\frac{T_{y y}-T_{x x}}{2}\right)^{2}\right)}
\end{gathered}
$$

Dickinson et al. (2009) showed that the advantage of the anomalous expression's independence is given in the vertical axis only, increasing the confidence of mapping the geological contact information with depth. The result is better obtained by combining the results of both from direct comparison with the original $T_{z z}$ anomaly field (i.e., a positive trend in $\operatorname{InVar} T_{x z} T_{y z}$ is correlated with a negative linear trend in $\operatorname{InVar} \_T_{x y} T_{x x} T_{y y}$ maps in an anomalous edge in $T_{z z}$ ).

\section{IV.5.1.2. Strike Lineaments}

The impact of these two techniques is an improved method for mapping subsurface geology in a qualitative manner. These equations can be solved in different way. The result is a measure of the strike angle (or strike direction) to identify linear features from subsurface geology.

Pedersen and Rasmussen (1990) obtained a formula for the calculation the strike direction from the gradient tensor:

$$
\tan 2 \theta_{s}=2 \frac{T_{x y}\left(T_{x x}+T_{y y}\right)+T_{x z} T_{y z}}{T_{x x}^{2}-T_{y y}^{2}+T_{x z}^{2}-T_{y z}^{2}}
$$


Observe that the rotating of the coordinate system in the vertical axis aims to minimize the sum of the squares of the three tensor components involving a derivative in $x$-direction. The method produces an estimate of $\theta_{s}$ (strike angle) in every observation site. The strike direction is evaluated based on its geological importance and continuity along the line which, within a defined tolerance, can be chained together to form lineaments. (Dickinson et al. 2009).

It should be noted that the pattern of anomalies so produced is dependent of the coordinates. However, it can only use patterns and shapes of the gravity gradient anomalies with the outline designed.

Various combinations of the gravity gradient components can be used to simplify its complex pattern by adding an improvement and helping in the interpretation of the data. For example: amplitude of the horizontal gradient of vertical gravity $\left(\mathrm{T}_{\mathrm{z}}\right)$; amplitude of the total gradient or analytic signal of $T_{z}$; and the differential curvature, which is also known from the early torsion balance literature as the horizontal directive tendency (HDT). The amplitude of the horizontal gradient of $T_{z}$ can be used as an edge-detector or to map body outlines. The analytic signal can be used for depth interpretation. The magnitude of the differential curvature emphasizes greatly the effects of the shallower sources (Saad, 2006).

Amplitude of the horizontal gradient of vertical gravity $\left(\mathrm{T}_{\mathrm{z}}\right)$ :

$$
h_{T}=\sqrt{T_{z x}^{2}+T_{z y}^{2}}
$$

Amplitude of the total gradient or analytic signal of $T_{z}$ :

$$
A_{A S}=\sqrt{T_{z x}^{2}+T_{z y}^{2}+T_{z z}^{2}}
$$

Differential curvature:

$$
C_{T}=\sqrt{\left(T_{x x}-T_{y y}\right)^{2}+\left(2 T_{x y}\right)^{2}}
$$

Saad (2006) describes the combining GG products to obtain the three invariants above showing the usefulness in simplifying and highlighting the complex pattern of the anomalies about the source, providing further enhancements to the high frequency of anomalies due to shallow sources and producing coordinate-independent or invariant anomalies. These are easier to interpret than the original gradient components. Other coordinates independent invariants can be obtained and also used to interpret the data using different combinations of GG components. For example, one can 
compute also the horizontal and total gradient of $T_{x}$ and $T_{y}$ as well as those already described by Pedersen and Rasmussen (1990).

Gravity gradiometry data differ in many aspects of the 'conventional' terrestrial gravity data. An important difference is in the bandwidth which is narrow for the gravity gradient data. The bandwidth allows an increased retention of the signal with short wavelength (high frequency) generated by shallow and intermediate geological features that are not retained in conventional ground gravity data. This increased sensitivity allows a significant increase in the resolution of the anomalous bodies (Braga, 2006).

Each tensor component of the gravity gradient corresponds exclusively to the size, shape, depth and density of the mass anomaly providing a constraint during the process of interpretation.

All the five independent components are used in the process of interpretation for determining, for example, the center of mass $\left(\mathrm{T}_{\mathrm{xz}}\right.$ and $\left.\mathrm{T}_{\mathrm{yz}}\right)$, the edges of the body $\left(\mathrm{T}_{\mathrm{yy}}\right.$ and $\left.\mathrm{T}_{\mathrm{xx}}\right)$ and the corner $\left(\mathrm{T}_{\mathrm{xy}}\right)$ of the structure that causes the anomaly. The $T_{z z}$ component is the one that closely resembles the standard gravity (Braga, 2006). But this is not always true. It can work very well for rectangular prism!

\section{IV.5.2. Tensor Rotation}

The gravity gradiometry data are largely obtained in a fixed coordinate system NED, thereby, many geological scenarios can produce enhanced imaging of the target features using alternative coordinate systems. Dickson et al. (2009) presented the underlying transformation of the tensor in a relatively simple process selecting a set of tensor components to be transformed, such that

$$
\begin{array}{cc}
T_{x z}^{\prime}=T_{x z} \cos \theta+T_{y z} \sin \theta & \text { IV-16 } \\
T_{y z}^{\prime}=-T_{x z} \sin \theta+T_{y z} \cos \theta & \text { IV-17 } \\
T_{y y} M_{x x}=\left(T_{y y}-T_{x x}\right) / 2 & \text { IV-18 } \\
T_{x y}^{\prime}=T_{x y} \cos 2 \theta+T_{y y} M_{x x} \sin 2 \theta & \text { IV-19 } \\
T_{y y} M_{x x}^{\prime}=-T_{x y} \sin 2 \theta+T_{y y} M_{x x} \cos 2 \theta & \text { IV-20 } \\
T_{x x}^{\prime}=-\frac{T_{z z}}{2}-T_{y y} M_{x x}^{\prime} & \text { IV-21 } \\
T_{y y}^{\prime}=-T_{z z}-T_{x x}^{\prime} & \text { IV }-22
\end{array}
$$


where $\theta$ is the angle of rotation about the down axis.

In order to better understand the gravity gradients signal, we simulate the gravity field effect from a simple rectangular prism model following the formulation given in Nagy et al. (2000).

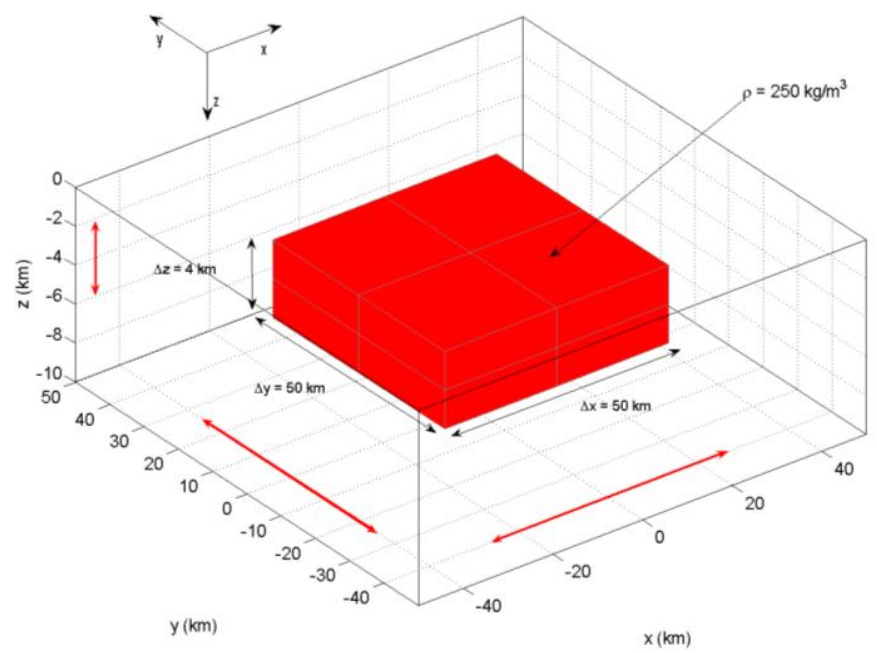

Figure IV-6: Anomalous mass represented by a rectangular prism with dimensions $(\Delta x, \Delta y, \Delta z)=(50,50,4)$ $\mathrm{km}$ at an average depth of $4 \mathrm{~km}$ centered in the origin of the xy-plane of the north-east-down (NED) coordinate system, which the positive $x$-axis correspond to north, which the positive $y$-axis correspond to east and positive $z$ to down.

Figure IV-6 shows the orientation and the dimensions of the simple prism hypothetically constucted to demonstrate the gravity gradient. The prism mass has a constant density $(\Delta \rho)$ of $250 \mathrm{~kg} / \mathrm{m}^{3}$ and is centered in the origin of the $100 \mathrm{~km}$ x $100 \mathrm{~km}$ grid of the xy-plane with average depth of $4 \mathrm{~km}$ with respect to the north-east-down (NED) coordinate system. From the analysis of a single prism of positive density contrast, it is usually verified that the vertical component of the gravity anomaly $\left(T_{z}\right)$ shows a diffuse circular anomaly centered on the prismatic body (Figure IV-7). 

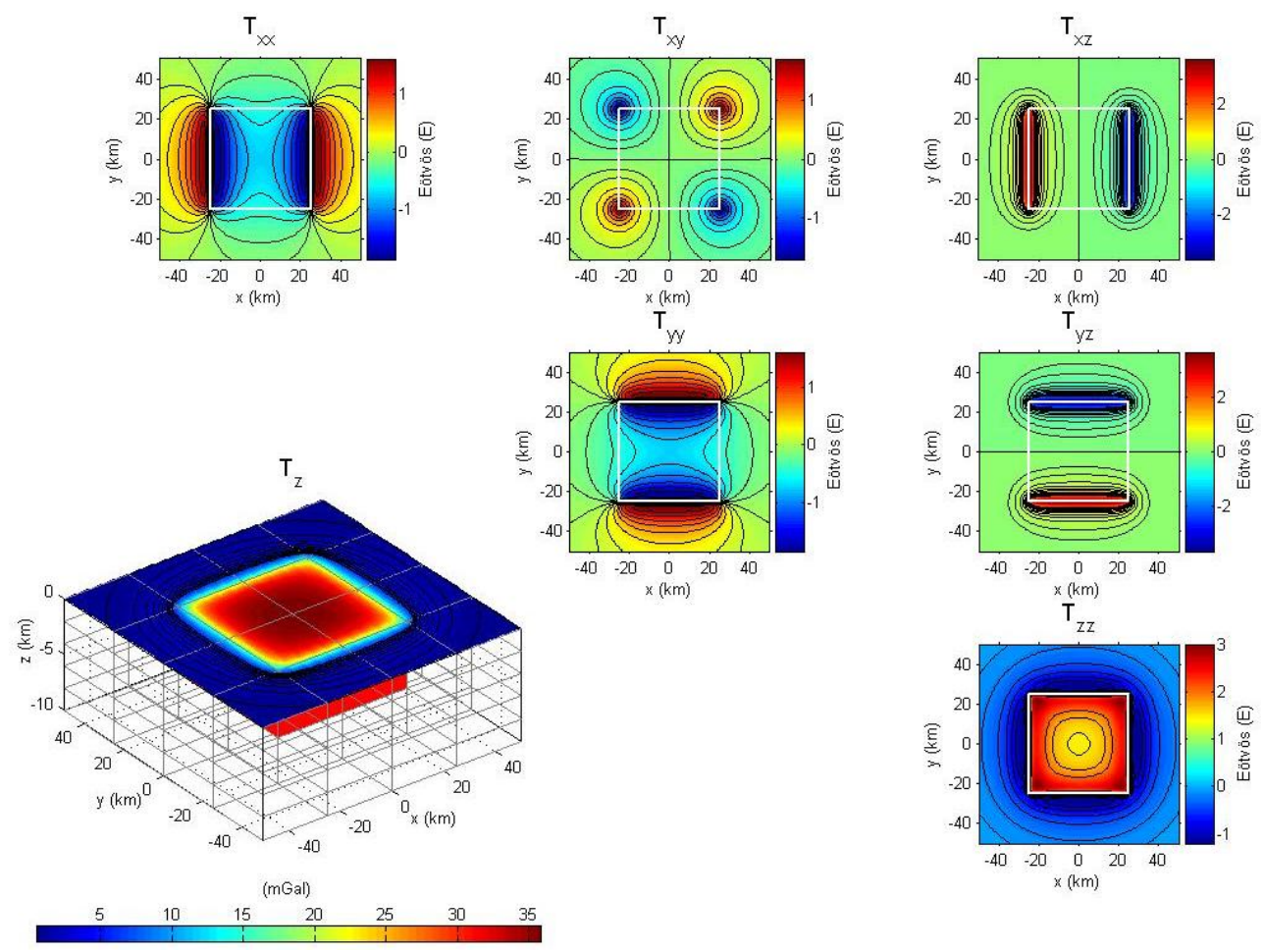

Figure IV-7: Example of the gravity gradients derived from anomalous mass (prism) with dimensions $(\Delta \mathrm{x}$, $\Delta y, \Delta z)=(50,50,4) \mathrm{km}$ at an average depth of $4 \mathrm{~km}$. The vertical gravity component $\mathrm{T}_{\mathrm{z}}$ is displayed in the lower left corner together with schematic 3-D prism for viewing at depth. Gradients $\mathrm{T}_{\mathrm{ij}}$ (with $i, j$ representing the three axes $x, y, z$, are plotted together with the white box in the xy-plane representing the lateral dimension of the 3D prism model.

The six gravity tensor components can be recovered from a gravity gradiometry survey providing a powerful tool to delineate the characteristics of the body. The gravity gradients are aproximatelly related to the edges, borders, corners and center of mass of the anomalous masses, which in this case is a single prism model. The components were calculated on a xy-plane above the center of the prism $(\mathrm{z}=-4 \mathrm{~km})$. Due to the symmetry, only the upper diagonal part of the gravity gradient tensor is shown in Figure IV-7. The $\mathrm{T}_{\mathrm{xx}}$ gradients highlight the $\mathrm{x}$-axis (or east-west) edges of the prism by measuring the east-west changes in east-west gravity; the $\mathrm{T}_{\mathrm{y}}$ highlights the $\mathrm{y}$-axis (or north-south) edges of the prism by measuring the north-south gravity trending boundaries. $\mathrm{T}_{\mathrm{zz}}$ highlights all the edges of the anomaly, as it can be considered as a combination of $\mathrm{T}_{\mathrm{xx}}$ and $\mathrm{T}_{\mathrm{yy}}$ with a sign change. $\mathrm{T}_{\mathrm{xz}}$ and $\mathrm{T}_{\mathrm{yz}}$ gradient data outlines the north-south and the east-west mass anomaly axes, respectively, containing the center of mass of the box. They also help to highlight the north-south and east-west edges. Although less intuitive, $\mathrm{T}_{\mathrm{xy}}$ shows distinctive circular anomalies associated with the corners of the body. 

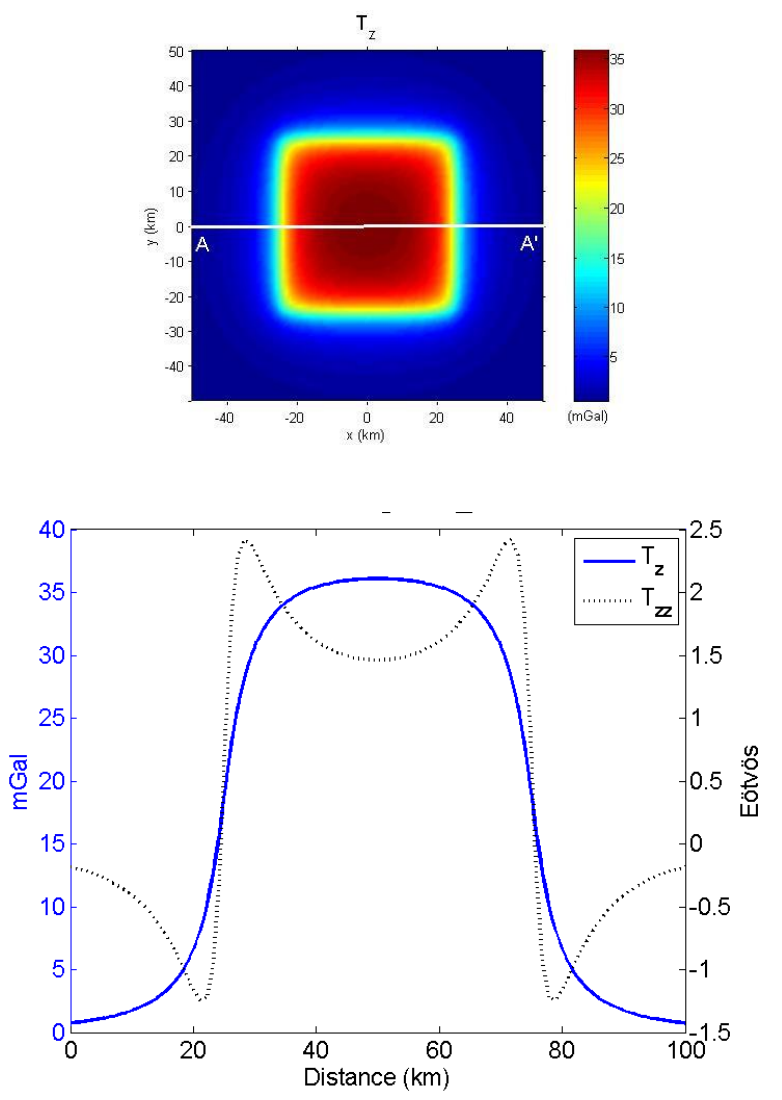
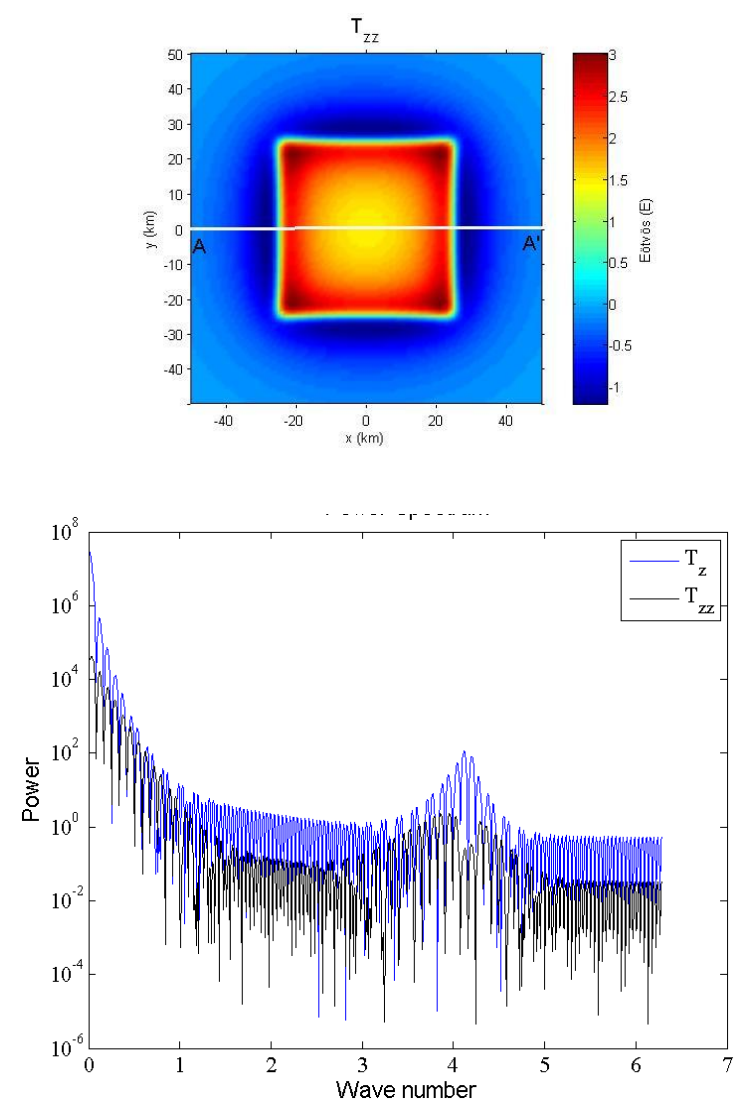

Figure IV-8: At the top the profiles $\mathrm{AA}^{\prime}$ along $\mathrm{x}$-axis to $\mathrm{y}=0$ are plotted together with the vertical components of the gravity field (gravity anomaly $-T_{z}$ and gravity gradient $-T_{z z}$, respectively). At the bottom the gravity field values (in the left) and the power spectrum (in the right) along the profile AA' show the enhanced curve and resolution of the gravity field components $\mathrm{T}_{\mathrm{z}}$ and $\mathrm{T}_{\mathrm{zz}}$.

Figure IV-8 compares the gravity field values and the power spectrum on profile AA' for the gravity anomaly (vertical component $-\mathrm{T}_{\mathrm{z}}$ ) and the vertical gravity gradient $\left(\mathrm{T}_{\mathrm{zz}}\right)$ caused by the same rectangular prism shown in Figure IV-6. It is clear by comparison in the profile that there is a greater information level for the process of interpretation obtained from the $T_{z}$. However, there is a greater sharpness and separation of the gravity gradient anomalies showing, in principle, a higher ability to detect the prism edges.

The power spectrum shows the steep curve of the $\mathrm{T}_{\mathrm{zz}}$ gravity gradient component reflecting a possible improvement in the resolution of the observed field. The power spectrum suggests that the resolution of the gravity gradients improve significantly the capacity of detect the position of the anomalous mass (prism), i.e., the gravity gradients highlight better the anomalous body.

Although the gravity tensor accurately maps subsurface density contrasts caused by the geologic structures, the gravity gradients are often underused, as in the classic interpretation methods the $\mathrm{T}_{\mathrm{zz}}$ component is widely used. Thus, little attention is given to the horizontal components of the gravity 
tensor, that could be of great importance if it were represented in combination with the other components in order to better identify the anomalous sources and the local geological setting.

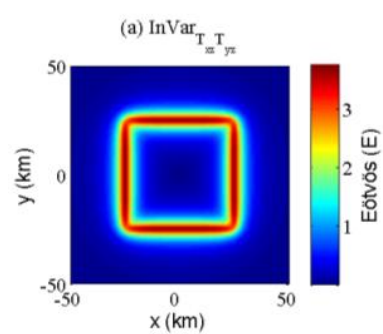

(c) Invariance $\mathrm{I}_{1}$
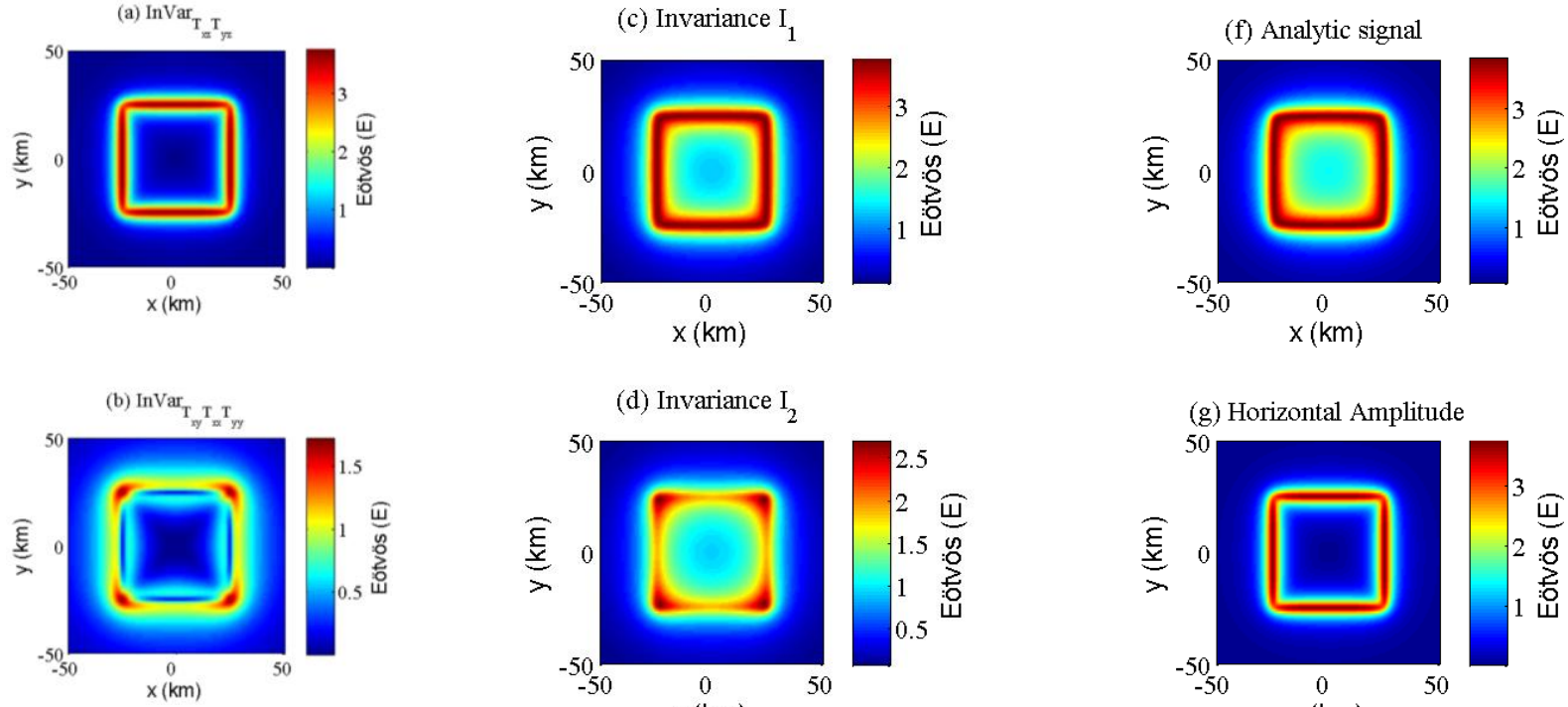

(d) Invariance $\mathrm{I}_{2}$
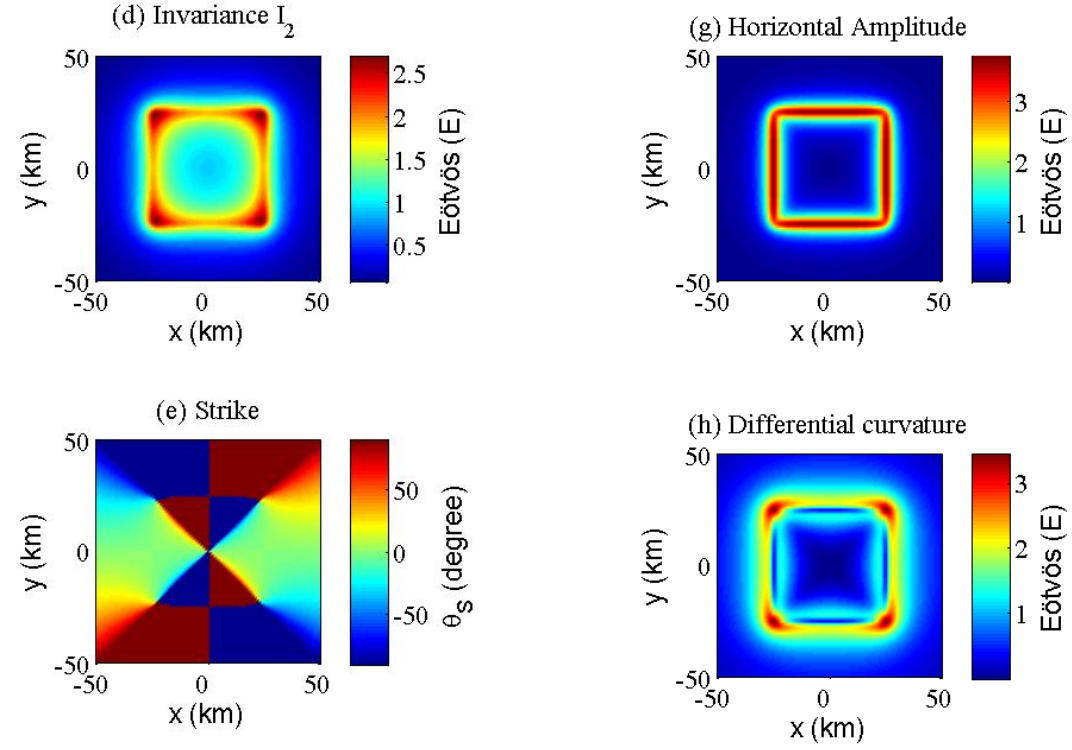

Figure IV-9: Representation of the gravity tensor using some invariances for highlight the anomalous mass, according eqs. IV-8 to IV-15.

In most of the cases involving real gravity tensor data it is necessary to use the invariances to obtain a best representation of the gravity tensor components via simultaneous combinations given by eqs. IV-8 to IV-22. Notice that the prism is clearly mapped (Figure IV-9) following the eqs. IV-8 to IV-15, respectively.

One notices also that the strike lineament technique obtained in Figure IV-9(e) would illustrate the dominant geological signature of the area if there exists a trend in a certain direction on the region. In this case, a single prism, we are not able to see the trend because it doesn't exist in this hypothetical model. However, according to Murphy and Brewster (2007), the identification of the lineaments on geological structures is normally possible if the estimates of the strike directions at each point are assessed based on their geological significance and continuity along a line with a simple rule of thumb. 

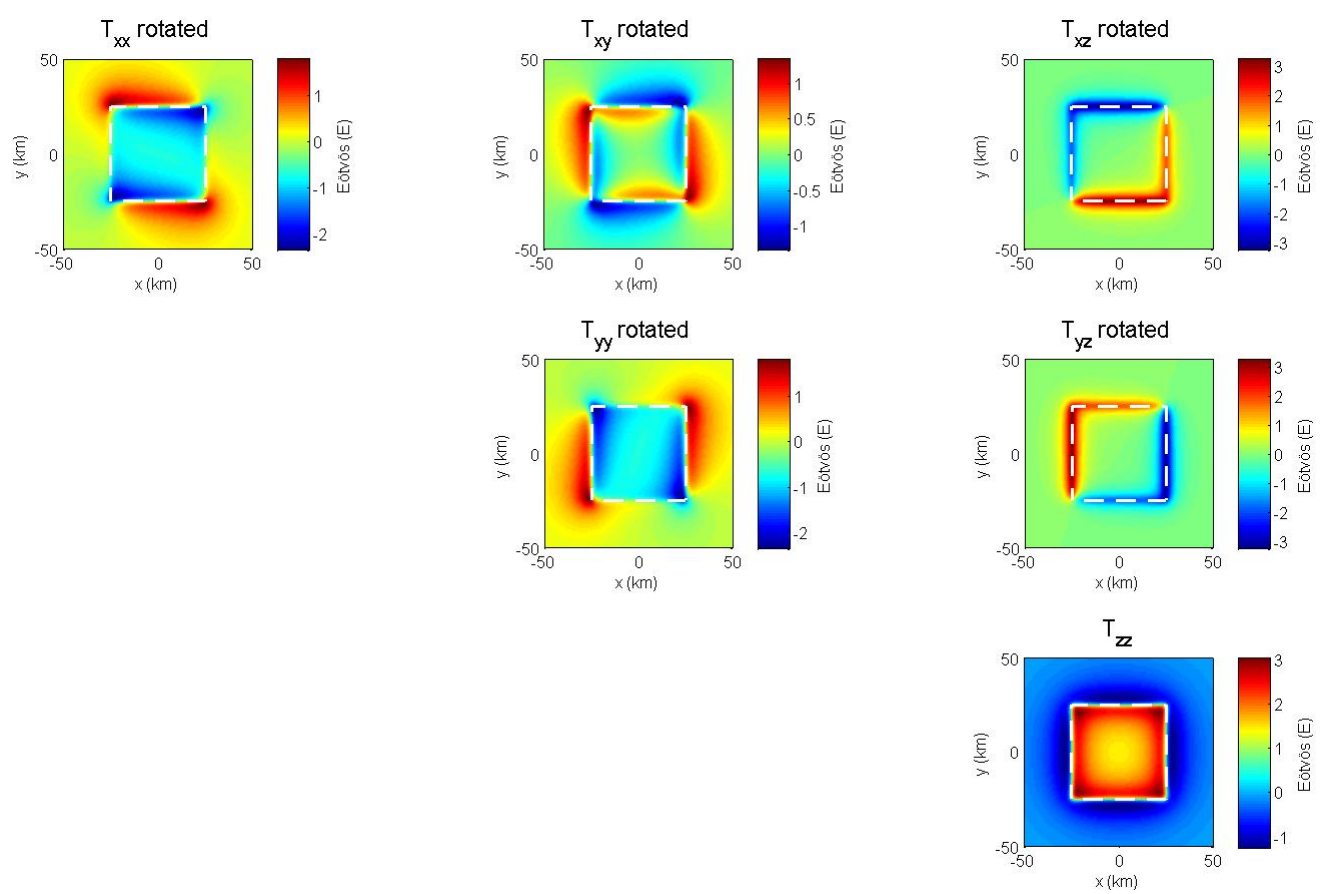

Figure IV-10: Response derived from hypothetical single prism model (dashed white box) in a rotated tensor coordinate system of 120 degrees about the $\mathrm{x}$-axis, simulating a structural feature to be enhanced in the northwest direction.

The tensor rotation (Figure IV-10) is recommended in some geological scenarios, producing an enhanced imaging of the target features (Dickson et al., 2009).

It is apparent that the combined use of the gravity tensor components is able to define in some extent the geological setting of a region. These imaging techniques include the use of rotational invariants, strike lineaments and rotations of the tensor coordinates. Thus, the correct application of these techniques can help and improve the interpretation of the gravity gradient maps for geophysical studies. 


\section{PROCESSING THE GOCE DATA}

The GOCE mission is based on a sensor equipped with a GPS receiver for satellite-to-satellite tracking (SST-hl) in the high-low mode, plus a sophisticated satellite gravity gradiometry (SGG), providing a huge data set consisting of millions of orbital data (derived from SST) and very precise in-orbit gravity gradiometry data (Sunkell, 2002). This data contain abundant information about the Earth's gravity field on a global scale, from very low to high frequencies. This gravity field information is represented by a set of spherical harmonic coefficients up to degree and order 250 , which corresponds to a half wavelength of about $80 \mathrm{~km}$ of spatial resolution.

There are only four GGs, $V_{x x}, V_{y y}, V_{z z}$ and $V_{x z}$, with very high accuracy; $\mathrm{V}_{\mathrm{xy}}$ and $\mathrm{V}_{\mathrm{yz}}$ are less accurate as a consequence of the gradiometer configuration that consists of six three-axis accelerometers being two ultrasensitive axis and one less sensitive axis, built and tested on Earth in a 1-g environment (ESA, 1999).

The scientific processing of the GOCE data, known as Level 1b to Level 2 processing, is done by the high-level processing facility (HPF), which is part of the GOCE Ground Segment (Koop et al. 2007). This preprocessing stage get the Level 1b gravity gradients (GGs) derived from the gradiometer observations which have been calibrated in flight using satellite shaking and star sensor data. After many transformations the data becomes EGG_TRF_2 L2 gravity gradients in LNOF (see Annex A) with corrections externally calibrated in a local north-oriented frame, including corrections due to the temporal gravity variations (e.g., ocean tides, pole tides, non-tidal) to isolate the static gravity field part, outliers fill-in gravity gradients for data gaps with flags (if detected) and their GG error estimates (Koop et al., 2007; Gruber et al., 2009).

The Level 2 gradients together with precise science orbits are derived as a global gravity field model, represented by spherical harmonic coefficients. In particular, the GGs may be directly used in Earth sciences, typically for geophysical/oceanographic applications focusing on smaller spatial scales (Koop et al. 2007), using the gravity gradients transformed from the GRF to the LNOF system (see frames system in GOCE satellite at ANNEX A) by HPF in GOCE level 2 Products, released as a Track_GO_CONS_EGG_TRF_2 file (Figure V-1).

However, to use of the released EGG_TRF_2 Level 2 Products requires the extraction and preparation of all the additional correction needed to remove the GOCE GGs noise (shift/drift) in crossover (XO) points (Figure V-2) due to the different orbit heights at each orbit of the satellite. In 
this work, we have analyzed the 21 GOCE track files available in the study area to obtain such a correction using the crossover errors, and then we have removed a linear trend along the time, using standard least-squares parameter estimation.

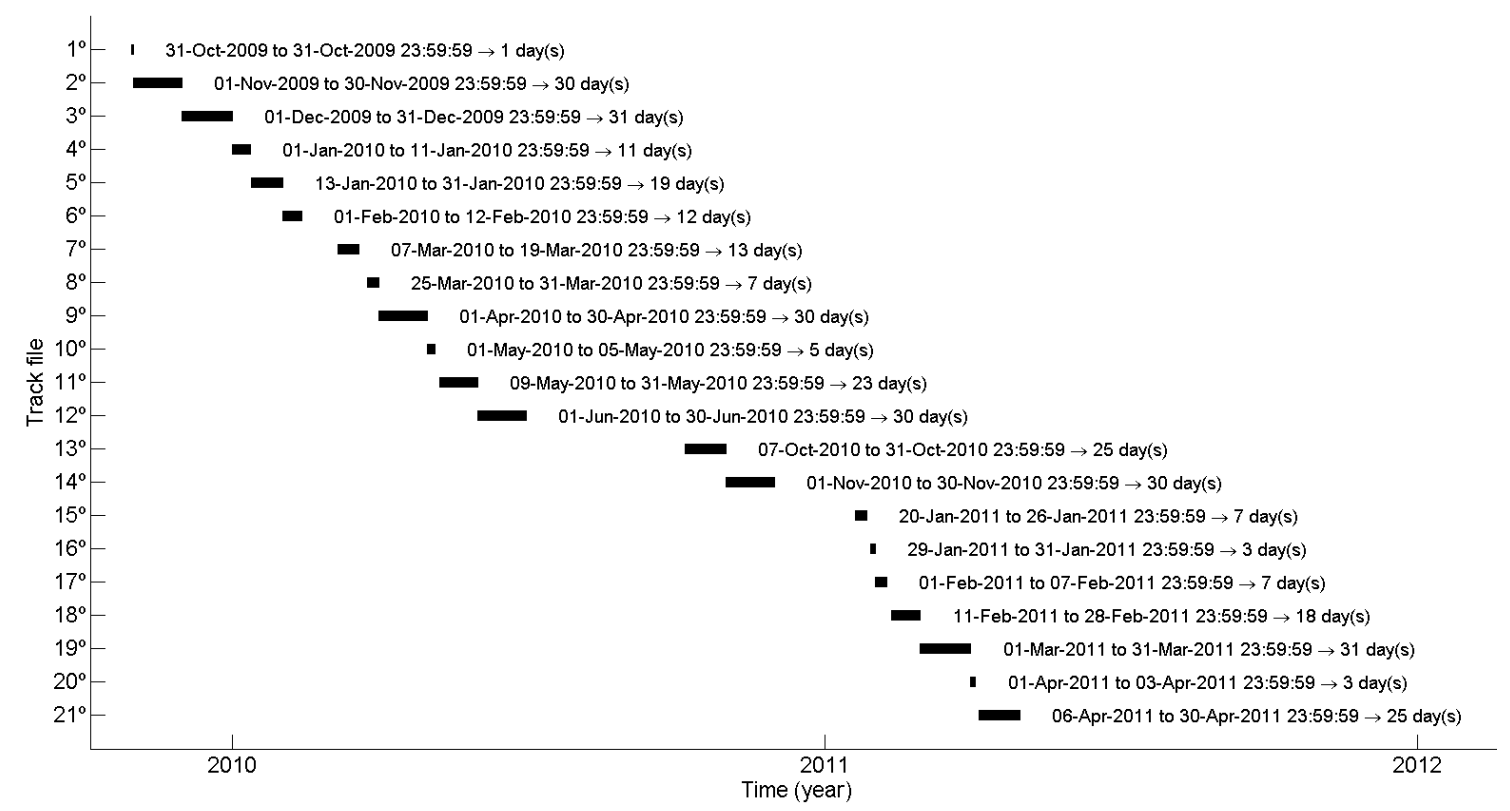

Figure V-1: Track files coverage of the GOCE gradiometric data provided by GOCE level 2 products covering the period from 10/2009 to 04/2011 (each bar corresponds to the time span of the orbit).

Gravity gradiometer data are normally affected by high-frequency noise originated from the movement of the platform. Low pass filters are often applied to remove such motion-related noise. The filtering, however, does not discriminate between signal and noise and removes both from frequencies outside the pass band (Koop et al. 2007). The GOCE accelerometers are designed to give the highest achievable precision in the measurement bandwidth (MBW) between 5 and 100 $\mathrm{mHz}$, which corresponds to a resolution along track of $40-8000 \mathrm{~km}$. The diagonal gravity gradients in LORF do not exceed the precision of $4 \mathrm{mE} / \sqrt{\mathrm{Hz}}$ in the MBW (Bouman et al., 2005).

\section{V.1. GOCE Satellite Track Cross-Overs}

The cross-overs (XOs) technique has been applied very successfuly not only in satellite altimetry but in other geophysical observations collected by oceanographic vessels, remotely-sensed data, airborne collection campaigns, or terrestrial measurements of various types obtained along crisscross traverses. The crossovers allow to detect possible systematic temporal errors, and to check the inherent accuracy of the gradiometer system (Wessel, 1989; Bouman et al. 2005; Jarecki and Müller, 2008; Wessel, 2010). 
The basic principle of crossover in order to remove a drift in GOCE gradiometric data sets follow the steps described in Albertella (2000). Firstly identifying the satellite orbit crossovers, which do not really exist three-dimensionally due to the orbit eccentricity, that do not allow repeated measurements, and then removing the strongly orientation-dependent character of the orbits, due to the alignment of the satellite to be different on the ascendig and on the descending intersecting tracks. Therefore, these crossovers do not follow the simple concept of having data points collected at the same position in space, but they can be computed for the same position $(\varphi, \lambda)$ of the ground track on a two-dimensional reference defined by their projection at the surface (aproximated by a sphere).

According to Albertella (2000), the measurements $V_{i j}^{*}$ of GOCE's gravity gradiometer should show no differences at the orbit crossovers:

$$
V_{i j, 1}^{*}=V_{i j, 2}^{*}
$$

where the indices $i, j$ represent the three axes of gradiometer $x, y, z$, and the indices 1,2 mean that each ground track crossover has been found by intersection of two ascending and descending tracks, here obtained by the interpolation of seven or at least three data points along-track around the specific crossover (Figure V-2) using the method of Akima (1972). 

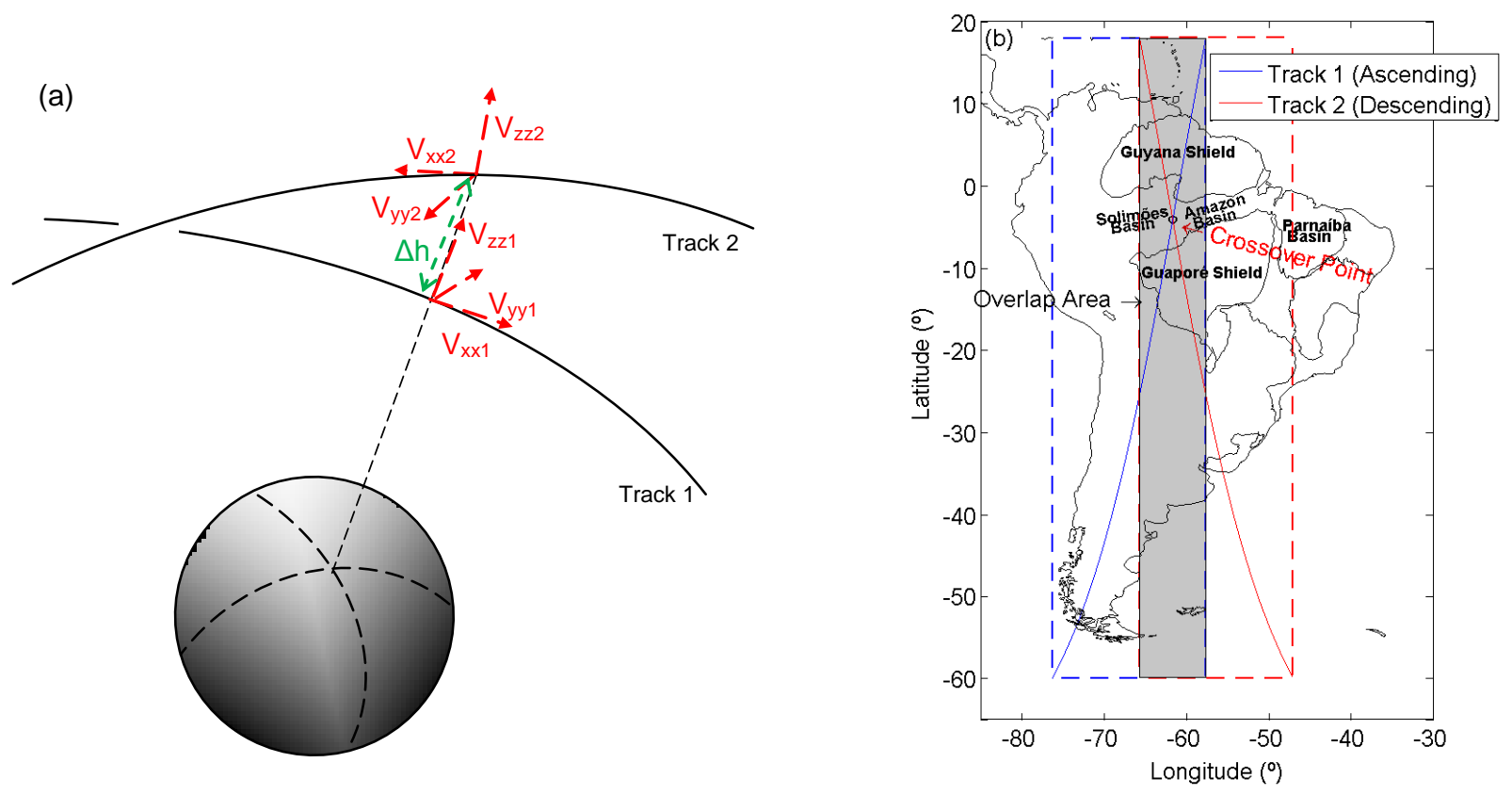

Figure V-2: Cross-over geometry of the SGG satellite tracks. Schematization of the satellite orbit cross-over in (a) "the same position in 3D space", (Modified from Bouman et al., 2005); and (b) the same geographical position on a two-dimensional projection over the surface of the study area.

Thus, for each ground crossover, i.e. the same (geographical) position $(\varphi, \lambda)$, we can write

$$
\varphi_{V_{i, j, 1}}=\varphi_{V_{i, j, 2}} \lambda_{V_{i, j, 1}}=\lambda_{V_{i, j, 2}}
$$

As already mentioned, due to the orbit eccentricity, the satellite altitude differs in those projected positions, causing the existence of height differences $\Delta h_{12}$, that can be as high as $\sim 13 \mathrm{~km}$, causing measurement differences "at the same point in space" (crossovers) on the GOCE observations.

$$
h_{V_{i, j, 1}} \neq h_{V_{i, j, 2}}
$$

Moreover, the different orientation of the gradiometer axes along each ascending and descending track must be considered, which leads to further measurement differences by rotating the measurements or by applying a reduction:

$$
V_{i, j, 1} \neq V_{i, j, 2} \text {, etc. }
$$

The XO differences can be used, in principle, with any available gravity quantity, because the measured variables are theoretically equivalent, to reduce the discrepancies between the tracks. One 
method of doing this is to use modeled differences from simulated gravity gradients calculated from an existing geopotential model - e.g. EGM96, EGM2008 or EIGEN-GRACE.

According to Jarecki et al. (2006), the reduction can be calculated as

$$
\operatorname{red}_{V_{i j, X O}}=V_{i j, 1 G M}-V_{i j, 2 G M}
$$

After this reduction, the $\mathrm{XO}$ differences are:

$$
\Delta V_{i j, X O}=V_{i j, 1}-V_{i j, 2}-\operatorname{red}_{V_{i j, X o}}
$$

As a reduction is necessary for compensating the height differences and in order to avoid a loss of quality in the measurements, we have used the reduction concept by linear trend estimation, and we did not apply any spacial filter to preserve important frequencies in the full gradient signal.

Following Bouman et al. (2005), we can use another way of reduction by introducing a model error in the crossovers calculated from external validation methods (using auxiliary data from a geopotential model to simulate gravity gradients at the same position of the GOCE data points). Thus, the height differences in the crossover points lead to measurement differences in the gravity gradients that should be reduced to the same reference height and to the same orientation of the gradiometer axes along each track by applying

$$
V_{i i}\left(h_{1}\right)=V_{i i}\left(h_{2}\right)-V_{i i h}\left(h_{1}\right) \Delta h_{12}-V_{i i \alpha}\left(h_{1}\right) \Delta \alpha_{12}
$$

where $V_{i i h}$ is the derivative of the gradients in the vertical direction and $V_{i i \alpha}$ is the derivative with respect to the satellite orientation, which can be computed from the geopotential models (e.g., EGM2008) by simple numeric differentiation together with the height $\left(\Delta h_{12}\right)$ and direction $\left(\Delta \alpha_{12}\right)$ differences.

However, as we have no information about the direction of the gradiometer axes from EGG_TRF_2 Level 2 Products, we will apply a reduction obtained from the crossover differences analysis, which can easily be estimated by the least-squares adjustment (linear trend) of the gravity gradient differences with respect to the time differences or to the height differences in the crossovers

\section{V.2. Linear Trend Estimation}

In practice this is a technique based on the assumption that the geophysical field is continuous from track to track and along the track. Even though the geology may be variable, the observed data will 
tend to show significant correlations between the satellite orbit tracks. However, this method is only feasible if the track is free of systematic errors (for instance, without misalignments of the accelerometers, leveling, scale factor mismatches, etc) for a reference satellite height. As it is known that the orbit eccentricity makes the altitude of the satellite to be different at the crossing positions, it is necessary to use the crossover technique.

The time stamped in each collected data point can be used for such a correction, since we have neglected the effects of the periodic errors (e.g. Fourier-type periodic disturbances), as discussed in Jarecki and Müller (2008) and Koop et al. (2002).

Following Koop et al. (2002), let $V_{i j}^{G}$ represent the geophysical field measurement differences, which are a function of the observed gradients and the standard error model for the external calibration of the gradiometer measurements. This function can be constructed as

$$
V_{i j}^{G}(t)=V_{i j}^{R}(\varphi(t), \lambda(t))+V_{i j}^{*}+V_{i j}^{\prime}(t)
$$

with $V_{i j}^{*}$ considered as a constant bias corrupting the real gradients $V_{i j}^{R}$; however, applying the crossover gradient differences, the constant bias cancels out, and reappears only in the magnitude of the errors. The linear trend $V_{i j}^{\prime}$ is the basic error feature. It projects linearly into the crossover differences (V-6), while the real gradient $V_{i j}^{\prime}$ in the reoccupied position $\varphi\left(t_{1}\right)=\varphi\left(t_{2}\right), \lambda\left(t_{1}\right)=\lambda\left(t_{2}\right)$ :

$$
\Delta V_{i j}^{G}=V_{i j}^{G}\left(t_{1}\right)-V_{i j}^{G}\left(t_{2}\right)=V_{i j}^{\prime} \cdot\left(t_{1}-t_{2}\right)=V_{i j}^{\prime} \cdot(\Delta t)
$$

Thus, the crossover errors (or crossover differences $-\Delta V_{i j}^{G} \rightarrow V_{i j}^{\prime}$ ) can be expressed as a function of time $t, f(t)$. The corrected measurements $V_{i j}^{C}$, i.e., the difference between $V_{i j}^{G}$ and $f(t)$, are

$$
V_{i j}^{C}=V_{i j}^{G}-f(t)
$$

Due to the geophysical field to be continuous and correlated track to track and along-track, the 'corrected' measurements $V_{i j}^{C}$ in each track point should match, so that the difference between the two measurements at the crossover should be minimal,

$$
R^{2}=\left\|\Delta V_{i j}^{G}-f(t)\right\|^{2}=\min
$$

Once a model $f(t)$ is selected, the XO error function $f(t)$ can be determined from the crossover differences (i.e., $V_{i j}^{G}\left(t_{1}\right)$ and $V_{i j}^{G}\left(t_{2}\right)$ associated with the time difference $\Delta t=t_{1}-t_{2}$ ) using standard least-squares parameter estimation. The measurement $V_{i j}^{G}$ is corrected using equation $\mathrm{V}-11$, where 
the gradients serve as a new reference 'free of systematic errors along-track', and this procedure is repeated for all along track point of the entire GOCE data set obtained (Figure V-1).

The success of the systematic trend correction in the GOCE data is given by a crossover error model that adjusts the $V_{i j}^{\prime}$, which may not correspond to a geological meaningful model. For instance, if $f(t)$ in eq. $(\mathrm{V}-11)$ fits $\Delta V_{i j}^{G}$ perfectly, we have no crossing errors. Obviously this is physically incorrect, as the orbit eccentricity do not allow exact repeated measurements in the crossing positions. A Matlab program was elaborated to estimate the crossover errors along one or more tracks fitting the measurements that best defines the crossover error model.

The simple model of a crossover error function $f(t)$ in a polynomial form can be given by

$$
f(t)=a_{0}+a_{1} t+a_{2} t^{2}+\cdots+a_{k} t^{k}
$$

where $k$ is degree of polynomial and $a_{k}$ are the coefficients. The residual is given by

$$
R^{2}=\sum_{i=1}^{N}\left[V_{i j}^{G}-\left(a_{0}+a_{1} t+a_{2} t^{2}+\cdots+a_{k} t^{k}\right)\right]^{2}
$$

The coefficients $a=\left(a_{0}, a_{1}, \ldots, a_{k}\right)^{\mathrm{T}}$ can be resolved easily in a least-squares sense. For $k=1$, the equation reduces to the linear solution. In this case, we assumed the crossover errors represent a linear trend along the time.

The orbit of ground track in the along-track direction is provided from the EGG_TRF_2 Level 2 products at the altitude of about $250 \mathrm{~km}$, with the position and GGs information with a sampling rate of $1 \mathrm{~Hz}$. The main orbit characteristics are: major semi-axis $6628 \mathrm{~km}$, inclination 96.6 and eccentricity 0.001 (Jarecki and Müller, 2008).

The first step to obtain the cross-over correction was to break each EGG_TRF_2 products GOCE Level 2 into smaller tracks generating new tracks equivalent to ascending or descending tracks. Figure V-3 shows, for instance, the ground tracks in the South America from GOCE Level 2 Products (Track_GO_CONS_EGG_TRF_2_20110211T000000_20110228T235959_0001, see Figure V-1). The 18 days orbit of this test data comprises a time span from February 11 to February 28, 2011, with $1 \mathrm{~Hz}$ sampling interval, and have been broken into ascending and descending tracks, resulting in 61 ascending and 61 descending tracks; 1332 crossovers were found into this test area $\left(60^{\circ} \leq \varphi \leq 18^{\circ}\right.$ in latitude and $-86^{\circ} \leq \lambda \leq-30^{\circ}$ in longitude $)$. 
In the same form, each GOCE gradiometric data set covering the period from 10/2009 to 04/2011 (Figure V-1) was splitted into new ascending and descending tracks that were stored in a database set and posteriorly checked for intersection. Thus, the whole GOCE gravity gradients data set in the study area have been analyzed using the satellite track crossovers.

When we compare an ascending track with a descending track from the same GOCE data set (i.e. an unique GOCE track file) we get the so-called "internal crossovers". The "external crossovers" are criss-cross points found when making the comparison of the ascending track with descending track from two different GOCE data sets (Figure V-1).

Once all XOs were found (internal and external) in the test area, we have estimated the linear trend and report the crossover error (COE) and mean values for all observables in the corrected track files. The values of the observations at the intersections are interpolated from the nearby along-track values using the specified linear, cubic, or Akima (1972) spline interpolator, and the reduction procedures (such as long-term trend) are applied. The crossover information for each track pair is appended to a growing data file with all $\mathrm{COE}$ obtained to date. Here, we have used the Akima spline interpolation (Akima, 1972) to estimate the data values at the intersection points (i.e. to find the crossover values) because it is a special spline which is stable to the outliers, in contrast, for example, to the cubic spline, that can introduce spurious oscillations in the neighborhood of an outlier (Wessel, 2010).

In the test study area given by Figure V-3 representing South America for whole track files depicted in the Figure V-1 534.769 XOs points have been found, and the position, the GPS time, the satellite height and the measured gradients were interpolated using the described procedure. 


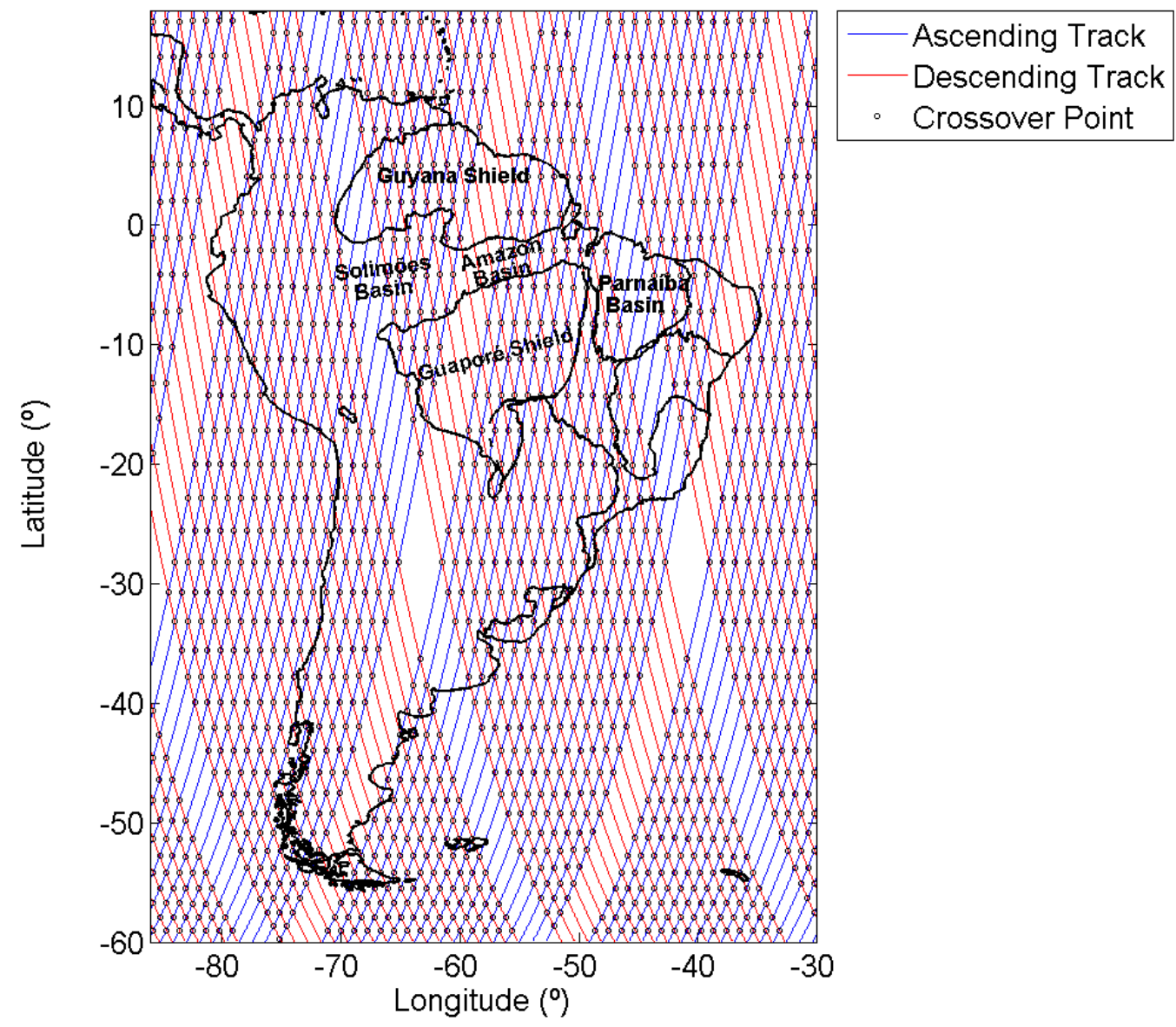

Figure V-3: Satellite ground orbit based on the GOCE data track arc (blue and red lines represent the ascending and descending tracks, respectively) from 18 orbit days acquired on February, 2011 in a test area for the crossover analysis.

The results of the linear trends of the gravity gradients with respect to height differences $\Delta \mathrm{h}$ are shown in Figure V-4. 

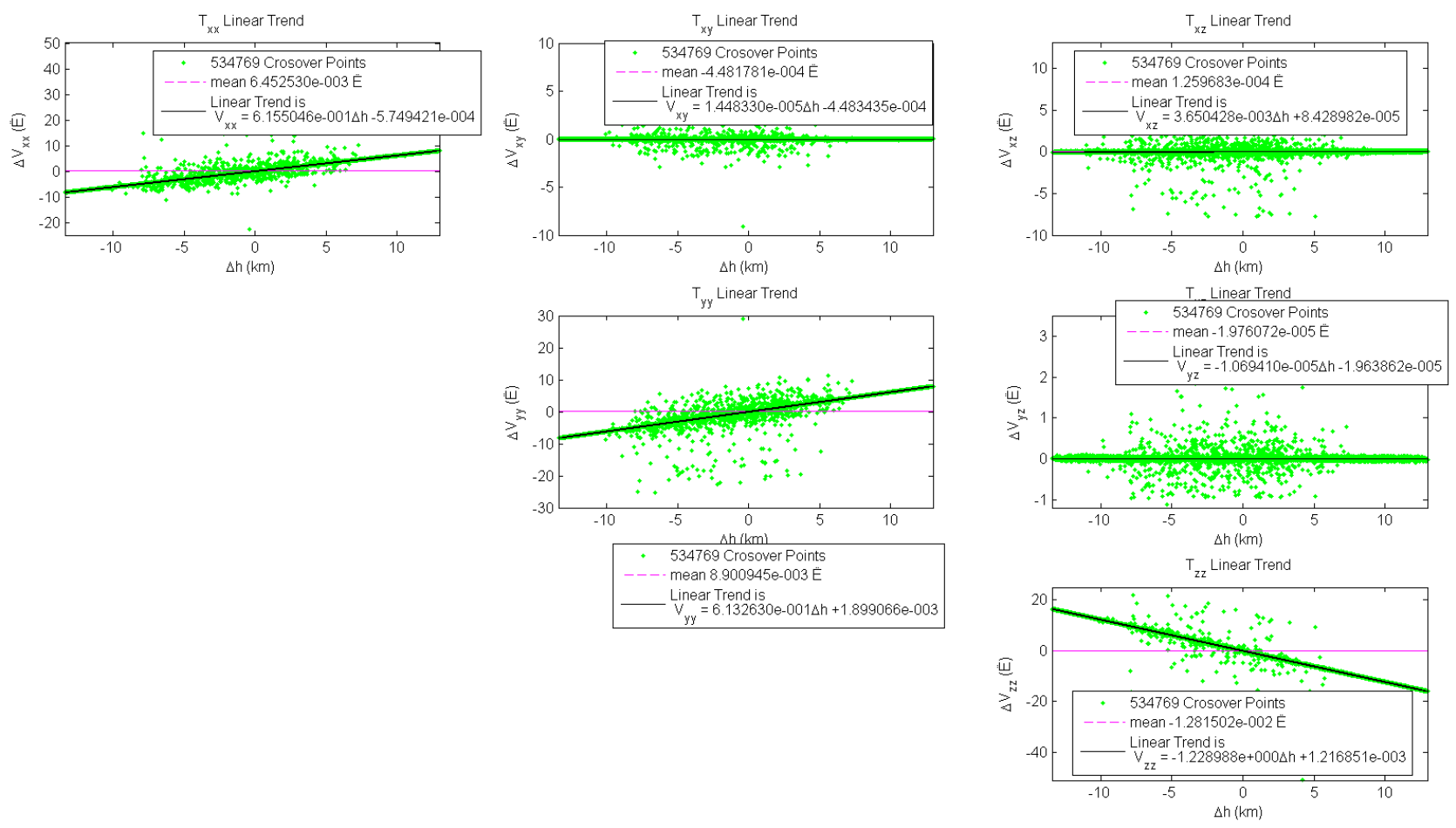

Figure V-4: XO differences of the whole data set of GOCE level 2 products covering the period from 10/2009 to 04/2011 (in 361 days) discussed in Figure V-1, showing a linear trend clearly visible from the least-squares estimation.

In the Figure V-4 one can observe that the off-diagonal gradients measurements presented a nearly noise-free signal. Therefore, we will apply the linear trend ( $k=1$ to eq. $\mathrm{V}-13)$ removal only for the diagonal tensor components.

Figure V-5 exhibits the tensor vertical component (Vzz), in the left, from EGG_TRF_2 GOCE data without the crossover correction and filtering MBW, and, in the right, the tensor vertical component derived from a geopotential model at a height of $250 \mathrm{~km}$. 

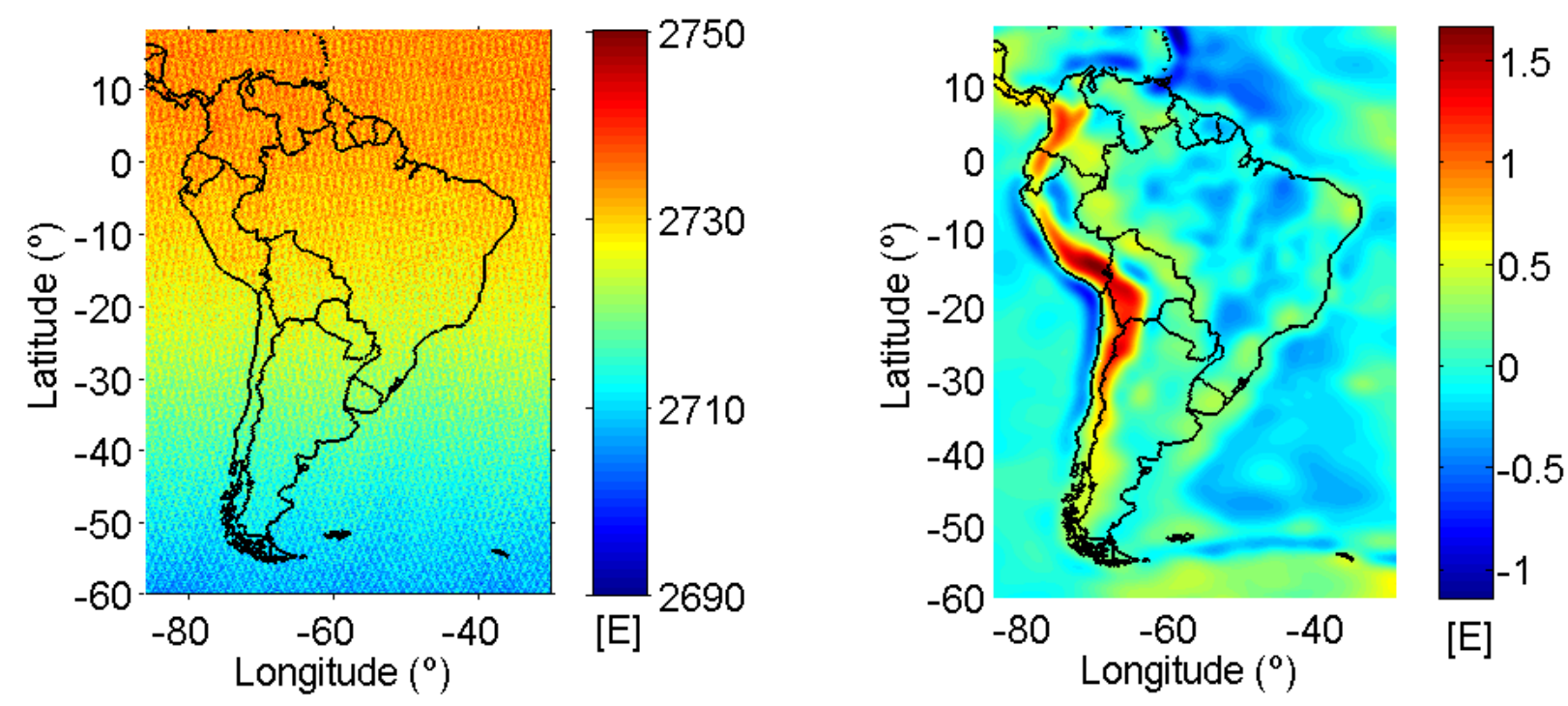

Figure V-5: Comparison of the Vzz component from (a) EGG_TRF_2 products GOCE Level 2 data without XO errors removal and (b) from geopotential GOCE-only gravity model (Pail et al., 2011) up to degree and order 250 calculatade in the satellite altitude of $250 \mathrm{~km}$.

The effect of the linear trend superposed to the GOCE data set was estimated directly from the crossover differences by least-squares adjustment. As discussed in Jarecki and Müller (2008), the effects of the interpolation errors on crossovers can cause discrepancies of the original crossover differences. Nevertheless, it is recommended to use a more robust trend estimation method like the one described in Jarecki and Müller (2008) and/or a trend estimation from a large set of XO differences time intervals for minimizing the effect of outliers (e.g., Table V-1).

The assessment of the interpolation errors on the trend estimation for different time intervals is summarised in Table V-1, considering that the investigated track sections were all in the study area (Figure V-3) and then the track data set for all terrestrial globe (Figure V-6) (only 1 and 11 days) denominated "1 revolution". 


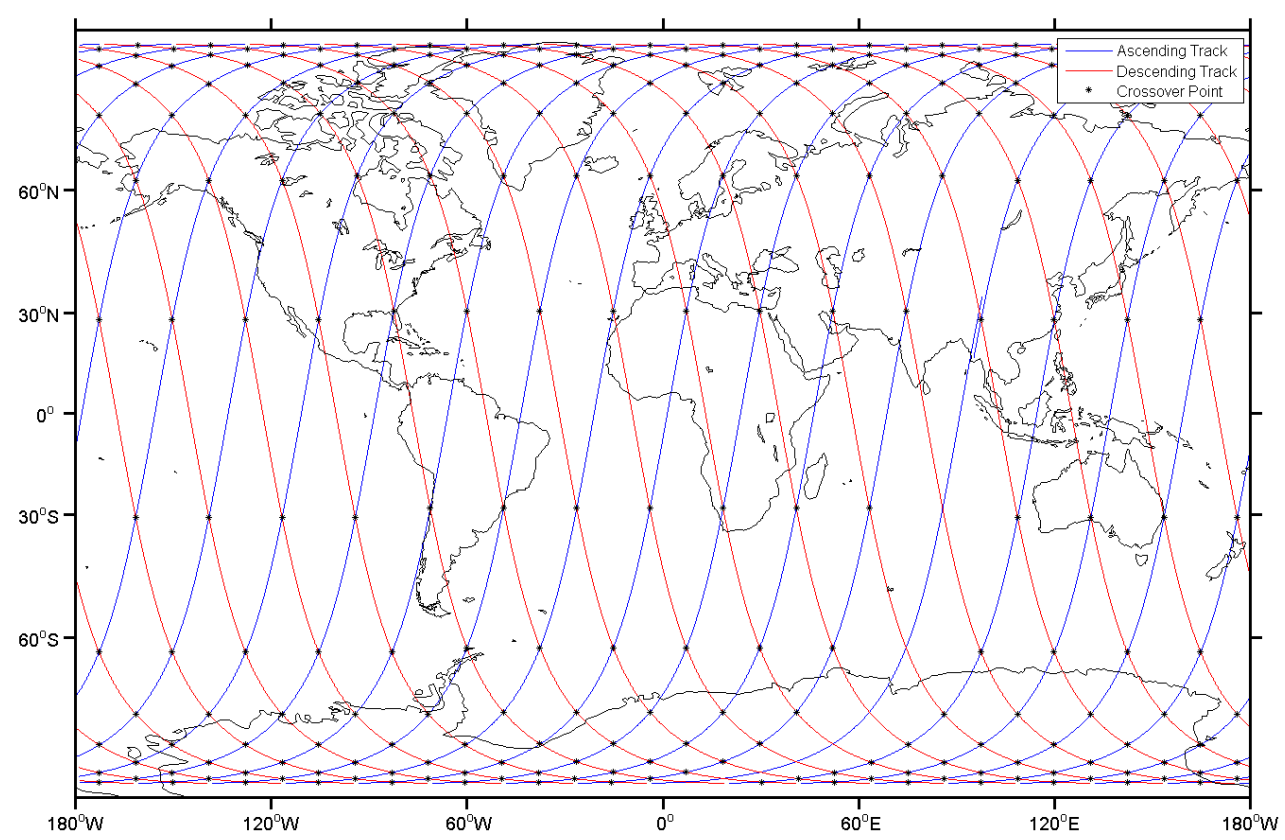

Figure V-6: Covered on all Earth for 1 day track from GOCE Level 2 Products Track_GO_CONS_EGG_TRF_2 at 31 October 2009.

Table V-1: Estimation of linear trends from XO gravity gradient differences $\left(\Delta \mathrm{V}_{\mathrm{zz}}\right)$ of the GOCE data set using different combinations (in height variation) of the tracks in the test area and in the global area.

\begin{tabular}{cccc}
\hline $\begin{array}{c}\text { track section } \\
\text { investigated }\end{array}$ & $\begin{array}{c}\text { crossovers with tracks } \\
\text { from }\end{array}$ & $\begin{array}{c}\text { estimated trend } \\
\text { std }[\mathrm{mE} / \mathrm{d}]\end{array}$ & \# samples (XOs) \\
\hline \hline arc & $\begin{array}{c}\text { 361 d (whole data set } \\
\text { only in study area) }\end{array}$ & $\begin{array}{c}1.228988 \\
1.864492\end{array}$ & ca. 534.769 \\
1 revolution & $1 \mathrm{~d}$ (global area) & -1.232420 & ca. 248 \\
& & 0.0291720 & \\
1 revolution & $11 \mathrm{~d}$ (global area) & -1.231484 & ca. 28.425 \\
& & 0.029146 & \\
\hline
\end{tabular}



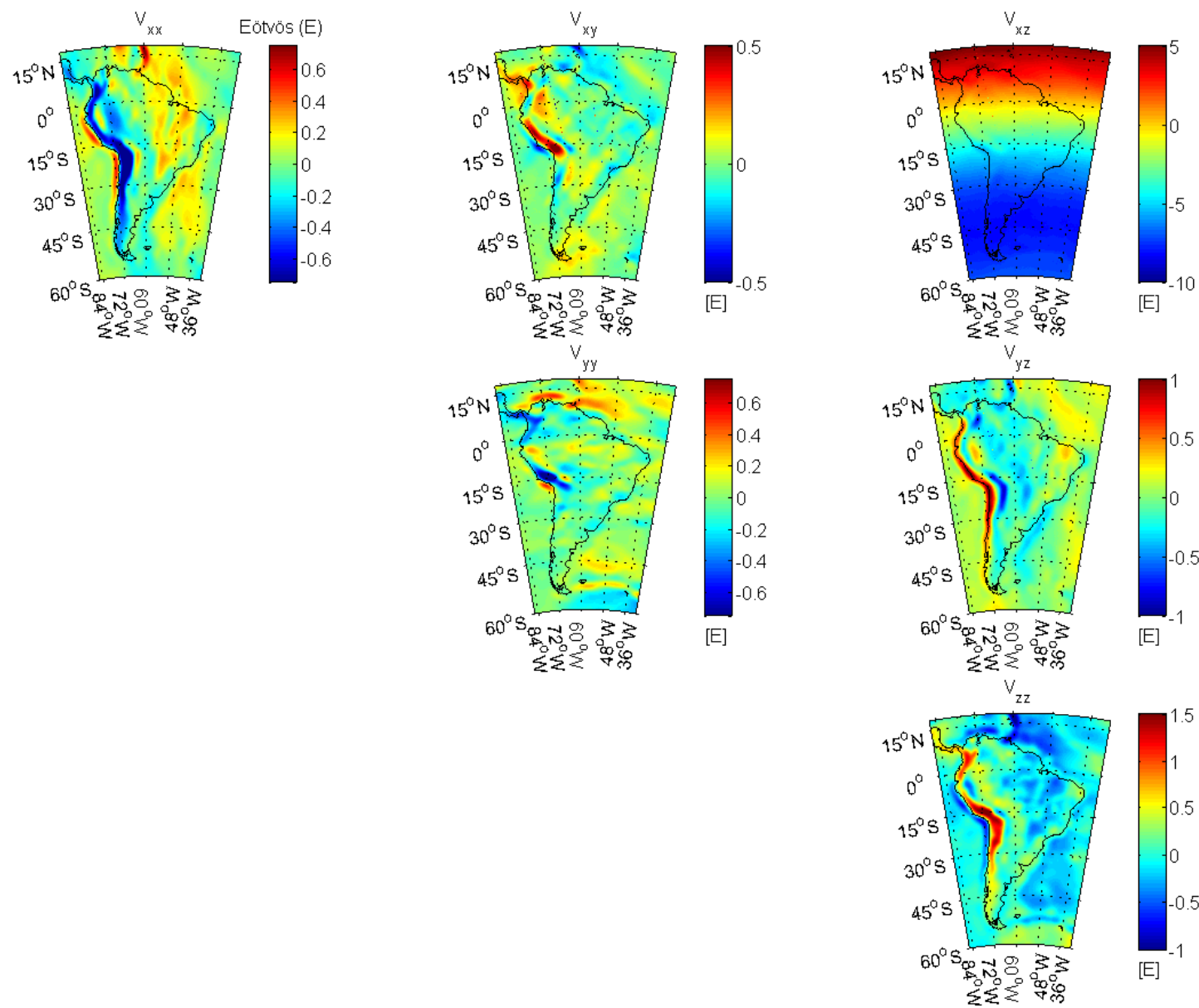

Figure V-7: Gravity gradients at the mean satellite height $(\mathrm{h} \approx 250 \mathrm{~km})$ from cross-over corrections.

The analysis of the results (Figure V-7) shows that the component $V_{x z}$ seems to be less accurate than the others gravity gradients components, and its values are almost 10 times greater than all the other components. This observation will be discussed in the next chapters. 


\section{TOPOGRAPHIC CORRECTION}

In an environment of irregular topography, the undulations of topography above and below the elevation level of a gravity observation point are referred as terrain correction. Terrain correction is necessary when the gravity effect due to topography between any station and the base station is over the accuracy of gravimeter (Forsberg, 1984).

Topographic and isostatic reductions are evaluated to eliminate the effects of the two most dominant and best known density anomalies of the earth: the visible topography and its associated compensation at depth. Generally, such gravity field effects are nominated "terrain effects" (Forsber, 1984).

According Forsberg (1984), the term "terrain corrections (TC)" commonly applied will be reserved for a correction to the Bouguer reduction, to give the true (unlinear) effect of the topography on gravity anomalies.

Helmert (1884) proposed a few methods for mathematically computing a potential field with no masses external to the geoid. The Stokes' integral requires also a gravitational potential with effect of the topographic masses above the geoid, as well as the isostatic balance masses removed (i.e., topographic-isostatic reduction of gravity) (Heiskanen \& Moritz, 1967). Helmert's $2^{\text {nd }}$ method of condensation removing the topographic masses and restores them on a condensed mass layer at the geoid and the attractive property of having a small indirect effect (Lambert 1930). Martinec (1998) said all existing Helmert's $2^{\text {nd }}$ condensation approach in topographic effects use the concept of planar approximation of the geoid which describes the actual situation only very roughly. Only in Martinec (1993) begun to be studied in great detail to spherical effects. Smith et al. (2001) quantify the errors in using planar approximations and introduces spherical prism approach for terrain correction.

Gravity anomalies provide important constraints for determining the geological properties and history of the Earth. The Gravity Missions by Satellite have also mapped the gravity fields that provided insights on the Earth's internal mass properties. Already the topographic reductions help differentiate free-air anomalies for components of 
uncompensated terrain and other crustal and subcrustal mass variations (Asgharzadeh et al., 2007).

The modelling of topographic effects in gravity gradients as observed by Gravity Field and Steady State Ocean Circulation Explore (GOCE) is based on the numerical evaluation of functionals of Newton's integral extending over the domain of the topographic masses which include the masses of the continents as well as the oceanic masses. The GOCE gravity gradient mission launched in late 2009 is resolving further details of the Earth's gravity field to degree and order 250, until the present day, at roughly $250 \mathrm{~km}$ altitude.

TC are needed in various applications such as geoid computation, interpretation of crustal structure as well orthometric correction (Hwang et al., 2003). Most of these methods are computed by algorithm based on the Fast Fourier Transform (FFT) and is suitable for grid-wise computation. The other algorithm is based on the direct integrations of the TC integrals and is ideal for point-wise computation (Hwang et al., 2003). The most widely used method for terrain correction is the Hammer's method (Hammer, 1939), which many geophysicists are still using it for terrain correction. Forsberg (1984) computed in effect of topographic masses by direct calculation of prisms deduced from the digital terrain model. Hwang et al., 2003 used a rigorous pointwise method that is based on Gaussian quadrature. Heck \& Seitz (2007) computed with a tesseroid method.

Beside the topographic and density information which define the geometry and mass of the particular tesseroids, their spatial arrangement has to be fixed. Even though the used tesseroid formulas are given in a spherical manner, these bodies can be set up on different reference surfaces approximating MSL (Mean Sea Level). Tesseroids are well suited for the decomposition if the topography of the Earth is represented by a DTM (Digital Terrain Model) which is usually given in geographical coordinates.

A much more effective approach analyzing gravity data over a finite spherical is to represent the anomalies by gravity effects of an equivalent point source distribution or related to the masses of a fixed distribution of gravity point poles by least-squares inversion (Asgharzadeh et al., 2007). Due the geological significance of the existing and growing volumes of regional (large scale) terrain elevation and satellite gravity data in study area, there is great need for computing theoretical anomalous gravity fields from 
geological and geophysical models in spherical coordinates. For this, we used the tesseroids - 1.1 software developed by Uieda (2011), which use the notion about tesseroid introduced by Anderson (1976), as described in Heck \& Seitz (2007) shown previously in this thesis.

The topographic data used to the calculation of topographic reductions was from ETOPO1 Global Relief Model, a global relief model of Earth's surface that integrates land topography and ocean bathymetry. The National Geophysical Data Center (NGDC) department of the National Oceanic and Atmospheric Administration (NOAA) has developed the ETOPO1 that was built from numerous global and regional data sets with a 1 arc-minute resolution in order to improve the ETOPO2v2 Global Relief Model (Amante \& Eakins, 2008).

Thus the topographic data represented in the Figure VI-1 were used from ETOPO1 model with a grid 1 minute (Amante \& Eakins, 2008).

Just as Heck \& Seitz (2007), for this calculation, the topographic surface of the Earth is often divided in spherical prism as described in Chapters previous and your calculate combined effect of a list of tesseroids on given computation points from the tesseroids 1.1 Beta software by Uieda (2012).

The calculation of the Gravity Gradient Tensor (GGT) and gravity anomaly (gz) due to topographic masses using tesseroids was obtained from Digital Elevation Model (DEM) as such ETOPO1 model given on a resampled regular grid in 10' equal-spaced grid together with its corresponding density values. Here, for this method is assumed that the heights into and/or above sea level (reference level - zero depth meter) signal land is considered to be the average terrain density $2.67 \mathrm{~g} / \mathrm{cm}^{3}$ and negative heights signal ocean is considered the constant density of $-1.64 \mathrm{~g} / \mathrm{cm}^{3}$ (i.e., the difference between the mean ocean saltwater density $1.03 \mathrm{~g} / \mathrm{cm}^{3}$ and the reference crustal density $2.67 \mathrm{~kg} / \mathrm{m}^{3}$ ). 


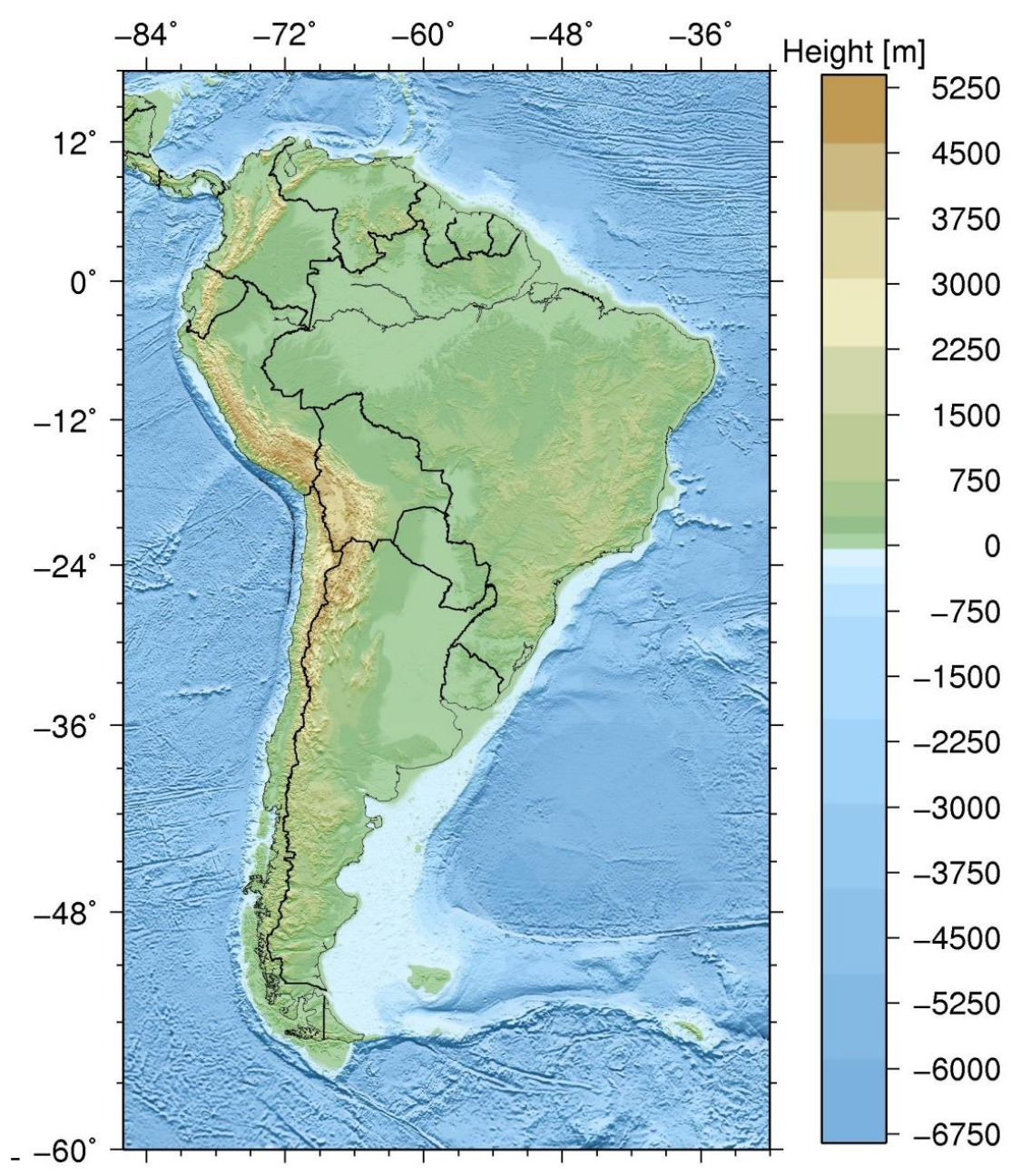

Figure VI-1: Topography and bathymetry from ETOPO1 global relief model (Amante \& Eakins, 2008).
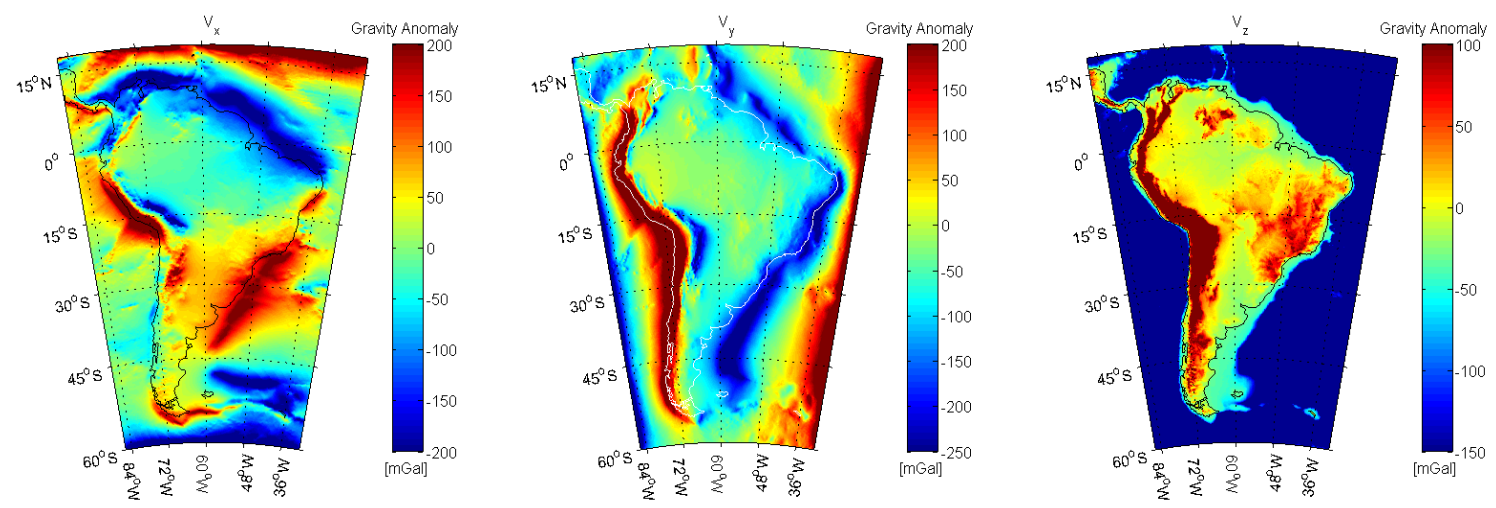

Figure VI-2: Effect caused by topographic masses using tesseroids at $250 \mathrm{~km}$ altitude for gravity anomalies from resampled ETOPO1 DEM 10' grid. 

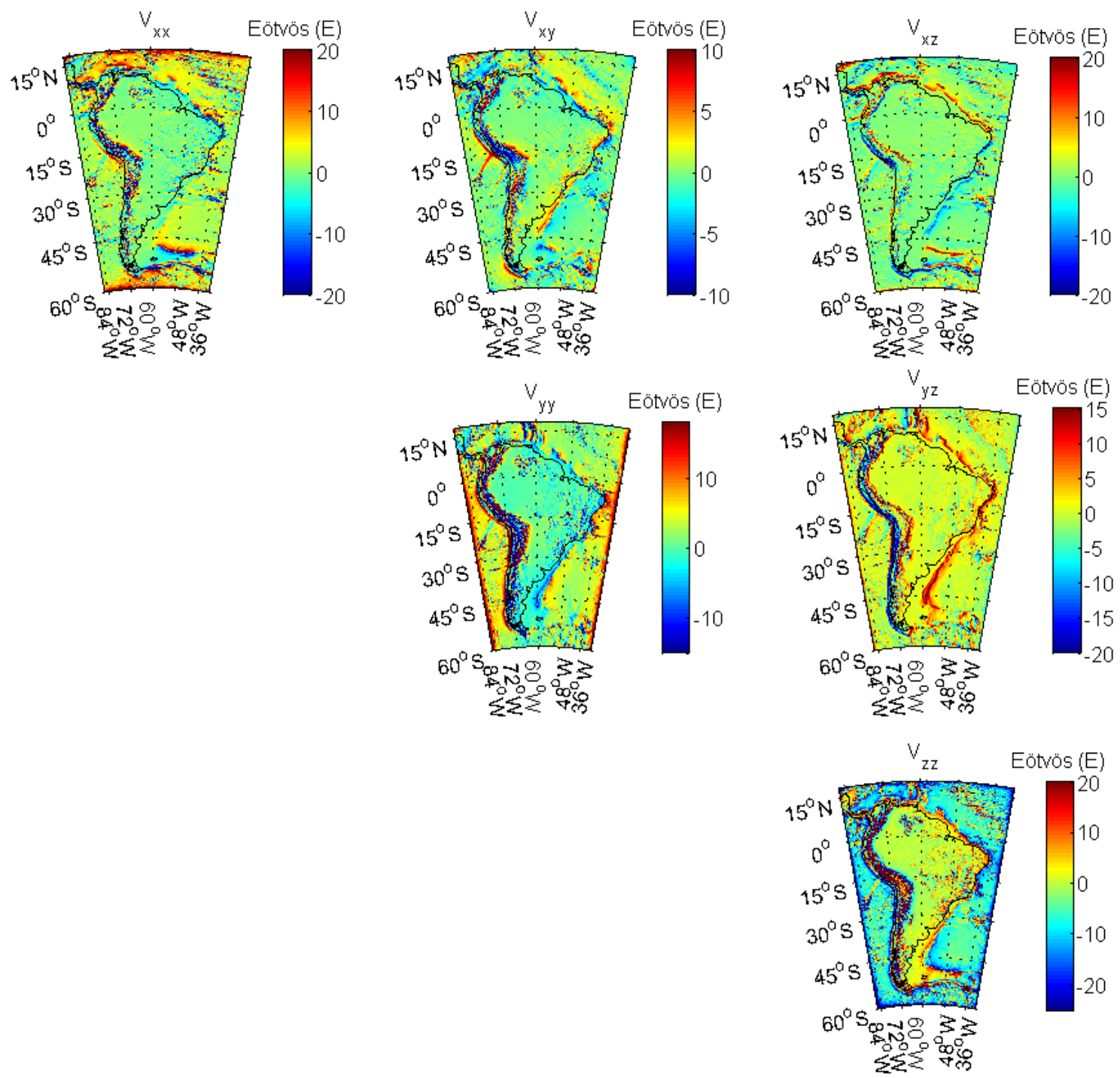

Figure VI-3: The resulting gravity effect on topography corresponding gravity gradients at altitude higher than regional height from resampled of the ETOPO1 DEM per 10 by 10 arc minute grid cell.

As described above the terrain correction to gravity field due the topographic masses irregularities can be estimated from geometric element used in the forward gravity modelling processes such as prisms calculated from the Digital Terrain Model as computed by Forsberg (1984) relative to a smooth mean height surface. Here, the topographic reduction in gravity anomaly and GGT is performed from the effect of topographic masses by applying forward gravity modelling in space domain using tesseroids (See section III.3) deduced from ETOPO1 DEM at Earth's surface using a mean height level chosen to be higher than the regional topographic height. This is because the tesseroids-1.1 program does not guarantee the accuracy of the calculation at 
zero height (Uieda et al. 2011). So, for area in South America, $6570 \mathrm{~m}$ mean height was used for estimate topographic masses effect. Also, we calculate the same effect at 250 $\mathrm{km}$ height cosidering that is the GOCE satellite mean height, which has been derived the gravity field data.
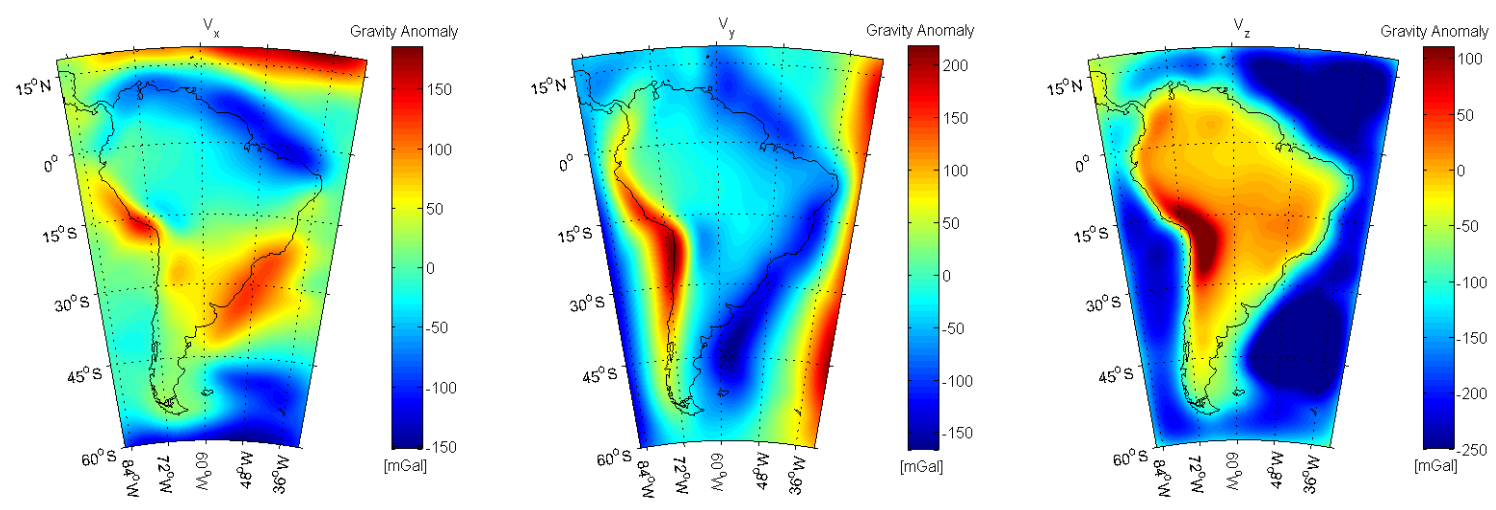

Figure VI-4: Effect caused by topographic masses using tesseroids at $250 \mathrm{~km}$ height for gravity anomalies from resampled of 10 arc-minutes ETOPO1 DEM.
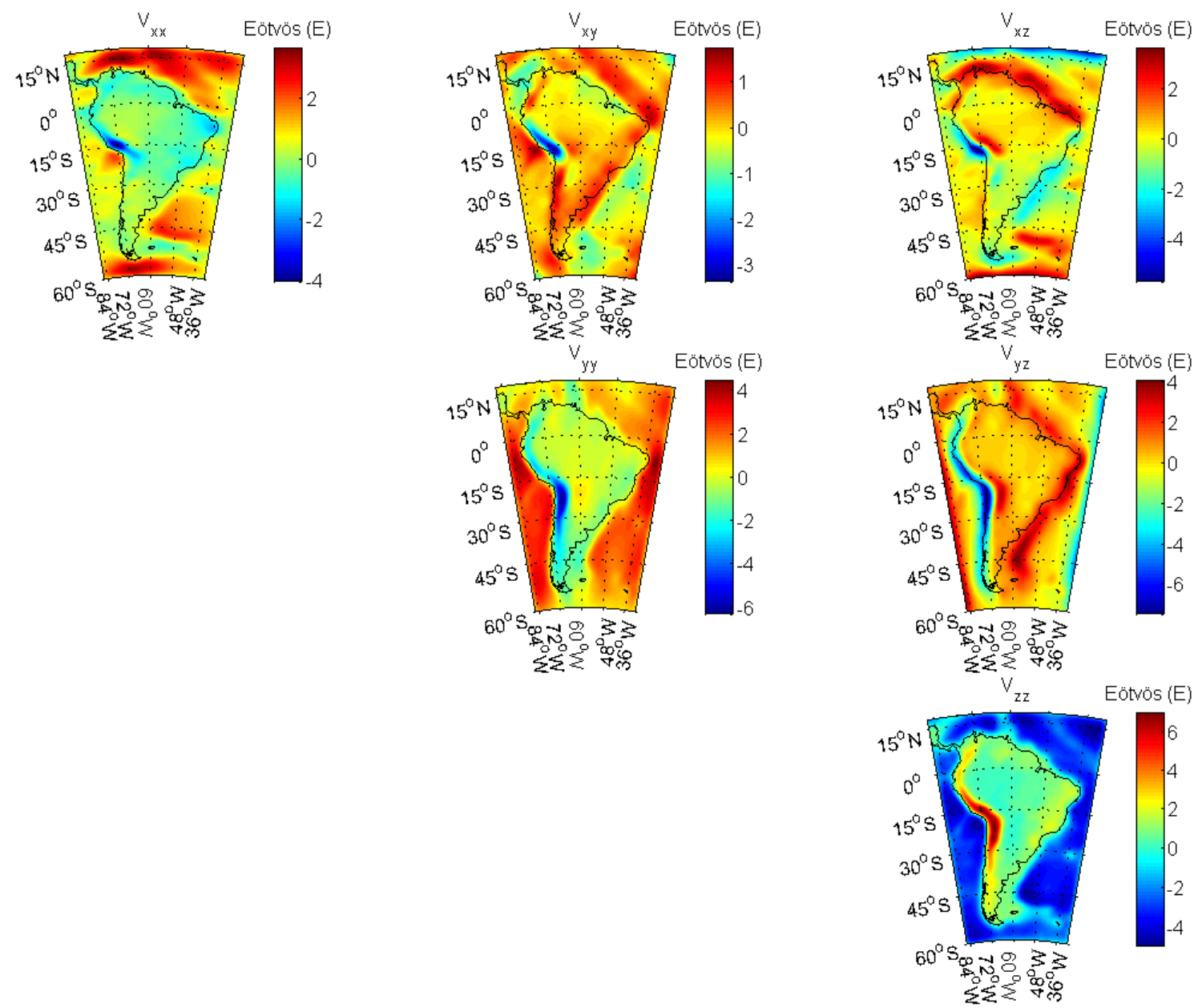
Figure VI-5: Effect caused by topographic masses using tesseroids at GOCE satellite height $(\mathrm{h}=$ $250 \mathrm{~km}$ ) for GGT from resampled ETOPO1 10' grid DEM.

Likewise, we obtained gravity modelling from others geological targets as Moho and basin sediments from seimological Moho thickness, depth and isopach models computing tesseroid masses and/or prism masses by LithoFlex program (Braitenberg et al., 2007) as discussed in next chapter. 


\section{VII.1. Overview}

The mantle densities seem to exert an important control on the formation of the basins and the study of the gravity field, the potential and the gradient tensor, coupled with the isostatic state of the lithosphere in the region, is an essential tool by which one can classify these important structures (Braitenberg and Ebbing, 2007).

Because of its large-scale size, the heavy coverage by tropical jungle, which limits the access and acquisition of geophysical measurements and geological parameters, little detailed and reliable information is available about the Amazon and Solimões Basin, one of the greatest geological domains of South America, located at the northern part of Brazil. Thus, coupled the lack of good terrestrial gravity data the Amazon and Solimões Basin profit greatly from the gravity satellites. The recent GOCE satellite mission, whith gradiometry on board, contributes greatly to improve the available gravity field, consequently, is of fundamental importance to characterize adequately the region. In this study, spherical coordinates have been used in the calculations of the gravity field potential from EGM2008 (Pavlis et al., 2012) and GO_CONS_GCF_2_TIM_R3 (Pail et al., 2011) GGMs published in terms of spherical harmonics according to what was discussed and recommend in APPENDIX A.

The models associated to the gravity field are composed of different wavelengths that represent the density variations on different depths within the Earth. Therefore, the geoid or the observed gravity acceleration (and its derivatives) can be separated into different wavelengths by approximations used commonly in the regional-residual separation of gravity anomalies for exploration uses.

Bowin (1983) showed that there is an approximate relation between the spectral content (information about wavelength) of the geoid and the depth of the anomalous mass which generates a particular wavelength. Similarly, the gravity anomaly corresponding to the same anomalous point can also be derived. Therefore, the relationships can be combined to obtain a boundary depth at which a mass distribution can exist to create the observed gravity and geoid anomalies in the earth's surface. Using spectral relationships 
in the spherical harmonic representation of the free-air anomaly and geoid height, one can produce an estimate of the maximum depth of the anomalous masses as a fraction of the Earth's radius depending on the spherical harmonic degree.

The sedimentary basins may be correlated with the geoid, but this is not always the case. This discrimination points towards different density characteristics in the integrated crustal column (Braitenberg and Ebbing, 2007). Other important observation constrained to the evolution of big sedimentary basins is the presence of volcanic structures at some time-stage and at some depth at the basins. In particular, the brazilian Amazon, Solimões and Parnaíba Paleozoic basins present a broad area where sill intrusions are frequent, and they might have a thickness of up to $500 \mathrm{~m}$ and an estimated volume intruded into sediments of about $240,000 \mathrm{~km}^{3}$, probably related to the break-up of South America and Africa (Wanderley Filho et al., 2006).

Variations in the crustal thickness of large regions are usually attributed to downward deflection beneath the basin if it is associated with the load-driving subsidence within the crust. Furthermore, important observations in these basins are related to the deviation of the observations from the classic isostatic equilibrium model, that predicts the crustal thickness exclusively from the topographic and sedimentary loads. Instead of crustal thinning, a high density mass distribution in the crust and upper mantle appears to be a typical feature present in these large structures, that may be caused by a mean density distribution of the intruded material or a partial replacement of the lower crust by mantle material, continental underplating, or passive upwelling of partial melt during rifting and extension of the lithosphere (Braitenberg and Ebbing, 2007; Nunn and Aires, 1988).

In this case, isostatic gravity anomalies that can be modeled by an equivalent to the Airy model can be used to identify additional crustal loads, indicating under-compensation if a positive isostatic gravity anomaly is found or an over-compensation otherwise, as the zero isostatic anomaly corresponds to the isostatic equilibrium. The isostatic models are calculated for considering either crustal or sub-surface loads, the latter constituted by sediments and intruded material of high density such as diabase sills and dykes.

\section{VII.2. Model Validation}

The sediment thickness map (Figure VII-1a) in the continental areas was obtained from the data base of Bizzi et al. (2004) (basement depth underlying the sedimentary 
package); where not available the sediment thickness was hand-digitized using an isopach map from de Matos and Brown (1992), Wanderley Filho et al. (2005) and Eiras and Wanderley Filho (2006) and/or from the global sediment map digitized on a $1^{\circ} \mathrm{x} 1^{\circ}$ scale (Laske and Masters, 1997). In the oceans the digital global sediment thickness model published by the NOAA at National Geophysical Data Center (NGDC) with a grid spacing of 5 arc-minutes by 5 arc-minutes (Divins, 2003) was used, although we will not go into details in this thesis, as our interest area is only in the Amazon and Solimões Basins.

The density contrast used for the sedimentary basin rocks was defined relative to the reference continental crust density $2670 \mathrm{~kg} / \mathrm{m}^{3}$ was considered to be between the basement and the sedimentary rocks ranging from 150 to $370 \mathrm{~kg} / \mathrm{m}^{3}$ considering the increasing of the sedimentary package thickness (i.e., correspondent to the increase in density values from 2300 to $2520 \mathrm{~kg} / \mathrm{m}^{3}$ with increase of the sediment thickness). As reported in Nunn and Aires (1988), we have also assumed a average density model of the sedimentary rocks $2550 \mathrm{~kg} / \mathrm{m}^{3}$. For ocean sediments, we have assumed an average density about $2300 \mathrm{~kg} / \mathrm{m}^{3}$ (Fischer et al., 1996) (Figure VII-1).

(a) Sediment thickness

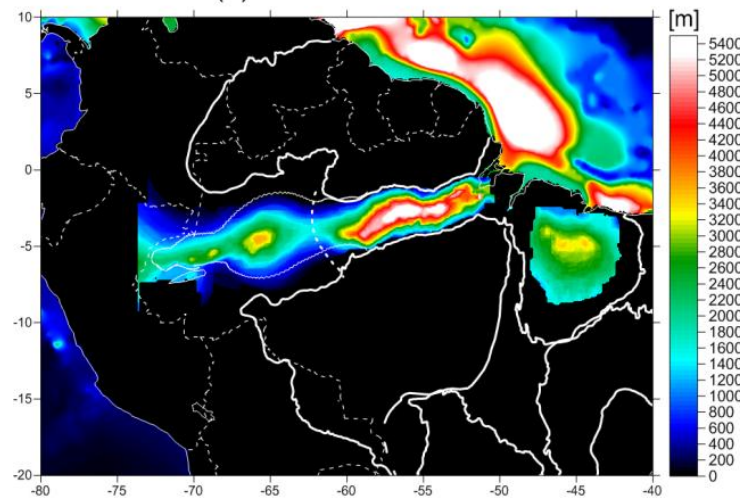

(c) Diabase sills model: gravity effect

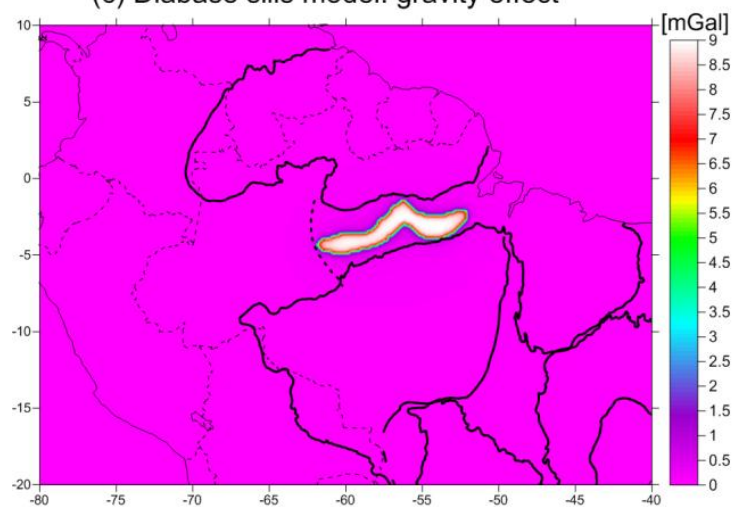

(b) Gravity Effect in sediments

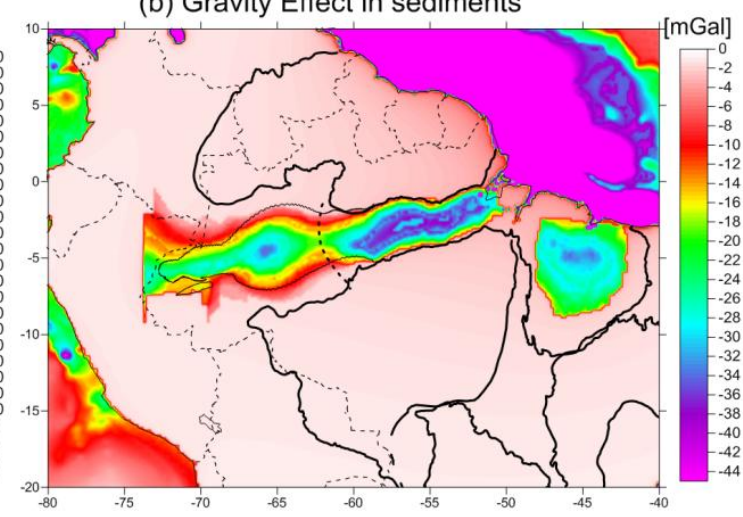

(d) Effect of the gravity anomaly (Sills underlie sediments)

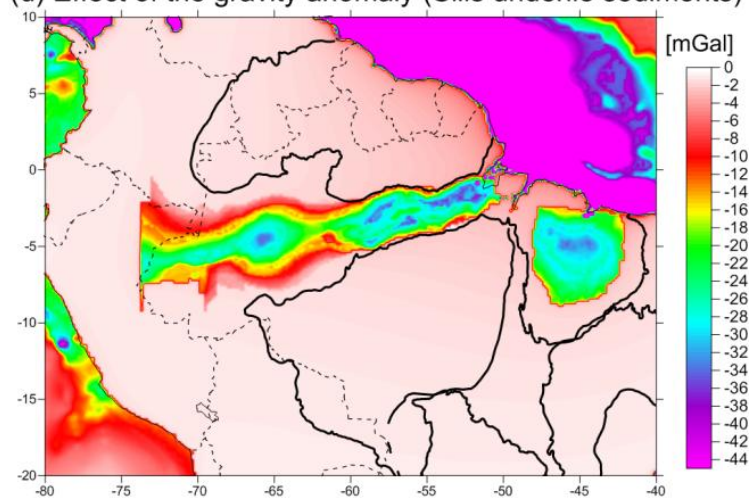

Figure VII-1: Forward gravity modellig for sediment package and diabase sills from our 
assumed density models. (a) sediment thickness from Bizzi et al. (2004); (b) gravity effect in sediments; (c) gravity effect in diabase sills; (d) gravity effect sills plus sediment. P.s: gravity effect is calculated from forward modelling using tessroids.

We have also simulated the low density basin sediments being intruded by a denser material, reproducing the diabase sills and dykes reported in Wanderley Filho et al. (2006), that postulate that the crust has been intruded by denser material with a density of $3000 \mathrm{~kg} / \mathrm{m}^{3}$ beneath the basin, attributing the density to the 'intruded material' as being the same of the Cambrian age pyroxenite body drilled beneath the north-central part of the Amazon basin (according to Nunn and Aires, 1988) in order to explain the observed positive gravity anomalies in the basin region.

The fact of the high gravity anomalies being coincident, nearly, with the axis of the syneclise, suggesting shallow ultra-basic bodies, together with the underlying aulacogenic strata, led to the classic interpretation of a rifting mechanism as the initial driving mechanism for the subsidence of the Amazon Basin, according to Milani and Zalán (1999); so, we also have simulated diabase sills that lie into the sedimentary basins. For this, we replaced the load of low-density sediments by higher-density material with a density of $3000 \mathrm{~kg} / \mathrm{m}^{3}$ for an average thickness of $500 \mathrm{~m}$ in the basins axis (Figure VII-1c). Figure VII-2 represents the contribution of the sediments and the sills into the basin system.

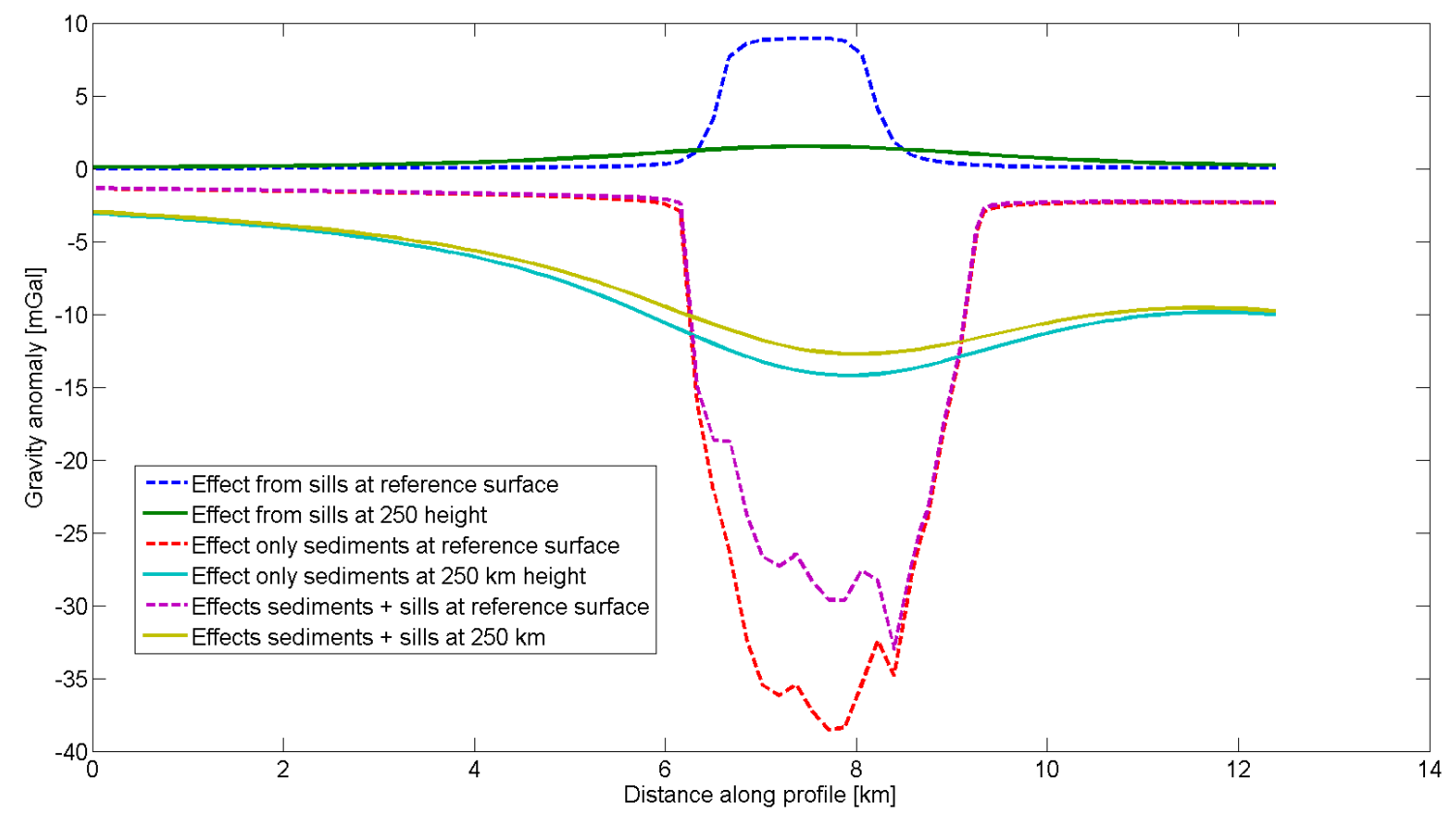


Figure VII-2: Gravity components along the profile A-A' that transects the Amazon Basin. See profile location plotted in Figure VII-3.

In order to calculate the forward model by the tesseroids program already described in the previous chapters, we have calculated the grids of the density distribution and thickness of the sediments, as shown in Figure VII-1.

In the same way, we also have calculated the gravity effect of the crustal thickness. The results from Lloyd et al. (2010) indicate that the seismological Moho is thicker beneath the central axis of the Amazon basin, flanked by a slightly thinner crust which becomes to be thicker towards the northwest and southeast of the Guyana and Guaporé shields, indicating that the load-driving subsidence of the Amazon Basin can be within the crust, which is in agreement with the observed positive anomaly at the center of the basin.

These authors have considered a crustal density model with an intruded crustal material of density $3000 \mathrm{~kg} / \mathrm{m}^{3}$, and so the response in the observed gravity is a positive anomaly caused by this crustal load. However, the positive gravity signal from Moho is broader than the positive gravity anomaly observed at the center of the basin.

In order to obtain the representative response of the crustal and upper mantle structures, the geoid undulations were calculated with GOCE satellite-only GGM (Pail et al., 2011) up to degree 250, and the longest wavelength contribution was removed by subtracting the degrees smaller than 10 degree in the spherical harmonic expansion (Figure VII-4a). This reduction corresponds approximatelly to subtracting the components of the gravity field with wavelengths greater than $2000 \mathrm{~km}$ in the mid-latitudes (Braitenberg \& Ebbing 2007).

The Bouguer anomaly (Figure VII-3a) derived from the GGM (Pail et al., 2011) has been corrected to remove the effect of the topographic masses estimated from forward gravity modelling using tesseroids (see section III.3) with the ETOPO1 DEM data; this modelling used a mean height level chosen to be higher than the regional topographic height, as shown in chapter V. The Bouguer anomaly so obtained has also been analyzed in comparison with terrestrial data where available (Figure VII-3b).

Furthermore, the Bouguer gravity anomaly was also calculated in a simplified form from the geopotential model (Figure VII-3c), subtracting the attraction of the Bouguer plate $(2 \pi \mathrm{G} \rho \mathrm{H})$ from the classical gravity anomaly. This approximation for the 
topography-reduced gravity anomaly is calculated by using the spherical approximation with the topographic heights $\mathrm{H}$ calculated from the model DTM2006 used up to the same maximum degree as the gravity field model (Barthelmes, 2009, eqs. 107 and 126). The simple Bouguer gravity anomaly was used for $\mathrm{H} \geq 0$ (rock with density constrast $\rho$ $=2670 \mathrm{~kg} / \mathrm{m}^{3}$ ), and for $\mathrm{H}<0$ (water with density contrast $\rho=(2670-1025) \mathrm{kg} / \mathrm{m}^{3}$, according Barthelmes, 2009). This simplified model of the Bouguer anomaly has been calculated from the facilities available at the International Centre for Global Earth Models (ICGEM). 
(a) Bouguer anomaly from topographic correction with tesseroids

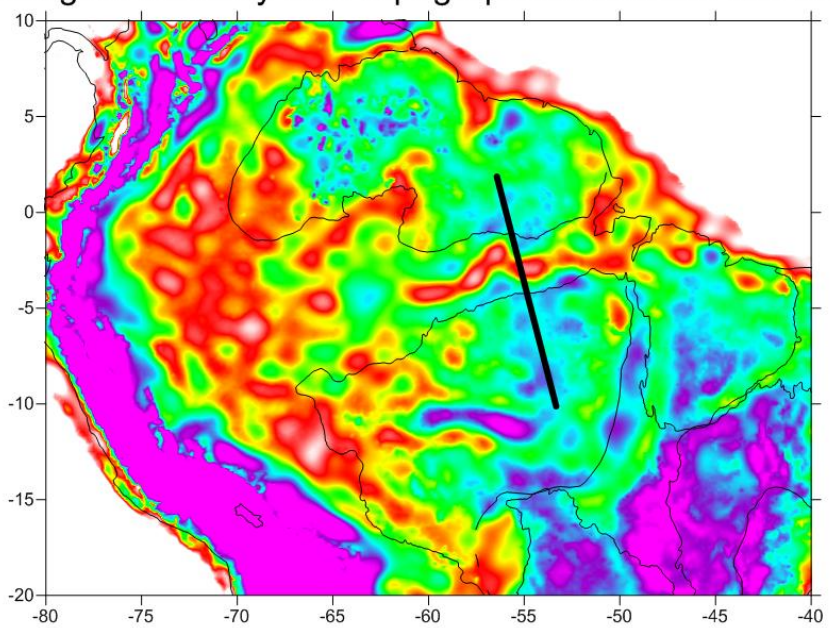

[mGal]

(b) Bouguer Anomaly from terrestrial data

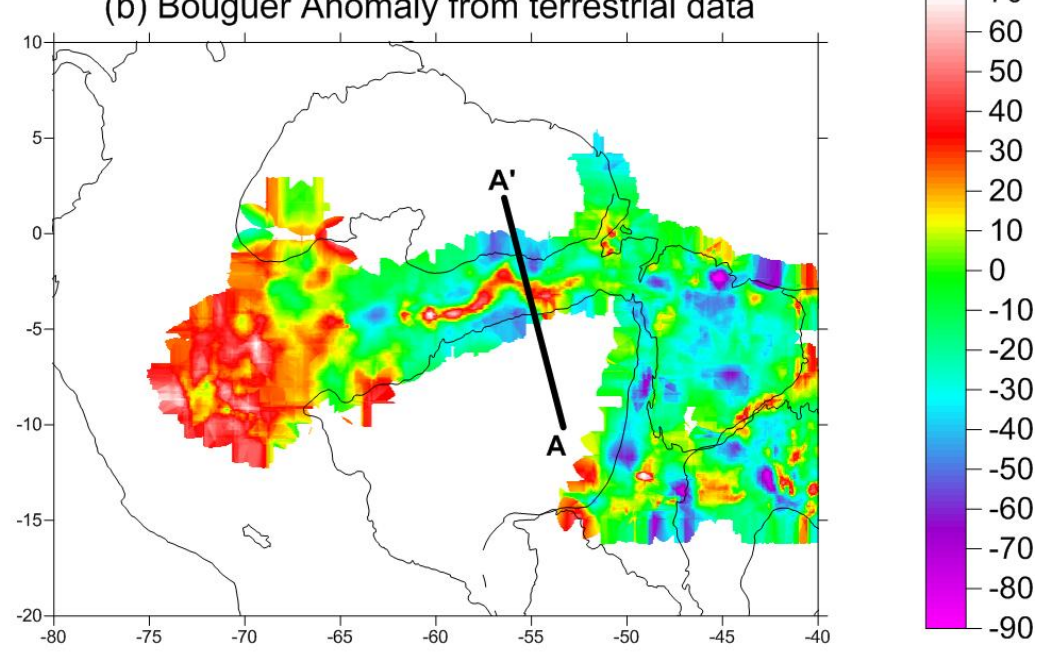

(c) Bouguer anomaly reduced from Bouguer plate development in spherical harmonic

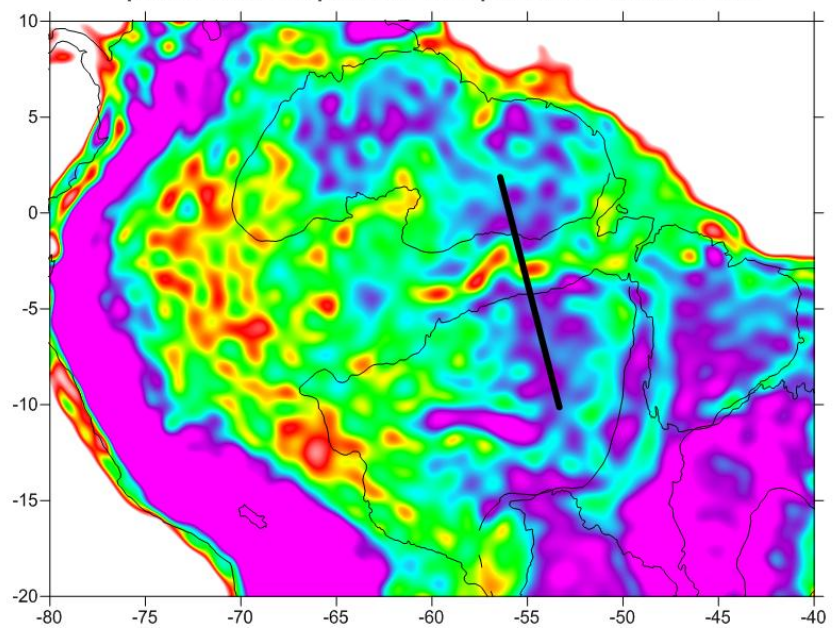

Figure VII-3: Representation of the Bouguer gravity anomaly in different aspects: (a) gravity anomaly calculated by tesseroids without the topographic effects; (b) Bouguer anomaly from the available terrestrial measurements; and (c) Bouguer gravity anomaly calculated in spherical 
harmonics removing the Bouguer plate effect from the classic gravity anomaly.

The Bouguer anomaly represents mainly the crustal sources and provides an outline for the crust thickness variations in younger tectonic areas. In the case of cratonic areas, the base of the crust is expected to show little variation and features observed in the Bouguer anomaly maps should be mainly caused by the density variations in the crust and upper mantle (Braitenberg \& Ebbing 2007).
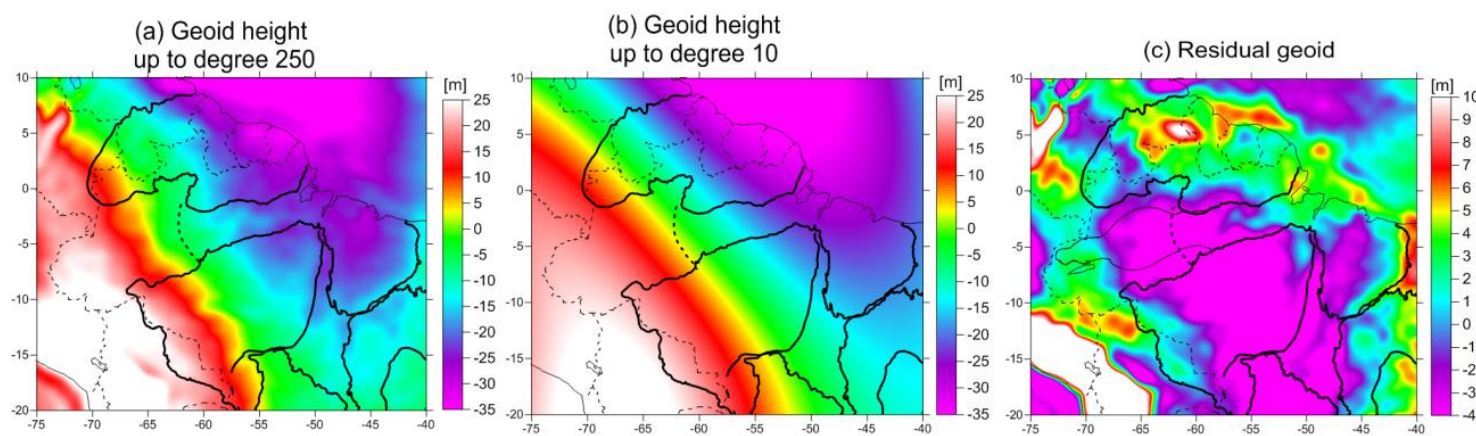

(d) Gravity anomaly

(e) Gravity anomaly
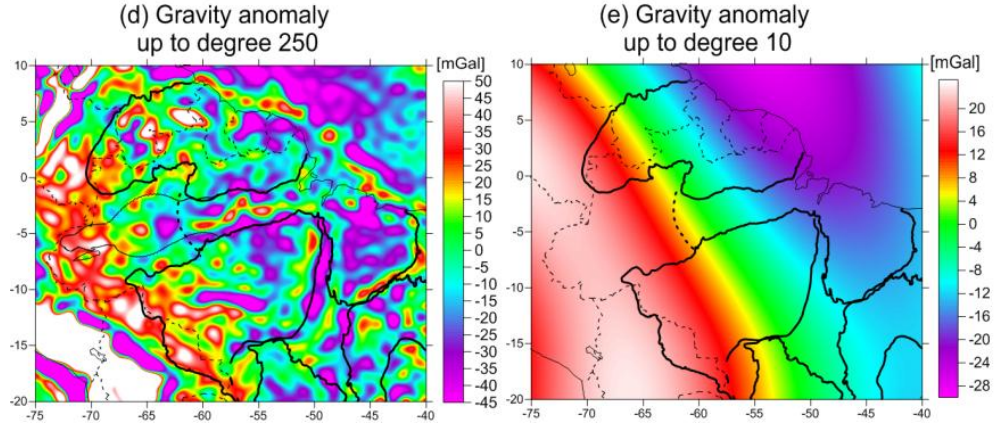

(f) Residual Gravity anomaly

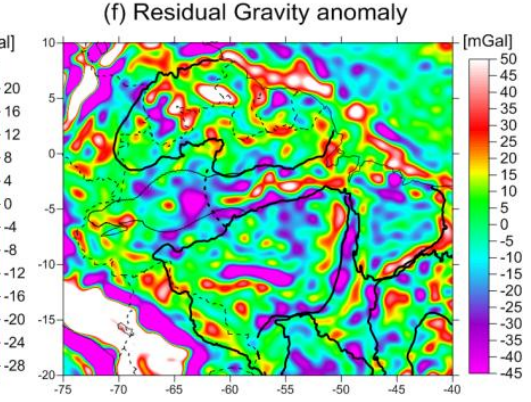

Figure VII-4: (a) Geoid calculated by harmonic expansion up to degree and order 250; (b) geoid calculated by harmonic expansion up to degree and order 10; (c) Residual geoid, being the difference (a)-(b); (d) gravity anomaly - free-air (mGal) calculated by harmonic expansion up to degree and order 250; (e) free-air anomaly (mGal) calculated by harmonic expansion up to degree and order 10 (f) Residual free-air anomaly (mGal) on Amazon and Solimões Basins, being (d)-(e). Data: GO_CONS_GCF_2_TIM_R3 (Pail et al., 2011).

The Figure VII-5 depicts the Bouguer anomaly along the profile AA' crossing the Amazon basin. The Solimões and Amazonas basins stretch for over $3000 \mathrm{~km}$ in the west-east direction and approximately $500 \mathrm{~km}$ in the north-south direction, where the sediments reach the thickness of 5,000 to 6,000 meters (Silva, 1987); in the Parnaíba Basins this thickness reaches 3,400 m (Caputo et al. 2005).

The Bouguer anomaly map displays a chain of gravity highs about $+30 \mathrm{mGal}$ to +60 $\mathrm{mGal}$ over the basin, roughly coinciding with the maximum thickness of sedimentary 
rocks, and therefore, it should outline the most central part (the trough) of the Amazon Basin. However, the gravity highs are flanked by gravity lows of $-40 \pm 20 \mathrm{mGal}$, coinciding with a thicker crust region, as reported by Lloyd et al. (2010) (Figure VII-7). The relatively high values of the Bouguer anomaly in the region of the basin indicate a crustal thinning or thickening of the crust and/or upper mantle, since the sediments would contribute to lower the signal of the Bouguer anomaly (Figure VII-2). Thus, if relatively high values of the Bouguer anomaly are observed, there must be either a shallower Moho or a crustal/upper mantle densification, to balance the negative signal produced by the sediments. This is the situation observed in the Amazon basin region. However, there is a lateral shift when we compare the position of the maximum Moho thickness beneath the basin and the position of the maximum Bouguer anomaly (Figure VII-5).

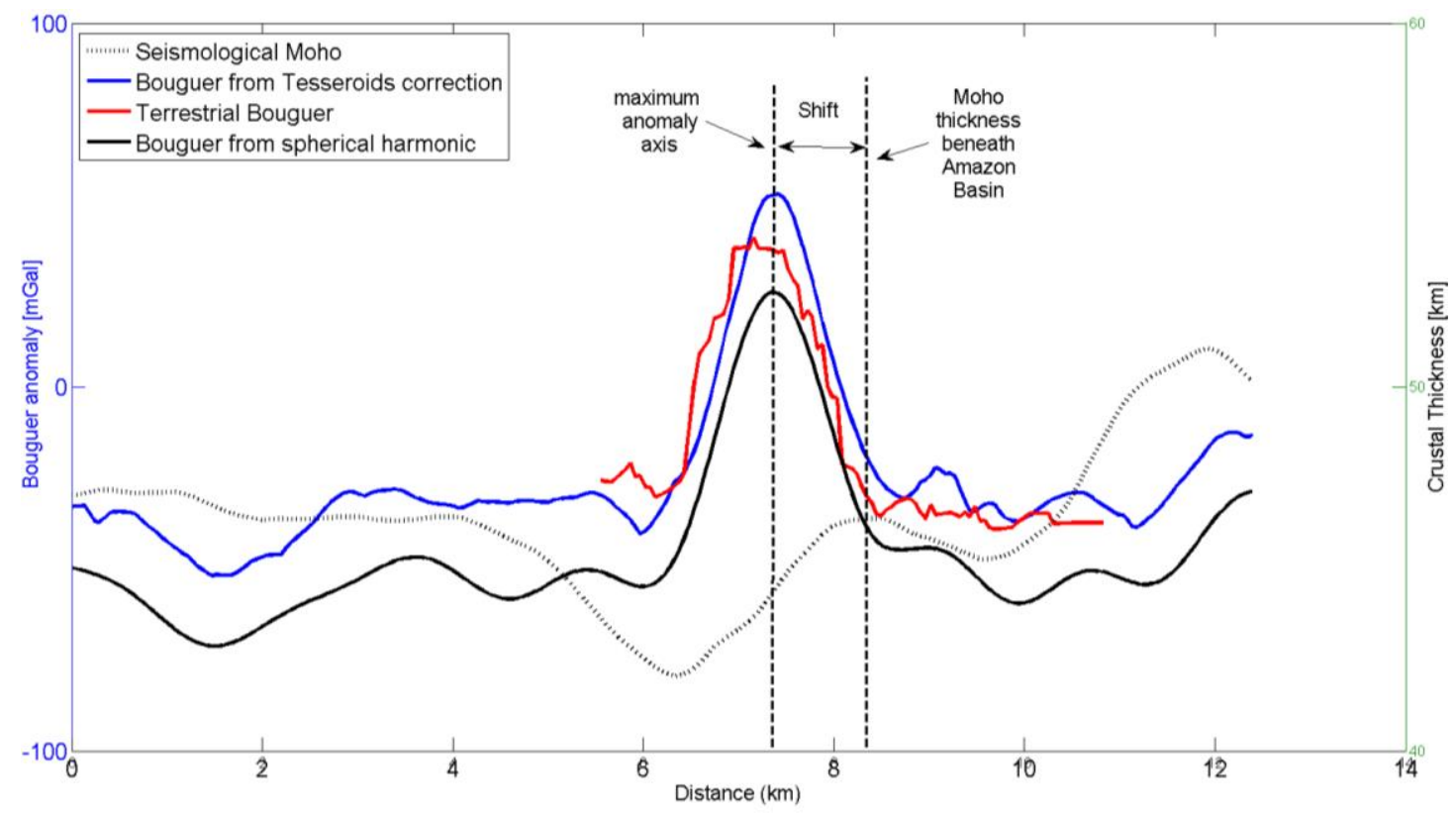

Figure VII-5: Profiles of the Bouguer anomalies presented in Figure VII-3 in comparison with the modeled crustal thickness.

The Figure VII-6(a) shows the gravity disturbance calculated by the GOCE satelliteonly model (Pail et al. 2011) up to degree and order 250, and one can see, for example, that the gravity disturbance provides a more detailed map, but the delineated features are similar to those found in the gravity anomaly maps (Figure VII-4d), since the magnitude of the gravity disturbance is directly related to the disturbing potential, and, 
in turn, the gravity anomaly can be expressed as a linear combination of the disturbing potential and its normal derivative (Heiskanen \& Moritz, 1967).

The maps showing the components of the deflection of the vertical (Figure VII-6b and c) present the north-south and east-west variations resulting from heterogeneities within the Earth. As seen in previous maps, the sediment thickness in the Solimões and Amazon Basin is characterized by these components. These quantities appear more neatly in the region of the Parnaíba Basin, identifying, for instance, in the meridian component, the east-west variations that mark the sedimentary rocks of the Parnaíba Basin. As well, we can also find tectonic structures such as the Vilhena Arch and gravity anomalies in Parecis Basin caused by sedimentary rocks deposited during Cretaceous.

Some authors (Bizzi et al., 2004) have postulated the division of the Parnaíba Basin into four sub-basins (Parnaíba, Alpercatas, Grajaú and Espigão-Mestre basins) that originated from successive basins/cycles, but this subject will not be investigated in the present work. 

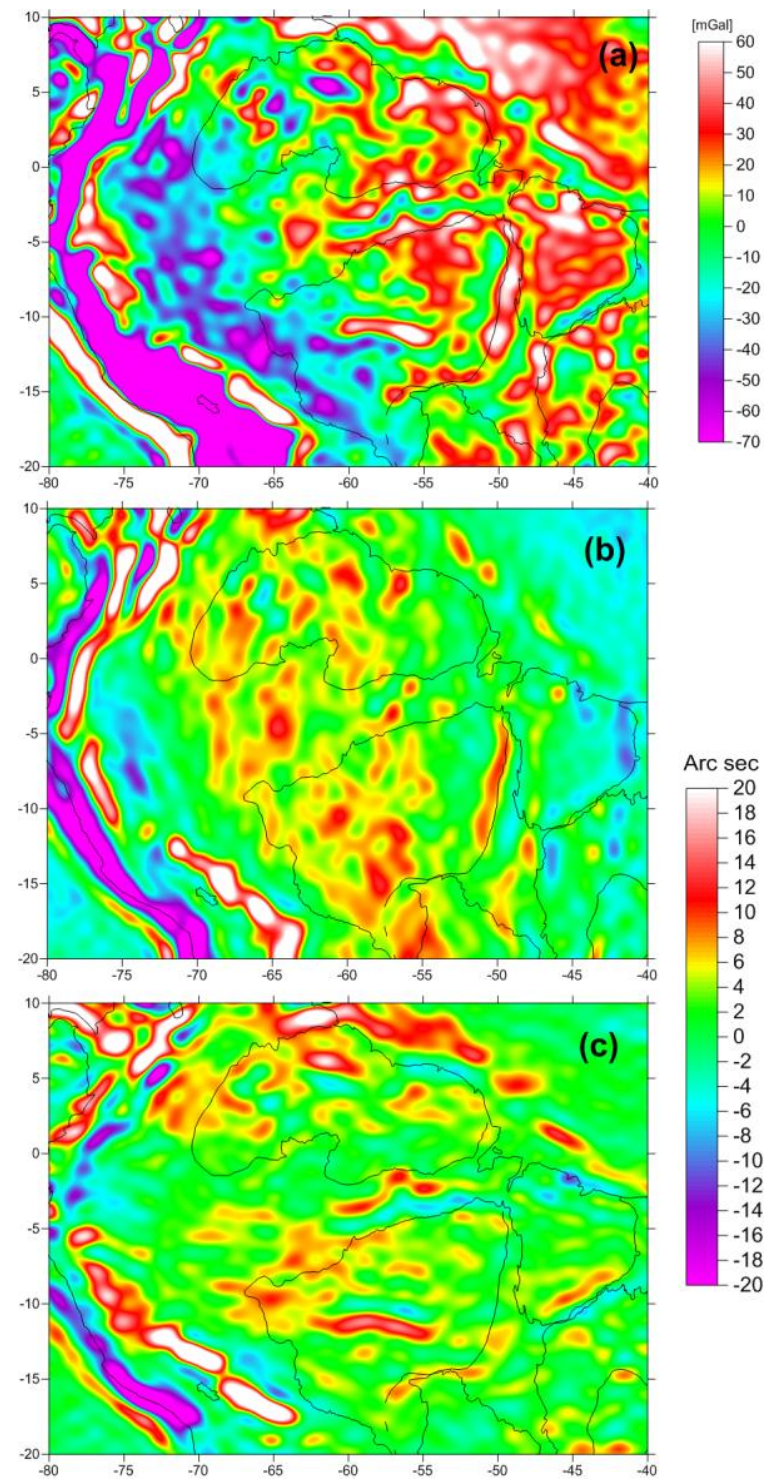

Figure VII-6: (a) Gravity disturbance; Deflection of the vertical components: (b) the meridian east/west $(\eta)$ components and (c) the prime vertical or north/south $(\xi)$. Data obtained from GO_CONS_GCF_2_TIM_R3 model (Pail et al., 2011).

The crustal thickness values were derived by Lloyd et al. (2010) from receiver functions (RF) from 20 temporary broadband seismic stations deployed across the eastern Brazil, including teleseismic and some regional events that provided the earthquake data for the RF analysis. This study has suggested that the Moho depth and the Moho relief vary slightly with the age within the Precambrian crust, and has also revealed an anomalous deep Moho beneath the oldest core of the Amazonian Craton.

These results about the variations in depth of the crust/mantle boundary (Moho) show the consistency of the gravity low and the other values already obtained with 
seismological stations within the study area. The result can be interpreted by the presence of a thinner crust towards the north of the study area, albeit the absence of more stations in the northern part of the craton does not permit the conclusion of the existence of a possible crustal thinning, and even if it exists, it is not evident whether it follows to the north direction or stays just under the intracratonic basin. Note that Moho depth thicknes along a NW-SE trend (exactly as the direction of the profile AA', which is centered on this anomaly) going through the shields and the Amazon basin, which covered an area coinciding to the portions of the Central Amazonian and VentuariTapajos Provinces.

According to Lloyd et al. (2010), the $\mathrm{Vp} / \mathrm{Vs}$ ratio is smaller in the eastern part, suggesting a differentiated lower crust of the central part of the Amazon Craton. Or rather, the Moho anomaly is weaker in the Amazon Basin compared to adjacent shields. The crustal thickness of the Amazon Craton is greater than $50 \mathrm{~km}$ towards the east of the Guyana shield increasing continuously through the Amazon Basin within the Central Brazil shield, and a high density in the lower crust or upper mantle must be taken into account.

Indeed, the northern region of Brazil has deficiency about information on crustal thickness (Moho depth) and Poisson's ratio (Vp/Vs). Such information is of great importance for characterizing the area and further to assist in the improvement of the calculated models for the region.

The Amazon and Solimões basins follow the types of deep basins with the presence of a linear gravity high that can reach $+50 \mathrm{mGal}$. The explanation given by Nunn \& Aires (1988) for this signal is a supposed rift aborted below the basin. Currently, it is known that the rifts below the Amazon, Solimões and Parnaíba Paleozoic interior basins have in their sediments intrusions of diabase sills and dykes, mainly in the form of sills, in an event known as Penatecaua Episode during late Triassic to early Jurassic (Wanderley Filho et al. 2006).

The geoid height in the Parnaíba Basin reveals a large-scale residual variation, but it does not show a clear correlation with the basin itself. In contrast, a correlation is observed in the Amazon basin (Figure VII-4).

The geoid undulations (Figure VII-4a) for the basins show greater variability, but even with the good correlation found within the basins by Braitenberg \& Ebbing (2007), the 
topographic effect, the sedimentary loads, and the high density in the lower crust and/or upper mantle appear to contribute to this variability in the geoid signature of these structures.

(a) Seismological Moho

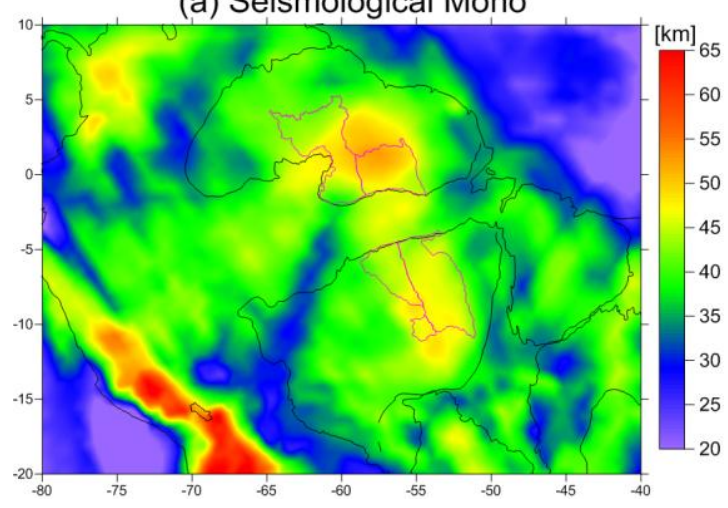

(b) Gravity from seismological Moho

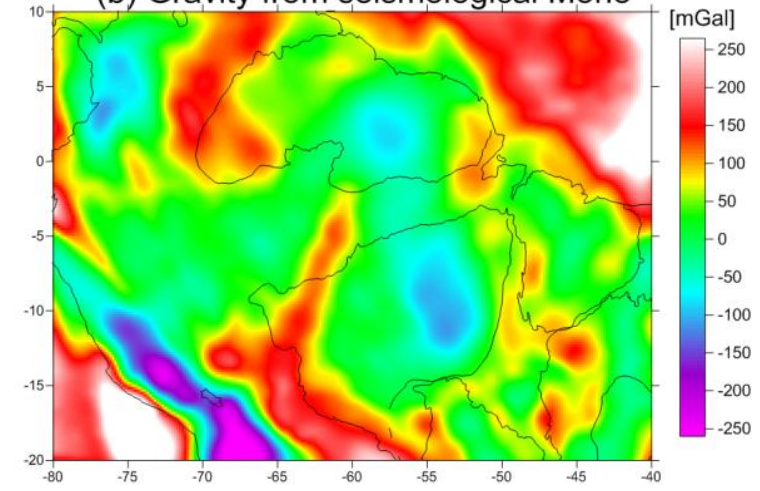

Figure VII-7: (a) Moho depth map (crustal thickness) in the Solimões, Amazonas Basin (from Lloyd et al. 2010) and the (b) gravity anomaly from it.

Indeed, we have found a pronounced low in the residual geoid in the basins studied in this work, as shown in Figure VII-4c, that displays a clear correlation between the geoid signature and the area of greatest crustal thickness (Figure VII-7), coinciding with the Tapajós-Parima and Central Amazon provinces in the Amazon Craton (purple dashed line in the figure), as proposed from a geochronological model (Bizzi et al., 2004, see Figure II-3).

In Figure VII-8 and Figure VII-9 we present all the five independent components of the gravity gradient tensor used in the interpretation process in Earth's surface and satellite height, respectively. The combinations of these gravity gradients are used to calculate the anomalous signature invariants, shown in Figure VII-10.

The rates of change of each gravity component in relation to the change in the position in the three coordinate directions were also obtained by calculating the second derivative of the gravity disturbance component obtained from the GO_CONS_GCF_2_TIM_R3 model (Pail et al. 2011). 

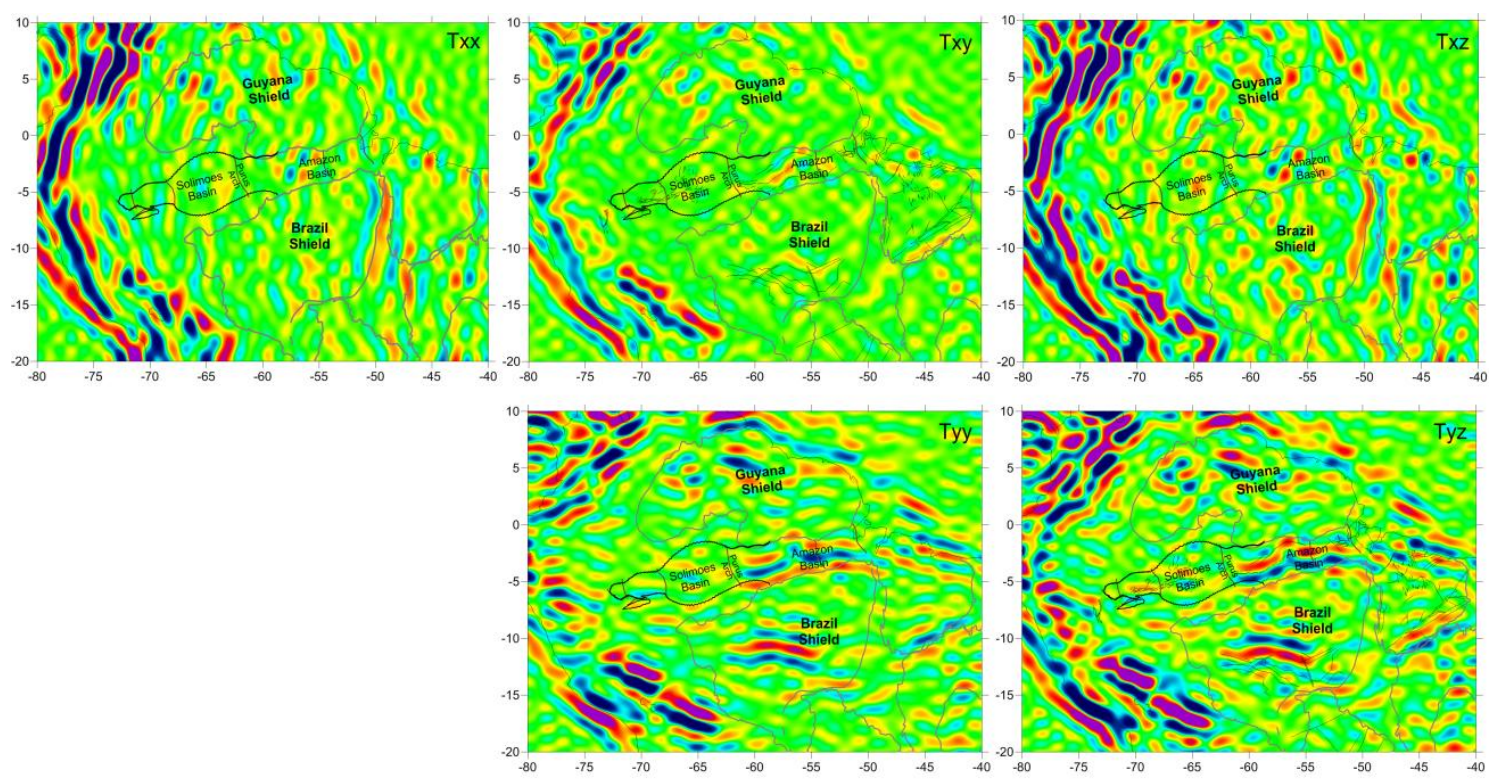

Eötvös $(E)$ ou $1 \mathrm{E}=0.1 \mathrm{mGal} / \mathrm{km}$

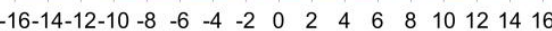

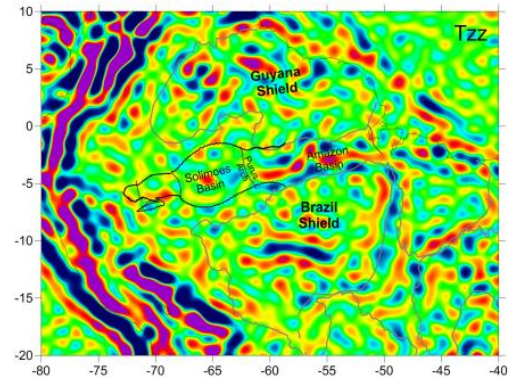

Figure VII-8: Gravity tensor components from GOCE only-satellite from GO_CONS_GCF_2_TIM_R3 (Pail et al. 2011). The Txy and Tyz components were despicted together with the major structures of the basin (black line). Data CPRM (Bizzi et al. 2004). 

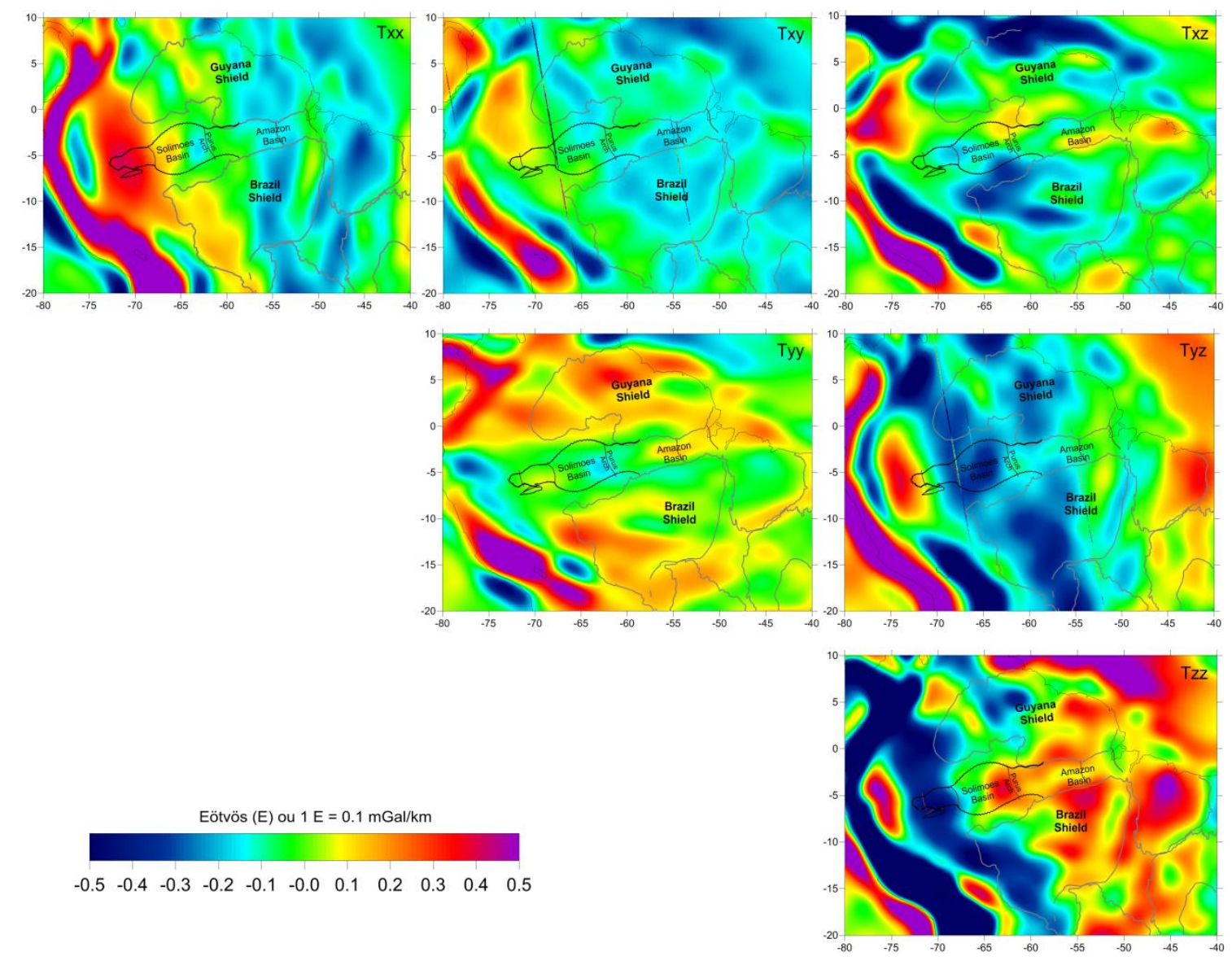

Figure VII-9: Gravity tensor components from GOCE at $250 \mathrm{~km}$ satellite height. 
(a) Horizontal amplitude

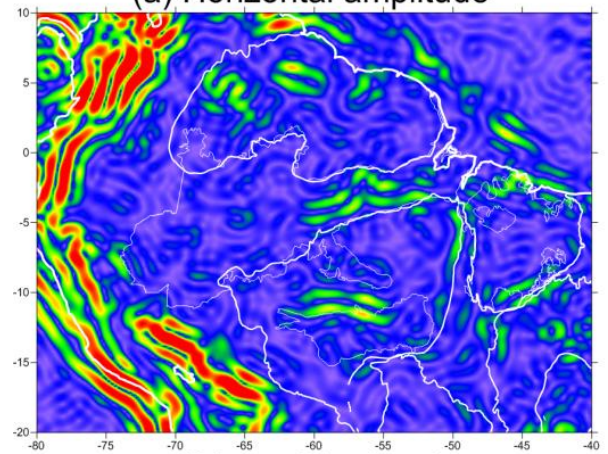

(b) Analitic signal

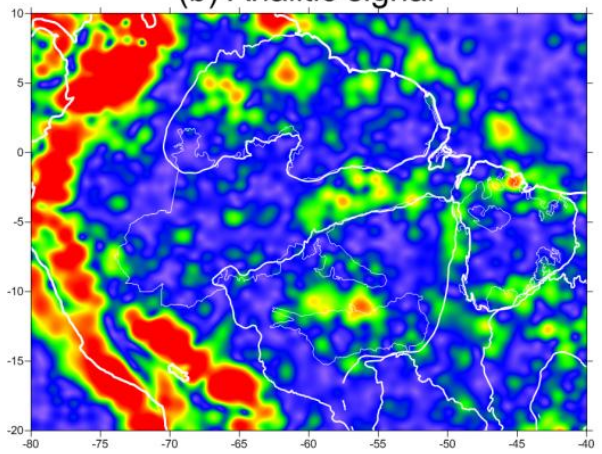

(c) Differential curvature

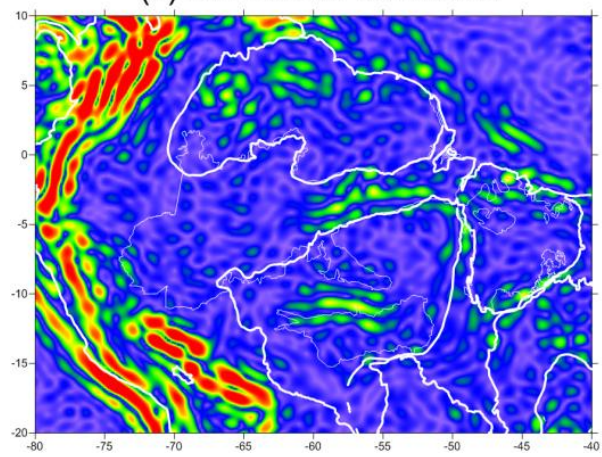

(d) Horizontal amplitude

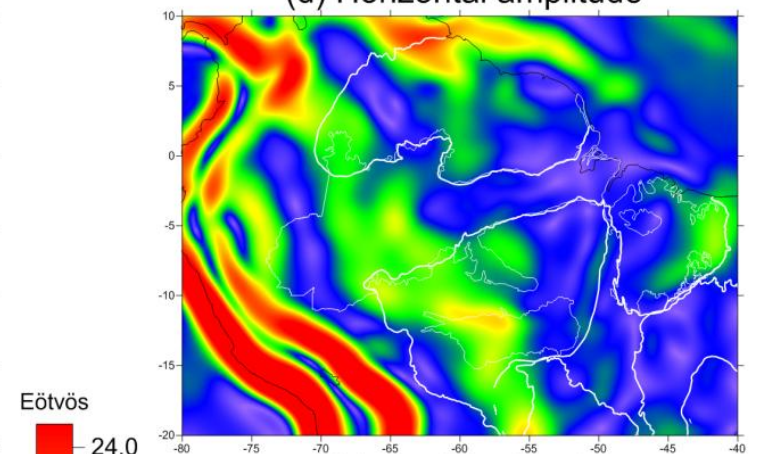

(e) Analitic signal
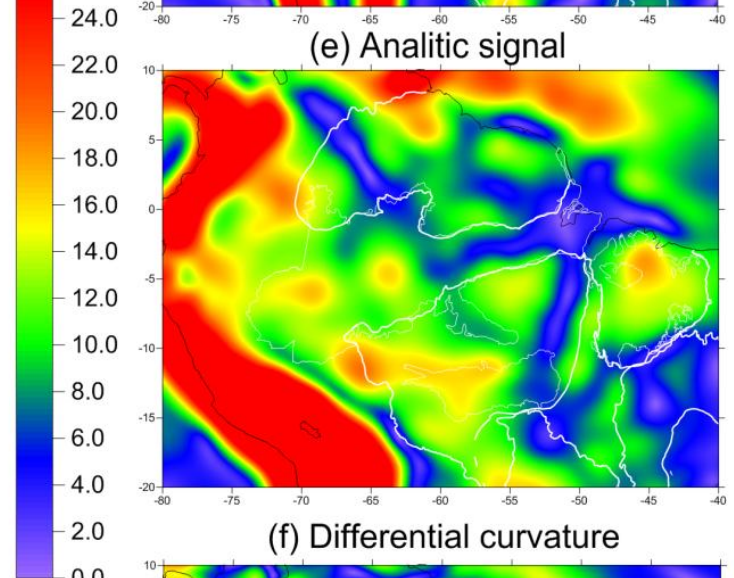

(f) Differential curvature

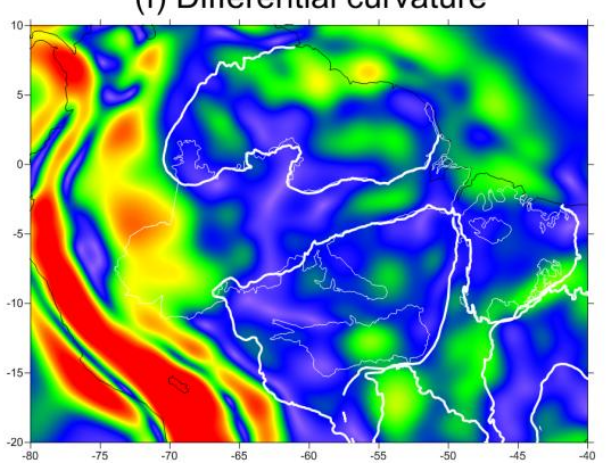

Figure VII-10: (a) Amplitude of the horizontal gradient; (b) Amplitude of the total gradient or analytic signal of $T_{z}$; and (c) The differential curvature from data obtained in Figure VII-8. (d), (e) and (f) are the same previous definitions however for the GOCE satellite height at $250 \mathrm{~km}$.

Figure VII-8 shows that the gradient tensor components have a good correlation with the structures present in the surface, as indicated by the geological studies of the region. However, as we don't have significant information about the subsurface geology, it is quite difficult to analyze the data from the individual components of the gravity gradient tensor, but the combination of the gradient components in invariants quantities (also controversy, the inavariants are contested and taken as filters) may bring an improvement to the interpretation of the gravity tensor data (Figure VII-10). Already, 
the Figure VII-9 seems to emphasize the deeper tectonic structures of the lower crust and/or upper mantle.

The amplitude of the horizontal gradient on the Amazon Basin in Figure VII-10a shows an elongated trend in the ENE-WSW direction, bounded on the north and on the south by the Guyana and Brazilian shields, respectively, on the east by the Gurupá Arch, and on the west by the Purus Arch, that are large structures pointed out by many authors (Nunn \& Aires, 1988; Wanderley Filho, 1991; Wanderley et al. 2005). While the amplitude of the horizontal gradient on the Amazon Basin at $250 \mathrm{~km}$ height, in Figure VII-10d, shows also a anomaly elongated in the ENE-WSW direction, however broader, stretching for all Amazon basin which can be representative of the deeper structures.

The analytical signal Figure VII-10b can help in the interpretation of deeper sources, and in the study region it seems to highlight the structural hinges on the floor of the basin aligned roughly parallel to the northern and southern margins, which are separated by lower relative subsidence zones (the so-called north and south platforms or shields) in relation to the deepest intermediary sector, i.e., the central trough, where the majority of the sedimentary rocks are from Paleozoic age, reaching depths that can exceed 5,000 m, as described by Cunha et al. (1994).

Figure VII-10c can be interpreted as the magnitude of the curvature of the gravity field, which strongly emphasizes the effects of shallower sources; in this case, it can be associated with outcrops and sediments of the Amazon Basin that are restricted to the edges of the basin, in areas where the rock packages are cut crosswise by drainage, or else some neo-Paleozoic quarries mining limestone, also located in the marginal zones of the basin (Cunha et al., 1994).

Obviously, only the interpretation of the gravity field elements is not feasible to characterize all the structure of these complex basins. This task only can be accomplished by the joint interpretation of the structural maps, seismic data, Bouguer anomaly, magnetic anomaly and isopach charts discussed in a few published studies or even limited to internal reports of companies bound to the exploitation of hydrocarbons such as Petrobras (for example, Aires, 1984; Linsser, 1958; Araújo, 1972; Oliveira and Castro, 1971; apud Wanderley Filho et al., 2005).

According to Wanderley Filho et al. (2005), the major NW-SE faults existent in the Amazon Basin, denominated Jari-Pacajaí, Paru-Anapu, Faro-Juruti and Manacapuru- 
Rio Negro, remained active at least until the Tertiary. They bisect and displace the depocenter of almost all the lithostratigraphic units and the axis of the positive gravity anomalies. It is postulated that the NW-SE movement would not surpass the Carboniferous. These authors postulate that analyzing the isopach maps of the PermoCarboniferous and Cretaceous-Tertiary Sequence, one can perfectly identify the influence of the transversal lineaments to the basin.

It's possible to detect positive gravity anomalies in the Iquitos, Purus and Gurupá Archs, as well as in Vilhena and Serra Formosa Archs in the Parecis Basin, Ferrer-Urbano Arch in the Parnaíba Basin and Tocantins-Araguaia Lineament limiting the Parnaíba Province to the west with the Tocantins Province. Among the large features are Purus and Gurupá Arches, and edge-faults mainly in the Amazon Basin.

Purus Arch is a structural element oriented in the NW-SE direction, separating the Amazon and the Solimões basins, and it can be easily characterized in the gravimetric maps derived from GOCE satellite-only model. In the gravimetric map this arch corresponds to a minimum Bouguer anomaly indicating that there is a thick sedimentary package below it, which was evidenced by well drillings. In the region of the arch, the basin basement consists of Middle Proterozoic sediments (Prosperança formation). The Gurupá Arch is a structural element with direction NW-SE defining the boundary between the Amazon Basin and the Marajó Graben. This feature is clearly identified from the seismic interpretation and borehole data (Wanderley filho et al. 2005), and also from the gravimetry data (Figure VII-4, Figure VII-6 and Figure VII-8).

We have obtained a new representation of the gravity field by applying a topographic correction to the data calculated at the altitude of the GOCE satellite. This procedure involves the calculation of the equivalent free-air anomaly derived from the geopotential model (Pail et al., 2011) at the height of $250 \mathrm{~km}$. After that, the topographic masses effect at $250 \mathrm{~km}$ was removed, so that, a "Bouguer anomaly equivalent" at $250 \mathrm{~km}$ was obtained.

One should notice that the anomalous gravity low in the northern of the Amazon craton (Guyana Shield) highlights the Marioni-Itacaiunas and Central Amazonian structures, as defined in Cordani et al. (2007). Other structure that is well delineated is the continuation of the Amazonian Province into the Brazil Shield. This suggests that these structures, which are nowadays separated by sedimentary basins, have deeper 
corresponding parts. This may corroborate the assumptions that these blocks, indeed, are separated in the Amazon Basin region, where there may have been a transcurrent movement, as described in Lobato (2011). Another obtained model, correspondent to the terrain reduction for the $\mathrm{V}_{\mathrm{zz}}$ gravity component on the Earth's surface and at the satellite altitude, also highlights these structures, and may be detecting some anomalous mass distributions present in the lower crust and/or upper mantle in that region.

The isostatic anomaly model representing the mantle and crustal masses also shows this pattern, corroborating the idea of a crust thickening due to the possible movement of the molten magma rising from the mantle into the basin during the opening of the South Atlantic, what should have reactivated the pre-existent weakness zones, permitting the relative movements of these large blocks.

(a) Equivalent to Bouguer anomaly at height of $250 \mathrm{~km}$

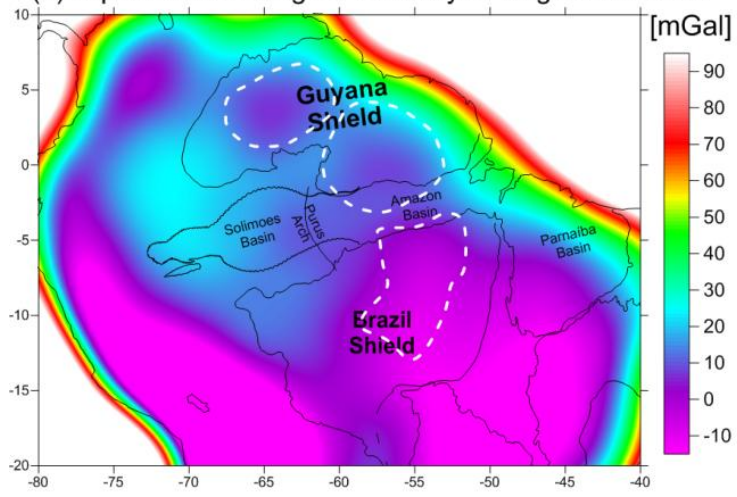

(c) Tzz component corrected topography at height $250 \mathrm{~km}$
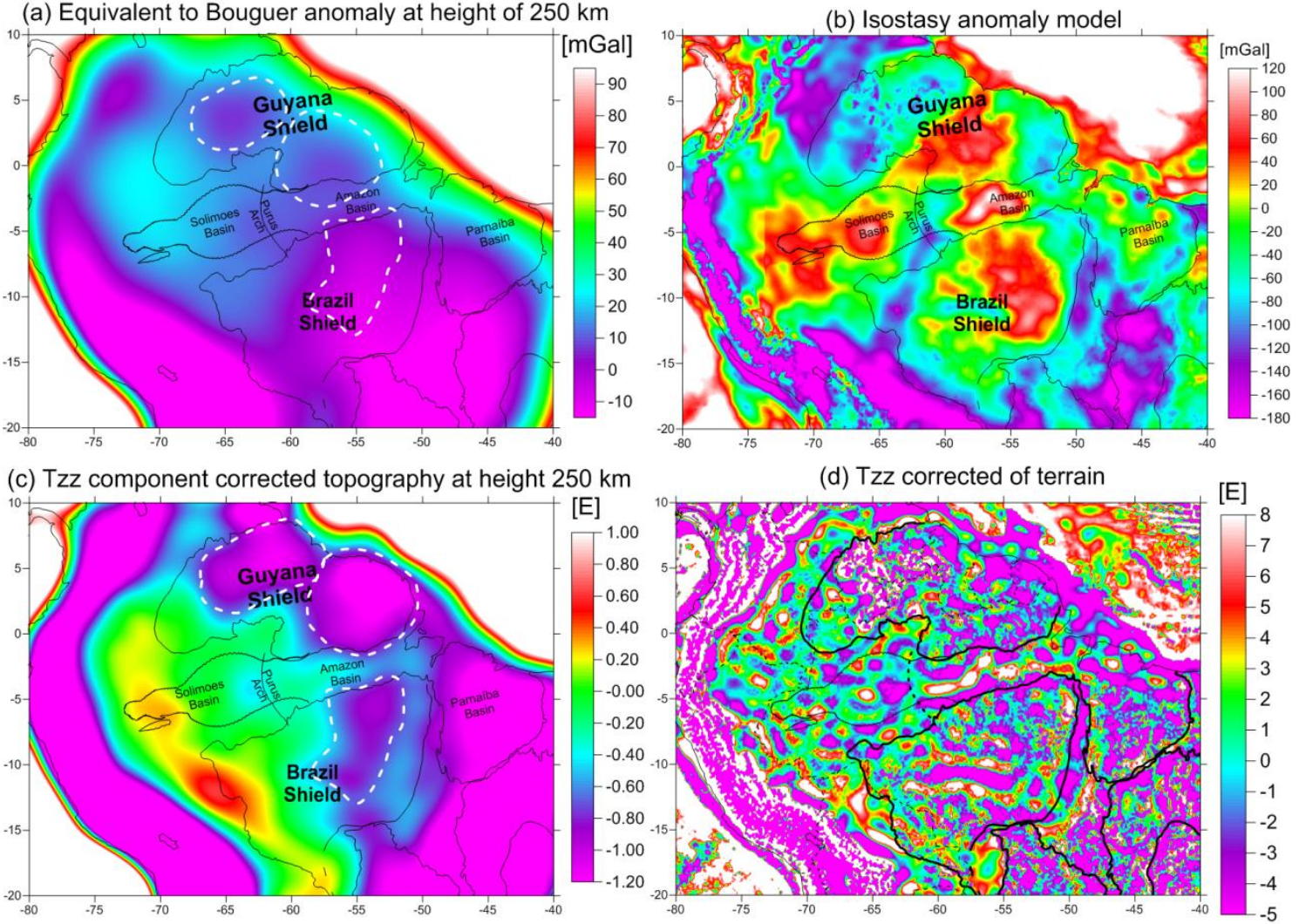

Figure VII-11: (a) An "equivalent Bouguer anomaly" at the height of $250 \mathrm{~km}$; (b) The gravity isostatic model; (c) $V_{z z}$ calculated at the height of the GOCE satellite $(250 \mathrm{~km})$ and (d) $V_{z z}$ calculated at the surface (both (c) and (d) corrected for the effect of the topographic masses in the respective height). (Dotted white lines show the probable structures of the mantle inferred in the present study) 
This result shows that the $\mathrm{V}_{\mathrm{zz}}$ component corrected for the effect of the terrain permitted to highlight the edges of the main cratons and provinces within the study area. The isostastic anomaly shows that the area should be slightly in equilibrium for all Amazonian craton, but there might be a large structure in the lower crust and upper mantle around the northern and southern part of the Amazon Basin where the topographic loads should be overcompensated (this can be inferred from the positive anomalies that exist in these regions).

This anomalous pattern follows its exposures straddle along a NW-SE trend approximately $2100 \mathrm{~km}$ long and $800 \mathrm{~km}$ wide involving parts of Brazil, Suriname, Guyana and Venezuela coinciding to the western and east portions, respectively, of the Central Amazonian and Ventuari-Tapajos Provinces into Amazonian Craton (as defined by Cordani and Teixeira, 2007 in Figure II-4).

\section{VII.3. Challenges and Limitations}

The challenges in the methodology used in this work came from the possibility of applying the principle of Satellite Gravity Gradiometry (SGG) in the study of large sedimentary basins. The SGG collected by the GOCE Mission with a tri-dimensional (3-D) gradiometer aims to measure the gravity gradient components of the Earth's gravity field, providing a new regional aspect for the most accurate global geopotential models, and important along-tracks measurements at the height of approximately 250 $\mathrm{km}$.

This task for itself is already a challenging one, and, additionally, we had a delay in the availability of the along-track gravity gradients measured by the GOCE satellite due to the (successive) delay in the launching of the GOCE mission. As an alternative, we had to work with the existing geopotential models obtained from data of other gravity missions, such as the GRACE mission. When the Level 2 Products became available, there were many problems to the preparation of the GOCE data, since the GOCE Level 2 Product Data was in XML data files (EGG_NOM_2) and had to be converted into ASCII files or equivalent, to be adequately processed. The analysis and the processing of these huge quantity of data for searching and calculating the corrections for the crossovers errors was a very complicated task, and demanded a lot of (precious) time in the present work, as it should demand in the future in any work involving these valuable data. 


\section{VII.4. Significant Contributions and Insights}

The first contributions of the present work were added to the original work flow of the thesis due to the delay in the launching and in the calibration of the GOCE mission, and consisted in an important aspect: the comparison of the main available Global Gravity Models (for example, EGM2008 (Pavlis et al., 2008)) in the study area with the available terrestrial data, that has detailed and accurate information on the shortwavelength part of the field. After the release of the first reliable GOCE models (Pail et al., 2011), this analysis was extended to these models, helping in evaluating areas where the terrestrial data has problems (See more details in Appendix A).

After the release of the Level 2 products, the original research proposal could be revisited, and the results so obtained showed that the use of this kind of data can contribute to the improvement of the understanding of the solid Earth processes, in particular those that occur in the lithosphere and the upper mantle underlying large sedimentary basins.

\section{VII.5. Recommendations for Future Research}

The upward continuation of the TGG data reduces the effects of noise and density variations near the Earth's surface (that are caused mainly by the attraction of the Earth's topographic and/or isostatic masses), and it improves the representation of the gravity field from mass heterogeneities signals present in deeper anomalous sources, like the lower crust and the upper mantle.

One approach that could be recommended involves the inverse process, consisting in analyzing the gravity gradients measured by GOCE mission, at the satellite height (about $250 \mathrm{~km}$ ), in order to obtain the equivalent values of these quantities referenced to the mean sea level (MSL). This is not a trivial task because it is an ill-posed problem regarding the numerical stability in the gravity modelling. According to Grombein et al. (2011), the harmonic downward continuation can be done by smoothing the observed GGT GOCE data using the topographic and the isostatic reductions, in a removerestore technique.

Also, is should be very important to adjust the multi-component gravity gradiometer along-track data provided by the GOCE mission to adequately recover the threedimensional (3-D) density distribution in large geological structures. 
This work has shown that the gravity field elements obtained from the GOCE mission can improve the knowledge about the deep Earth's structures, such as the crust/mantle boundary and the neighborhood. The improvement to the field was obtained through the low orbit altitude and the gradiometric observations on board the satellite. It is particularly apt for recovering density variations in the earth's crust and mantle. As an example of the potential of this methodology in the characterization of large geological provinces, we have obtained results that recover an old 'surpassed' idea that stated that the northern and southern portion of the Amazonian craton, separated by the Solimões and Amazonas basins, would be two different blocks, and that these basins had originated at the borders of these two portions.

In the past, this discussion had not evolved because the evidences shown by the traditional Amazonian Craton geology has been entirely built from a few geophysical (some gravity, scarce magnetic and seismic), petrological and geochronological data, collected exclusively with the purpose of helping the mining and the exploration of hydrocarbons in the Amazon basin and the Carajas Mineral Province (considered the largest mineral province in the world). So, even the sparse available data distribution is restricted and limited to the sedimentary basin and some mining field, and does not permit the characterization of this large and geologically complex region.

Variations in the crustal thickness usually obey the isostatic response due to crustal stretching and the mass deficit due to the basin filling with lighter sediments, that accompanies downward deflection of the basin-basement associated with the subsidence. Instead of crustal thinning, high density masses in the crust and mantle appear to be a typical feature present in the large sedimentary basins, caused either by the presence of an intermediate density intruded material or by a partial replacement of the lower crust by the mantle material, continental underplating, or passive upwelling of molten magma during rifting and extension of the lithosphere (Nunn and Aires, 1988; Braitenberg \& Ebbing 2007).

Recent new paleomagnetic evidences for the Amazon craton is challenging the scientific geological and geophysical community. Although the rocks of the northern portion of the craton (Guiana Shield) and the rocks of the southern portion (Brazilian Shield) have ages of settlement that are close together, which corroborates the idea of a single cratonic block, the paleomagnetic poles obtained from rocks of these regions point out that in a certain geological period a transcurrent 
motion between these blocks must have occurred (Ricardo Trindade, 2012, personal communication). This could be the result of the relative movements of the Guiana Shield, situated at the north of the Amazon basin, and the Brazilian Shield, situated at the south. Although this is only a preliminary additional evidence that points to the controversial hypothesis of the existence of these blocks, one should notice that, as pointed out by Lobato (2011), all the types of geophysical data that were available in the past in these regions were so bad in quality and in distribution that even broad structures could not be detected at that time. 


\section{BIBLIOGRAPHY}

Akima, H., 1972. Algorithm 433: interpolation and smooth curve fitting based on local procedures [E2]. Commun. ACM, \#oct\#, 15(10), pp. 914-918.

Albertella, A., Migliaccio F., Sansò F., Tscherning C.C., 2000. The space-wise approach - Overall scientific data strategy, in: From Eötvös to mGal, Final report, ESA/ESTEC Contract No. 13392/98/NL/GD, Ed. H.Sünkel.

Alves, D. B. \& Vaz, P. T., 2006. "Folhelhos verdes" carboníferos da Bacia do Solimões: cinzas vulcânicas (K-bentonitas)/Carboniferous "green shales" of the Solimões Basin: volcanic ashes (Kbentonites). B. Geoci. Petrobras, nov. 2005/maio 2006, 14(1), pp. 171-176.

Amante, C. \& Eakins, B. W., 2008. ETOPO1 1 Arc-Minute Global Relief Model: Procedures, Data Sources and Analysis. Boulder, CO: National Geophysical Data Center, NESDIS, NOAA, U.S. Department of Commerce.

Amaral, G., 1974. Geologia Pré-Cambriana da região amazônica. s.l.:Universidade de São Paulo.

Anderson, E., 1976. The effect of topography on solutions of Stokes' problem., Kensington: s.n.

Asgharzadeh, M. F. et al., 2007. Spherical prism gravity effects by Gauss-Legendre quadrature integration. Geophysical Journal International, 169(1), pp. 1-11.

Barthelmes, F., 2009. Definition of Functionals of the Geopotential and Their Calculation from Spherical Harmonic Models: Theory and Formulas Used by the Calculation Service of the International Centre for Global Earth Models (ICGEM), Http://icgem.gfz-potsdam.de. s.1.:GFZ.

Bell, R. E., 1998. Gravity gradiometry. Scientific American, \#jun\#, 278(6), pp. 74-79.

Bell, R. E., Anderson, R. \& Pratson, L., 1997. Gravity gradiometry resurfaces. The Leading Edge, 16(1), pp. 55-59.

Biancale, R. et al., 2000. A new global Earth's gravity field model from satellite orbit perturbations: GRIM5-S1. Geophys. Res. Lett., 27(22), pp. 3611-3614.

Bispo-Santos, F. et al., 2012. Tectonic implications of the 1419 Ma Nova Guarita mafic intrusives paleomagnetic pole (Amazonian Craton) on the longevity of Nuna. Precambrian Research, 196-197(0), pp. 1-22.

Bizzi, L., Schobbenhaus, C., Vidotti, R. \& Gonçalves, J., 2004. Geologia, tectônica e recursos minerais do Brasil: texto, mapas $\backslash \&$ SIG. 1 ed. s.l.:Serviço Geológico do Brasil, CPRM, Ministério de Minas e Energia, Secretaria de Minas e Metalurgia. 
Bouman, J. et al., 2005. Calibration and Validation of GOCE Gravity Gradients. In:: SansFernando, ed. International Association of Geodesy Symposia. s.1.:Springer Berlin Heidelberg, pp. 265-270.

Bouman, J. et al., 2009. Preprocessing of gravity gradients at the GOCE high-level processing facility. Journal of Geodesy, \#jul\#, 83(7), pp. 659-678.

Bowin, C., 1983. Depth of principal mass anomalies contributing to the earth's geoidal undulations and gravity anomaliesâ^—. Marine Geodesy, 7(1-4), pp. 61-100.

Braga, M. A. S., 2006. Modelagem numérica e validação de dados tensoriais de aerogradiometria gravimétrica $3 D-F T G$, Rio de Janeiro: s.n.

Braitenberg, C. \& Ebbing, J., 2007. The Gravity Potential Derivatives as a Means to Classify the Barents Sea Basin in the Context of Cratonic Basins. EGM 2007 International Workshop Innovation in EM, Grav and Mag Methods:a new Perspective for Exploration. Capri, Italy, s.n.

Braitenberg, C. et al., 2007. JOINT GRAVITY AND ISOSTATIC ANALYSIS FOR BASEMENT STUDIES - A NOVEL TOOL. s.l., s.n.

Bruinsma, S. et al., 2010. 2010. Bergen, Noway, s.n.

Caputo, M., Iannuzzi, R. \& Fonseca, V., 2005. Bacias sedimentares brasileiras: Bacia do Parnaíba.. Fundação Paleontológica Phoenix, ano 7(81), p. 6pp..

Clancy, T., 1984. The hunt for Red October. Annapolis, Md. :: Naval Institute Press.

Clancy, T., 1984. The hunt for Red October / Tom Clancy. Annapolis, Md. :: Naval Institute Press.

Cordani, U. G. \& Teixeira, W., 2007. Proterozoic accretionary belts in the Amazonian Craton. Geological Society of America Memoirs, \#jan\#, Volume 200, pp. 297-320.

Cordani, U. et al., 1979. Evolução Tectônica da Amazônia com Base nos Dados Geocronológicos. In: Congreso Geológico Chileno, 2, Arica, Anais, 137-138.. s.1., Arica, Chile, pp. 137-138.

Cordani, U., Teixeira, W., D'Agrella-Filho, M. \& Trindade, R., 2009. The position of the Amazonian Craton in supercontinents. Gondwana Research, \#jun\#, 15(3â€“4), pp. 396-407.

Coutinho, M., 2008. Província Mineral do Tapajós: geologia, metalogeniae mapa previsional para ouro em SIG. Rio de Janeiro: CPRM.

Cunha, P., Gonzaga, F., Coutinho, L. \& Feijó, F., 1994. Bacia do Amazonas. Boletim de Geociências da PETROBRAS, Volume 8, pp. 47-55. 
de Matos, R. M. D. \& Brown, L. D., 1992. Deep seismic profile of the Amazonian Craton (northern Brazil). Tectonics, 11(3), pp. 621-633.

Dickinson, J. L., Brewster, J. R., Robinson, J. W. \& Murphy, C. A., 2009. Imaging Techniques for Full Tensor Gravity Gradiometry Data. 11th SAGA Biennial Technical Meeting and Exhibition, Issue September, pp. 84-88.

Divins, D., 2003. Total Sediment Thickness of the World's Oceans $\backslash \&$ Marginal Seas. Boulder, CO., NOAA National Geophysical Data Center.

Eiras, J., 1996. Influência tectônica do arco de Carauari na sedimentação fanerozóica da bacia do Solimões, Norte do Brasil. Salvador, Brasil, Abstracts Volume, pp. pp. 50-53..

Eiras, J. et al., 1994. Bacia do Solimões. Boletim de Geociências da Petrobras, 8(1), pp. 17-45.

Eiras, J. \& Wanderley Filho, J. R., 2006. Bacias sedimentares brasileiras: Bacia do Solimões. Fundação Paleontológica Phoenix, ano 8(nº 85), p. 6pp.

Eötvös, L. \& Szabó, Z., 1998. Three fundamental papers of Loránd Eötvös. Budapest: Eötvös Loránd Geophysical Institute of Hungary.

ESA, 1999. Gravity field and steady-state ocean circulation mission (GOCE), Report for mission selection, in: The four candidate Earth explorer core missions SP-1233 (1), s.l.: European Space Agency.

Fischer, G. e. a., 1996. Report and Preliminary Results of the METEOR-Cruise M 34/4, RecifeBridgetown, 19.3.-15.4.1996. Bremen: s.n.

Forsberg, R., 1984. A Study of Terrain Reductions, Density Anomalies and Geophysical Inversion Methods in Gravity Field Modelling. Reports of the Department of Geodetic Science and Surveying, No. 355, The Ohio State University, Columbus, Ohio.

Förste, C. et al., 2011. EIGEN-6 - A new combined global gravity field model including GOCE data from the collaboration of GFZ Potsdam and GRGS Toulouse.. Munich 2011, s.n.

Förste, C. et al., 2008. The GeoForschungsZentrum Potsdam/Groupe de Recherche de Gèodésie Spatiale satellite-only and combined gravity field models: EIGEN-GL04S1 and EIGEN-GL04C. Journal of Geodesy, Volume 82, pp. 331-346.

Francis, E. H., 1982. Magma and sediment-I Emplacement mechanism of late Carboniferous tholeiite sills in northern Britain: President's anniversary address 1981. Journal of The Geological Society, Volume 139, pp. 1-20. 
Grombein, T., Seitz, K. \& Heck, B., 2010. Modelling topographic effects in GOCE gravity gradients, Potsdam: GEOTECHNOLOGIEN.

Grombein, T., Seitz, K. \& Heck, B., 2011. Smoothing GOCE Gravity Gradients by Means of Topographic-isostatic Reductions. s.1., s.n.

Groten, E., 1989. Airborne and satellite borne gravimetric studies. Advances in Space Research, 9(1), pp. 17-27.

Gruber, T. et al., 2000. GRIM5-C1: Combination solution of the global gravity field to degree and order 120. Geophys. Res. Lett., 27(24), pp. 4005-4008.

Gruber, T., Rummel, R., Abrikosov, O. \& Hees., R. v., 2009. GOCE Level 2 Product Data Handbook GO-MA-HPF-GS-0110, s.1.: s.n.

Gruber, T., Rummel, R., Abrikosov, O. \& van Hees., R., 2009. GOCE Level 2 Product Data Handbook GO-MA-HPF-GS-0110, s.1.: s.n.

Hammer, S., 1939. Terrain corrections for gravimeter stations. Geophysics, 4(3), pp. 184-194.

Hammond, S. \& Murphy, C., 2003. Air-FTG ${ }^{\mathrm{TM}}$ : Bell Geospace's airborne gravity gradiometer - a description and case study. ASEG Preview, 105(105), pp. 24-26.

Heck, B. \& Seitz, K., 2007. A comparison of the tesseroid, prism and point-mass approaches for mass reductions in gravity field modelling. Journal of Geodesy, Volume 81, pp. 121-136.

Heiskanen, W. A. \& Moritz, H., 1967. Physical Geodesy. 1993 reprint ed. San Francisco: W.H. Freeman.

Helmert, F., 1884. Die mathematische und physikalische Theorien der hoheren Geodasie. Volume 2 .

Hopkins, J., 1975. Gravity Gradiometry - A Rebirth.. Canadian Journal of Exploration Geophysics, v. 11(n. 1), pp. p. 34-37.

Huang, J., Véronneau, M. \& Mainville, A., 2008. Assessment of systematic errors in the surface gravity anomalies over North America using the GRACE gravity model. Geophysical Journal International, 175(1), pp. 46-54.

Hwang, C., Wang, C.-G. \& Hsiao, Y.-S., 2003. Terrain correction computation using Gaussian quadrature. Computers \&amp; Geosciences, \#dec\#, 29(10), pp. 1259-1268. 
Jarecki, F. \& Muller, J., 2008. Robust Trend Estimation from GOCE SGG Satellite Track CrossOver Differences. In:: M. G. Sideris, ed. International Association of Geodesy Symposia. s.1.:Springer Berlin Heidelberg, pp. 363-369.

Jarecki, F., Wolf, K., Denker, H. \& Muller, J., 2006. Quality Assessment of GOCE Gradients. In Flury J, Rummel R, Reigber C, Rothacher M, Boedecker G, Schreiber U (eds.). In:: Observation of the Earth System from Space. Springer, Berlin Heidelberg New York: s.n.

Jekeli, C., 1981. Alternative methods to smooth the Earth's gravity field, 19820014947: s.n.

Jekeli, C. \& Zhu, L., 2006. Comparison of methods to model the gravitational gradients from topographic data bases. Geophysical Journal International, 166(3), pp. 999-1014.

Jorgensen, G., Kisabeth, J. \& Routh, P., 2001. The role of potential field data and joint inverse modelling in the exploration of the deepwater Gulf of Mexico mini-basin province. Petroleum Frontiers, 17(4), pp. 18-35.

Keller, W. \& Sharifi, M., 2005. Satellite gradiometry using a satellite pair. Journal of Geodesy, Volume 78, pp. 544-557.

Kiamehr, R., 2006. The impact of lateral density variation model in the determination of precise gravimetric geoid in mountainous areas: a case study of Iran. Geophysical Journal International, Volume 167, pp. 521-527.

Kiamehr, R. \& Eshagh, M., 2008. EGMlab, a scientific software for determining the gravity and gradient components from global geopotential models. Earth Science Informatics, Volume 1, pp. 93-103.

Kiamehr, R., Eshagh, M. \& Sjoberg, L. E., 2008. Interpretation of general geophysical patterns in Iran based on GRACE gradient component analysis. Acta Geophysica, Volume 56, pp. 440-454.

Koop, R., Bouman, J., Schrama, E. \& Visser, P., 2002. Calibration and error assessment of GOCE data, in Vistas for Geodesy in the New Millenium, edited by J. Adam and K.-P. Schwarz, vol. 125 of International Association of Geodesy Symposia. Springer.pp. pp. 167-174.

Koop, R., Gruber, T. \& Rummel, R., 2007. The status of the GOCE hibgh-level processing facility. Frascati, Italy, s.n.

Lambert, W. O., 1930. The reduction of observed values of gravity to sea level. Journal of Geodesy, Volume 26, pp. 107-181.

Laske, G. \& Masters, G., 1997. A Global Digital Map of Sediment Thickness. s.1., s.n. 
Lee, J., 2001. FALCON gravity gradiometer technology. Explor. Geophys., \#jan\#, 32(4), pp. $247-$ 250.

Lemoine, F. et al., 1998. The Development of the Joint NASA, GSFC and NIMA Geopotential Model EGM96, Greenbelt, MD, USA: s.n.

Lerch, F., Wagner, C., Richardson, J. \& Brownd, J., 1974. Goddard Earth Models (5 and 6), Greenbelt/Maryland: s.n.

Lloyd, S. et al., 2010. Moho map of South America from receiver functions and surface waves. $J$. Geophys. Res., \#nov\#, 115(B11), pp. B11315--.

Lobato, F., 2011. Shale gas, oil, minerals processing offer synergies in Brazil's Amazon basins. Oil I\& Gas Journal, 109(10), pp. 54-67.

Martinec, Z., 1993. The stokes problem with 3D Newtonian rheology in a spherical shell. Computer Physics Communications, Volume 76, pp. 63-79.

Martinec, Z., 1998. Boundary value problems for gravimetric determination of a precise geoid. Lecture notes in Earth Sciences, vol 73. Springer, Berlin Heidelberg New York.

Milani, E. \& Zalán, P., 1999. An outline of the geology and petroleum systems of the Paleozoic interior basins of South America. Episodes, 22(3), pp. 199-205.

Montana, C., 1992. Program to calculate the gravitational field and gravity gradient tensor resulting from a system of right rectangular prisms. Computers \& Geosciences, Volume 18, pp. 587-602.

Moritz, H., 2000. Geodetic Reference System 1980.

Murphy, C. A., 2007. Interpreting FTG Gravity data using horizontal Tensor components. s.1., s.n.

Murphy, C. A. \& Brewster, J. R., 2007. Target Delineation using Full Tensor Gravity Gradiometer data. s.l., s.n.

Nabighian, M. N. et al., 2005. Historical development of the gravity method in exploration. Geophysics, 70(6), pp. 63ND-89ND.

Nagy, D., Papp, G. \& Benedek, J., 2000. The gravitational potential and its derivatives for the prism. Journal of Geodesy, Volume 74, pp. 552-560.

Nagy, D., Papp, G. \& Benedek, J., 2002. Corrections to "The gravitational potential and its derivatives for the prisma". Journal of Geodesy, Volume 76, pp. 475-475.

Nunn, J. A. \& Aires, J. R., 1988. Gravity Anomalies and Flexure of the Lithosphere at the Middle Amazon Basin, Brazil. J. Geophys. Res., 93(B1), pp. 415-428. 
Pail, R., 2005. A parametric study on the impact of satellite attitude errors on GOCE gravity field recovery. Journal of Geodesy, Volume 79, pp. 231-241.

Pail, R. et al., 2011. First GOCE gravity field models derived by three different approaches. Journal of Geodesy, 10, 85(11), pp. 819-843.

Pavlis, N.K., Holmes, S.A., Kenyon, S.C., and Factor, J.K., 2008. An Earth Gravitational Model to Degree 2160: EGM2008, presented at the 2008 General Assembly of the European Geosciences Union, Vienna, Austria, April 13-18.

Pavlis, N. K., Holmes, S. A., Kenyon, S. C. \& Factor, J. K., 2012. The development and evaluation of the Earth Gravitational Model 2008 (EGM2008). Journal of Geophysical Research, \#apr\#, 117(B4), p. B04406+.

Pedersen, L. B. \& Rasmussen, T. M., 1990. The gradient tensor of potential field anomalies; some implications on data collection and data processing of maps. Geophysics, 55(12), pp. 1558-1566.

Petrovskaya, M. S. \& Vershkov, A. N., 2006. NonSingular Expressions for the Gravity Gradients in the Local North-Oriented and Orbital Reference Frames. Journal of Geodesy, Volume 80, pp. 117127.

Reed, G. B., 1973. Application of kinematical geodesy for determining the shorts wave length components of the gravity field by satellite gradiometry. Ohio State University, Department of Geodesy, Science, Report No. 201, Columbus, Ohio.

Reigber, C., Lühr, H. \& Schwintzer, P., 2002. CHAMP mission status. Advances in Space Research, 30(2), pp. 129-134.

Rogers, M., 2009. An investigation into the feasibility of using a modern gravity gradient instrument for passive aircraft navigation and terrain avoidance, Wright-Patterson Air Force Base, Ohio: Air Force Institute of Technology.

Rummel, R., 1986. Satellite gradiometry. In:: H. Sankel, ed. Mathematical and Numerical Techniques in Physical Geodesy. s.1.:Springer Berlin / Heidelberg, pp. 317-363.

Rummel, R. et al., 2002. Dedicated gravity field missions - principles and aims. Journal of Geodynamics, 33(12), pp. 3-20.

Saad, A., 2006. Understanding gravity gradients — a tutorial. Leading Edge, 25(8), p. 942-949. 
Santos, J. O. S. et al., 2000. A New Understanding of the Provinces of the Amazon Craton Based on Integration of Field Mapping and U-Pb and Sm-Nd Geochronology. Gondwana Research, 3(4), pp. 453-488.

Silva, O. B., 1987. Análise da Bacia do Solimões: revisão litoestratigráfica, magmatismo e geoquímica, Ouro Preto: s.n.

Smith, D. A., Robertson, D. S. \& Milbert, D. G., 2001. Gravitational attraction of local crustal masses in spherical coordinates. Journal of Geodesy, Volume 74, pp. 783-795.

Stockwell, C., 1968. Geochronology of stratified rocks on the Canadian Shield. Can. J. Earth Sci, Volume 5, pp. 693-8.

Stokes, G. G., 1849. On the variation of gravity on the surface of the Earth. Cambridge Philosophical Society., VIII(Trans. Cambridge Philos. Soc.), pp. 672-695.

Sunkel, H., 2002. From Eotvos to mGal, WP1: In-orbital calibration and local gravity field continuation problem, s.l.: s.n.

Tapley, B. D. et al., 2004. GRACE Measurements of Mass Variability in the Earth System. Science, 305(5683), pp. 503-505.

Tapley, B. D., Bettadpur, S., Watkins, M. \& Reigber, C., 2004. The gravity recovery and climate experiment: Mission overview and early results. Geophys. Res. Lett., \#may\#, 31(9), p. L09607.

Tapley, B. D. et al., 1996. The Joint Gravity Model 3. Journal of Geophysical Research, Volume 101, pp. 28029-28049.

Tapley, B. et al., 2007. The GGM03 Mean Earth Gravity Model from GRACE. s.1., s.n.

Tapley, B. et al., 1997. The TEG3 Earth Geopotential Model. s.1., s.n., pp. 453-460.

Tassinari, C. C. G., 1996. O mapa geocronológico do Cráton Amazônico no Brasil : revisão dos dados isotópicos, São Paulo: s.n.

Tassinari, C. C. G. B. J. S. G. M. C. M. M. J. B. L. J. M. (., 2000. The Amazonian cráton. In: Cordani, U. G.; Milani, E. J.; Thomaz Filho, A.; Campos, D. A. (eds.). Rio de Janeiro, s.n., s.n.

Tassinari, C. C. G. et al., 1996. Geochronological Systematics on Basement Rocks from the Rio Negro-Juruena Province (Amazonian Craton) and Tectonic Implications. International Geology Review, 38(2), pp. 161-175.

Tassinari, C. \& Macambira, M., 1999. Geochronological Provinces of the Amazonian Craton. Episodes, 22(3), pp. 174-182.. 
Teixeira, W., Tassinari, C. C. G., Cordani, U. G. \& Kawashita, K., 1989. A review of the geochronology of the Amazonian Craton: Tectonic implications. Precambrian Research, 42(3-4), pp. 213-227.

Tohver, E. et al., 2006. Restored transect across the exhumed Grenville orogen of Laurentia and Amazonia, with implications for crustal architecture. Geology, Volume 34.

Uieda, L., Bomfim, E.P., Braitenberg, C., Molina, E.C., Optimal forward calculation method of the Marussi tensor due to a geologic structure at GOCE height. In: 4th International GOCE User Workshop, 2011, Munich. 4th International GOCE User Workshop, 2011. v. 1. p. 1-5.

Uieda, L., 2012. Tesseroids Documentation, http://tesseroids.readthedocs.org/en/latest/index.html: s.n.

Wahr, J., Molenaar, M. \& Bryan, F., 1998. Time variability of the Earth's gravity field: Hydrological and oceanic effects and their possible detection using GRACE. J. Geophys. Res., 103(B12), pp. 30205-30229.

Wanderley Filho, J.R., 1991, Evolução estrutural da Bacia do Amazonas e sua relação com o embasamento. Dissertação de Mestrado, Instituto de Geociências, UFPa, 125p.

Wanderley Filho, J. R., Melo, H., Fonseca, V. \& Machado, M., 2005. Bacias sedimentares brasileiras: Bacia do Amazonas. Fundação Paleontológica Phoenix, ano 7(nº 82), p. 6pp..

Wanderley Filho, J., Travassos, W. \& Alves, D., 2006. O diabásio nas bacias paleozóicas amazônicas - herói ou vilão?. Boletim de geociências da Petrobrás, nov.2005/maio 2006, V. 14(1), pp. 177-184.

Wenzel, G., 1998. Ultra-high degree geopotential models GPM98 A, B and C to degree 1800. Trieste, 7-12 September. (www.gik.uni-karlsruhe.de), s.n.

Wessel, P., 1989. XOVER: A cross-over error detector for track data. Computers \&amp; Geosciences, 15(3), pp. 333-346.

Wessel, P., 2010. Tools for analyzing intersecting tracks: The x2sys package. Computers \&amp; Geosciences, \#mar\#, 36(3), pp. 348-354.

Yi, W., Murböck, M., Rummel, R. \& Gruber, T., 2010. Performance analysis of GOCE gradiometer measurements. s.1., ESA/ESTEC.

Zuidweg, K. \& Mumaw, G., 2007. Airborne gravity gradiometry for exploration geophysics: The first five years. Istanbul, Turkey, s.n. 
This appendix is a exact transction from GOCE Level 2 Data Handbook (see, Gruber et al., 2009, charpter 4.4.1)

\section{A.1. GRF - Gradiometer Reference Frame \& ARF - Accelerometer Reference Frame}

GRF is the coordinate system in which the components of the gravity gradient tensor are measured by GOCE (see Figure A.1). The GRF represents the Three-Axis Gradiometer common reference for the mutual positioning and alignment of the three One Axis Gradiometers and for the positioning and orientation of the whole instrument with respect to external reference frames. Nominally the origins of all one-axis gradiometer reference frames (OAGRF) coincide in one intersection point. The corresponding axes of each of the 3 OAGRF's are parallel and point in the same directions. The corresponding 6 accelerometer reference frames (ARF) are parallel and point in the same direction. 


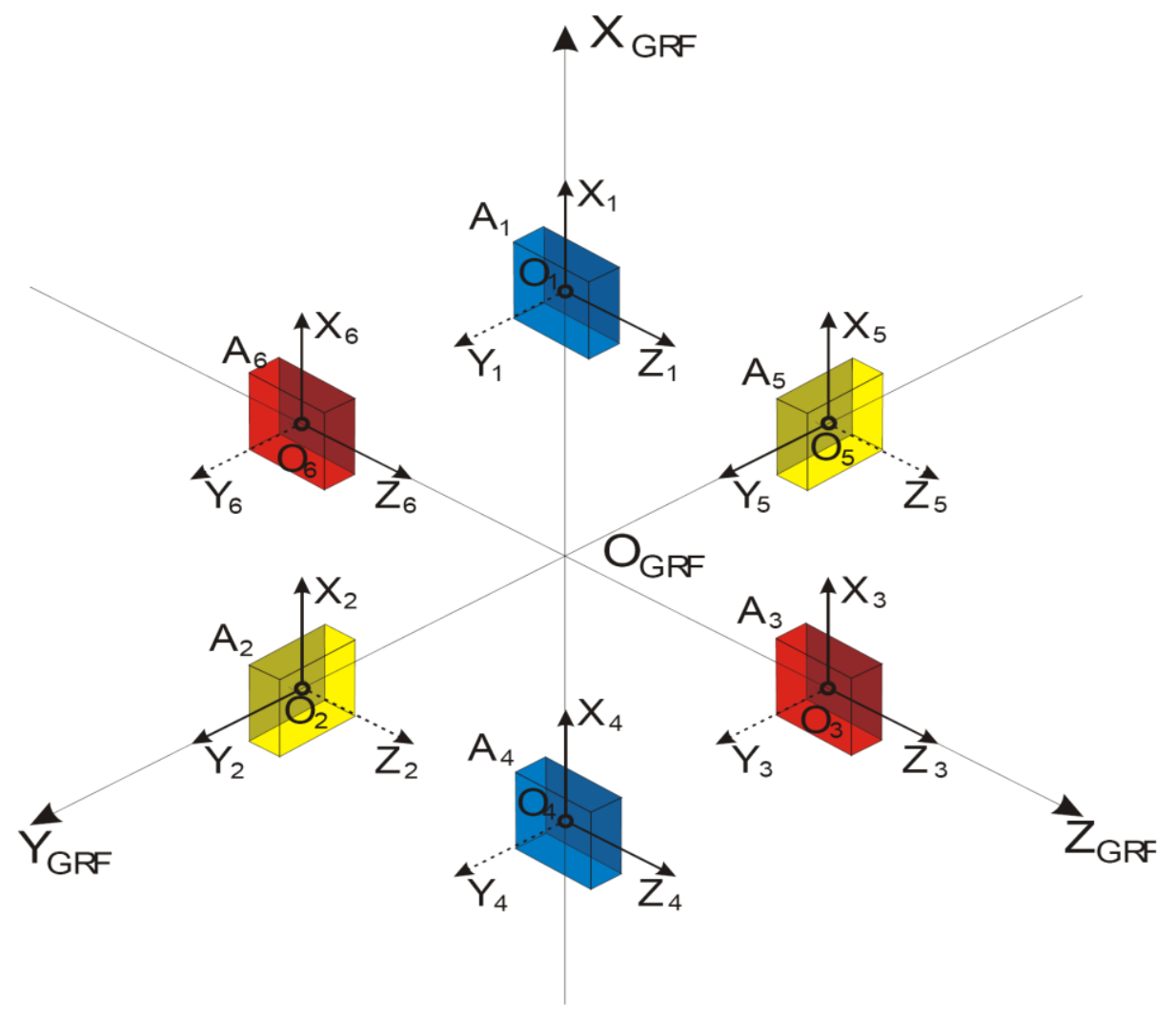

Figure A.1: Notation and location of the 6 accelerometers of the GOCE gradiometer in the GRF and with all 6 ARF's. The axes of the ARF shown by solid arrows are aligned with ultra sensitive axes of the accelerometer. The axes of the ARF shown by dashed arrows are aligned to the less sensitive axes of the accelerometer. Each colour represents a one-axis gradiometer. The shadowed surfaces represent the locations of the lower plates (and the sole plates).

\section{A.1.1. LORF - Local Orbital Reference Frame}

The origin OLORF is located at the actual satellite centre of mass; XLORF axis (roll) is parallel to instantaneous direction of the orbital velocity vector $(\mathrm{V})$ with the same sign as this vector.

YLORF axis (pitch) is parallel to instantaneous direction of the orbital angular momentum (N), with the same sign as $\mathrm{N}$ ( $\mathrm{V}$ and $\mathrm{N}$ are orthogonal by definition, since $\mathrm{N}=\mathrm{R} \times \mathrm{V}$, where $\mathrm{R}$ is the vector from the Earth centre to the origin). The ZLORF (yaw) axis is parallel to $\mathrm{V} \times \mathrm{N}$, with the same sign as $\mathrm{V} \times \mathrm{N}$

\section{A.1.1.1. Orientation of GRF/LORF in Space}


Figure A.2Figure shows how the fundamental reference frames are related to each other. The GRF does not fully coincide with the LORF. In science mode the satellite will operate in drag-free mode for the flight direction only with platform attitude controlled by the magnetorquers over the poles. Since the magnetorquers can only operate close to the pole, the yaw steering mode allows the roll angle to accumulate at the equator by a few degrees. The maximum yaw angle value of $3.5^{\circ}$ is reached at the equator due to out-of-plane forces caused by Earth rotation. Thus the satellite will be yaw steered to within $\pm 3.5^{\circ}$ (with respect to the LORF) in order to minimise lateral forces and torques.

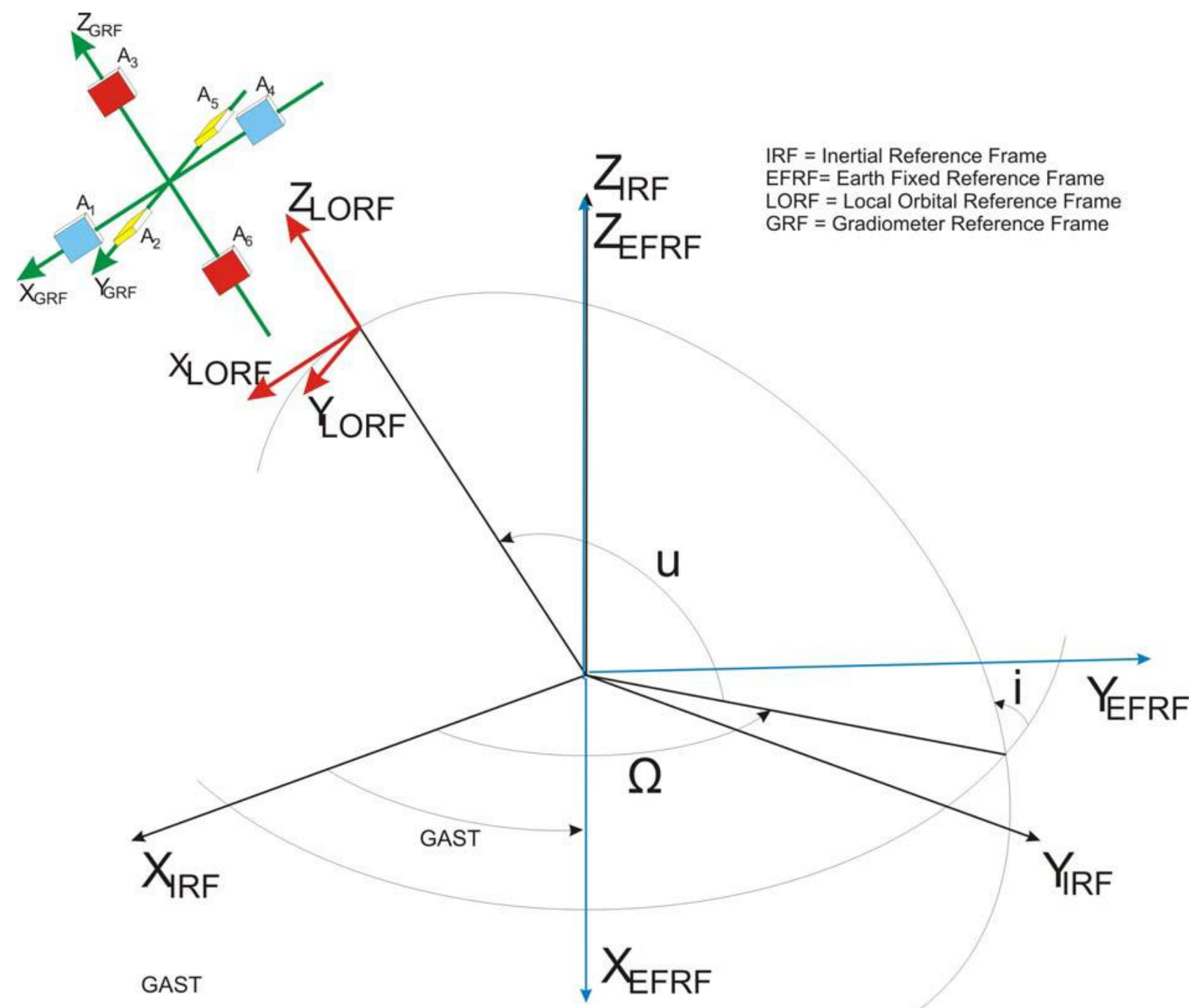

Figure A.2: Definition of fundamental Reference Systems for GOCE.

\section{A.2. Earth-Fixed Reference Frame (EFRF)}

The Earth-Fixed Reference System (EFRF) is a spatial reference system co-rotating with the Earth in its diurnal motion in space. The EFRF is an orthogonal, right-handed system. Its origin is at the 
Earth's center of mass (geocenter), the orientation is equatorial (z-axis is the direction of the pole). The $\mathrm{x}$-axis is fixed in the equatorial plane in direction to the Greenwich meridian. The angle between the $\mathrm{x}$-axis of the inertial reference frame (defined by the vernal equinox) and the Greenwich meridian is the Greenwich Apparent Sideral Time (GAST).

\section{A.3. Local North Oriented Frame (LNOF)}

The Local North Oriented Frame (LNOF) is a right-handed North-West-Up frame with the X-axis pointing North, the Y-axis pointing West and the Z-axis Up. The calibrated gravity gradients of the EGG_TRF_2 products are provided in this system.

- The origin $\mathrm{O}_{\mathrm{LNOF}}$ is located at the nominal satellite centre of mass

- $\mathrm{Z}_{\mathrm{LNOF}}$ is defined as the vector from the geocenter to the origin $\mathrm{O}_{\mathrm{LNOF}}$, pointing radially outward,

- $\mathrm{Y}_{\mathrm{LNOF}}$ is parallel to the normal vector to the plane of the geocentric meridian of the satellite center of mass, pointing westward,

- $\mathrm{X}_{\mathrm{LNOF}}$ is parallel to the normal vector to the plane defined by $\mathrm{Y}_{\mathrm{LNOF}}$ and $\mathrm{Z}_{\mathrm{LNOF}}$.

In geocentric latitude and East longitude $(\varphi, \lambda)$ of the GOCE center of mass in the CTRS (Conventional Terrestrial Reference System) the 3 axes are defined as follows:

$$
Z_{L N O F}=\left(\begin{array}{c}
\cos \varphi \cos \lambda \\
\cos \varphi \sin \lambda \\
\sin \varphi
\end{array}\right) ; Y_{L N O F}=\left(\begin{array}{c}
\sin \lambda \\
-\cos \varphi \\
0
\end{array}\right) ; X_{L N O F}=\left(\begin{array}{c}
-\sin \varphi \cos \lambda \\
-\sin \varphi \sin \lambda \\
\cos \varphi
\end{array}\right)
$$

\section{A.4. Time System}

All GOCE products are time-tagged in GPS-time. This time will be derived by correlating the onboard time with the GPS time. In case no GPS time is available (due to receiver outage) the GPS time is automatically determined by correlating the on-board time with UTC and applying the constant and leap second time shift.

\section{Reference}

Gruber, Th., Rummel, R., Abrikosov, O., van Hees., R. 2009. GOCE Level 2 Product Data Handbook GO-MA-HPF-GS-0110, Issue 4.1, European GOCE Gravity Consortium. 


\title{
APPEDIX A MUTUAL EVALUATION OF GLOBAL GRAVITY MODELS (EGM2008 AND GOCE) AND TERRESTRIAL DATA IN AMAZON \\ BASIN, BRAZIL \\ E.P.Bomfim ${ }^{1,2}$, C.Braitenberg ${ }^{2}$ and E.C.Molina ${ }^{1}$
}

\author{
${ }^{1}$ University of São Paulo, Institute of Astronomy, Geophysics and Atmospheric Sciences - IAG. \\ São Paulo, Brazil; \\ ${ }^{2}$ University of Trieste, Department of Mathematics and Geosciences, Trieste, Italy
}

\begin{abstract}
The gravity observations of the satellite GOCE have a global homogeneous coverage and precision. This data set constitutes an independent new tool to control the quality of terrestrial gravity data. Terrestrial data reach higher resolution and precision, but can be affected by errors due to factors such as different vertical geodetic datums, wrong position in latitude and longitude, geodynamic effects and gravimeter drift, which tends to accumulate over long distances. Terrestrial data recover gravity signals at shorter wavelengths compared to the GOCE satellite, but the average gravity anomaly values can be compared to the GOCE derived values which are bandlimited to lower frequencies.
\end{abstract}

We consider the area of the Amazon Craton, and in particular the Solimões, Amazon and Parnaiba Basins, and part of the Tocantins and São Francisco Provinces in Brazil, to estimate the systematic errors in terrestrial gravity data. We calculate the average terrestrial gravity anomaly by spatial averages applying Gaussian, inverse square distance and simple averages, which allows to compare the long- and medium- wavelength part of the terrestrial gravity anomalies with the gravity field derived from GOCE. We also consider the combined satellite-terrestrial model EGM2008 up to degree and order 250 (i.e., maximum expansion from satellite GOCE). The results show that the 
systematic errors range from about -69.6 to $44.1 \mathrm{mGal}$ with a RMS value of $11.6 \mathrm{mGal}$. The mean value over the study area is about zero, obtaining $-0.9 \mathrm{mGal}$ difference between the Gaussian average of the terrestrial gravity data and the gravity data from the GOCE satellite-only model and is smaller than the commission error associated to the geopotential model. Also, we verified that 38.2 per cent of the study area does not present systematic errors, as their difference is within the commission error of $5.06 \mathrm{mGal}$ of the GOCE model in the harmonic expansion up to degree 250 . The comparison of the terrestrial data with the model EGM2008 gives slightly smaller differences, which can be attributed to the fact that the EGM2008 contains terrestrial data. The results vary only slightly according to the type of averaging used, with improved values for the Gaussian average. The analysis also shows where the terrestrial data are scarce and require an improvement in data coverage in order to correctly represent the gravity field. The method we propose can be directly used to control other gravity data bases and constitutes a tool for the quality assessment of terrestrial gravity observations.

\section{INTRODUCTION}

Global Geopotential Models (GGMs) make use of spatially averaged terrestrial data in order to include short-wavelength spherical harmonic coefficients and to improve estimates of the Earth's gravity field (Jekeli 1981, Wahr et al., 1998, Tapley et al. 2004, Chen et al., 2006). In this work we will use the Gaussian averaging function (Jekeli, 1981), the inverse square distance weighted average and a simple average to analyze the available terrestrial gravity data in the Amazon Basin area, Brazil, in order to compare them with the satellite-only and mixed satellite-terrestrial geopotential models. The terrestrial data allow to have detailed and accurate information about the short wavelengths of the gravity field, and we can estimate a mean gravity anomaly corresponding to the long wavelengths, comparable to the resolution of satellite observations.

The spherical harmonic gravity models obtained from geodetic satellite missions describe the lowdegree components of the Earth's gravity field homogenously and accurately. The terrestrial gravity 
anomalies are accurate at short-wavelengths, but are highly susceptible to the systematic errors at medium- and long wavelengths, as pointed out by Heck (1990). Therefore, as described in Amos and Featherstone (2003), the terrestrial gravity anomalies don't form a flawless set of data to test GGMs, especially the satellite-only GGMs derived from the satellite gravity field missions. For the same reasons combined GGMs (e.g. EGM2008, Pavlis et al., 2012) can carry with them spurious errors from the terrestrial gravity data.

The main goal of this paper is to use the gravity field derived from the GOCE satellite-only model (Pail et al., 2011) to make a regional quality assessment of the terrestrial gravity data. Since the terrestrial gravity data are often used to validate the satellite data, the existence of systematic errors in the terrestrial gravity data may cause serious problems in the development of the GGMs. Furthermore we analyze the differences between EGM2008 and GOCE, and EGM2008 and the terrestrial data to compare the performance of this field in the study area. In order to study this subject, we start from the accuracy estimates of the commission error associated to the GGMs in the form of expected degree error of the gravity anomaly (free-air anomaly) for GOCE (Pail et al., 2011) and EGM2008 (Pavlis et al., 2008).

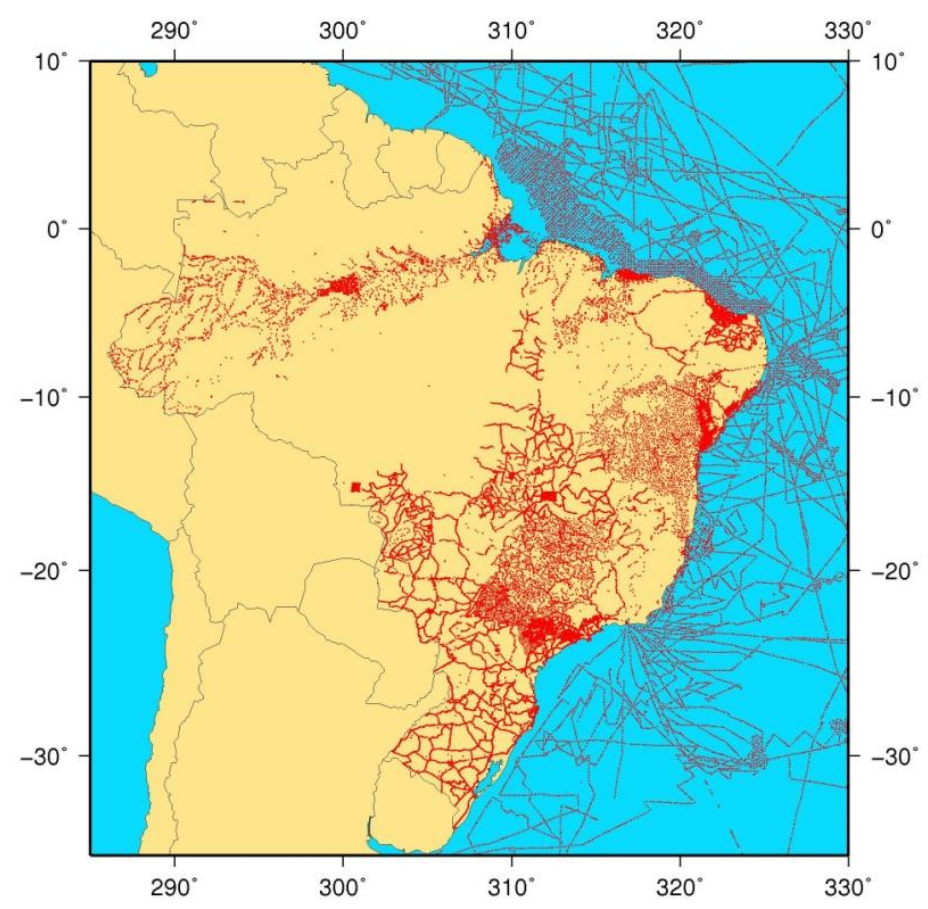


Figure 1: Terrestrial gravity anomalies available in Brazil (Courtesy IAG/USP).

The terrestrial gravity anomalies are relatively precise, nevertheless they are often contaminated by systematic errors such as geodetic datum errors, positioning errors (mainly elevation), reduction errors, geodynamic effects and instrumental errors (e.g. gravimeter drift), which tends to accumulate over long distances (Amos and Featherstone, 2003). These and other systematic errors were studied by Heck (1990). Roland and Denker (2003) showed that the largest error components come from inconsistencies in the gravity observations and the horizontal and vertical positioning reference systems. It is almost impossible to estimate and correct these errors due to the lack of quantitative information about them (Huang et al., 2008).

Huang et al. (2008) described a method to assess the systematic errors of the low spherical harmonic degrees due to errors in the surface gravity anomalies. For this they used three types of techniques on averaging process surface data, such as low-pass filtering, the inverse Stokes integral, and spherical harmonic analysis. Only a few authors estimated the systematic errors in the global terrestrial gravity data (Mainville \& Rapp, 1985; Pavlis, 2000; Amos \& Featherstone, 2003), and Véronneau \& Huang (2003) also used the averaging filter and the inverse Stokes integral techniques to estimate systematic errors in the GGMs.

As the Brazilian territory has continental dimensions, the gravity data were collected by many institutions and with different aims. Figure 1 maps the distribution of the terrestrial data in Brazil, which is estimated to have a mean spatial resolution of 5 arc-minute in most of the area (Sá, 2004). Partially these data have been integrated in the global $5^{\prime} \times 5^{\prime}$ gravity database used to build EGM2008 (Pavlis et al., 2008).

The final combination solution of the EGM2008 was developed and evaluated by a least squares combination of the ITG-GRACE03S gravitational model and its associated error covariance matrix and the gravitational information obtained from a global set of area-mean free-air gravity anomalies defined on a 5 arc-minute equiangular grid. As described in Pavlis et al. (2012), they formed the 
final grid by merging terrestrial, altimetry-derived, and airborne gravity data. Over areas where only lower resolution gravity data were available, the higher degree spectral content was supplemented with gravitational information implied by the topography.

The EGM2008 is complete to degree and order 2159 with additional coefficients extending up to degree 2190. In order to compare this model with the GOCE satellite-only model (Pail et al., 2011) we compute the EGM2008 values up to degree and order 250, the maximum available degree of the GOCE model.

\section{STUDY AREA AND A GENERAL OUTLINE OF THE GEOLOGY}

The study area embraces the region of the Amazon, Solimões and Parnaíba sedimentary basins and a small part of Tocantins, São Francisco and Borborema Provinces in Brazil (Figure 2).

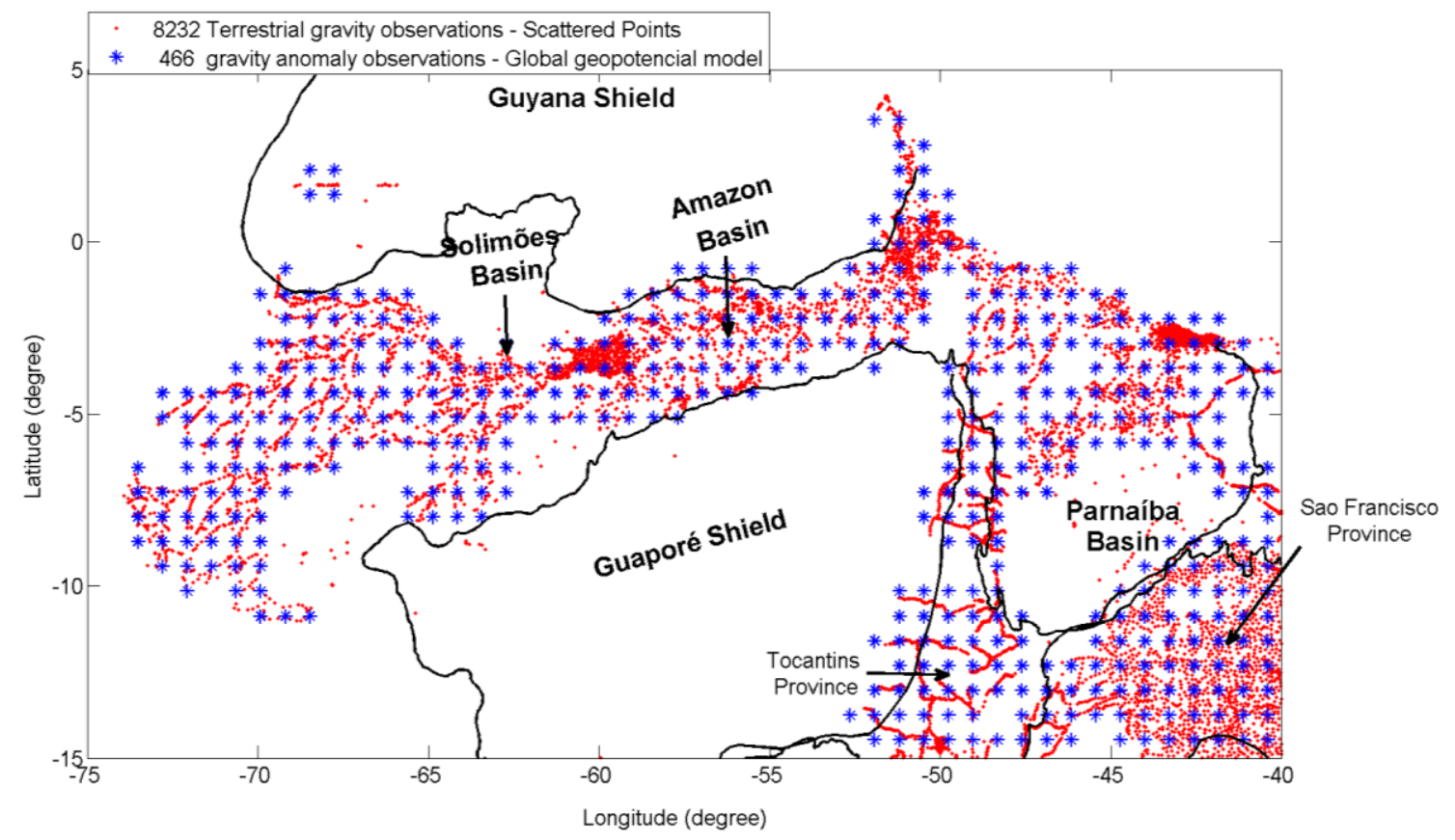

Figure 2: Availability of terrestrial gravity data (red) used to estimate the gravity field on a regular grid with approximately $80 \mathrm{~km}$ spacing (blue dots). These averaged values will be used in the comparison with the GGMs.

Geologically, the area comprises the Solimões, Amazon and Parnaíba paleozoic basins. Amazon and Solimões basins are classified as intracratonic paleozoic basins. Together they cover almost 
$1,000,000 \mathrm{~km}^{2}$. The basins belong to an intracontinental rift system that straddles the border between the Brazil and Guyana Shields, covering some 4,500 $\mathrm{km}^{2}$ of the Brazilian territory. The Parnaíba Province is also a paleozoic that covers some $600,000 \mathrm{~km}^{2}$, filled with Ordovician to Early Triassic sediments, mostly of marine environment, but also with fluvio-deltaic and desertic contributions (Bizzi et al., 2004).

The terrestrial Bouguer anomaly map shows a chain of gravity highs that transect the Amazon Basin and are roughly coincident with the maximum thickness of the sedimentary rocks (Figure 3). The structure of the Amazon Basin is presently not perfectly known, and several hypotheses exist to explain the positive and negative axial signals (Nunn and Aires, 1988; Eiras et al., 1984). It is essential to have a reliable gravity field and have perfect knowledge on the precision of the terrestrial field.

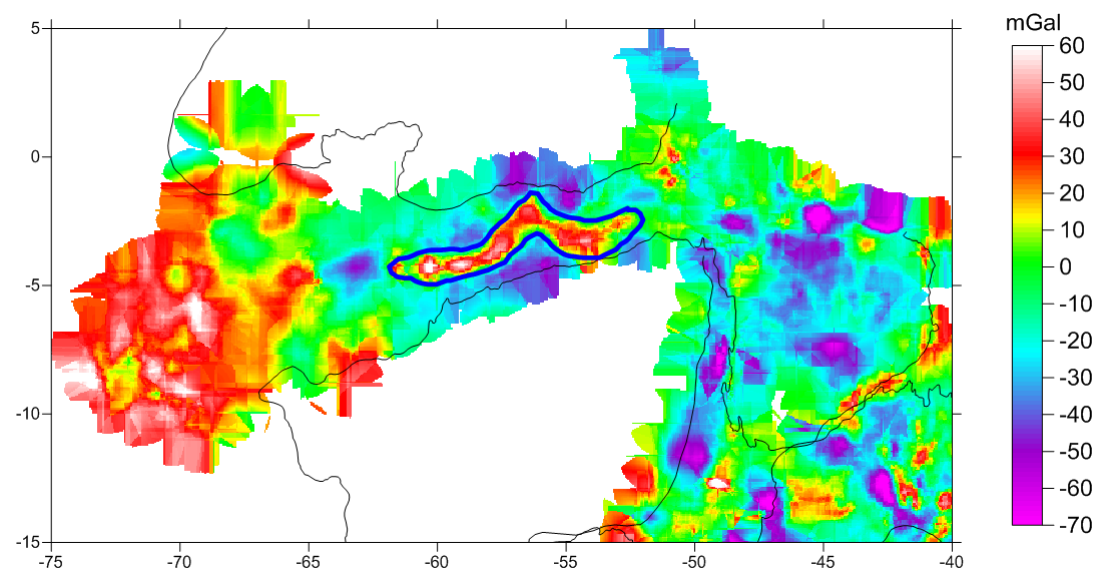

Figure 3: Bouguer anomaly map obtained from terrestrial data. The blue line delineates a chain of gravity highs that is discussed in the text.

\section{METHODS FOR ERROR ESTIMATION}

Our analysis requires the evaluation of the errors in the terrestrial data and the errors on the GOCE and EGM2008 spherical harmonic models. We also analyze the error of the difference between the terrestrial observations and the gravity derived from the GGMs. We proceed in three steps. The first describes the definition of the degree errors for the GGMs, the second the systematic errors in the 
low spherical harmonic degrees of the terrestrial data, and the third the procedure to correctly average the terrestrial data with an adequate spatial filter that corresponds to the maximum harmonic degree of the expansion of the GGM.

\section{Errors GOCE: From Degree Amplitude to Gravity Anomaly errors}

Wahr et al. (1998) defined the error of the geoid in terms of the GGM estimate as:

$$
\delta N(\theta, \phi)=a \sum_{l=0}^{\infty} \sum_{m=0}^{l} P \operatorname{lm}(\cos \theta)\left(\delta C_{l m} \cos (m \phi)+\delta S_{l m} \sin (m \phi)\right)
$$

where $\delta C_{l m}$ and $\delta S_{l m}$ are the errors of the geopotential models coefficients. Then the spatial variance of the geoid error, taken over the entire globe, is

$$
\delta \sigma_{s p}^{2}=\frac{1}{4 \pi} \int_{0}^{2 \pi} d \phi \int_{0}^{\pi} \sin \theta d \theta \delta N^{2}(\theta, \phi)=a^{2} \sum_{l=0}^{\infty} \sum_{m=0}^{l}\left(\delta C_{l m}^{2}+\delta S_{l m}^{2}\right)
$$

The degree amplitude or degree variances from the geopotential model error is defined as

$$
\delta N_{l}=a \sqrt{\sum_{m=0}^{l}\left(\delta C_{l m}^{2}+\delta S_{l m}^{2}\right)}
$$

The error estimate of the gravity anomaly is obtained similarly. Therefore the RMS (Root Mean Square) anomaly errors at degree $l$ are computed by:

$$
\delta g_{l}=\frac{G M}{a^{2}} \sum_{m=0}^{l}(l-1) \sqrt{\left(\delta C_{l m}^{2}+\delta S_{l m}^{2}\right)}
$$

$\delta N_{l}^{2}$ and $\delta g_{l}^{2}$ are the geoid and gravity anomaly degree variances that can be estimated by using the standard error of the disturbing potential coefficients $\delta C_{l m}, \delta S_{l m} . G M$ is the gravitational constant multiplied by the Earth mass and $a$ the equatorial radius. The degree $l$ is a measure of the spatial scale of the spherical harmonic, as the spatial resolution expressed as half-wavelength is given by 
$20,000 \mathrm{~km} / l$. So $\delta N_{l}^{2}$ and $\delta g_{l}^{2}$ are a measure of the contribution to the variances at degree $l$, their sum up to maximum degree $L$ the variance for all terms up to a given spatial scale.

The cumulative error in gravity anomaly is shown in Fig. 4 for spherical harmonic coefficients up to degree and order 250 and is about $1.61 \mathrm{mGal}$ for EGM2008 and $5.06 \mathrm{mGal}$ for GOCE. The GOCE model we use is the third TIM release GO_CONS_GCF_2_TIM_R3 of Pail et al. (2011).

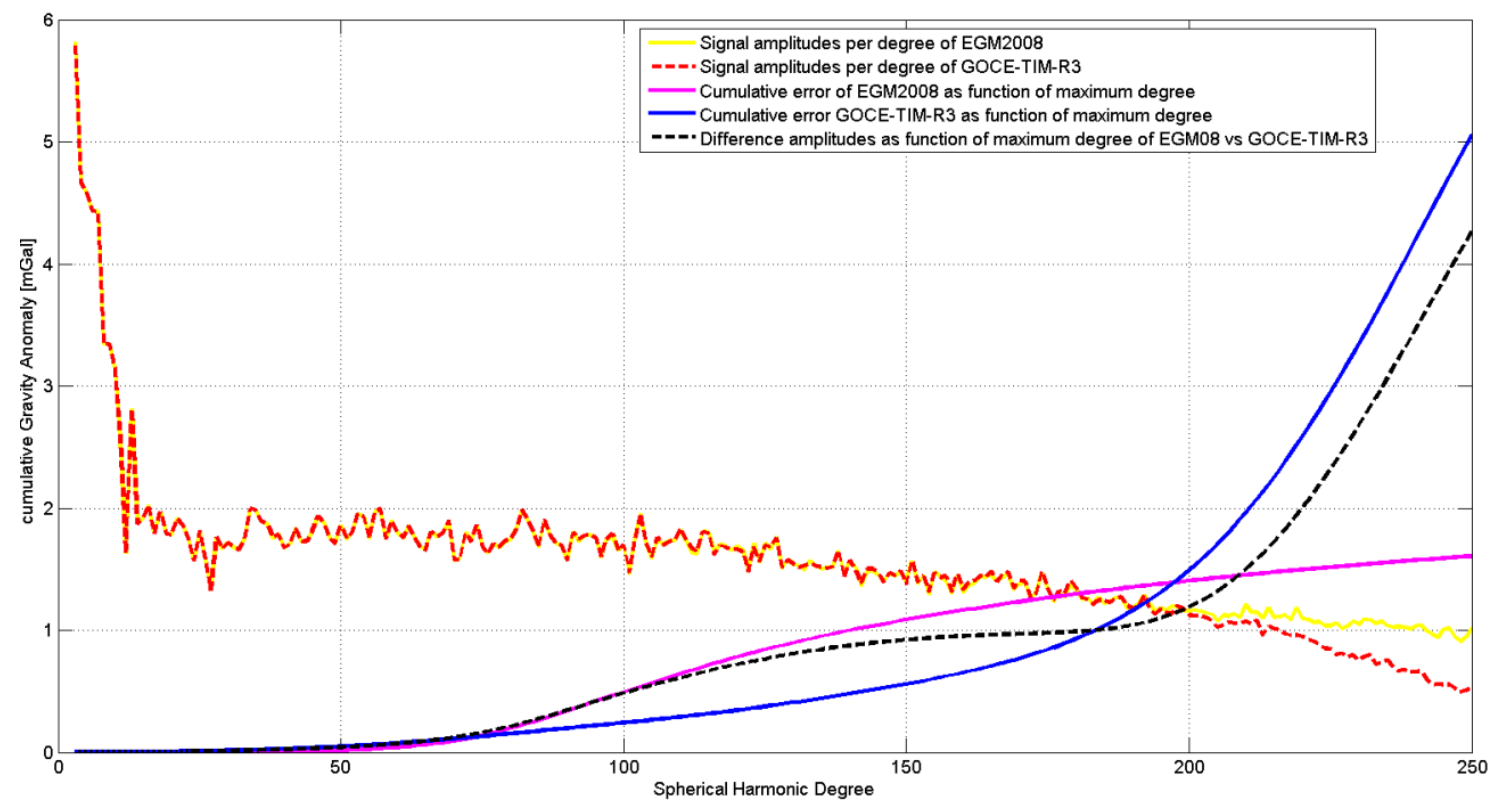

Figure 4: RMS errors in the gravity anomaly from the geopotential models GOCE and EGM08 in the gravity anomaly (free-air), signal, error and difference between EGM08 and GOCE.

\section{Systematic errors of low spherical harmonic degree in surface gravity anomalies}

The systematic errors of low spherical harmonic degree in the terrestrial gravity anomalies were studied by Huang et al. (2008), expressing the Earth gravity field in terms of GGM can be modeled by spherical harmonic expansion as follows

$$
\Delta g^{G G M}=\sum_{l=2}^{L} g_{l}+\epsilon_{L}^{G G M}
$$


where $\Delta g^{G G M}$ is the gravity anomaly; $L$ is the maximum degree of the global geopotential model (GGM); $g_{l}$ is the spherical harmonic component of degree $l$ and $\epsilon_{L}^{G G M}$ is the commission error associated with the GGM.

Similarly, the terrestrial gravity anomaly $\Delta g^{T G}$ described in spherical harmonics can be expressed by

$$
\Delta g^{T G}=\sum_{l=2}^{\infty} g_{l}+\epsilon_{L}^{T G}+\epsilon_{H}^{T G}+\epsilon_{l}
$$

The second and third terms of the summation are the low and high-degree systematic errors, respectively. The last term $\epsilon_{l}$ is the random error. By subtracting eq. (5) from eq. (6), we obtain

$$
\Delta g^{T G}-\Delta g^{G G M}=\sum_{l=L+1}^{\infty} g_{l}+\delta \epsilon_{L}+\epsilon_{H}^{T G}+\epsilon_{l}
$$

where

$$
\delta \epsilon_{L}=\epsilon_{L}^{T G}-\epsilon_{L}^{G G M}
$$

As discussed in Huang et al. (2008) for the satellite models, we assume that if the error of the GGMs is much smaller than the systematic error in the terrestrial gravity data, $\delta \epsilon_{L}$ is approximately the low-degree systematic error in the terrestrial data below of the maximum degree $L$. Thus, we can rewrite eq. (7) as

$$
\delta \epsilon_{L}=\Delta g^{T G}-\sum_{l=L+1}^{\infty} g_{l}-\epsilon_{H}^{T G}-\epsilon_{l}-\Delta g^{G G M}
$$

obtaining the estimate of $\delta \epsilon_{L}$. In order to remove the high degree field components, and high degree systematic and random errors, Huang et al. (2008) smoothed $\Delta g^{T G}$. Here, we smooth the observation through spatial averaging as shown in the section below.

\section{Spatial Averaging}


Before comparing the terrestrial observations with the field derived from GOCE and EGM08, the observations have to be smoothed so the averaged field corresponds only to the long-wavelength part of the field and spatial resolution is adequate for the GOCE geopotential model.

Here, we will use three averaging functions, the simple average, the inverse square distance, and the Gaussian averaging function (Jekeli, 1981). The terrestrial data have more detailed and accurate information at short-wavelengths, with respect to the satellite observations, and these will be used to obtain a mean gravity anomaly corresponding to the long-wavelengths. The idea is to get the averaged gravity anomaly from the terrestrial data at the corresponding grid point of the gravity anomalies calculated from the geopotential global models (for example: EGM2008 and GOCE up to degree and order 250) so that we can make comparisons between the gravity anomalies at long wavelengths obtained from the global geopotential models and the terrestrial data, and estimate the errors of the terrestrial data.

The simple average of the gravity anomalies is defined as follows:

$$
\overline{g z}=\frac{\sum_{1}^{n} g z_{i}}{n}
$$

where $g z_{i}, i=1 \ldots n$ are the $n$ gravity anomaly observations.

We define the inverse quadratic distance as the weighting function for the weighted average, since the gravitational field decreases as the inverse square of the distance

$$
\overline{g z}=\frac{\sum_{i=1}^{n} g z_{i}{ }^{1} / r_{i}^{2}}{\sum_{i=1}^{n} 1 / r_{i}^{2}}
$$

where $r$ is distance between the observation point and the averaged point at the regular grid (Figure 7). 
The Gaussian average is also a weighted average, where the weight is the Gaussian averaging function $W(\alpha)$ for the radius at $r$.

$$
\overline{g z}=\frac{\sum_{i=1}^{n} g z_{i} \cdot W\left(\alpha_{i}\right)}{\sum_{i=1}^{n} W\left(\alpha_{i}\right)}
$$

where the Gaussian averaging function or operator $W(\alpha)$ is supposed to depend only on the kernel $\alpha$ (i.e. the spherical distance between the computation point and integration point), where the region of integration is a spherical cap centered at the computation point (Jekeli, 1981). The function is normalized so that the global integral of $W$ is equal 1 (Wahr et al.,1998):

$$
\begin{gathered}
W(\alpha)=\frac{b}{2 \pi} \frac{e^{-b(1-\cos \alpha)}}{1-e^{-2 b}} \\
b=\frac{\ln 2}{(1-\cos (r / a))}
\end{gathered}
$$

where $r$ is the averaging radius (i.e., the distance on the Earth's surface at which $W$ has dropped to half of its value at origin $(\alpha=0)$, where the distance on the Earth's surface $=a \alpha, 0 \leq \alpha \leq \pi)$ and $a$ is the Earth's mean radius $(\sim 6371 \mathrm{~km})$.

In terms of the spherical harmonic development, Jekeli (1981) showed that the coefficients $W_{l}$ of the Gaussian weighting function can be obtained following the recursion formula (Equation 15).

$$
\begin{gathered}
W_{0}=\frac{1}{2 \pi} \\
W_{1}=\frac{1}{2 \pi}\left[\frac{1+e^{-2 b}}{1-e^{-2 b}}-\frac{1}{b}\right] \\
W_{l+1}=-\frac{2 l+1}{b} W_{l}+W_{l-1}
\end{gathered}
$$



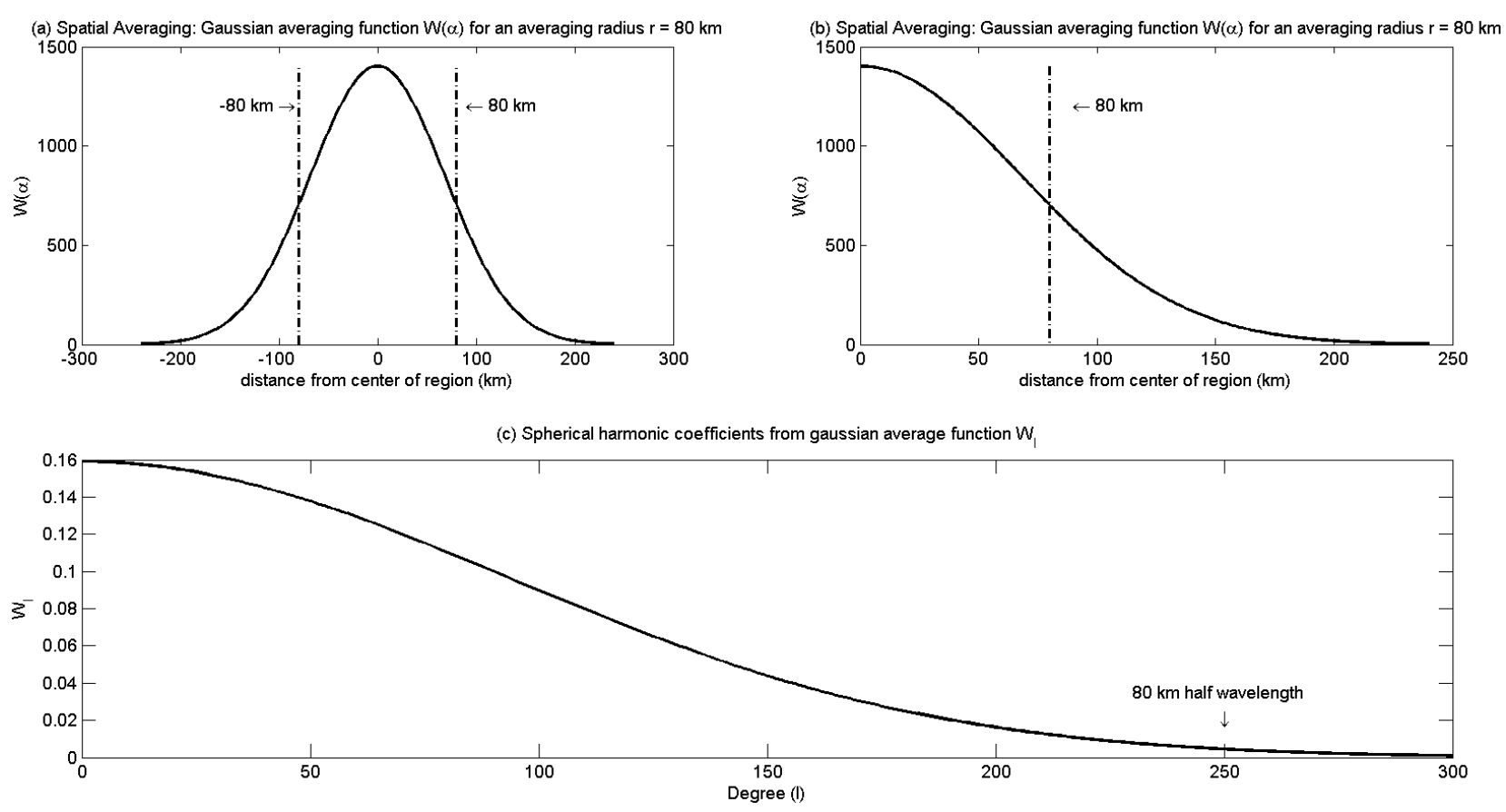

Figure 5: (a) Spatial averaging: Gaussian averaging function $W(\alpha)$ (continuous line) for the averaging radius $r=80 \mathrm{~km}$ (vertical stippled line); (b) Zoom on (a) for positive distance from center of region; and (c) Spherical harmonic coefficients of Gaussian averaging function for the same averaging radius $r=80 \mathrm{~km}$.

Figure 5 shows the Gaussian weighting function $W(\alpha)$ and the spherical harmonic coefficients $W_{l}$ up to degree and order 300; the degree 250 corresponds to the averaging radius $r=80 \mathrm{~km}$ that was used for smoothing the terrestrial data.

\section{DATA ANALYSIS}

In order to avoid a significant portion of systematic errors related to positioning errors, or rather, the inconsistencies in the gravity and in the altitude due to measurement uncertainties of data acquired in the 70's, at first we have checked the altitudes in the terrestrial database and compared them with the SRTM (Shuttle Radar Topographic Mission) altitude data interpolated at the same point. The histogram of the altitude differences was used to analyze the mean and the standard deviation of these differences, and then discard the gravity measurements with errors greater than the 99 percent confidence interval. We consider acceptable only those gravity points in which the altitude difference with SRTM lies within 3 standard deviations of the mean. The eliminated data could also be related to the interpolation errors. However, it was verified that the altitude differences higher 
than three standard deviation coincide or are very close, to the SRTM grid points of 3 arc second (approximately $90 \mathrm{~m}$ ) resolution (Jarvis et al., 2008) and therefore cannot be explained by interpolation errors.

Among the originally 8320 terrestrial altitude data compared with the SRTM altitudes, we have found only 33 points that could not be compared with SRTM data, as they had NaN (Not a Number) values in SRTM. These points were then interpolated with ETOPO1 altitude data (Amante and Eakins, 2008) which has a resolution of 1 arc minute (spatial resolution $\sim 1850 \mathrm{~m}$ ).

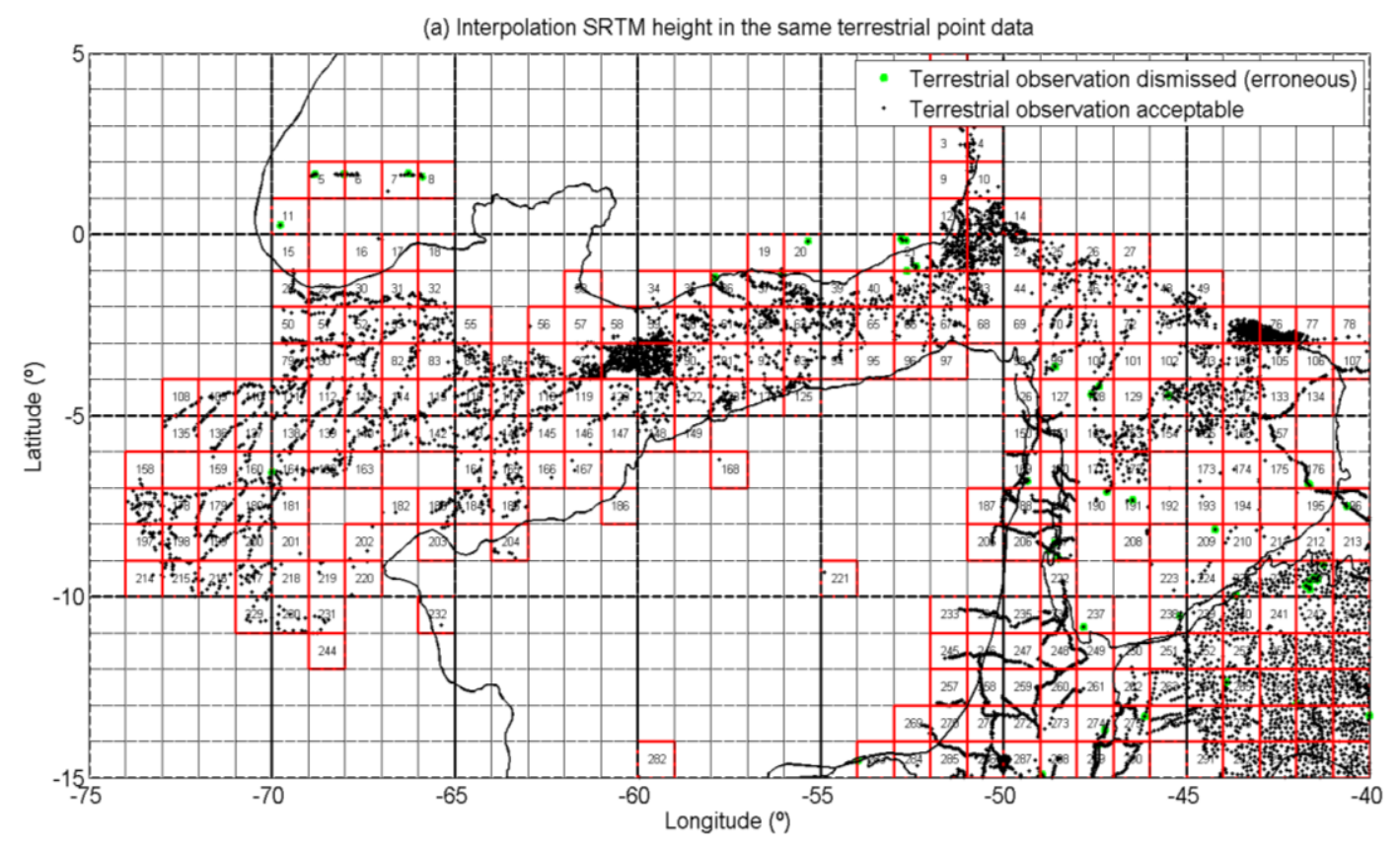




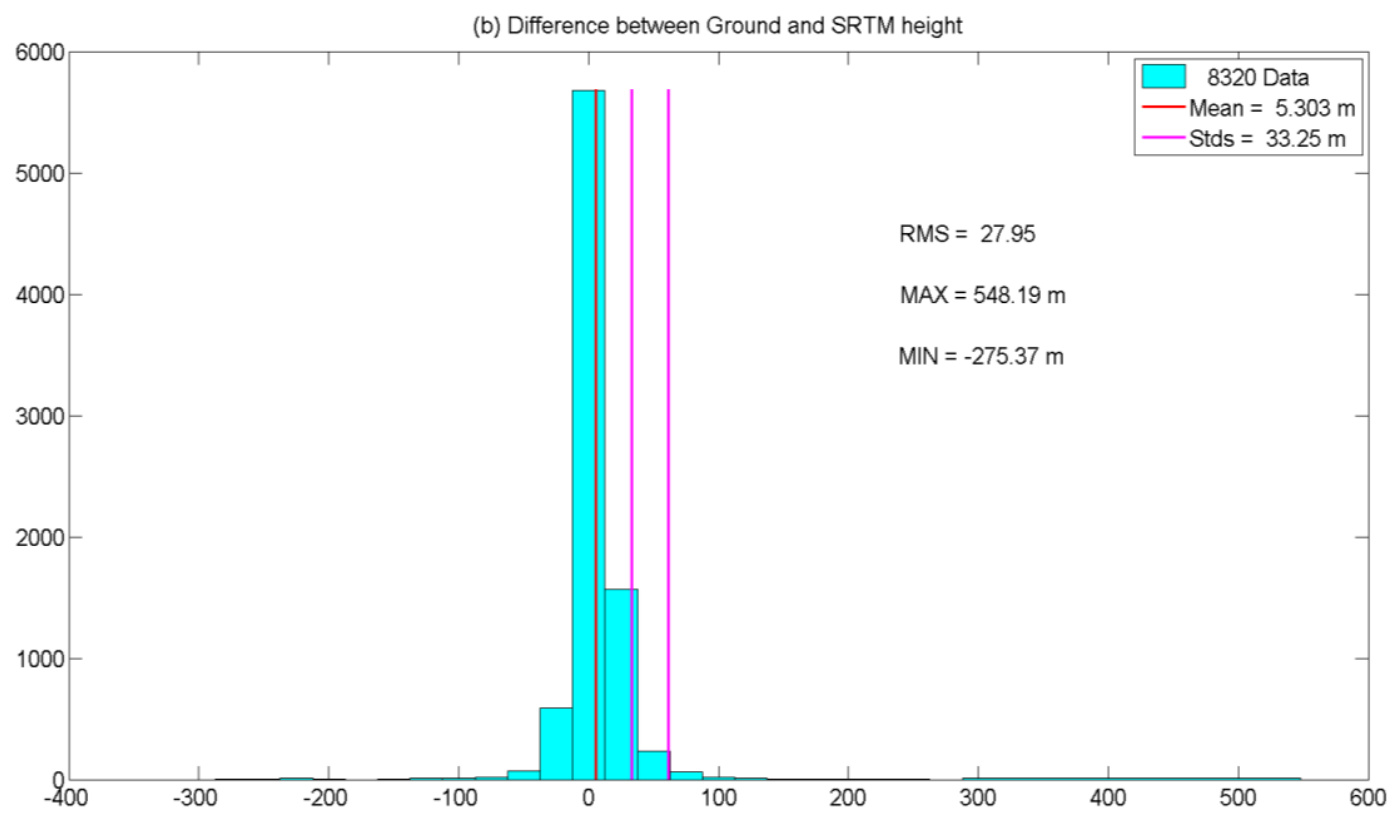

Figure 6: Comparison of data from terrestrial altitudes and interpolated SRTM altitudes at the same points: (a) subdivision of the study area in tiles of $1^{\circ} \times 1^{\circ}$ to overcome overload of the computer's memory in interpolating; and (b) histogram and statistic of the differences between the interpolated SRTM altitudes with the terrestrial altitude data.

To facilitate the calculations and not to overload the computer's memory, the study area was subdivided into tiles of $1^{\circ} \times 1^{\circ}$, resulting in 700 tiles in the region. Only 287 blocks had gravity data and were interpolated to obtain the SRTM altitude data at the same points of the terrestrial height data (Figure 6a). 

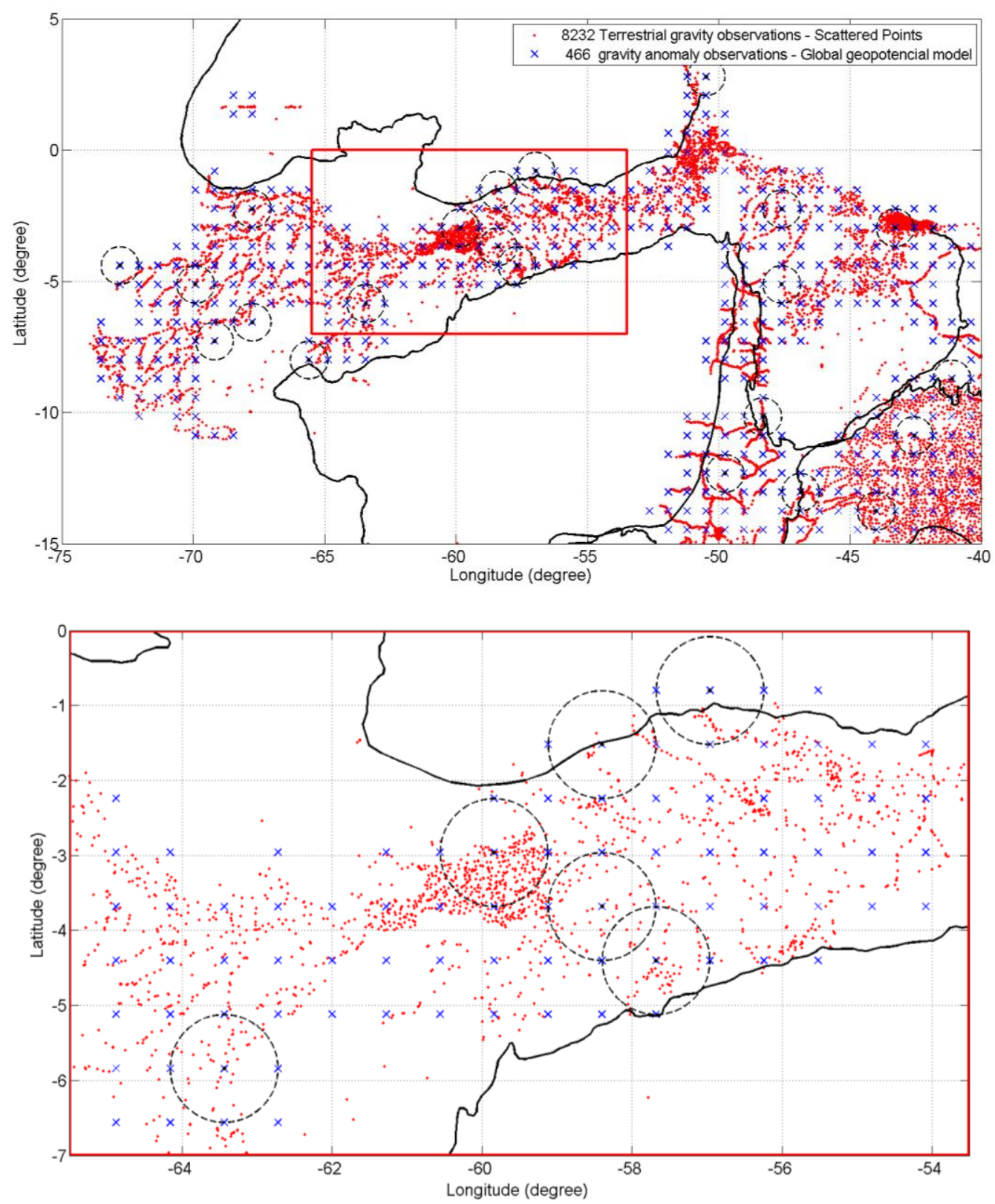

Figure 7: Schematic figure showing how the averages were estimated from terrestrial data within a radius of $80 \mathrm{~km}$ (black circle) to obtain the long-wavelength field. 8232 terrestrial data measurements are distributed sparsely (red dots) and 466 data from the geopotential models (blue cross) are distributed on a regularly spaced grid of $80 \times 80 \mathrm{~km}$ grid spacing. The radius is centered in each of the 466 regular grid points.

The differences between the interpolated SRTM heights and the terrestrial altitude data in the histogram (Figure 6b) showed a standard Gaussian distribution with a mean value of $5.3 \mathrm{~m}$ and a standard deviation of $33.2 \mathrm{~m}$. Some anomalous points in the height differences were found greater than 90 meters, and we assumed that these points probably have wrong altitudes in terrestrial data. 
Only 88 of 8320 values showed height differences higher than 3 standard deviations of the mean. Figure 6a depict 88 points (bold-faced blue dots) that have been considered erroneous (gross errors) and so should be discarded. All the other 8232 remainder points (lightweight blue dots) were considered acceptable within the confidence interval ( 3 standard deviations). Finally, a total of 8232 reliable terrestrial data were used for our main study to obtain a regional assessment of the terrestrial gravity observation errors.

We proceed now in applying the averaging process to the terrestrial data presented in Figure 2 . We calculate the gravity anomalies for the two global geopotential models EGM2008 and GOCE (Pail et al., 2011) up to degree and order 250 , which is equivalent to a maximum spatial resolution of 80 $\mathrm{km}$ half-wavelength. The comparison between the obtained values (Figure 7) allows us to estimate the errors of the terrestrial gravity data when compared to the gravity anomalies obtained from the geopotential models. The interest is to investigate whether this approach allows us to make a regional quality assessment and detect the systematic errors of the terrestrial observations (Figure 8 through 13).

The scattered values of the terrestrial gravity anomaly data points were averaged within a radius of $80 \mathrm{~km}$ from regularly spaced grid points using simple, inverse square distance and Gaussian averages given by equations Eq. (10), Eq. (11) and Eq. (12), respectively.

We estimated the gravity anomaly differences between the averaged terrestrial data and the GOCE model or the averaged terrestrial data and the EGM2008 model, and also between the GOCE and EGM2008 models, in order to determine the low-degree systematic errors in the terrestrial gravity measurements from eq. (9). 


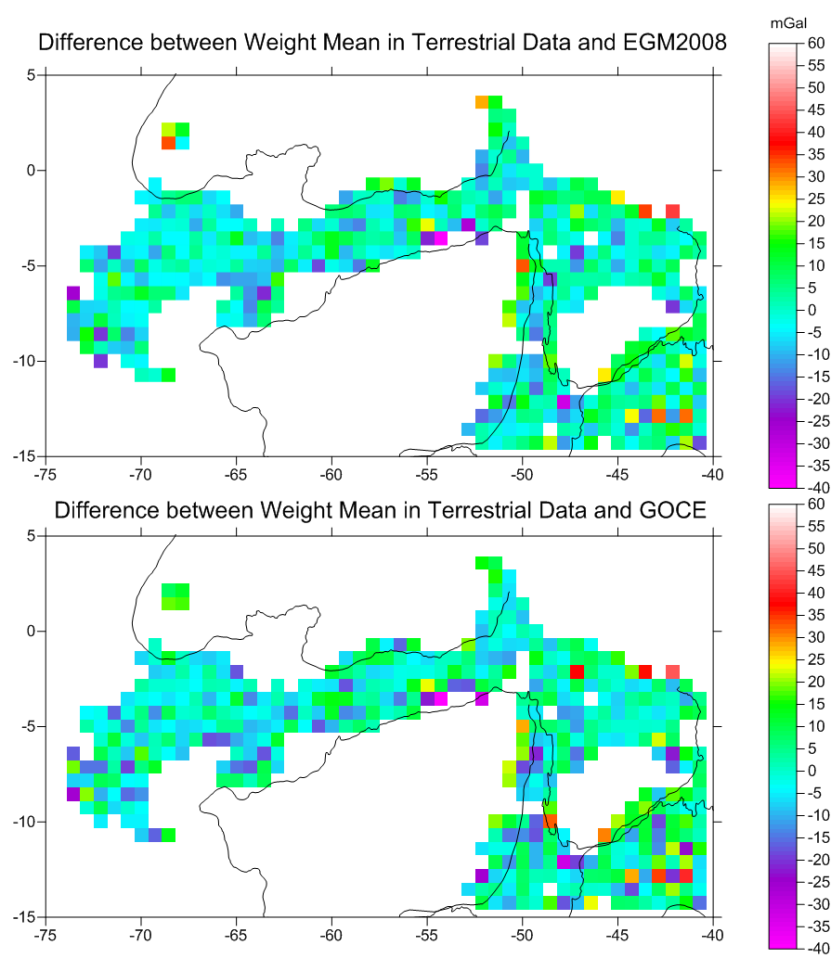

Figure 8: Differences between gravity anomaly estimated from the weighted inverse square distance average of terrestrial data and the gravity anomaly calculated from the a) EGM2008 and b) GOCE geopotential model up to degree and order 250 . The spatial resolution is $80 \mathrm{~km}$. 


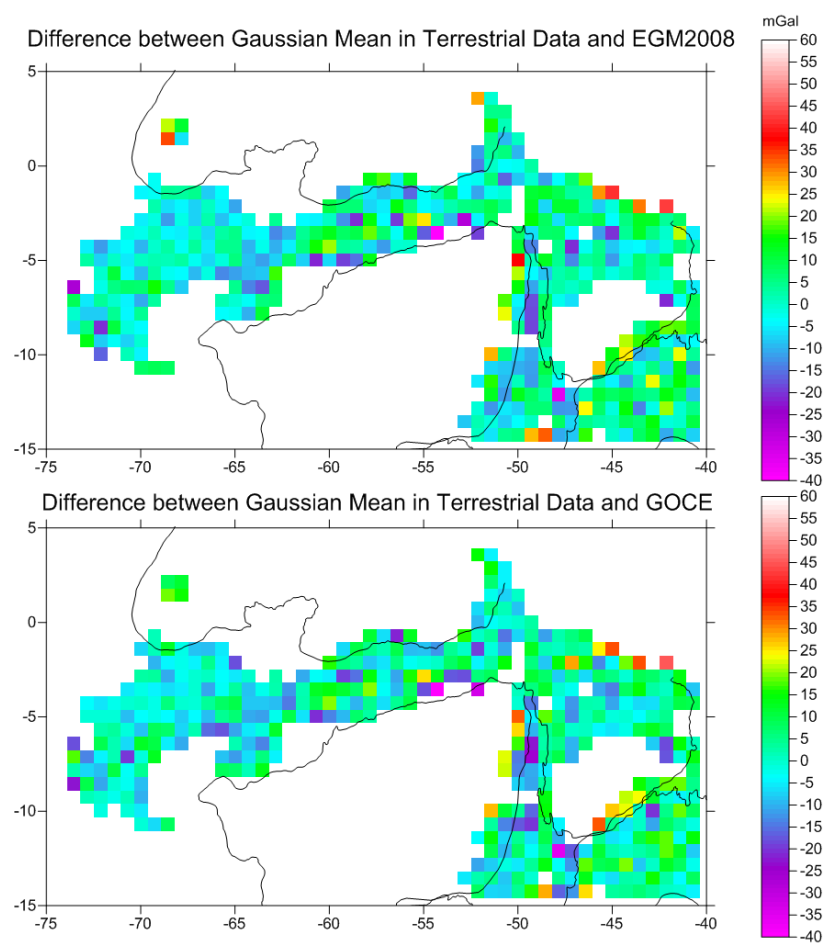

Figure 9: Differences between gravity anomaly estimated from the Gaussian average of terrestrial data and the gravity anomaly calculated from the a) EGM2008 and b) GOCE geopotential models up to degree and order 250 , respectively. The spatial resolution of $80 \mathrm{~km}$. 

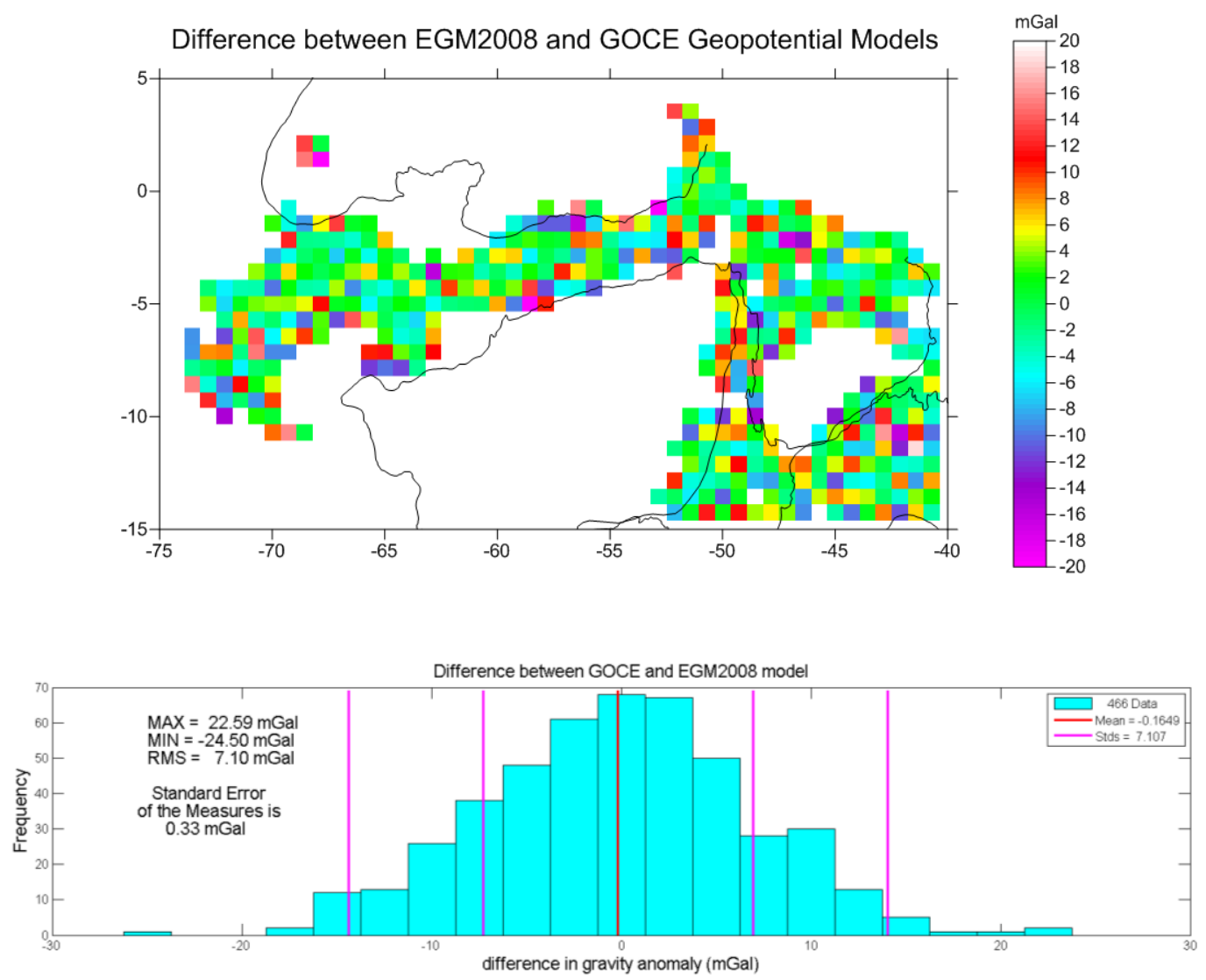

Figure 10: (a) Differences between the gravity anomaly of EGM2008 and GOCE geopotential models up to degree and order 250, respectively. The spatial resolution is $80 \mathrm{~km}$; (b) histogram of the gravity anomalies differences between EGM2008 and GOCE.

Figure 10 shows the comparison between the GGMs, i.e. the difference between the gravity anomalies from GOCE and EGM2008 models, which are due to commission errors of the finite spherical harmonic expansions. The EGM2008 can be affected by errors in the terrestrial data, because only up to degree 70 does it contain purely satellite observations. We expect a smaller difference between the GGMs due to the low commission errors of the models (Figure 4) when compared to the differences between the averaged terrestrial and GGMs measurements (Figure 11).

As showed in Braitenberg et al. (2011) and Alvarez et al. (2012), this analysis permits controlling and testing the quality of terrestrial data, for example, airborne campaigns. The EGM08 global gravity field in some regions shows problems that can be traced back to missing data or poor quality of the terrestrial gravity data used as input. As the GOCE data are independent of terrestrial data, 
they can produce a new quality assessment tool for GGMs of higher resolution, and are also adequate to assess the quality of terrestrial observations even if the spatial resolution of the terrestrial data is higher than that of the GOCE model. Geological structures can be studied with EGM08 data, as far as the terrestrial data points used to calculate the model are available at the required resolution and of sufficient precision. In this aspect the GOCE data, as an independent source with high quality information, can be a valuable tool to work with, provided that the error analysis is successfully conducted.

The differences between the averaged terrestrial data points and the values calculated from the GGMs at the same point are shown in Figure 11. The mean values of the differences are near zero, with little variations according to the filtering scheme used in the terrestrial mean data calculation. These small values are within the commission error of about $1.61 \mathrm{mGal}$ and $5.06 \mathrm{mGal}$ for gravity anomalies from EGM2008 and GOCE geopotential models up to degree 250, respectively. For this, we assume that the points which have deviations in the same order of the commission errors are considered as errorless, and that points that lie within 2 standard deviations of the mean can be considered acceptable.

The histograms allow us to identify also the areas (Figure 12) with the greatest systematic errors (here considered greater than two standard deviations from the mean). Comparison to the gravity maps obtained from terrestrial data and EGM08 and GOCE show that the errors are in the order of the gravity values (Figure 13).

In Figure 12 the results are mapped. Green tiles are considered the most reliable areas, free of systematic errors, as they are within the commission error of the respective geopotential model. The blue tiles have systematic errors considered acceptable, and are within two standard deviations of the mean, and the red tiles have large systematic errors, greater than two standard deviations, defining the areas where the terrestrial data cannot be used for further study. 

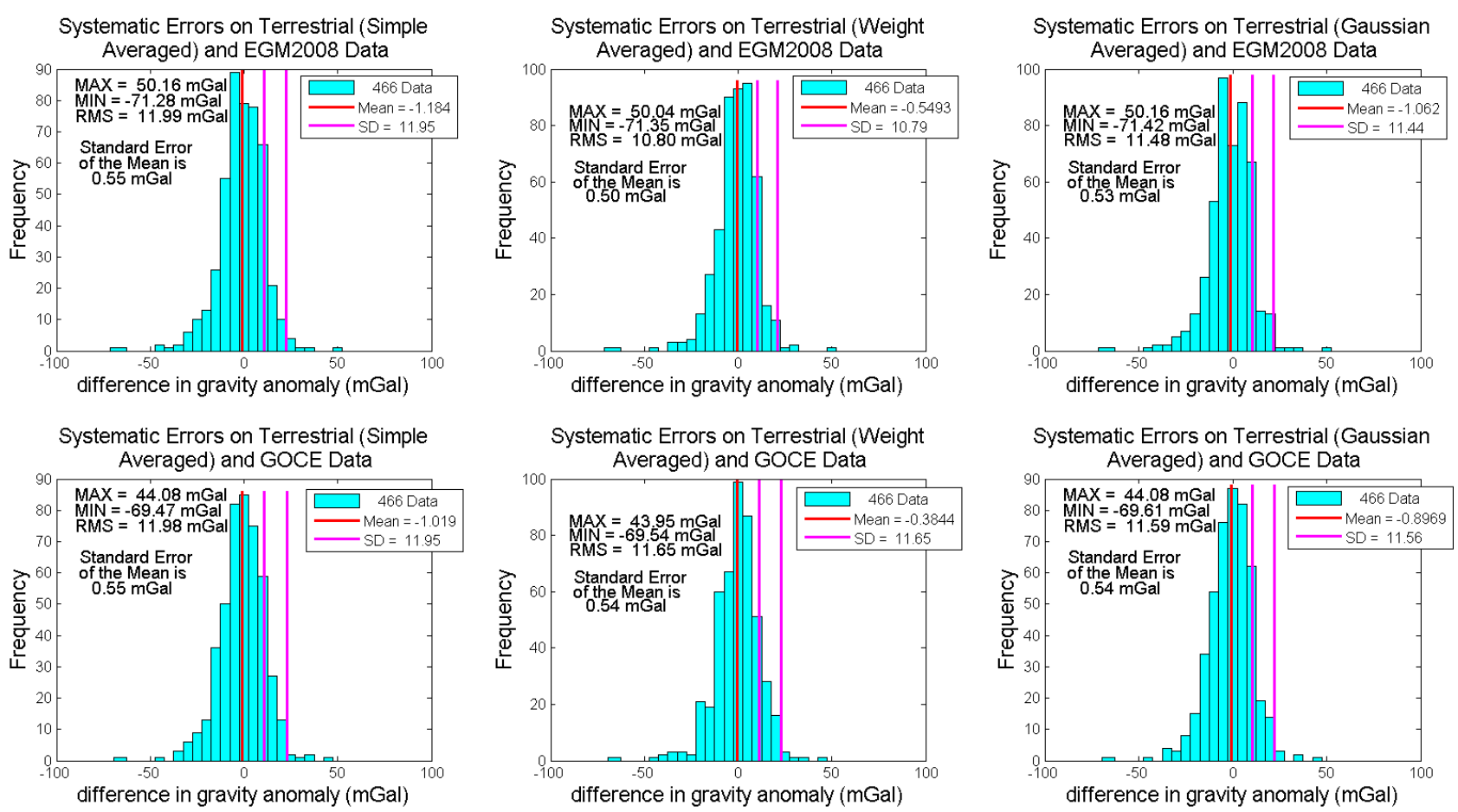

Figure 11: Systematic errors of gravity anomaly elements obtained for (averaged terrestrial data EGM2008) (upper) and (averaged terrestrial data - GOCE) (lower): the averaged terrestrial data refers to simple, weighted and Gaussian gravity anomaly mean, respectively in the left, center and right column.

We have also verified that the highest amount of systematic error-free area was 38.2 percent using the Gaussian average with the GOCE model, although with the differences respect to EGM2008 slightly higher percentages were obtained for the areas without systematic errors. Probably, this is due to the fact that EGM08 includes some of the same terrestrial gravity data, which carried eventual systematic errors. 

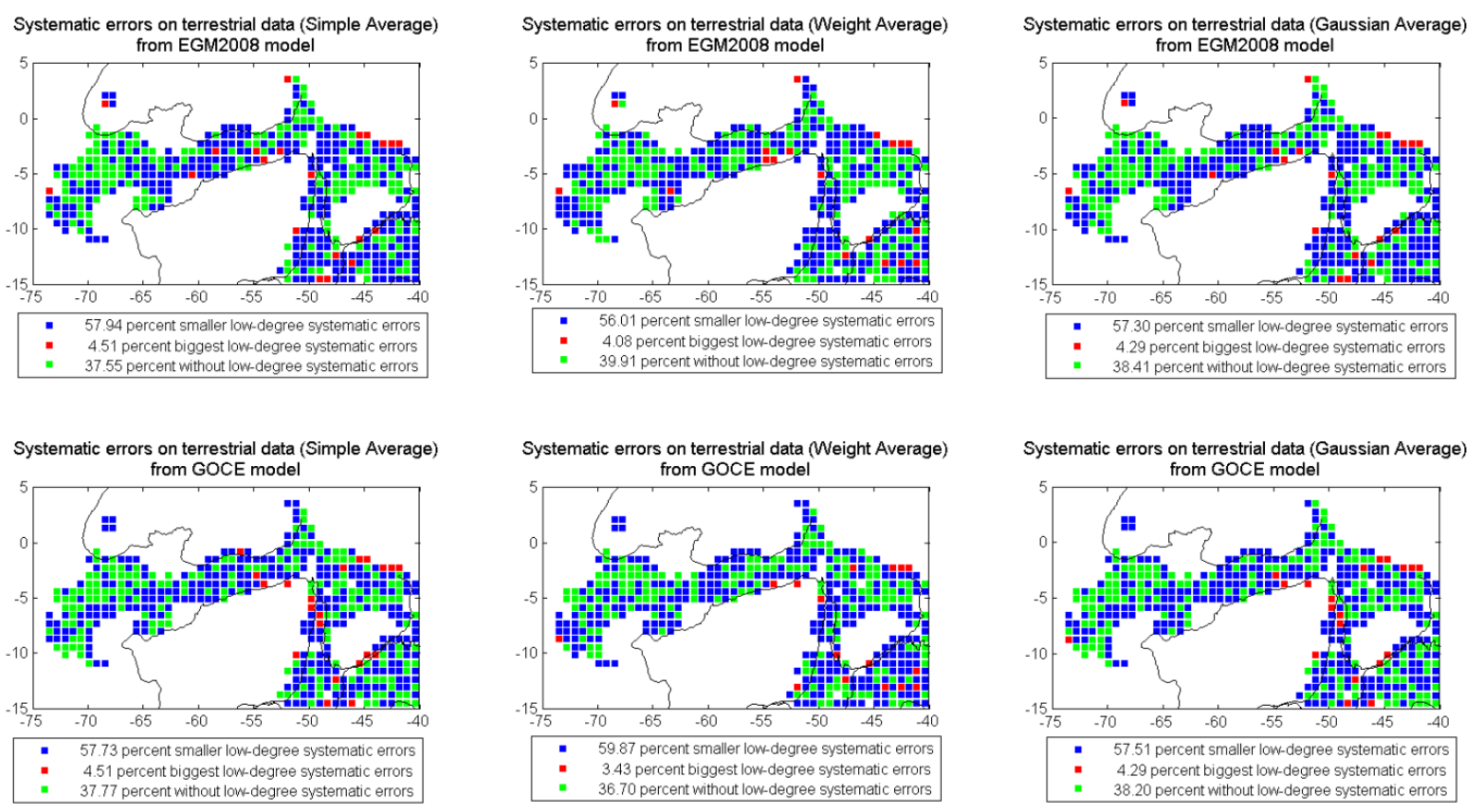

Figure 12: The low-degree systematic errors of the terrestrial gravity data indicates the locations where the terrestrial measurements should not be used for geological studies.

If we compare the distribution of the observed scattered gravity data with the systematic error map, we find that the areas with smaller systematic errors correlate with areas of higher data density. The error estimates (Figure 11 and Figure 12) are robust with respect to the type of spatial average filter used, as the results do not differ significantly.

Figure 13 shows the free-air anomaly for the models EGM2008, GOCE and terrestrial data. 


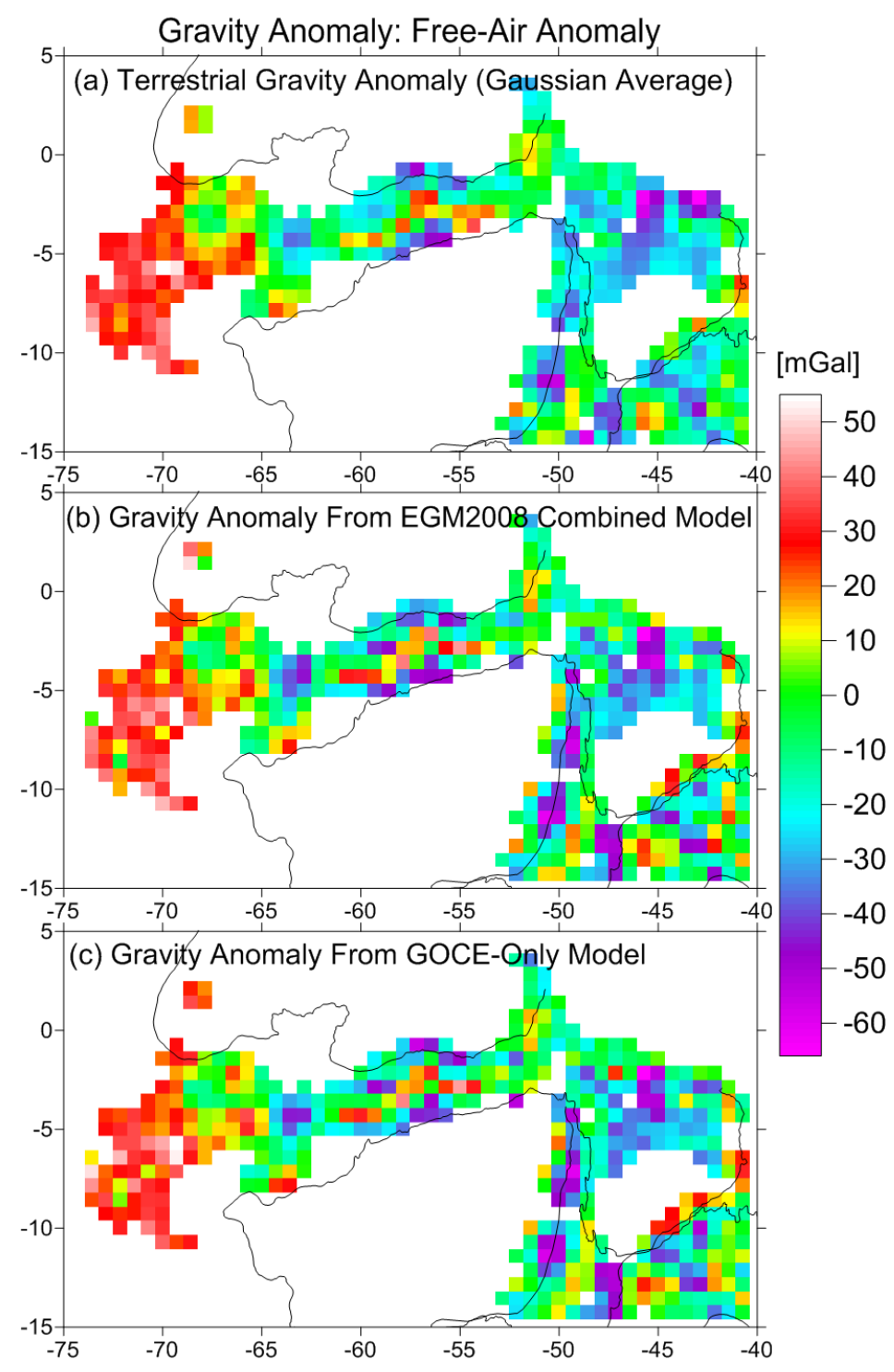

Figure 13: Free-air gravity anomaly from terrestrial, combined gravity model (EGM2008 - Pavlis et al., 2008) and satellite-only gepotential model (GOCE - Pail et al., 2011) data, respectively.

\section{Description of the gravity fields in relation to geology}

The free-air gravity anomaly maps show approximately a chain of gravity highs of $+15 \mathrm{mGal}$ to $+35 \mathrm{mGal}$ that transect the Amazon Basin, roughly coincident with the maximum thickness of sedimentary rocks (Nunn and Aires, 1988). This gravity high is flanked by gravity lows to the north and south. Nunn and Aires (1988) interpreted the flanking gravity anomaly lows as being primarily due to the presumed downward deflection of the crust/mantle boundary beneath the basin. 
The relatively high values of the gravity anomaly in correspondence to the basin axis point to a possible densification of the crust or upper mantle, or to the presence of intrusive rocks, because the sediments contribute to lower the gravity anomaly signal, as well as the Moho, which has a depth of about $42 \mathrm{~km}$ or more (Lloyd et al., 2010). In particular, the presence of possible diabase sills lying within or beneath the Amazon Basin has been postulated by some authors, and originated during late Triassic to early Jurassic, in an event known as the Penatecaua magmatism (Eiras et al.,1994). These igneous rocks may have migrated in a natural way following the sedimentary beds down dip causing the presence of a high density material that transects the Amazon Basin roughly coincident with the maximum thickness of the sedimentary rocks present in the basin.

\section{CONCLUSIONS}

The differences between the regional terrestrial gravity anomalies smoothed in order to remove the high degree components and the satellite-only gravity anomalies recovered from satellite GOCE showed that the terrestrial gravity anomalies in the study area are affected by low-degree (up to $L=250)$ systematic errors. The statistical analysis in terms of histograms of the gravity differences reveal systematic errors in the terrestrial data, showing that the region in the study area presents about $4.3 \%$ of data points with large systematic errors (considering large errors as values greater than two standard deviations from a mean which is close to zero) and $38.2 \%$ data points with are high quality (i.e. without systematic errors). The most appropriate averaging of the terrestrial data is accomplished with the Gaussian smoothing procedure. The systematic errors have a mean value close to zero, which is smaller than the commission errors associated to the EGM2008 and GOCE models.

The terrestrial data are also compared to the EGM2008 global model that was built with both satellite and terrestrial data. The resulting systematic errors on terrestrial data are slightly lower than those found with the GOCE model, probably by the simple fact that the EGM2008 model contains the gravitational information derived from a global terrestrial data set (Pavlis et al., 2012); as it is 
known that the terrestrial gravity data are often contaminated by systematic errors, such errors could be included in the geopotential model.

The satellite-only derived geopotential model of GOCE does not present such systematic errors. The present analysis shows that the GOCE model is reliable to define the areas where the terrestrial data show greater systematic errors and should be used only with care or not be used at all for accurate geophysical modelling.

One final point is that we can see the effect of varying amount and irregular distribution of the available terrestrial data in the study region, which is common to most inaccessible areas of our planet. Thus, we can identify the existence of terrestrial data gaps that correlate with the large systematic errors.

The scheme we propose has been illustrated for the Amazon Basin, but is easily applied to any other area. An important application could be the systematic control of terrestrial databases by national agencies. We predict that cross-national datum shift which affect the gravity value could be detected in databases that include gravity anomalies from different nations.

\section{ACKNOWLEDGEMENTS}

We thank PETROBRAS, ANP and IAG-USP (Institute of Astronomy, Geophysics and Atmospheric Sciences - University of São Paulo) for the use of the terrestrial data, the Italian Space Agency (ASI) for supporting the GOCE-Italy project, the Ministero dell'Istruzione, dell'Universita' e della Ricerca (MIUR) under project PRIN, 2008CR4455_003 for financial support, and ESA for granting of AO_GOCE_proposal_4323_Braitenberg, the University of Trieste and the University of São Paulo for supporting part of this research, as well, scholarships from CAPES and CNPq, in Brazil, for financial support. We acknowledge the use of EGM2008 (Pavlis et al., 2008) and GOCE (Pail et al., 2011) gravity models.

\section{REFERENCES}


Alvarez, O., Gimenez M., Braitenberg C., Folguera, A. (2012) GOCE Satellite derived Gravity and Gravity gradient corrected for topographic effect in the South Central Andes Region. Geophysical Journal International, pp. 1-19, doi: 10.1111/j.1365-246X.2012.05556.X

Amante C. and Eakins B.W., 2008. ETOPO1 1 Arc-Minute Global Relief Model: Procedures, Data Sources andAnalysis, National Geophysical Data Center, NESDIS, NOAA, U.S. Department of Commerce, Boulder, CO.

Amos MJ., Featherstone WE., 2003. Comparisons of recent global geopotential models with terrestrial gravity field data over New Zeland and Australia. Geom. Res. Austr. 79: 1-20.

Bizzi, L.A., Schobbenhaus, C., Vidotti, R.M., Gonçalves, J.H., 2004. Geologia, Tectônica e Recursos Minerais do Brasil. 1. ed.Brasilia: Editora Universidade de Brasília. v. 01. 674 p.

Braitenberg C., Mariani P., Pivetta T. (2011). GOCE observations in exploration geophysics. Proc. of '4th International GOCE User Workshop', Munich, Germany, 31 March - 1 April 2011 (ESA SP696, July 2011).

Chen, J.L., C.R. Wilson, K.W. Seo, 2006. Optimized smoothing of gravity recovery and climate experiment (GRACE) time-variable gravity observations.J. Geophys. Res., 111, B06408.

Eiras, J.F., Becker, C.R., Souza, E M, Gonzaga, F.G., Silva, J.G.F., Daniel, L.M.F., Matsuda, N.S., andFeijó, F.J., 1994, Bacia do Solimões: Boletim de Geociéncias da Petrobras, v. 8, no. 1, pp. 1745.

Jarvis A., H.I. Reuter, A. Nelson, E. Guevara, 2008, Hole-filled seamless SRTM data V4, International Centre for Tropical Agriculture (CIAT), available from http://srtm.csi.cgiar.org.

Jekeli, C., 1981. Alternative methods to smooth the Earth's gravity field, Technical report \#327, Geodetic Science, Ohio State University, Ohio.

Heck, B., 1990. An evaluation of some systematic error sources affectingterrestrial gravity anomalies, Bull. Geod., 64, 88-108. 
Heiskanen, W. \& Moritz, H., 1967. Physical Geodesy. W. H. Freeman and Company,San Francisco, 364 p.

Huang J., Veronneau M., Mainville A., 2008. Assessment of systematic errors in the surface gravity anomalies over North America using the GRACE gravity model. Geophys. J. Int.175: 46-54, doi: 10.1111/j.1365-246X.2008.03924.x.

Lloyd, S., van der Lee, S., França, G.S., Assumpção, M. and Feng, M., 2010. Moho map of South America from receiver functions and surface waves, J. Geophys. Res., 115, B11315, doi:10.1029/2009JB006829.

Mainville, A. \& Rapp, R., 1985. Detection of regional bias in $1^{\circ} \times 1^{\circ}$ mean terrestrial gravity anomalies. Bureau Gravimetrique International, Bull d'Information, 57, 143-154.

Nunn, J.A. \& Aires, J.R., 1988.Gravity anomalies and flexure of the lithosphere at the middle Amazon basin, Brazil, J. Geophys. Res., 93, 415-428.

Pail R., Bruinsma S., Migliaccio F., Foerste C., Goiginger H., Schuh W.-D, Hoeck E, Reguzzoni M., Brockmann J.M, Abrikosov O., Veicherts M., Fecher T., Mayrhofer R., Krasbutter I., Sanso F. \& Tscherning C.C. (2011): First GOCE gravity field models derived by three different approaches. Jounal of Geodesy, 81:11, doi: 10.1007/s00190-011-0467-x.

Pavlis, N.K., 2000. On the modelling of long wavelength systematic errors in surface gravimetric data, in Geodesy Beyond 2000 - The Challenges of the First Decade, pp. 131-136, ed. Schwarz, K.P., Springer-Verlag, Berlin, Heidelberg.

Pavlis, N.K., Holmes, S.A., Kenyon, S.C., and Factor, J.K., 2008. An Earth Gravitational Model to Degree 2160: EGM2008, presented at the 2008 General Assembly of the European Geosciences Union, Vienna, Austria, April 13-18. 
Pavlis, N.K., Holmes, S.A., Kenyon, S.C., and Factor, J.K., 2012. The development and evaluation of the Earth Gravitational Model 2008 (EGM2008), J. Geophys. Res., 117, B04406, doi:10.1029/2011JB008916.

Roland M. and Denker H., 2003. Evaluation of Terrestrial Gravity Data by New Global Gravity Field Models. In: Tziavos IN, ed, Gravity and Geoid - 3rd Meeting of the International Gravity and Geoid Commission, Thessaloniki, Greece, August 26;30, 2002, Publishing Ziti: 256-261.

SÁ, N.C.de, 2004. O campo de gravidade, o geóide e a estrutura crustal na América do Sul: novas estratégias de representação. Tese de Livre Docência, Departamento de Geofísica, IAG/USP, São Paulo - SP, 136 pp. T0401

Tapley, B.D., Bettadpur, S., Ries, J., Thompson, P. \& Watkins, M., 2004. GRACE measurements of mass variability in the earth system, Science. 305, 503- 505.

Véronneau, M. and Huang, J., 2003. Correction of systematic errors in surface gravity anomalies using satellite gravity solutions, in Gravity and Geoid, pp. 217-222, ed. Tziavos, I.N., EITI publications, Thessaloniki.

Wahr, J., Molenaar, F. and Bryan, F., 1998. Time variability of the Earth's gravity field: hydrological and oceanic effects and their possible detection using GRACE, J. geophys. Res., 103(B12), 30 205-30 229.305,503-505. 